\title{
Applying an Ecosystem Approach to Community Health Research in Rural Northern Ghana
}

\author{
CRESCENTIA DAKUBO
}

A thesis submitted to the Faculty of Graduate Studies in partial fulfillment of the requirements for the degree of

\author{
Doctor of Philosophy
}

Department of Geography and Environmental Studies

Carleton University

\author{
C Copyright \\ Crescentia Dakubo \\ January 2006
}




$\begin{array}{ll}\begin{array}{l}\text { Library and } \\ \text { Archives Canada }\end{array} & \begin{array}{l}\text { Bibliothèque et } \\ \text { Archives Canada }\end{array} \\ \begin{array}{l}\text { Published Heritage } \\ \text { Branch }\end{array} & \begin{array}{l}\text { Direction du } \\ \text { Patrimoine de l'édition }\end{array} \\ \begin{array}{l}\text { 395 Wellington Street } \\ \text { Ottawa ON K1A 0N4 }\end{array} & \begin{array}{l}\text { 395, rue Wellington } \\ \text { Ottana ON K1A ON4 } \\ \text { Canada Oa }\end{array}\end{array}$

Your file Votre référence ISBN: 0-494-13392-9

Our file Notre référence

ISBN: 0-494-13392-9

NOTICE:

The author has granted a nonexclusive license allowing Library and Archives Canada to reproduce, publish, archive, preserve, conserve, communicate to the public by telecommunication or on the Internet, loan, distribute and sell theses worldwide, for commercial or noncommercial purposes, in microform, paper, electronic and/or any other formats.

The author retains copyright ownership and moral rights in this thesis. Neither the thesis nor substantial extracts from it may be printed or otherwise reproduced without the author's permission.
AVIS:

L'auteur a accordé une licence non exclusive permettant à la Bibliothèque et Archives Canada de reproduire, publier, archiver, sauvegarder, conserver, transmettre au public par télécommunication ou par l'Internet, prêter, distribuer et vendre des thèses partout dans le monde, à des fins commerciales ou autres, sur support microforme, papier, électronique et/ou autres formats.

L'auteur conserve la propriété du droit d'auteur et des droits moraux qui protège cette thèse. $\mathrm{Ni}$ la thèse ni des extraits substantiels de celle-ci ne doivent être imprimés ou autrement reproduits sans son autorisation.
In compliance with the Canadian

Privacy Act some supporting forms may have been removed from this thesis.

While these forms may be included in the document page count, their removal does not represent any loss of content from the thesis.
Conformément à la loi canadienne sur la protection de la vie privée, quelques formulaires secondaires ont été enlevés de cette thèse.

Bien que ces formulaires aient inclus dans la pagination, il n'y aura aucun contenu manquant. 


\begin{abstract}
The purpose of this thesis is two-fold. First, I seek to demonstrate that health problems facing rural communities in northern Ghana cannot be fully understood and resolved without situating them in their broader historical, political and socioeconomic contexts. Many reports point to the increasing spatial and social health disparities throughout the country. In particular, rural communities in the northern regions have persistently fared worse in many health dimensions including infant, child and maternal mortality rates. Efforts by Ghana's health sector to curb these growing health disparities have been less successful. The questions posed by this thesis then are: 1) why does poor health seem to persist in rural northern Ghanaian communities, 2) why has public health research and intervention been less successful in reversing these poor health trends, and 3) what alternative health interventions can be used to improve rural community health and reduce the existing health disparities?

The study makes use of a community-based ecosystems approach to health research in a village in the Upper West Region of Ghana. It integrates three theoretical frameworks: political ecology of health, ecosystems approaches to human health, and community-based participatory action research. Political ecology of health examines rural northern Ghanaian health problems by situating them within Ghana's colonial, postcolonial and structural adjustment policies. Participatory action research advocates people-centred health development and provides space for indigenous and subjective views.
\end{abstract}


Methodologically, I worked jointly with an interdepartmental research team and two groups of community participants, men and women. We explored people's perceptions of health, ill health, major health concerns and their underlying causes. A strategic planning process was used to map out a vision for a 'healthy community'. The study reveals that most of the underlying causes of poor rural health lie outside the purview of the health sector and suggest the need for concerted efforts amongst various stakeholders. The study also demonstrates that local people understand these causes and if given the space, can contribute to finding solutions that are meaningful to them both culturally and ecologically. From an ecosystem perspective, this study constitutes one of the first in rural northern Ghana, and provides a foundation for similar studies to be conducted in other parts of the country and elsewhere. 


\section{ACKNOWLEDGEMENTS}

I am greatly indebted to a number of people for bringing this thesis to fruition. First, I would like to thank the members of my advisory committee, Dr Fiona Mackenzie, Dr. Edward Jackson and Dr. Fran Klodawsky for guiding and inspiring me throughout this academic journey. To Fiona, my supervisor, your scrutiny, ideas and gift of critical thinking has steered me through paths I could never walk alone. I am grateful for all your thoughtful insights through this process. To Dr. Fran Kladowsky, I am particularly grateful for the wealth of knowledge and enthusiasm you bring to this thesis. I enjoyed all those stimulating discussions we had prior to my going to the field. They calmed down my nerves immensely. I am also grateful for drawing my attention to all the useful materials, and encouragement to participate in events and opportunities that complement this academic exercise. To Dr. Edward Jackson, your invaluable insight into participatory action research and Ghana made your contribution to this thesis very worthwhile. I am grateful for all your critical input and in particular, for all the material support, especially, in printing off volumes of material for me at a time when I needed it most. Thank you to all three of you for making this journey less intimidating than I had envisioned.

To the chief, elders and people of Charia, thank you for accepting me once again at your doorsteps. I am very grateful to both the men's and women's groups I worked with. The enthusiasm and knowledge you bring to this study is unparalleled. Even though the benefits of the study seemed remote, you still came out to share those tree shades with me, and we learned together. Although I was not able to decode all our conversations, I walked away more knowledgeable than I came in and for that I am grateful. To all those women, who occasionally cooked for me, I can never say enough thank you.

My sincerest thanks to members of the research team, Ms. Anastasia Abobo, Mr. Mathias Puozaa, Mr. Peter Naah, Edmond, and Saaka, for all the time you spent with me throughout this study. Your ideas, contributions and sense of community dynamics were critical in completing a successful fieldwork. I am also grateful for all your insights in interpreting and making sense of our discussions. To all the government officials who helped me with information and/or granted me interviews, I am especially grateful for that. In particular, I would like to thank, Dr. Banka, Dr. Sangber-Der, the Director of Environmental Protection Agency (UWR), Upper West Health Data specialist (Mr. Owusu Ansah), Director of Ministry of Agriculture and other extension workers, the Wa Regional Forestry Officer, Mr. Sylvester Gyogluu, and the entire medical staff of Charia community clinic for your support. Special thanks to the traditional healers and herbalists - Petro Kuru and Alhaji Alhassan Abubakari - for sharing your special knowledge with us.

To my family, thank you for putting up with a daughter, wife and mother who for the most part of her life has been immersed in another world. To my three boys, Collins, Ethan and Bernard, thank you for keeping me sane. Your occasional calls for attention keep me grounded. I promise to make up for all the soccer games you have missed over all these years. To my husband, Gabriel, thank you for putting your career on hold to support mine. I am grateful for all your sacrifices and your encouragement throughout 
these long years. You urged me on, just when I thought it was over. Thank you. To my mother, I am most grateful for all the advice and encouraging conversations we have had over the phone all these years. Your words of wisdom urge me on and hopefully, from now onwards; I will remember to say my rosary daily. I am also grateful for the thoughtful prayers and concern of our 'extended family' and friends here in Canada, most especially Reverend Armand Danis and Mary, and Dr. Ken Brown and Shann.

To my financers, without your support this thesis would never have been fruitful. I am greatly indebted to the Ecohealth Program Initiative of the International Development Research Centre of Canada (IDRC) for granting me an award to undertake the fieldwork for this study. I am also grateful for all the opportunities you offered me during my program; not only did the opportunity to work with you support me financially but complemented my academic training with a hands on experience. I also wish to thank the Department of Geography and the family of Dr. Thomas Betz for honouring me with their foundation award. To Dr. Iain Wallace and Dr. Fraser Taylor, thank you for all the assistance grants you bestowed on me, just to keep me going. I am most grateful.

Finally, I am grateful to all the staff and faculty of the Geography Department for creating such a warm atmosphere for foreign students. In particular, I would like to thank Dr. Fraser Taylor for giving me the chance to start with, to Hazel, Judy and Elsie for all the warm and caring concerns about my family, and to Dr. Simon Dalby and Fiona for giving me the opportunity to teach GEOG. 3209. To the students of that class [Winter, 2004] and all those I tutored, thanks for challenging me to read at night while you slept. To my indispensable TA, Emily Wilson, I could not have done it alone without your creative abilities. Last but not the least, I wish to thank my colleagues and other PhD students, Darren, Diego, Regina, Xiao, Dr. Fiona Coyle, Andrew and Jamie for all the thoughtful exchanges during the course of my study. Thank you and I wish you the best of luck in your studies and careers. 


\section{TABLE OF CONTENTS}

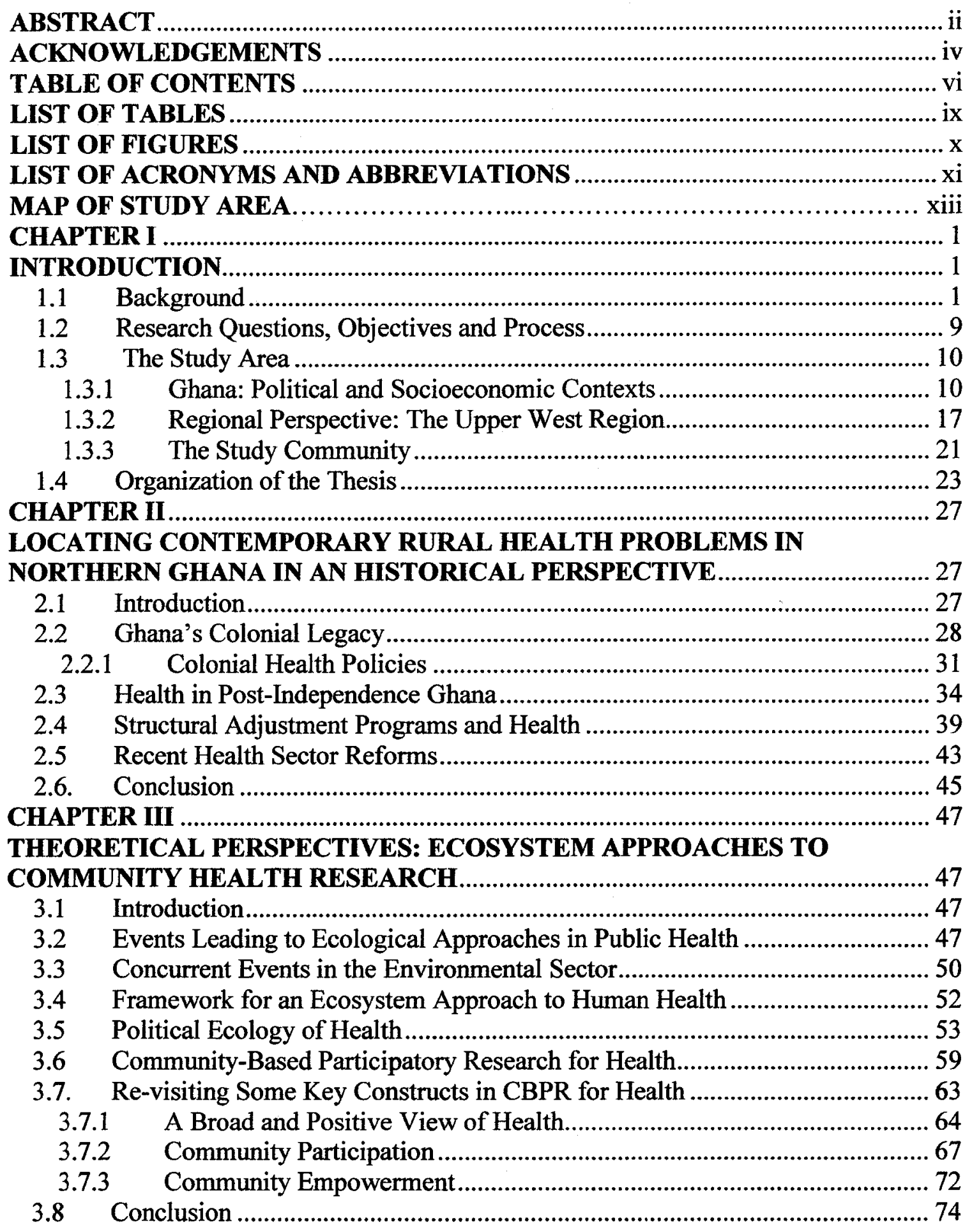




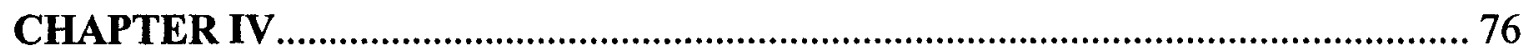

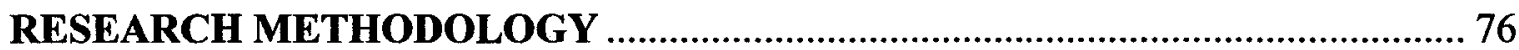

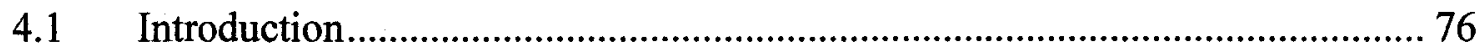

4.2 Participatory Action Research ……………………..................................... 77

4.2.1 Capturing lived experiences as different, diverse and complex ............... 80

4.2.2 Reflexive Practice in Public Health ....................................................... 82

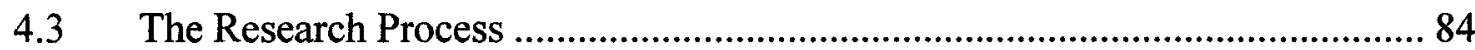

4.3.1 Entering the Community the Second Time Around .................................. 86

4.3.2 Meeting the Research Participants......................................................... 88

4.3.3 Data Gathering Tools ............................................................................ 92

4.3.4 Focus Group Discussions..................................................................... 94

4.4 The Strategic Planning Process......................................................................... 95

4.5 In-depth Follow-up Interviews ...................................................................... 99

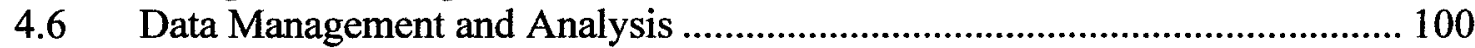

4.7 Reflecting on the Research Process: Challenges and Ethical Dilemmas......... 101

4.7.1 Participatory Research as Transformative and Empowering .................. 102

4.7.2 Identity and the Politics of Representation ............................................... 105

4.7.3 Dealing with Vulnerability ...................................................................... 109

4.7.4 Understanding the Changing Socio-political Landscape ......................... 111

4.7.5 Establishing Equal Partnerships............................................................. 113

4.7.6 Group Processes: Are All Knowledges Captured? ................................... 115

4.8 Conclusion .............................................................................................. 117

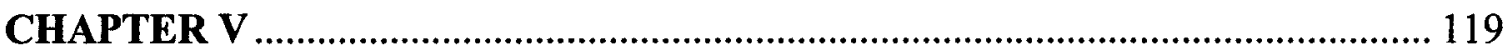

HEALTH AND HEALTH PROBLEMS FROM THE COMMUNITY'S

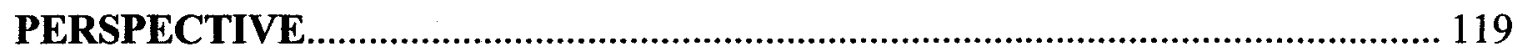

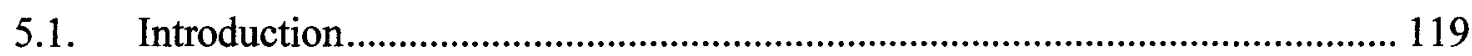

5.2 Men's and Women's Conceptions of Health and Ill Health ........................... 122

5.3 Contrasting Participants' Concepts of Health with Other Notions of Health. 130

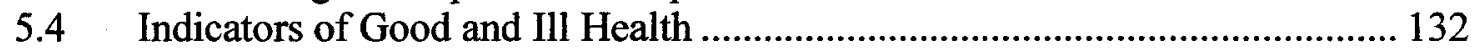

5.5 Perceptions of Major Health Problems in the Community ............................... 135

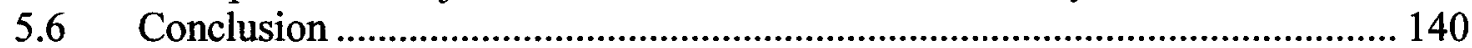

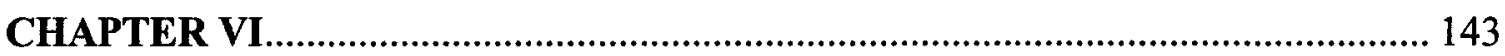

UNDERSTANDING THE FACTORS AFFECTING HEALTH IN THE

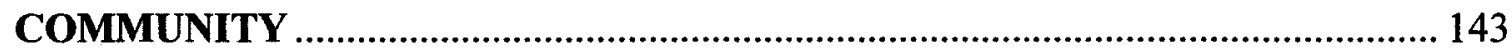

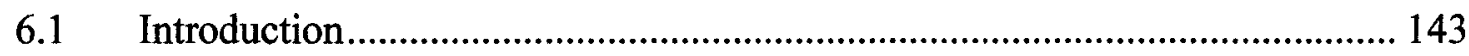

6.2 Climatic Variability, Agricultural Productivity and Health............................. 148

6.3 Ecological Disturbances and Exposure to Disease Vectors............................. 157

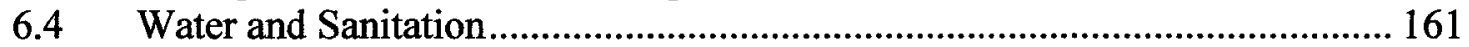

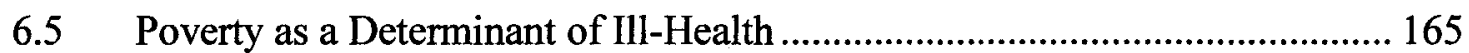

6.5.1 Poverty, Environmental Degradation and Ill Health................................ 170

6.5.2 Poverty, Housing and Ill Health........................................................ 175

6.5.3 Poverty, Education and Ill Health......................................................... 176

6.6 Accessibility and Utilization of Health Services ............................................ 180

6.7 Gender Roles, Environment and Health ....................................................... 184

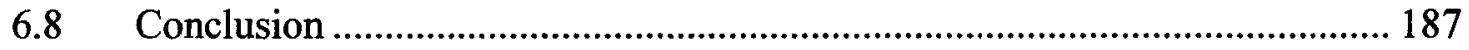

vii 


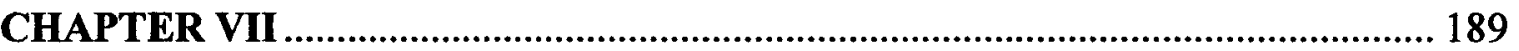

PLANNING FOR A HEALTHY COMMUNITY ……....................................... 189

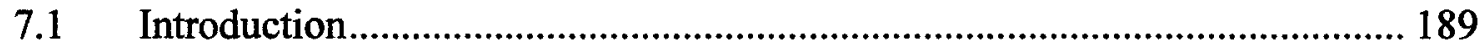

7.2 Creating a Vision for a Healthy Community .................................................. 191

7.3 Identifying the Underlying Contradictions to a Healthy Community ............. 200

7.4 Assessing Our Strengths and Resources ......................................................... 209

7. 5 Strategic Directions and Systematic Actions for a Healthy Community........ 212

7.5.1 Building Community Capacity to Sustainably Manage Local

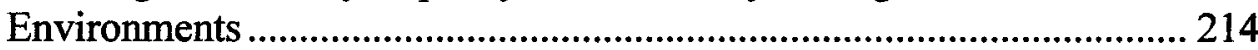

7.5.2 Strengthening Intersectoral Collaboration ............................................216

7.5.3 Broaden the Concept of Community Participation................................. 218

7.5.4 Strengthen Environment and Health Education and Communication.... 220

7.5.5 Building on Local Knowledge Systems................................................ 223

7.5.6 Building Community Capital: Integrating the Strategic Directions ........ 228

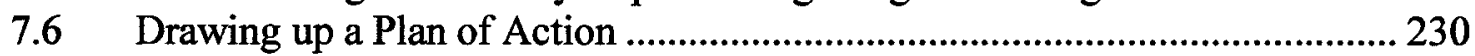

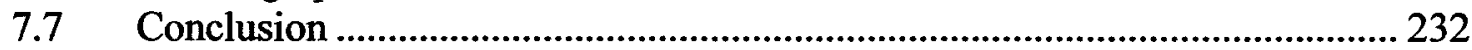

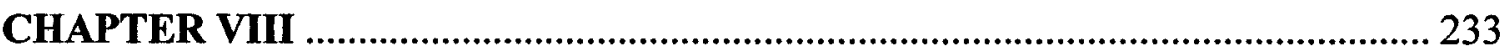

CONCLUSIONS AND FUTURE DIRECTIONS ................................................. 233

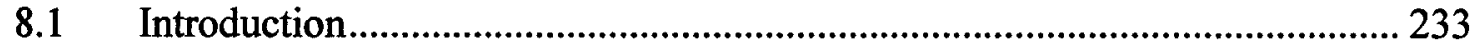

8.2 Explaining the Persistence of Poor Health in Rural Northern Ghana.............. 236

8.3 Re-examining Public Health Research and Intervention in Ghana ................. 239

8.4 In Search of Alternatives: A Community-Based Ecosystem Approach toHealth

Research.....................................................................242

8.5 Intersectoral Collaboration: Potentials and Limitations .................................245

8.6 Contributions and Future Directions....................................................... 250

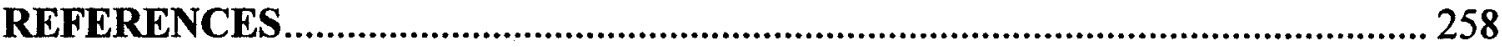

APPENDIX I: FOCUS GROUP DISCUSSION CHECKLIST ............................ 284

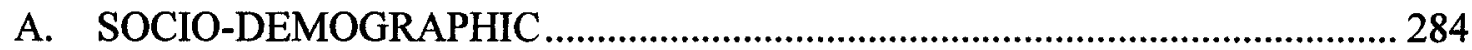

B. CONCEPTS \& INDICATORS OF HEALTH AND ILL HEALTH....................285

C. PERCEPTIONS OF COMMUNITY HEALTH............................................... 285

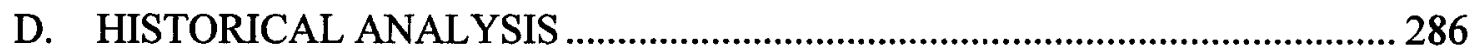

E. FRAMEWORK FOR A STRATEGIC PLANNING PROCESS ………………..286

APPENDIX II: COVER LETTERS AND CONSENT FORMS ............................... 288

A. COVER LETTER FOR RESEARCH PARTICIPANT ………………………..... 288

B. RESEARCH PARTICIPANT CONSENT FORM ...............................................289

C. COVER LETTER FOR MEMBERS OF THE RESEARCH TEAM..................290

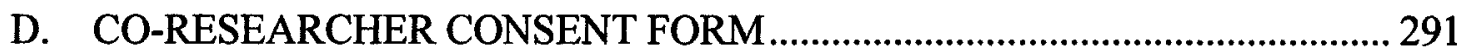




\section{LIST OF TABLES}

Table Page

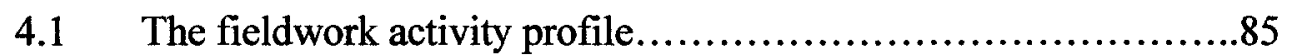

4.2 Characteristics of community participants........................92

5.1 Participants' subjective indicators of good and ill health...........133

5.2 Top ten community health problems identified by participants and compared to community health data.............................137

6.1 Major community changes identified by participants..............149

7.1 Vision elements identified by participants......................193

7.2 Barriers inhibiting the realisation of a healthy community.........202

7.3 Perceived strengths of community participants....................210

7.4 Community- and household-level activities to reduce the incidence of malaria, diarrhoea, and ARIs.

7.5 Actions for environmental and health education and

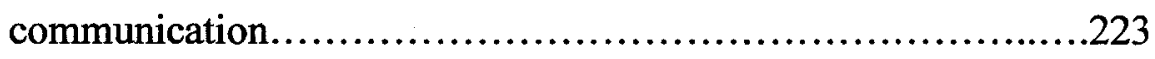

7.6 Medicinal plants identified by participants......................227 


\section{LIST OF FIGURES}

Figure

Page

1.0 Map of the study area.................................

7.1 Healthy community model............................198 


\section{LIST OF ACRONYMS AND ABBREVIATIONS}

CBPR Community Based Participatory Research

CSM Cerebrospinal meningitis

CWIQ Core Welfare Indicators Questionnaire

CWSA Community Water and Sanitation Agency

DAs District Assemblies

DALY Disability Adjustment Life Years

DANIDA Danish International Development Assistance

DDT Dichloro-Diphenyl-Trichloroethane

DfID Department for International Development (UK)

EU European Union

GDHS Ghana Demographic and Health Survey

GDP Gross Domestic Product

GHS Ghana Health Service

GLSS Ghana Living Standard Survey

GOG Government of Ghana

GSS Ghana Statistical Service

GTZ Gesellschaft Technische Zusammenarbeit

GWCL Ghana Water Company Limited

HIPC Highly Indebted Poor Country initiative

IMF International Monetary Fund

IMR Infant mortality rate

INCONCERT Initiatives for conservation in Northern Communities Entrepreneurship, Resources and Training

ISSER Institute of Statistical, Social and Economic Research

JSS Junior Secondary School

KVIPs Kumasi Ventilated Improved Pit Latrines 
MDGs Millennium Development Goals

MOE Ministry of Education

MOFA Ministry of Food and Agriculture

$\mathrm{MOH} \quad$ Ministry of Health

MTADP Medium Term Agricultural Development Programme

MTDP Medium Term Development Programme

MTEF Medium Term Expenditure Framework

MTHS Medium Term Health Strategy

NDF Nordic Development Fund

NDPC National Development Planning commission

NGOs Non-Governmental Organizations

NPP New Patriotic Party

PHC Primary Health Care

POW Programme of Work

PRSP Poverty Reduction Strategy Paper

SAP Structural Adjustment Programme

SOEs State Owned Enterprises

SPP Strategic Planning Process

SSS Senior Secondary School

SWAP Sector Wide Approach

U5MR Under five mortality rate

UPCD University Partnership Cooperation and Development

UN United Nations

UNAIDS United Nations Programme on HIV/AIDS

UNDP United Nations Development Programme

UNICEF United Nations Children's Fund

USAID United States Agency for International Development

UWR Upper West Region

WB World Bank

WHO World Health Organization

WHO-AFRO World Health Organization Regional Office for Africa

xii 


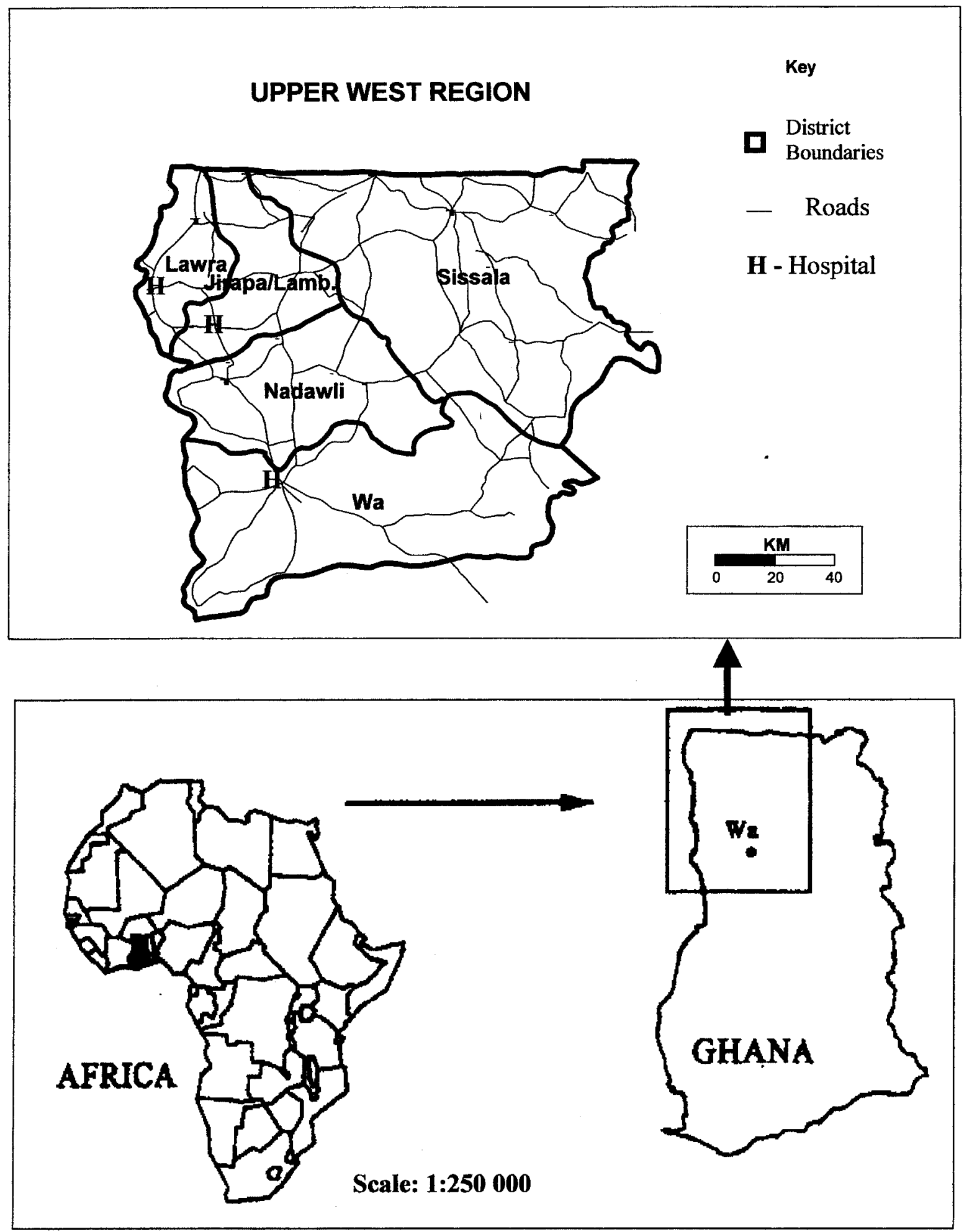

Figure 1. Map of the Study Area

Source: District Health Management Team, Wa, Upper West Region, Ghana. 


\section{CHAPTER I \\ INTRODUCTION}

\subsection{Background}

Recently, there have been increasing calls for public health research to broaden the search for causes of ill health from the individual to include social and environmental determinants and their role in creating health disparities (Jones and Moon, 1993; Kearns, 1995; Green et al., 1996; Labonte, 1997; Schwab and Syme, 1997; Israel et al., 1998;

Dyck et al., 2001; Schulz et al., 2002; Leung et al., 2004; Schultz and Northridge, 2004).

Consistent with this are also calls for the use of more community-based participatory research approaches that involve participants in all phases of the research process, and to raise community consciousness and empower people to respond to their health concerns in a proactive manner (Robertson and Minkler, 1994; Schwab and Syme, 1997; Laverack and Labonte, 2000).

This call for change is precipitated, in part, by the inability of the focus on individual level risk factors to explain the growing health inequalities that characterize today's society (House and Williams, 2000). Many of the underlying causes of today's health problems stem from factors such as poverty, homelessness, unequal world order, globalization and regional marginalization. The vulnerable in society, the poor, rural residents and those at the bottom of the socioeconomic ladder continue to bear a disproportionate portion of the burden of disease (Schulz et al., 2002). These new health concerns and their underlying causes defy conventional, individual-focused public health approaches and require integrated interventions that span beyond the health sector. Thus, 
finding effective means to understand and intervene in the socioeconomic, political and environmental factors that contribute to health disparities remains one of the most pressing problems facing public health practitioners today (ibid).

In Ghana, many reports point to growing spatial and socioeconomic health inequalities (World Bank, 2003; WHO, 2001; Ghana Poverty Reduction Strategy Paper [GPRSP], 2003; Ghana Statistical Services and Macro International Inc. [GSS/MI], 2003). According to a recent study on the profile of health inequalities in Ghana, cited in World Bank (2003: 8), a general trend of health improvement in the Ghanaian populace over the past decade is masked by wide health disparities among administrative regions, between northern and southern parts of the country, rural and urban areas, and between various socioeconomic groups. The study asserts that the largest differential in health outcomes is by region of residence, with the three northern regions: Upper West, Upper East, and Northern consistently faring poorly in many health dimensions, compared to their Southern counterparts. The under-five mortality rate in these regions is 2.5 times higher than in the Greater Accra Region. Whereas the rate in Greater Accra Region is 62 deaths per 1000 live births, it is 171 in the Northern Region, 156 in the Upper West Region and 155 in the Upper East Region (World Bank, 2003: 8). Also, the Greater Accra Region with about $12 \%$ of the national population accounts for $42 \%$ of total public doctors and $18 \%$ of hospital beds of the whole country. In contrast the northern regions with $20 \%$ of the population account for $6 \%$ of total doctors and $14 \%$ of the total hospital beds in the country. Similarly, data from 1988 to 1998 showed consistently poor performance in many health dimensions in rural areas compared to their urban 
counterparts (ibid:8). Education and income levels are lowest in rural areas and in the northern parts of the country, and these seem to be reflected in poor health outcomes.

Yet, like many other countries, Ghana's health sector has not been successful in reducing these health disparities, partly because of the predominant use of Western biomedical approaches which fail to examine the underlying causes of health problems and the factors perpetuating their persistence, instead focusing on treating the symptoms, disease. In this thesis, I argue that health problems facing rural communities in northern Ghana cannot be fully understood and improved without situating them in broader historical, political and socioeconomic contexts. In so doing, I examine the impact of colonial and postcolonial policies on rural health development and how these policies created and sustained spatial and socioeconomic inequalities and health disparities in Ghana. I also locate the current health problems within the context of Ghana's economic crisis and structural adjustment programs. Subsequently, I analyse research carried out with a group of local residents in a rural community in the Upper West Region of Ghana, making use of a community-based ecosystem approach to health, to identify the community's major health concerns and devise potential intervention strategies.

Ghana's health care system is modeled around western biomedical approaches, which is often curative-oriented, disease-focused and mostly urban-based. In the next chapter, I will situate Ghana's health system within an historical perspective to allow for a better understanding of its emergence and consequences. This health model, sometimes referred to in the literature as the conventional approach, primarily considers the individual as responsible for his/her health outcomes. It defines health as the absence of disease, with disease being associated largely with known and controllable risk factors 
such as poor hygiene, poor diet, and poor precautionary measures (Wallack and Montgomery, 1996). As a result, the individual is seen as the appropriate focus for intervention to control risk factors, with those interventions typically consisting of providing 'expert' knowledge and skills for changing unhealthy behaviors and lifestyles (Pierce, 1996; Susser and Susser, 1996). In cases where disease eradication is the focus, technocentric (e.g. x-rays for tuberculosis; feeding programs for malnutrition) and hospital-based techniques are the preferred modes of action. However, by relying on medical technologies as solutions to health problems, medical professionals and researchers increasingly come to understand health problems in terms of the technologies available, preventing them from considering the complexity of factors shaping them and alternative intervention approaches (Randall, 1998). Also, an overriding emphasis on the individual tends to hold people responsible for their health outcomes, while ignoring the sociopolitical contexts in which individual decision-making and action takes place (Minkler, 1994; Neubauer and Pratt, 1981). For example, in the case of the poor and vulnerable in society, holding the individual responsible for health choices does not only lose sight of poverty itself as a significant cause of ill health, but also fails to recognize that poor people correspondingly have little opportunity to control the circumstances and events that affect their lives (Syme, 1998).

These shortcomings have led to calls for broad-based ecological approaches to public health research and intervention, sometimes referred to in the literature as the 'new public health' (McLeroy et al., 1988; Stokols, 1992, 1996; Freudenberg et al., 1995; Green et al., 1996). Ecological approaches recognize the importance of human agency in taking conscious decisions and actions about one's health, but encourage the integration 
of such perspectives within reciprocal relationships between people and their social and physical environments. An analytical framework for this approach therefore consists of a nested range of factors acting at varying levels to influence health. These levels include the individual (knowledge, attitudes, behaviors, social support systems); family or household (gender relations, power structures, division of labour, access to health resources); community (community networks, power structures, infrastructure) and public policies (rural/urban, community participation). By using a multi-level analysis, researchers can then target specific areas for appropriate interventions.

In this study, I combine the ecological approach with a political ecology analytic framework to counter dominant, yet simplistic, explanations about the persistence of poor health status in rural Ghana. For example, in Ghana, many explanations of poor health still border on blaming the victim, including people's feckless attitudes, ignorance on the part of rural folks and poor hygiene (Twumasi, 1979; Aidoo, 1982). Also, many health problems are seen to result from the lack of human and financial resources and limited international aid (Aidoo, 1982). Such conceptions reduce health concerns to resourcebased problems, failing to question the reasons underlying such resource scarcity. Also, lacking in such explanations is contextualising Ghana's current health practices within its colonial legacy. For example, Ghana's health system was designed to serve colonial masters who were based in coastal towns and ports, and so many health facilities were located in urban areas to the neglect of rural areas (Twumasi, 1981; Kunfah, 1996). Health services focused on the elimination of tropical diseases to allow for colonial capitalist expansion. Thus, technological remedies such as spraying mosquitoes with DDT, and developing vaccines to counter diseases, took precedence over preventive 
measures such as providing clean water, sanitation, and good housing. This was done only for selected populations: colonial masters, and subsequently the labour force (Aidoo, 1982; Twumasi, 1981). Such selective emphasis on where, who, how and what seems to have persisted until the present.

Also, one would have thought that, with independence would come reforms to reverse these health inequalities. As discussed in the next chapter, these changes, although initiated by Dr. Kwame Nkrumah, could not take root partly because of the persistence of the colonial class-based structures that still favoured elites, and so continued to organize health services to suit them. Further, Ghana's continuous dependence on foreign capital and external expertise meant that health decisions and policies were determined externally. International health organizations such as the World Health Organization (WHO) and the United Nations Children's Fund (UNICEF) became the new centres of medical expertise, and their policies did not differ much from the colonial era (Randall, 1998). Large-scale disease eradication and immunization campaigns became the favoured approaches as they demonstrated concrete evidence in terms of coverage and the number of people immunized, as well as justified the judicious use of donors' money. Diseases that could easily be addressed through technological solutions were placed high on the list of priority health concerns (ibid).

Globally, by the early 1970 s, many academics and international health professionals expressed concern about the failure of top-down and capital-intensive strategies to address the health needs of developing country nationals (George, 1976; Doyal, 1979). This concern was closely linked with the growing appreciation of the potential of grassroots efforts to respond to people's own health concerns through popular 
participation and self-reliance as had been demonstrated by the successes in China, Cuba and Tanzania's barefoot doctors (Navarro, 1972; Sidel and Sidel, 1973; Matomora, 1986). In response to these concerns a number of international health initiatives were instituted. Notable among them were the Alma Ata Declaration on Primary Health Care (PHC) (WHO, 1978) and the Ottawa Charter for Health Promotion (WHO, 1986). But with growing economic crisis, among other reasons, the community-oriented principles of these initiatives failed to be firmly rooted in many African countries, including Ghana. As discussed in the next chapter, the implementation of structural adjustment programs further worsened the existing health disparities in Ghana (Konadu-Agyemang, 2000; 2001).

From a methodological standpoint, critics argue that the conventional approach to health research tends to use positivist and top-down methods which rarely involve people in defining and solving their own health problems. As such, many see community-based participatory research approaches as suitable alternatives that give voice and power to those affected by a problem, to influence the research process and take action to respond to their health concerns (Gaventa, 1981, 1993; Fals-Borda and Rahman, 1991; Hall, 1992; Maguire, 1996; Wallerstein, 1999). Israel and colleagues (2003) describe community-based participatory research (CBPR) in public health as 'a partnership approach to research that equitably involves community members, organizational representatives, and researchers in all aspects of the research process' (p.54). Together these groups contribute their 'unique strengths and shared responsibilities' to enhance understanding of a given phenomenon and integrate the knowledge gained with action to improve the health and well-being of community members (ibid). In doing so, CBPR 
shifts the decision-making authority away from experts and embraces the experiential knowledge of the average citizen (Brooks and Watkins, 1994).

Sympathetic to these arguments, I used participatory action research (PAR) to work with a group of local residents in Charia, the study community, with a view to generating critical consciousness about their health situations and to contribute in planning to resolve them. As Strasser (2003) points out, most rural communities ${ }^{1}$ around the world tend to experience poor health status because of inequitable resource allocations, marginalization and exploitatative relations. As a result they tend to experience high levels of poverty and high incidence of preventable diseases. Also, because of their close interactions with the biophysical environment, many of these diseases tend to be environmentally mediated. Thus, with the concentration of poverty, low health status and a high burden of environmental-related health concerns, there seems to be a great need to focus on improving the health of people in rural and remote areas. The World Health Organization (WHO) and the World Commission on Environment and Development (WCED), among others, have highlighted this need, and especially the requirement for frameworks that integrate the social and environmental determinants of health. As such, I make use of an ecosystem approach to human health, which not only focuses on an integrated understanding of the underlying health determinants, but also encourages health promotion through management of biophysical environmental resources. This study is therefore conducted with the view to contributing

\footnotetext{
${ }^{1}$ I use rural communities in a rather broad way, while cognizant of the heterogeneity that exists among rural populations. Through such use, I am by no way indicating a universalized experience or coping of problems.
} 
to refining the theoretical and methodological knowledge gaps in this emerging area of research.

\subsection{Research Questions, Objectives and Process}

I conducted this study with the view to responding to the following questions: 1) why does poor health seem to persist in rural northern Ghanaian communities; 2) why has past public health research and intervention not been very successful in improving rural health conditions; and 3) how might a community-based ecosystem approach to health research contribute to reducing existing health disparities and improving community well-being?

The objectives of the study are first, to explore local perceptions of major community health problems; second, to explore factors facilitating the occurrence of these health problems; and third, to engage community members and government officials in a joint participatory planning process to identify possible intervention strategies to promote community health and well-being.

I used participatory action research to work jointly with a research team and two groups of community participants, male and female. I formed an interdepartmental research team comprising community representatives and officials from various local government departments to help with the design and actual implementation of the research. Through a strategic planning process and focus group discussions, community members participated in most stages of the research, from identifying major community health problems to suggesting solutions to them. Participants also mapped out a vision depicting a 'healthy community' for themselves, and assessed their strengths, resources 
and constraints to achieving that vision. I conducted follow up in-depth interviews, with key informants, within and outside the community, to better understand some of the contextual issues that were not raised during group discussions.

\subsection{The Study Area}

The study was conducted in a small village called Charia in the Upper West Region of Ghana (see Figure 1). Before describing the village itself, I will briefly identify key aspects of Ghana with the view to locating it within Ghana's changing political and economic contexts. This is followed by a description of the Upper West region, situating it within the broader context of northern Ghana and drawing some relative comparisons with the national context. Finally, I describe Charia, locating it within the cultural context of the Upper West Region, and its special place among international development organizations. The description of the study area is based on information from scholarly material, national, regional and district level reports, documentation by international organizations and my own personal knowledge as a native and former resident of the area.

\subsubsection{Ghana: Political and Socioeconomic Contexts}

Ghana is a former British colony and in 1957 became the first African country to gain independence. Ghana's population is estimated at 21.3 million (2004) and growing at a rate of 2.4\% (WHO/UNAIDS, 2004) $)^{2}$. Life expectancy at birth (2004 estimate) is almost

\footnotetext{
${ }^{2}$ http://www.plusnews.org/AIDS/ghana.asp\#data. Last accessed September $22^{\text {nd }}, 2005$.
} 
58 years; crude death rate is 10 per 1000 ; and the total fertility rate is 4.2 (2000 estimate) (ibid). Infant and under-five mortality rates are pegged at 62/1000 and 105/1000 respectively (2000 estimates), and maternal mortality is pegged at a high rate of 540/1000 (2000 estimate) (ibid).

Administratively, Ghana is divided into ten regions and 110 decentralized districts. The organization of most statistical data is on a regional basis making regional comparisons quite feasible. However, because of a shared history, culture and socioeconomic concerns, I will make reference to Northern Ghana as encompassing the three northern regions: Upper West, Upper East, and Northern, and drawing comparisons between this broad area and other parts of the country. Northern Ghana is characterized by rural savanna ecological belts and has a relatively poor natural resource base. This region is often synonymous with poverty and underdevelopment. Northern Ghana stands in stark contrast to the South, which is located in the coastal and forest regions and is endowed with a rich natural resource base. The South is synonymous with prosperity and wealth. This pattern of uneven development, as I will illustrate in the next chapter, has in part been augmented by Ghana's colonial legacy.

Ghana has a mixed economy, consisting of a dominant agricultural sector (smallscale peasant farming) which absorbs about $60 \%$ of the total adult labour force, a relatively small capital intensive modern sector dominated by mining and other industrial activities, and a rapidly expanding informal sector dominated by petty traders, small artisans, technicians and small businessmen (WHO, 2001).

Politically, Ghana has had a chequered history of short and unstable reigns until recently. For example, between 1957 and 1992, there were seven regime changes: 
Nkrumah (1957-1966); Ankrah and Afrifa (1966-1969); Busia (1969-1972);

Acheampong and Akuffo (1972-1979); Rawlings (June 1979-September 1979); Limann (1979-1980); Rawlings (1981-1992; 1992-1996). Four of these were military regimes, and they came into power through coup d'etats (Aidoo, 1982; Boakye-Yiadom, 2004). In 1992, Flt. Lt. Jerry John Rawlings, then a military ruler, donned on civilian uniform and ushered his party and the country into democratic reforms. He continued to rule as a democratically elected leader until 2000, when the New Patriotic Party (NPP), led by Dr. John Kuffour took over office. The NPP is currently in their second term of office (2000$2004 ; 2004-2008)$.

Economically, Ghana's profile has undulated over the years. Immediately following independence, Ghana was in a better economic shape compared to other countries in Sub-Saharan Africa. It had a well-established export-based economy, was the world's leading producer and exporter of cocoa in 1957, exported $10 \%$ of the world's gold, and had foreign reserves of 200 million pounds (Konadu-Agyemang, 2000:471). With a per capita income of 50 pounds in 1957, Ghana was easily classified as a middleincome country.

However, by the mid 1960s, for a number of reasons including the lack of domestic integration of production and consumption, extensive dependence on foreign capital and the persistence of colonial class-based structures, Ghana's economy began to take a down turn. The GDP fell sharply, foreign reserves became depleted and Ghana's debt load rapidly increased (Konadu-Agyemang, 2001). In the early 1980s, Ghana's economic woes were further augmented with the migration of Ghanaian professionals including teachers, doctors, and nurses to neighbouring countries like Nigeria, as well as 
abroad (Konadu-Agyemang, 2000). It was these difficult conditions that led Ghana to seek advice from the International Monetary Fund (IMF) and World Bank, which subsequently led to the implementation of structural adjustment programs (SAPs). According to the IMF and the World Bank, Ghana's economic crisis, and those of other adjusting countries, was the result of over subsidized state enterprises, and excess expenditure on social services such as education and health. Thus, a reduction in government expenditure through privatization, currency devaluation, withdrawal of subsidies, and the introduction of cost recovery mechanisms would restructure the economy and lead to prosperity (Institute of Statistical, Social and Economic Research [ISSER], 1995; Hutchful, 2002). But as it turned out, except for some macro-level positive outcomes, many scholars have written about the negative effects of SAP with respect to the poor, the environment, gender and labour relations, agriculture, social welfare, education and spatial and socioeconomic inequalities (Cornia et al, 1987; Anyinam, 1989; Loewenson, 1993; Mackenzie, 1993; Dei, 1993; Konadu-Agyemang, 2000, 2001; Panford, 1994; GSS, 1994; Brydon and Legge 1996).

Recently, however, Ghana has embarked on a number of economic reforms that aim to consolidate the experiences of SAPs and to mitigate the adverse impact on the vulnerable. In 1995, Ghana unveiled a twenty-five year (1996-2020) economic policy framework called Ghana Vision 2020. Vision 2020 aims to transform Ghana to a middleincome country by the year 2020. It consists of a series of five-year development plans. The First Medium Term Development Plan 1996-2000 (MTDP), also referred to as Vision 2020: The First Step, focuses on five development themes: human development, economic growth, rural development, urban development, and an enabling environment. 
(GPRS, 2003). Also, in March 2001, Ghana adopted the Highly-Indebted Poor Country (HIPC) Initiative ${ }^{3}$. HIPC is seen as a means to enhance the economy's capacity to achieve its macroeconomic targets, and accumulate funds to spend on social services (Boakye-Yiadom, 2004). As a HIPC conditionality, Ghana has prepared a Poverty Reduction Strategy. The Ghana Poverty Reduction Strategy (GPRS, 2003) focuses on devising pro-poor strategies to reduce inequalities facing poorer regions and groups. Its principal objectives include, attaining a reduction in the incidence of poverty in both rural and urban areas; strengthening the capabilities of the poor and vulnerable to earn income; reducing gender and geographical and socio-economic disparities; and promoting a healthier, better educated and more productive population.

According to a recent report by the Ghana National Development Planning Commission, Ghana is projected as one of the few African countries to meet most of its social development targets for the Millennium Development Goals (Ghana National Development Planning Commission [GNDPC], 2002). This prediction is apparently based on steady progress in the country's political and economic reforms over the medium to long-term. For example, in 2003, real GDP growth was 5.2 percent, exceeding the 4.7 percent target, whilst the budget deficit (3.4 percent of GDP) slightly increased above the projected target (3.3 percent of GDP). Also, between 1991/92 and 1998/99, based on income levels, Ghana made considerable progress in reducing overall poverty levels from $52 \%$ to $40 \%$ of the population. Extreme poverty also declined from $37 \%$ to

\footnotetext{
${ }^{3}$ The HIPC Initiative was proposed by the World Bank and the IMF, and is supported by governments around the world. The initiative is the first comprehensive attempt to reduce the external debts of the world's poorest, most heavily indebted countries (see HIPC website).
} 
27\% of the population over the same period (Ghana Statistical Service [GSS] 2000a: 7$10)$.

However, as is true of the general improvement in health, recent poverty reduction has not been even across geographic regions and social groups. By income measure, poverty is more acute in the three northern regions compared to elsewhere in the country. For example, in 1999, nine out of ten people in the Upper East, eight out of ten in Upper West, and seven out of ten in the Northern Region were classified as poor (World Bank, 2003:57). Also between 1991/92 and 1998/99, a 1\% increase in extreme poverty was recorded in rural savannah areas compared to no change in extreme poverty in the urban savannah areas. The increase in overall poverty across these three northern regions is therefore largely a rural phenomenon, a case of the poor getting poorer, and an indication that policy measures to alleviate poverty have not been very successful in this region (GSS, 2000a). Food crop farmers, who constitute about 59\% of the population, seem to have experienced the highest incidence of poverty. This phenomenon is blamed on their relative isolation from markets, high cost of agricultural inputs and low levels of economic infrastructure (GPRS, 2003). There also remain significant disparities in household access to health, education and water by locality. While Accra and the urban coastal and forest zones have enjoyed significant improvement in their living standards, with even the poorest groups in these areas appearing to benefit, residents of the savannah and rural coastal areas have seen very little improvement in economic wellbeing.

From a health perspective, general improvements are seen in the continued rise in life expectancy at birth since 1988. Infant and under-five mortality rates declined over 
$25 \%$ during this same period (WHO, 2001; World Bank, 2003). However, as discussed at the beginning of this chapter, these general improvements mask wide disparities between regions and social groups, with the rural areas and northern parts of the country recording worse health indicators. Other determinants of health such as female literacy, access to safe drinking water, and disposal of liquid and solid wastes are also unevenly distributed.

For several decades, Ghana's disease profile has remained unchanged, with communicable and infectious diseases, undernutrition and poor reproductive health topping the list of hospital attendances. However, with changing lifestyles in urban areas, non-communicable diseases such as hypertension, diabetes, cancer and mental diseases are on the rise, as well as an increase in tobacco use, alcohol and other substance abuse. HIV/AIDS has become a major health issue in certain quarters of the country. The national HIV prevalence rate is 3.6\% (Ghana National AIDS Control Program, 2005) ${ }^{4}$, with a sero-prevalence rate of $3 \%$ (2001) among the adult population. An estimated 600,000 persons have already been infected with HIV, comprising mainly commercial sex workers in Accra and Kumasi with rates of $75.8 \%$ and $82 \%$, respectively (ibid). HIV prevalence is said to be lowest in the three northern regions (ibid).

In terms of the organization of the health system, Ghana has a three-tier health system: the regional, district and sub-district levels. Well-trained health personnel and relatively modern facilities are located at the regional and district hospitals, while minimally trained staff and community health nurses are located at the health posts and community clinics at the sub-district/community level. Health facilities at the community

\footnotetext{
${ }^{4}$ See Ghana National AIDS Control Program website
} 
level are basic and are meant to treat simple curative cases, promote child health, and manage pregnancy related cases. Difficult and complicated cases needing surgery or admission are referred to the district and regional hospitals, usually located much further away from rural communities.

Finally, with respect to national education levels, both primary and secondary school enrolments have been consistently high in the Greater Accra and urban regions compared to the North and rural areas (Konadu-Agyemang, 2000). Similarly, the number of untrained teachers in the rural areas still remains high. In the Upper West region, the overall adult literacy rate is $44.5 \%$, compared to the national average of $68.8 \%$. In the rural areas this rate further declines to $38.7 \%$. Female literacy rates are much lower than males. Nationally, a little over 6 out of every 10 men, but fewer than 4 out of every 10 women are literate (GSS, 2000b: 11).

\subsubsection{Regional Perspective: The Upper West Region}

The Upper West Region (UWR) is located in the north-western corner of Ghana (see Figure 1). It was formerly part of the Upper region, but in 1983 , linked to the government's decentralization program, the Upper region was divided into two: Upper West (UWR) and Upper East (UER). The UWR has an estimated population of 573,860 (2000 population census) and covers a land area of approximately 18,476 square kilometers, $12.7 \%$ of the total land area of Ghana. The population density is approximately 31 persons per square kilometer compared to a national average of 77 . There are however pockets of high and low densities in some sectors. 
Administratively, the region is divided into five districts namely: Wa, Jirapa/Lambussie, Lawra, Nadowli and Tumu. Wa is the regional capital and it is also the only major town with a heavy concentration of population and a reasonable quantity of basic and modern infrastructure and services.

The people of the Upper West Region are mostly rural settlers with a characteristic dispersed settlement pattern. The dispersed arrangement of houses accommodates the compound farming system. It is estimated that the modal household size is in the range of 10-14 persons which underpins the wide practice of the extended family system. About 80 percent of the members of most households are children, a figure which indicates a high dependency ratio.

There are three main ethnic groups: the Dagaaba, Waala, and Sissala, and three religious groups: Christians, Muslims and people adhering to an African traditional religion. The difference between the Dagaaba and Waala is more dialectic than ethnic. All three ethnic groups in the region practice the patrilineal system of inheritance. Also, there is a high degree of intermarriage across all three ethnic and religious groups.

The climate in the Upper West region is often described as 'harsh', with mean annual temperatures of between $28^{\circ} \mathrm{C}$ and $31^{\circ} \mathrm{C}$. The months of February, March and April are very warm and difficult for inhabitants. It is also within this period that cerebrospinal meningitis (CSM) occurs. The region has two seasons namely, the wet and dry seasons. The wet season occurs from May to September and the dry season from October and April. From November to January comes the Harmattan, the northeast trade winds. The mean annual rainfall varies between $840 \mathrm{~mm}$ and $1400 \mathrm{~mm}$, with an average of 71-89 wet days in the year. Most of the rainfall comes between June and September and 
is generally low and unreliable both in timing and duration. This erratic nature of the rainfall pattern makes it difficult to predict the rainfall distribution for any cropping season.

The region is predominantly a subsistence agricultural economy and over $80 \%$ of the region's inhabitants are engaged in it. Mixed farming dominates and crops cultivated include, guinea corn, groundnuts, maize, rice, yam, and millet. Although many inhabitants engage in agriculture, food production is low, and has been attributed to factors such as depleting soil conditions, use of outmoded farming equipment, unfavourable weather conditions, poor marketing outlets and lack of credit to support farming activities. Farming often occurs in two sites: the compound farm and the bush farm. Compound farms are located immediately around the house and are normally cultivated annually. Bush farms are larger and located further away, within an average walking time of two hours. They are mostly cultivated on a bush fallow system. In the context of a rural agrarian society, farming is regarded as the activity that any respectable man must undertake. If a man has no farm, his status in the society is considered dented. Women, on the other hand, are expected to support their husbands on the farm while undertaking other income generating activities.

The farm family is the primary source of labour on the farm. In rural parts of the region, average household size is about 24 with an average number of farm workers ${ }^{5}$ per household of about 14 (Gyogluu and Dakurah, 2000). Decisions on the utilization of available labour are made by the household head, and the division of labour follows

\footnotetext{
${ }^{5} \mathrm{~A}$ farm worker in a household is perceived as any household member who is 'old enough' to do farmwork of some sort.
} 
gender lines. The men do the tilling of the land for compound and bush farms, do all the weeding and cut down the crop stalks during harvesting. Women provide labour on their husbands' farms by gathering and burning debris, plucking crop heads, carrying the farm produce to the house and planting all crops except yam and cassava. They also plant their choice of crops (mainly vegetables) on their own fields, that are portions of the family farm. The social system also regards communal work as very significant. It is deemed to promote feelings of togetherness and mutual help. Group solidarity and action towards each other's well-being are an integral part of increasing one's cropping capacity and harmonizing social links and relations. This practice is a survival and mutual support strategy that is rooted in the belief that 'unity is strength' and has great implications for participatory development projects.

Land in the community is owned on a communal and customary basis with individual user rights (Payne, 1997). Traditionally, the power to dispose of land rests with the tendaamba, the earth priest. The earth priest is appointed from the clan or group of people who first settled permanently in the village and defined its boundaries. The tendaamba occupies a position that is very significant in terms of religion and politics. He gives land liberally to household heads based on need and land availability. The land is given free of charge, thus making it prohibited for sale. The recipient can only show appreciation by giving a token such as kola nuts or fowls to the tendaamba. Old fallow lands can be re-allocated to other farmers who need more land in villages with scarce land. Personal arrangements allow them to borrow from or lend to other farmers without the involvement of the tendaamba. Young men have access to land through their fathers. Young men can also request land from the village authorities if land is abundant. Women 
are not allocated land by the tendaamba, as married women are often considered 'strangers' in their marital home and do not have hereditary rights to land. However, women enjoy usufructuary rights on their husband's farms and old fallow communal lands. They can also use portions of their husband's land to cultivate their own crops; mostly vegetables and rice. This arrangement, however, depends on whether the husband has enough land to grow staple cereals for the household. Also, while it is prohibited to sell land in most rural communities in the region, this custom seems to be changing as urbanization creeps in and the demand for lan'd by potential retirees increases.

\subsubsection{The Study Community}

Charia, the village in which this study was conducted, is located in the Wa district of the Upper West Region. It is approximately 8 kilometers northwest of the regional capital, Wa, and typifies most of the characteristics described above in the regional profile. The community has a population of approximately 4,500 people. About $50 \%$ of males and $70 \%$ of females, 15 years and above, have not had any formal schooling. The village is predominantly a rural farming community, with about $90 \%$ of the population engaged in subsistence farming. The village has a rich deposit of clay and many women engage in pot making. Pottery, pito $^{6}$ brewing and charcoal making are the main economic activities undertaken by the women of Charia. Most men in the community are blacksmiths, carvers and petty traders. These activities are used to supplement crop and livestock incomes.

\footnotetext{
${ }^{6} \mathrm{Pito}$ is a local beer made from guinea corn.
} 
Like many rural communities in the region, degraded lands, depleting soil fertility and other environmental problems, characterize the village. Food security is undermined by low agricultural production. Health status is very poor compared to urban areas. The village has one health centre that treats minor cases. Major cases are referred to the regional hospital in Wa. Lack of timely transportation to the hospital often results in death, while lack of money for hospital fees forces many sick people to either stay home or resort to the use of traditional medicine.

Charia has been a favourable site for many international development activities. This has been explained in two ways. First, the people of Charia seem to have wellorganized community groups such as the Christian Women's Association, the Muslim Women's Group, the $31^{\text {st }}$ December Women's Groups ${ }^{7}$, and other Youth Groups. This makes organizing communal projects relatively easy. Also, community members seem very enthusiastic about community development projects. This was apparent during my first encounter with the community in 1996 , when I worked with them on a communitybased environmental management project.

The second explanation given for why Charia attracts many international development projects is because of its proximity to the regional capital, Wa. Charia is approximately 20 minutes drive from $\mathrm{Wa}$, and so allows development workers to live in the city and still be able to carry out their daily activities in the village. Significant among the international development projects in the community has been a Canadian International Development Agency (CIDA)-sponsored Environmental Management

\footnotetext{
${ }^{7}$ The $31^{\text {st }}$ December Women's Movement is a women's non-governmental organisation that was formed in 1982 by a former First Lady of Ghana, Nana Konadu Agyemang-Rawlings. The group draws attention to Ghanaian women's concerns and advocates for the political and socio-economic emancipation of women in the country.
} 
Literacy Project, which was later renewed as a Ghana-Canada IN CONCERT ${ }^{8}$ program under CIDA's Universities Partnership in Cooperation and Development (UPCD) Program. The first project was aimed at achieving both adult literacy and teaching local people about environmental conservation. So material on environmental conservation was developed into adult literacy manuals, and taught to local men and women. A second significant project has been a partnership between two Canadian Universities and other Ghanaian Universities and Institutions, with the fieldwork located in northern Ghana. The project is aimed at getting Ghanaian and Canadian institutions to work in concert to achieve common goals relating to resource conservation and entrepreneurship development through training. Charia has also been the site for a World Bank sponsored Savanna Agricultural Resource Development Project which promotes and supports agroforestry projects in the community.

\subsection{Organization of the Thesis}

I have used this introductory chapter to locate the thesis within its broad theoretical and methodological domains and to outline a road map for the thesis. I began by illustrating that this thesis adds voice to those calling for public health research to broaden its search for causes of ill health to include an understanding of the social, political, economic and environmental contexts that shape those health outcomes. I argue that, in order to understand and intervene upon the growing health disparities in Ghana, we need to

\footnotetext{
${ }^{8}$ IN CONCERT is an acronym for Initiatives for Conservation in Northern Communities: Entrepreneurship, Resources and Training.
} 
employ analytical frameworks that situate these problems within their historical and political antecedents. I also argue against the use of individual-level interventions, illustrating the usefulness of community-based participatory approaches in generating critical consciousness about the problem and ways to improve it. I conclude the chapter by outlining my research questions and objectives, followed by a description of the study area.

In Chapter II, I locate the current health disparities in Ghana within an historical context, outlining how colonial agricultural, health and other development policies led to an uneven development between the northern and southern parts of the country, as well as between rural and urban areas. I also illustrate how the health situation and health disparities failed to improve after independence amidst postcolonial policies, international health politics and structural adjustment programs. I conclude the chapter by charting the recent reforms being undertaken by the health sector.

Chapter III sets out the theoretical elements of the study. I begin by tracing the historical antecedents leading to the adoption of an ecological approach to public health research and how these have been complemented by parallel events in the environment sector. I then describe the three major theoretical frameworks that inform this thesis: the ecosystem approach to human health, the political ecology framework, and communitybased participatory approaches to health research. The key constructs in these approaches are discussed in light of recent theoretical developments from poststructuralist and feminist theory. 
In Chapter IV, I discuss the methodological considerations, key elements and principles underpinning the use of participatory action research. I discuss the various stages of the research process and how data were collected using a variety of methods including a strategic planning process, focus group discussions and in-depth interviews. I conclude the chapter by reflecting on my experiences in the field and the challenges and ethical dilemmas of the research process. The dynamic and political nature of the research and the need for constant negotiation between the researcher, the research team and research participants are also discussed.

The findings of the study are presented in Chapters V, VI and VII. In Chapter V, I present men and women's conceptions of health and ill health, and what they consider to be indicators of good health and poor health. Their responses are analyzed to reveal areas of broad consensus and difference between and among men and women, and how social and gender relations, and existing social structures shape those responses. Men and women's views are also contrasted with western constructions of health and ill health, and clashes between 'lay' and 'expert' views are discussed. Participants' accounts are analysed in light of poststructuralist ideas on health, examining how certain views and knowledge claims get privileged over others. The concluding section discusses what men and women perceive to be the major health problems facing the community. Their lists and rankings of community health problems are compared to community health records. The congruence and non-congruence of these community health problems between men, women and available health information is assessed. I make use of direct quotations from transcripts of group discussions in an attempt to reflect participants' points of view. 
In Chapter VI, I present participants' views of the factors influencing the occurrence of major health problems in the community. I analyse these through the lens of a political ecology of health approach, illuminating how ill health and the social patterning of disease are linked to and result from political and economic struggles over vital environmental and health resources. For purposes of organization, I discuss participants' accounts under two broad categories. First, are environmental conditions including climatic variability, agricultural productivity and health, ecological disturbances and the emergence of disease vectors and water and sanitation. The second category explores less proximate socioeconomic and cultural issues, including poverty, societal organization, and limited access to health services.

In Chapter VII, I present the findings of a strategic planning process, which explores participants' vision for a healthy community, their perception of obstacles preventing them from realizing that vision, and an assessment of their strengths and resources for achieving their vision. The implications of these findings for health interventions and community health promotion programs are then discussed alongside.

In the concluding chapter, Chapter VIII, I recap the major findings emerging from the study and discuss their implications for community health research. The pitfalls associated with using participatory action research for conducting a doctoral thesis are discussed and the theoretical and methodological contributions of the study to parent disciplines assessed. Finally, I outline areas for further research. 


\section{CHAPTER II}

\section{LOCATING CONTEMPORARY RURAL HEALTH PROBLEMS IN NORTHERN GHANA IN AN HISTORICAL PERSPECTIVE}

To overlook the roots or genesis of a problem is to treat it like a landscape which is given and whose history is unimportant to our approach to it [Aidoo 1982: 640].

\subsection{Introduction}

A fuller understanding of the health and development challenges facing northern Ghana (Upper West, Upper East, and Northern Regions) and other rural parts of the country can be better understood from an historical perspective, situating them within colonial and postcolonial policies and Ghana's past economic reforms. Through this historical account, I seek to demonstrate that the uneven development generated by the colonial administration between the Northern savanna regions, on one hand, and the Southern coastal and forest regions on the other, and between rural and urban areas, has had drastic and long lasting implications for health outcomes and health service delivery in Ghana. I draw on evidence of increasing spatial and social health disparities in Ghana, to illustrate how these were further augmented through the implementation of the World Bank and IMF sponsored structural adjustment programs. I conclude the section by reviewing the current policy reforms of the health sector and how this sector plans to redress health disparities and work towards the improvement of the health of all Ghanaians. 


\subsection{Ghana's Colonial Legacy}

Ghana came under colonial rule in the mid- $19^{\text {th }}$ century when the Bond of 1844 established a trade and political agreement between the British and the coastal areas (Aidoo, 1982; Sutton, 1989). The main objective of colonialism was to establish and strengthen favourable sociopolitical conditions for imperialist penetration and exploitation. This involved the extraction of natural resources and other primary goods for capital investment (Aidoo, 1982). Many infrastructural facilities such as schools, hospitals, roadways and economic projects were located in port towns and administrative centres, which were found in the Southern portion of the country (Arthur, 1991). The outlying northern half was considered as a 'labour-reserve' for southern Ghana (Plange, 1979; Aidoo, 1982; Songsore, 1989). However, as Sutton (1989) explains, this trend of resource concentration in the southern half of the country did not just begin with colonialism, but dates back to pre-colonial eras when European powers established their trading posts along the coast. They preferred the southern half to the north because the climate there was very favorable for agriculture and there was more external demand for the crops grown in the south than in the north. Also, the existence of rich mineral deposits and the close proximity to seaports influenced their decision to locate in the south. Besides, prior to British colonization of the coastal areas and the forest zones in 1844 , capital and labor from the north had already accumulated in the south through slave trade. Thus, many rural areas in the South were used for agribusiness and plantation developments. In some instances land in these areas was systematically appropriated for mining, lumbering, cash crop production, among other economic activities. Land 
appropriation was done mostly through the classification of large acres of idle land into Crown lands and also through the enactment of a series of ordinances to forcefully acquire land. In some cases, communal land was sold or leased to companies by the trustees (Arthur, 1991). The emphasis on export production encouraged infrastructural developments in Southern Ghana which was designed to facilitate exploitation of the valuable wealth of the forest areas. The success of these developments resulted in urbanization and the relative development of the region.

On the contrary, the achievements of cash cropping and mineral exploitation in the South were to have backwash effects on the North. The most important way in which the north was incorporated into the national economy was to provide labour for the southbased export economy, while remaining a predominantly subsistence agricultural area (Songsore, 1989). With growing need for labour in the South, many northern young men began migrating to work in the south. While the decision to migrate was often voluntary, there were times when labour was forcefully recruited for the mines through a law called the 'Master and Servant Ordinance' (Plange, 1979:671). This forceful recruitment depleted many villages of young, able-bodied men (Onoge, 1973; Aidoo, 1982). As Geest (2002:56) points out, in 1934, about 55 percent of the total work force in the gold mines was comprised of northerners. The conditions under which migrants lived and worked were deplorable, often resulting in high rates of morbidity and mortality (Thomas, 1973; Plange, 1979). Tuberculosis was often contracted by these miners, and upon return to their villages, they spread it widely.

In 1927 , the system of forced labor recruitment was abandoned and ten years later, a policy of indirect rule and direct taxation was introduced in the Northern 
Territories (Thomas, 1973; Fortes, 1945, cited in Geest, 2002). This new policy compelled the subsistent farmer to consider alternate ways to raise money for taxes. Seasonal labor migration seemed the preferred option for the northern farmer, since this was better paid than cash-crop cultivation (Sutton, 1989). In a way, forceful recruitment was replaced by a subtle and indirect policy that resulted in seasonal migration trends.

Migration by northern young men to southern Ghana continues today, although the trend and reasons for migrating differ between regions. According to Cleveland (1991), seasonal migration seems to have been replaced by permanent migration, as young men tend to stay away longer than just the dry season, which adversely affects agricultural production in northern communities (Thomas, 1973; Hart, 1974; Nabilla, 1975; Plange, 1979). Also, the reasons for migration have evolved to include: escaping family obligations and conflicts, scarce family land for farming, low agricultural productivity, and the quest for adventure (Arthur, 1991; Cleveland, 1991). Also there is a tradition that supports the notion that young men who return from the south are adventurous, are deemed to have 'seen the world' and so are ready for marriage.

There have been some mixed concerns when it comes to assessing the impact of migration on the migrant, his family, the community and the region as a whole. As discussed above, poor working and living conditions may affect the health of the migrant. His physical absence might increase the workload of family members, especially women, and affect agricultural productivity. On a positive note, however, others argue that remittances from migrants to their families are often enough to offset this increased workload by paying for hired farm labourers, as well as paying school fees for children or for setting up small-scale family businesses (Addo, 1975; Caldwell, 1975; Stark, 1976). 
During my interviews with women, many indicated that the mental stress and 'worrying' about the absence of a family member outweighed the benefits. From a community and regional perspective, though, it is assumed that migrants return to their communities with good organizing (labour) ideas for community development projects (Arthur, 1991). My conversations with men, however, indicated that such 'radical' views have the tendency to render one an 'outsider'.

In the 1970s and 80s, Ghana's government assessed the overall costs and problems associated with rural to urban migration as outweighing the benefits to the individual migrant, and instituted a number of policies aimed at retaining the rural population (Arthur, 1991). Some of these included the establishment of local industries for the processing of agricultural raw materials into finished or semi-finished commodities for rural consumption and export; new investment codes to provide tax credits and incentives to local and foreign companies willing to locate in depressed rural areas; and development of infrastructure to attract businesses to the rural areas. However, due to the lack of a comprehensive national development plan at the time, these policies had limited success (ibid).

\subsubsection{Colonial Health Policies}

Colonial health policies were primarily concerned with preserving the health of European masters, understanding the aetiology of tropical diseases and developing technologies to cure them (Doyal and Pennel, 1976; Aidoo, 1982). As such, disease and parasitic models dominated colonial medical thinking about Africa's health problems. There was emphasis on finding the cure for diseases like malaria, yellow fever and schistosomiasis so as to 
allow for the expansion of European colonization of the tropics (Farley, 1991, cited in Randall, 1998). With this system of health, colonial experts made most of the decisions about health, health care and its distribution (Randall, 1998). Indigenous views and health needs were rarely taken into account. Also, the broader determinants of health received little attention. Colonial medical authorities viewed broad-based efforts to deal with the underlying social and economic determinants of ill health as impractical, expensive, and unnecessary (ibid). At best, separate housing was developed to protect the health of expatriates. Bungalows with modern water supply and sanitary disposal systems were built for top government officials and merchants of mining companies (Twumasi, 1981). Thus, the provision of health services was selective.

The subordination of health services to the needs of colonial production largely determined the distribution of health services. In Ghana, many hospitals and clinics were located in the administrative centres, port towns, mining areas, and sites of production, signaling the beginning of urban-based health services (ibid). Rural areas were neglected except for a few clinics that were established by the Basel and Catholic Missionaries in the effort to convert pagans to Christianity (Twumasi, 1981). These services focused primarily on maternal and childcare and were designed to support the reproduction of converts (Randall, 1998).

There were also attempts by the colonial administration, in collaboration with missionaries, to tarnish traditional medicine, which was a major provider of rural health care. Traditional medicine was branded as unhygienic, superstitious and unscientific. Traditional healers were called 'witch doctors', and missionaries urged their followers to shun them, arguing that it was against Christian teaching to seek medical help from 
traditional healing. Also, campaigns were launched to enlighten urban dwellers and opinion leaders about the ignorance and insincerity of traditional healers (Twumasi, 1981). Despite these discretions, traditional medicine was not completely eliminated during the colonial period. Its image was tarnished and its evolution into modernity delayed until the postcolonial era when the nationalist government institutionalized it (Twumasi, 1975). A Traditional Medicine Practice law was passed in 2000 and the current government (the New Patriotic Party) has pledged to promote traditional medicine, make it safe and integrate it with the allopathic system (WHO, 2001). Although colonial health policies emphasized the preservation of the health of the European Master, it was also important to preserve the health of the African labourer (Aidoo, 1982). In order to continue with the economic activities vital to colonialism, the labour force had to be preserved, and so hospitals were established at mines and harbours to provide health services for both the workers and their European supervisors. With time, supporting domestic and clerical and technical staff was also allowed to benefit from modern medical services. This strategy was in response to the realization that cultural isolation did not prove to be an effective preventive measure to infections and epidemics, as the local people who worked closely with the European master could be carriers of possible infections.

In sum, the current rural health problems and the existing health disparities between rural and urban areas, and between the north and south, are deeply rooted in the colonial government's concern with the preservation of the health of the European elites first, and subsequently the African working force. As such, many health facilities were urban-based, located in southern centres of development, and were preoccupied with 
developing technological cures for 'tropical' diseases. The health of the rural populace and the northern labour force, which bore the brunt of capitalist exploitation, were left unattended.

\subsection{Health in Post-Independence Ghana}

After independence, many Ghanaians hoped for a reformed medical system. With a desire to fill the vacuum that was created by the sudden departure of expatriate health professionals, the nationalist government, led by Dr. Kwame Nkrumah, built new health centres, schools, colleges and universities and increased training for health professionals. Also, in an attempt to bridge the gap that was created between the north and the south, Nkrumah universalized free education and health care, built roads and other social infrastructure, and oversaw the establishment of big towns in the northern regions of the country (Ray, 1986).

However, the colonial legacy of disease-focused, curative-oriented and urbanbased health system prevailed after independence. Many health facilities continued to be built in urban areas and so most of the newly trained doctors stayed in the cities and towns rather than in rural areas. Preventive medicine, which was crucial for the health needs of rural people, received little attention (Twumasi, 1981; Aidoo, 1982). In the few cases where preventive health care took place, it was primarily based on the western biomedical model of health. As discussed previously, this model entreated the individual to protect his or her health by observing good hygienic practices, while ignoring other social causes. Communicable and preventive diseases were predominant in the rural areas 
and were blamed primarily on poor environmental sanitation, superstitions and the ignorance of mothers. Thus while mortality rates were decreasing in urban areas, children and nursing mothers were dying daily in rural areas (Twumasi, 1981). Reminiscent of the colonial period, preventive and broad based medicine was considered expensive. The provision of sanitation and waste management facilities, clean water supply, adequate drainage and sewerage systems in rural areas was seen as a waste of money. The costeffectiveness of preventing diseases, rather than curing them was not rational, partly because the entire health system and staff had uncritically adopted the biomedical approach.

From a continental perspective, Randall (1998) points out that international health politics played a key role in the persistence of disease-focused approaches to health interventions. After independence, it was hoped that newly independent African countries would play key roles in health policy decision-making. Instead the power of such decisions rested with the new centers of expertise for 'global' development, the United Nations system, including WHO, UNICEF and FAO. With little representation of African nations on the so-called 'expert committees' created by these organizations, the tendency that policies emanating from these bodies would address African health concerns was questionable. ${ }^{9}$ In addition, Randall (1998) and Litsios (1997) argue that the structure and mandate of these organizations were geared towards colonial health policies. For example, the United Nations system of agencies worked in ways whereby various agencies took on responsibilities for specific functions that were narrowly defined,

\footnotetext{
${ }^{9}$ For example, in the late forties and fifties, only one African country, Liberia, had a representative on the World Health Assembly.
} 
overlapped with others, and even competed among one another. Thus, despite the recognition that health could be enhanced through a concerted and integrated effort by these agencies, there was little if any cooperation between them. The separation of agency responsibility within the UN system meant that the activities of WHO and UNICEF mimicked the activities of colonial governments, became defined along narrow biomedical lines and seldom addressed the links between health and social and economic development (Litsios, 1997). Also, large-scale disease eradication programs were viewed as a means of establishing the legitimacy of these new agencies. Making a difference quickly was considered more important than sustainable outcomes in the policies adopted by WHO and UNICEF following World War II. Accordingly, a number of international health documents in the post war period expressed satisfaction in the ability of technology to overcome health problems in developing countries (Randall, 1998).

However, by the early 1970 s, some academics and health practitioners began to criticize unilateral, capital-intensive strategies and technology-based health care, such as had been used by the WHO and other agencies. Concurrently, there was growing appreciation of the potential of more community-oriented efforts based on disease prevention strategies, popular participation, and self-reliance as had been demonstrated by the successes in China and other places (Sidel and Sidel, 1973; Matomora, 1986).

In response to these concerns a number of international health initiatives were instituted. Notable among them were the Alma Ata Declaration on Primary Health Care (PHC) (1978) and the Ottawa Charter for Health Promotion (WHO, 1986). PHC was geared towards reorienting the development of health care in Africa. First, it emphasized the need for community participation in health planning and implementation, not only as 
a way of ensuring that health programs suited community needs, but also as a way of raising political consciousness and getting people to take responsibility for their own health (Asthana, 1996). Secondly, it sought to reduce and eliminate the existing disparities in the distribution of health resources. Broad-based health coverage rather that selective coverage was encouraged. Finally, PHC called for recognition of the social and economic causes of ill health. Intersectoral cooperation between health and other sectors such as agriculture, education, housing and energy among others, in solving health problems was also encouraged. The concept of community involvement in health promotion was also given credence in the Ottawa Charter for Health Promotion. The Charter expressed a new view of health, placing it firmly in the context of new ecological thinking (Kickbusch, 1999), and emphasizing the association among health improvement, stable ecosystems, and the protection of the environment.

However, in Ghana, primary health care failed for a number of reasons. One reason was that PHC was launched at the time of the implementation of economic adjustment policies (Asthana, 1996), and the introduction of user fees and cutbacks in health spending further worsened the plight of the poor and rural dwellers in terms of being able to afford basic health services. Also there seemed to be a striking mismatch between policy statements and actual implementation as related to decentralization and resource allocation within the framework of primary health care (Adjei et al., 1988; Vogel, 1988). For example, most health resources were still channeled to urban, hospitalbased curative health services rather than to the promotion of primary health care in rural areas. This form of providing comprehensive PHC was considered too expensive for developing country governments and was replaced by the Selective Primary Health Care 
Strategy (Walsh and Warren, 1979). Selective Primary Health Care was a strategy that selected and targeted a few diseases responsible for the greatest morbidity and mortality in the country, for which proven intervention existed. This form of health care has since been practiced in Ghana and puts particular emphasis on child health promotion (immunization, breastfeeding, growth monitoring, and oral rehydration therapy), and high-priority diseases such as diarrhoeal diseases, whooping cough, measles and neonatal tetanus. Notwithstanding some inroads made by this selective primary health care strategy, the emphasis on specific cases and specific population groups has resulted in an almost vertical, top-down system of care, rather than an intersectoral, integrated community-based health system (Adjei et al., 1988; Vogel, 1988). Disease rather than health is still the focus. Indigenous perspectives, and the promotion of self-help and the potential for local communities to play an active role in addressing their health concerns are still undermined (Randall, 1998). Thus, by the close of the 1990s, we had gone full circle; health intervention had once again become narrowly focused on disease rather than on achieving comprehensive well-being.

Also, according to Aidoo (1982) a number of committees were formed to look into addressing rural health concerns. Some of these included the Brachott Committee (1961), the Eastmon Committee (1966), and the Health Sector Committee (1971). Also pilot projects were set up in selected rural communities and included the Danfa Comprehensive Rural Health and Family Planning project ${ }^{10}$, which was financially sponsored by the WHO and USAID. A recent one is the Navorongo Health Project. But

\footnotetext{
${ }^{10}$ The Danfa project involved collaboration between the University of Ghana Medical School, the Ghana Ministry of Health and the School of Public Health of the University of California.
} 
as critics have observed, these new endeavours seem to be based on the same old western biomedical approach, although the principles underlying them might state otherwise, as was the case with the PHC (Randall, 1998).

In sum then, Ghana's independence did not completely succeed in reshaping the selective health system that was inherited from colonial rule. The persistence of colonialclass based structures that created new elites, and the continuous dependence on foreign capital and external health expertise reproduced conditions reminiscent of the past. The onset of economic crisis and the implementation of structural adjustment programs further impeded attempts by the government to integrate new international policy initiatives aimed at reorienting the health system.

\subsection{Structural Adjustment Programs and Health}

Many scholars conclude that the implementation of SAPs has had mixed effects, generating some positive effects at the macro level, while adversely impacting some individuals and the vulnerable in society (Institute of Statistical, Social and Economic Research [ISSER], 1995; World Bank 1995, 1996; Konadu-Agyemang, 2000). At the macro-level, the implementation of SAPs in Ghana seemed to have augmented trade, reversed the economic decline preceding SAPs, and reduced inflation (Herbst, 1993; Martin, 1993). It also seemed to have restored donor confidence and attracted foreign

investment (Huq, 1989; Boachie-Danquah, 1992; Anyinam, 1994; ISSER, 1995; World Bank 1995, 1996; Konadu-Agyemang, 2000). 
At the same time, during the implementation of SAPs, Ghana's external debt amounted to about US\$ 7510 billion in 1999 (Konadu-Agyemang and Takyi, 2001:25). Debt servicing took a substantial amount (62\%) of export earnings, leaving little money for basic social services such as education, health and nutrition (Konadu-Agyemang, 2000:472). The devaluation of the Ghanaian cedi made the importation of essentials such as food, drugs, machinery and school and medical supplies very expensive. Exploitation and export of natural resources also reached an unprecedented level in an attempt to reach previous earning levels (Konadu-Agyemang and Takyi, 2001). Unemployment and underemployment increased substantially. The state cut expenditures on public and social welfare services, and introduced user fees for health and education (Anyinam, 1994; Konadu-Agyemang, 2001).

The implications of cutbacks in health spending and the introduction of user fees have negatively impacted health in four important ways: first, an increase in mortality and morbidity rates; second, an increase in food insecurity and undernutrition; third, reduced access and utilization of health services; and fourth, development of centralized and socially averse health policies (Aninyam, 1989; Loewenson, 1993; Stock, 1995; Oppong, 1997; Turshen, 1999; Konadu-Agyemang, 2000).

Data reported by Kanji et al. (1991) showed rising rates of ill health and mortality among African countries implementing SAPs. For example, in countries like Madagascar, Ethiopia, Mali and Uganda, infant mortality rates that began to decline before SAPs, increased by up to $4-54 \%$ and under-five mortality rates by 3.1 to $90.9 \%$ (p 990-1). In Ghana, diseases such as yaws and yellow fever that had been considered eliminated began to re-surface (ibid). 
Similarly, household food security has been threatened by reductions in food subsidies and rising food prices. In the mid-1980s, the average wage in Ghana was sufficient to purchase only $30 \%$ of food needs (Cornia et al., 1987). As such, many households shifted their food consumption choices to poorer quality, high bulk and low energy food products (Loewenson, 1993). The promotion of the cash-cropping sector also put an extra burden on women in smallholder households to produce more crops for sale (Kanji et al., 1991; Mackenzie, 1993). Heavy workloads combined with the inability to meet the family's consumption needs undermined the nutritional status of both women and children, increasing their susceptibility to infectious disease and other maternal and child related morbidity and mortality. Within the adjustment context therefore, costs for social reproduction shifted to women, increasing their burden, exploiting their labour to finance international capital and ruling national elites, with dire consequences for their health and that of their children.

With respect to health services, Stock (1995) argues that cutbacks in health sector spending led to large staff layoffs and significant salary reductions. This created a situation of consulting clinics being mere empty spaces with no drugs nor adequate medical staff, since many doctors fled the difficult conditions. Also, as a cost recovery measure, the introduction of user fees made western medicine unaffordable for lowincome groups and rural dwellers, forcing them to turn to traditional and cheaper forms of medical intervention (Anyinam, 1989; Lavy and Quigley, 1993). User fees led to an immediate drop in hospital and clinic visits in both rural and urban areas (Enyimayew, 1988). Also, child immunization, attendance at malnutrition clinics, and antenatal clinics all fell substantially (Anyinam, 1989; GSS/MI 1998, 1999). 
Cutbacks in government expenditure also created conditions for drug manufacturers to dump low quality drugs in developing countries. The lack of foreign exchange in many countries reduced the government's ability to import medical supplies, including drugs and consumables such as syringes and bandages for public health. Due to shortages of drugs, patients issued with prescriptions turned to private pharmacies, where substandard and expired drugs were stacked. Reports indicate that drugs produced in Western countries for export to African countries at the time did not always meet the same high standards of safety and efficacy as those intended for sale in the country of manufacture (Ollila and Hemminki, 1997). In addition drugs unapproved, banned, or withdrawn in industrialized countries were marketed to developing countries, further exacerbating the already precarious health situation (ibid).

With respect to the impact of SAP on health policy, Loewenson (1993:724) argues that through SAPs, many proactive African health policies that were demandoriented and focused on responding to the health needs of their people have now been replaced by a supply-oriented system that is driven by questions of what is affordable and cost effective. Also SAP has widened the gap between communities and policy makers, with policy makers collaborating more closely with financial institutions than with their communities, to design and implement programs that can accommodate SAP (ibid.).

The overbearing social costs of SAPs led to calls by UNICEF and other international organizations for 'structural adjustment with a human face'; programs that would alleviate the suffering of the poor (Kanji et al., 1991). In 1987, Ghana adopted the 'Program of Action to Mitigate the Social Costs of Adjustment' (PAMSCAD). Among other activities, PAMSCAD was meant to provide employment and training for 
retrenched workers as well as provide funds for health care and education for the urban and rural poor. However, as critics point out, by providing health to the poor through acts of charity and as a marketable product for those who can pay, health has been redefined from being a basic human right to a charitable or marketable entity respectively (Loewenson, 1993). PAMSCAD has thus been deemed as ineffective, as it obscures the underlying causes of poverty and ill health and tends to become unstable over the longterm (Baldwin, 1991; Loewenson, 1993).

In conclusion, while SAPs seemed to have affected many people one way or another, I would argue that, as a result of minimal coping options, the poor, rural dwellers and vulnerable, bore a substantial portion of these adverse effects. Also, drawing from a number of sources, Konadu-Agyemang (2000) demonstrates that existing disparities in income, access to education, health care and other services, between rural and urban areas, and between northern and southern Ghana seem to have been augmented during the implementation of SAPs.

\subsection{Recent Health Sector Reforms}

As part of on-going efforts to improve Ghana's health sector and reduce health disparities, the Ministry of Health (MOH), in 1996, and in line with Ghana's Vision 2020, developed a Medium Term Health Strategy (MTHS) (MOH, 1996). This strategy aimed to: rehabilitate and expand infrastructure and logistics within the health sector; forge links between public and private health care providers; improve human resource 
development; and finally, strengthen and decentralize the management of the health care in the context of a Ghana Health Service (GHS).

The MTHS has been translated into two programs of work (POW). The first was implemented between 1997 and 2001. This was carried out in partnership with both internal and external partners ${ }^{11}$. The partnership between the $\mathrm{MOH}$ and development partners is guided by the principles of the Sector Wide Approach (SWAP), which requires donors to pool their resources into a common Health Fund, which is managed by the $\mathrm{MOH}$ in parallel with budgetary resources and common management arrangements.

The second POW (2002-2006) was refined to align with the health objectives of the Ghana Poverty Reduction Strategy (GPRS, 2003). One primary goal of this second POW is to improve the health status of the population while reducing socioeconomic and spatial health inequalities. Also, a broader definition of the health sector has been adopted to include government health services, traditional and non-government providers, civil society and community groups. Together, the Ghana Poverty Reduction Strategy (GPRS) and the POW-II make strong emphasis on: promoting equity of health outcomes with a special focus on diseases that affect the poor most; enhancing efficiency in service delivery; ensuring sustainable financial arrangements that protect the poor; and, strengthening links with health related sectors of society. It is expected that the health objectives of the Millennium Development Goals (MDGs) and the New Partnership for African Development (NEPAD) will inform this second five-year POW as it unfolds (WHO, 2001).

\footnotetext{
${ }^{11}$ Key players being DFID, DANIDA, the World Bank, the Netherlands, the European Union, and the Nordic Development Fund.
} 


\subsection{Conclusion}

In this chapter, I have located the existing health disparities and the health crisis facing rural communities and northern Ghana within an historical perspective. In so doing, I have sought to illustrate how colonial policies, driven by the need to preserve the health of European masters and the African labour force, pursued a health system that has been detrimental to rural health care, and still persists today. I have also illustrated how postindependence governments, despite attempts, failed to restructure the health system into a people-oriented one, partly because of the entrenchment of the colonial class-based structures, overdependence on external help and the onset of economic crises and their failed remedies. Finally, in another attempt at reform, the Ministry of Health, in conjunction with Ghana's poverty reduction strategy, has made reducing health disparities a central focus through its medium term health policy.

While it is comforting to see the health concerns of the poor as central to these new directions, I am concerned that since the actors are rarely different from previous efforts, the chance of succeeding this time around is questionable. As Randall (1998: 1516) points out:

' $[\mathrm{O}]$ ne is struck more by the continuity of approaches than by the creation of new ideas. Part of the answer must lie in the fact that nearly everyone involved in thinking about health in Africa shares a common biomedical paradigm. This is a product in part of the externality of decision-making and the lack of space for indigenous ideas and knowledge. Those who advocate a political economy of health perspective have had little to add, in part because of their inability to 
provide viable alternatives, short of social revolution; and in part because of the financial implications of such approaches'.

In the next chapter, I discuss the theoretical approaches underlying this study. 


\section{CHAPTER III}

\section{THEORETICAL PERSPECTIVES: ECOSYSTEM APPROACHES TO COMMUNITY HEALTH RESEARCH}

\subsection{Introduction}

In this chapter, I discuss the theoretical perspectives underlying ecological approaches to public health research and intervention. I begin by reviewing the literature on events leading to the onset of the ecosystem approach to human health, which I used in this study. Through this review, I demonstrate how the ecosystem approach resulted from a concurrent evolution in thought in both the public health and environmental sciences. This is followed by a discussion of the ecosystem approach and its key principles. Since the ecosystem approach alone does not engage in historical analysis and interrogation of the power structures surrounding environmental resource use and the resulting health implications, I draw on political ecology theorizing to complement the ecosystem approach in examining how these health inequalities are produced. Finally, I examine the key principles of community-based participatory research approaches. I problematize these in light of critical social theory and poststructuralist theorizing.

\subsection{Events Leading to Ecological Approaches in Public Health}

Ecological thinking in public health is not new. It dates back to the early nineteenth century with the emergence of the sanitary paradigm in Europe. This paradigm was organized around environmental concerns and a collection of hygienic practices that were 
thought to preserve health (Pedersen, 1996). With the discovery of microbes in the late nineteenth century, attention was shifted to specific micro-organic agents as the causes of disease. Much emphasis was placed on cause-effect linkages between microbes and epidemics, and emphasis on environmental action was shifted to personal prevention (Ashton, 1992). This era was, in turn, superseded by the treatment/therapeutic era, dating from the 1930 s to the early 1970 s, when public policy on health in many developed countries was dominated by a treatment orientation and many people perceived drugs as the solution to almost all health problems. The developing world was also socialized into accepting this model of health system, with state-of-the-art-hospitals and expensively trained health professionals (ibid). By the mid-1970s, many countries began experiencing a crisis in healthcare costs, as enormous amounts of resources were needed to sustain the high-technology medical care (Davies and Kelly, 1993). Developing countries became increasingly unable to provide basic health care.

While criticisms of the inappropriateness of the biomedical model of health care increased, McKeown (1971) argued that decrease in mortality rates in western countries over the past two centuries was largely due to improvements in the physical environment, an increase in food supplies, smaller family sizes, changes in social and economic conditions, preventive measures, and the control of infectious diseases, and not due to advanced medical care and technology (McKeown, 1971; 1976). Hence major improvements in health in the nineteenth century were not due primarily to medical interventions and therapeutic efficacy, but mainly due to improvements in the socioenvironmental determinants of health. McKeown's ideas and analysis were incorporated in a Canadian federal publication entitled, 'A New Perspective on the Health of 
Canadians', also known as the Lalonde Report (Lalonde, 1974). The report suggested that a broad range of factors influences human health including: human biology, social and physical environments, lifestyle and medical services. The report went on to advocate that human health would be greatly improved through environmental actions and the adoption of health-enhancing lifestyles. Unfortunately, emphasis was placed on the latter as it was more in tune with the existing biomedical model. Thus individual actions such as behaviour-modification - exercise, nutrition, habits - took precedence over community oriented approaches to health improvement. Health was, thus, increasingly seen as an individual's responsibility, rather than determined by social, political and environmental structures (Neubauer and Pratt, 1981; Lupton, 1994; Minkler, 1994).

The mounting criticisms of biomedicine and the publication of the Lalonde report (1974) laid the foundation for a 'new' public health movement, one that moved away from the lifestyle approach to embrace social, environmental and community aspects of health. This movement was underscored by a number of initiatives from the World Health Organization (WHO), starting with the Alma-Ata declaration on Primary Health Care in 1978, which gave formal recognition to the role of community participation in health (WHO, 1978). The concept of community involvement in health promotion activities was further endorsed in the 'Ottawa Charter for Health Promotion' (WHO, 1986). The Charter also emphasized the interrelations among health improvement, stable ecosystems, the sustainable use of natural resources, and the protection of the environment. Similar sentiments were expressed in subsequent declarations and initiatives including: the 'Health for All by the Year 2000' strategy, the Healthy Cities Project Initiatives, Healthy Public Policy Conference in Adelaide, Call for Action: Health 
Promotion in Developing Countries, and the Sundsvall Statement on Supportive Environments. The central elements underlying all these initiatives were to reorient medical services and health systems away from hospital care and towards primary health care; build healthy public policy, create supportive environments, strengthen community action, and develop personal skills. Also of primary focus were the poor and disadvantaged, people whose health problems should not be taken out of context.

The Ottawa Charter for health promotion was the first document to outline an agenda for the new public health by placing it firmly in the context of new ecological thinking (Kickbusch, 1999). The Charter expressed a new view of health and stated that caring, holism and ecology were essential issues in developing strategies for health promotion. At the same time, the concept of holistic management of environmental resources was being contemplated in the environmental sectors.

\subsection{Concurrent Events in the Environmental Sector}

While the health sector sought to understand and solve human health problems from a more ecological perspective, the environment and natural resources sectors also took parallel steps to move environment and natural resources management to an integrated approach, making explicit links between health, environmental sustainability and sustainable development (Rapport, 1989). In 1987, the report of the World Commission on Environment and Development, Our Common Future, also known as the Brundtland report, outlined a global agenda for change based on a strategy for sustainable development that focuses on health, environment and the economy (World Commission 
on Environment and Development, 1987). The report emphasized the role of human activities in changing the natural environment and the impact of these changes on human health. The report also emphasized the importance of intersectoral links and posed new challenges for integrating health and environmental concerns through its call for sustainable development. Similarly, the United Nations Commission on Environment and Development (UNCED, 1992) made explicit the links between health and underdevelopment (poverty), and between health and inappropriate development. Agenda 21 , the action plan proposed by UNCED, suggested the need to urgently address the basic health needs of the world's population by paying greater attention to the links between health and improvement of the physical and socioeconomic environments.

As such, an ecosystem health approach to resource management was proposed to embrace management strategies that consider humans as part of the ecosystem, and not its destroyers. Like the ecological approach to public health, the ecosystem health approach integrates expertise from a number of disciplines including, economics, medicine, anthropology, sociology, veterinary sciences, and ecology (Rapport, 1995; Rapport et al., 1999). A bridge between the two approaches - the 'ecosystem health approach' from the environmental sciences and the 'ecological approach to public health' from the health sciences - resulted in a new concept called the ecosystem approach to human health ${ }^{12}$ (Forget and Lebel, 2001; Lebel, 2003).

\footnotetext{
${ }^{12}$ In the health literature, this approach is sometimes referred to in short forms, as 'ecohealth', ecosystem health, ecosystem approach. However, care must be taken when using this term in the environmental sciences.
} 


\subsection{Framework for an Ecosystem Approach to Human Health}

The ecosystem approach to human health is guided by three key principles. First, is the recognition that the biophysical environment is both a source of health and ill health. Ecosystems (farmlands, water bodies, woodlands, rangelands, and forests), when healthy, are important sources of life-supporting services such as medicine, shelter, food, income, water and air purification, nutrient cycling, soil production, among others. Likewise, when ecosystems become 'unhealthy' as a result of, intensive agriculture, deforestation and reforestation, urbanization, increased consumerism, among others, they can adversely impact our health both directly and indirectly.

Second, is the recognition that managing the human environment and environmental resources in a sustainable way has the potential to improve health and reduce our exposure to environmental health risks. In developing countries, most health problems are environmentally-mediated and result from the consumption of contaminated food and water, use of biomass fuels, absence of adequate sanitary facilities, lack of adequate housing, and exposure to vector-borne diseases and zoonoses (malaria, schistosomiasis, rabies, and plague) (World Bank, 1997). Many of these health problems tend to be more pronounced in subsistence rural communities and are augmented by poverty. Given the costs associated with accessing basic health care, the implementation of the ecosystem approach not only acts as a good preventive measure but also saves those medicinal plants that are crucial for preserving rural health (Lebel, 2003). It is thus perceived as a win-win situation. 
Finally, the ecosystem approach situates human health in the dynamic interrelations of human-environment analyses (Forget and Lebel, 2001; Nielsen, 2001; Waltner-Toews, 2001, Dakubo, 2004). Human health is seen as influenced by a number of factors nested at various levels such as the individual, the family, the community, and the larger regional, national and international contexts (McLeroy et al., 1988;

Bronfenbrenner, 1990). These factors comprise biological, social, cultural, economic and physical environmental determinants of health.

From a methodological standpoint, the ecosystem approach emphasizes three core elements: community participation, social justice and gender equity, and transdisciplinarity. In a section below, I discuss the importance of meaningful community participation for health interventions. However, the ecosystem approach requires us to be sensitive to the differing needs of various social groups, and examine how factors like gender, age, class, religion, and race, influence people's access to health resources, expose them to different health risks, and coping strategies. Finally, given the complex interaction of factors that affect human health, no one single discipline or expertise can capture all these issues. So, the ecosystem approach encourages working from a transdisciplinary perspective, with a team of researchers and other stakeholders whose actions impact health directly and indirectly.

\subsection{Political Ecology of Health}

Political ecology is an analytical framework that incorporates political-economic considerations into society-environment relationships. Although the use of a political 
ecology perspective in health research is limited, applying the framework to the study of environmental health problems provides a comprehensive lens through which we can understand the role of gender relations, oppressive class relations, knowledge/power imbalances and the capitalist world system, in perpetuating and sustaining spatial and social health disparities. Political ecology penetrates a set of observable phenomena and attempts to give relational meaning to causal mechanisms which are not immediately apparent. It examines the environment in a social and political context, and how the state and social relations exert influences over environmental resources that may not be apparent (Mayer, 1992).

A number of conceptual elements inform political ecology: first, is an emphasis on a dialectical rather than a homeostatic analysis of society-environment interactions. The human dimensions of environmental change are not independent of the social context in which they occur, nor are they ever politically neutral. Also the social impact of environmental change, and the forces shaping it, are uneven and have both positive and negative effects on different social groups, who have different coping capabilities (Swyngedouw et al., 2002; Harper, 2004). Second, political ecology combines levels of analysis showing how the micro-level is connected to broader macro-levels. Like the ecosystem approach, it shows a chain of analysis from the individual, to the family, community, nation-state, and the wider international economy (Blaikie, 1995; Bryant, 1997). These linkages, combined with the recognition that ecological and social systems interact unevenly across time and space, lead to the understanding that humanenvironment relations are not always generalizable, but, instead, must be contextualized (Harper, 2004). Third, political ecology employs an historical analysis or 'event history' 
to understand how past events shape present conditions. According to Moore (1993: 382), 'how the past is remembered, constructed, and invoked in the present, as well as transformations in social relations of production critically influence cultural understandings and resource politics in the present'.

Finally, there is a focus on the agent and the social relations in which they are embedded. How axes of difference such as gender, age, and socioeconomic status, mediate access to, control over, and use of resources at varying scales and time is considered. For example, in terms of gender, scholars working in this area argue that society-environment relations are patterned by gender, and gender relations are fundamental to understanding resource access, use, and degradation around the world (Leach, 1991, 1994; Agarwal, 1992, 1994; Joekes et al., 1995). They also show how different land use practices by women and men create gendered knowledges of agroecological systems (Mackenzie, 1995; Rocheleau, 1995). These gendered environmental knowledges point to the realization that the very definition of environmental degradation does not vary only across different societies and cultures, but also by gender, class, and race within a particular society (Joekes et al., 1995; Leach et al., 1995; Shah and Shah, 1995).

In the context of health, then, political ecology argues that the cause of ill health lies just as much in social structures and relations as it does in microbes (Mayer, 1992). According to the political ecologist, the concept of causality and the determinants of ill health must be broadened to encompass social, political and economic factors, and must examine how the interaction of these factors leads to ecological change and subsequently to malnutrition and epidemics. As Turshen argues 'most analyses separate ecological 
change from malnutrition, political struggle from epidemics, and social aspects of disease from economic transformation' (Turshen, 1984: xi). Health promotion interventions therefore need to move beyond lifestyle changes and behavioural modification to fundamental social reorganization (Baer, 1996).

Some tenets of political ecology have been used in earlier works in the context of African health research. For example, Hughes and Hunter (1970) examined the connection between large-scale development projects (specifically dam construction) and increased incidence of diseases such as malaria and schistosomiasis in the Upper East Region of Ghana, and they emphasized the importance of understanding disease within the dual frameworks of modernization and sociopolitical developments. Turshen's (1984) work examined the impact of global, social, and economic forces and the impact of historical factors on diseases which appeared endemic in Tanzania, such as, trypanosomiasis. Her work adds a great deal to our understanding of disease in the colonial context.

Recently however, political ecology draws on poststructuralist theorizing and moves beyond macro-structural analyses of phenomena to consider how knowledge/power, truth regimes, difference and institutions mediate environmental struggles. This new direction, in part, responds to Peet and Watts' (1996) concern that environmental problems should not only be examined from a political-economic context, but should be combined with the discursive and ideological realms in which they are constructed. This, in turn, reveals how constructions of nature and politics actively shape material reality. 
Within this new 'poststructuralist political ecology', environmental struggles are theorized as both material and symbolic, discursive practices that embody power relations (Peluso, 1992; Rocheleau and Ross, 1995; Moore, 1996; Watts, 1998). For example, at the household level, poststructuralist political ecology employs a more textured form of understanding the micro-politics of people's struggles over access to productive resources, and how these are both struggles over material resources, as well as, over their symbolic meanings (Carney and Watts, 1990; Schroeder, 1993; Carney, 1996). Also, it examines the means by which control and access of resources or property rights are defined, negotiated, and contested within the political confines of the household (Peet and Watts, 1996).

The household is seen as a site of struggle and local power structures draw attention to the crucial role of family authority relations and property relations in structuring the gender division of labour and access to rural resources (Carney and Watts, 1991). In particular, domestic power, and the dominant male order in African households, is central to the process of vesting rights of access and control over people and resources within household social structures. Understanding the relations of domination within the household and the cultural representations that produce and reproduce them is necessary in understanding the politics, and the points of resistance, associated with rural African households, and how this is implicated in health outcomes of different social groups, especially women.

Poststructuralist political ecology also examines the ways in which knowledge and power interrelate to mediate political and ecological outcomes (Escobar, 1995; 
Fairhead and Leach, 1995; Peet and Watts, 1996). Central to this is the examination of ways in which the 'common-sense knowledge' which sustains and constitutes a society or culture is generated and reproduced (Fox, 1994; Escobar 1995; Mackenzie 1995). Poststructuralist political ecology engages in questions such as: Why are particular knowledges privileged? Whose knowledge counts? How is knowledge institutionalized? How are the facts contested? (Peet and Watts, 1996:11).

Finally, poststructuralist political ecology seeks to understand the power dynamics circulating through Western truth regimes related to North-South relations and explore and expose the power relations embodied in national and global conservation agendas and knowledge systems, including those environmental organizations that seem well-intentioned (Peluso, 1993; Schroeder, 1995; Goldman and Schurman, 2000). Some of these knowledge systems propose global norms of ecological conservation and social governance that elide heterogeneity and conflict and instead represent the world as rational, consensual, and easily molded for sustainability (Goldman and Schurman, 2000).

The alignment of the ecosystem and political ecology approaches therefore provides a comprehensive, integrated framework from which to better appreciate the dynamics of unequal power relations and how they shape patterns of health and ill health. This understanding allows for new suggestions on ways to change human-environment relations in keeping with goals of social justice and equity. 


\subsection{Community-Based Participatory Research for Health}

In the following sections I outline the epistemological and ontological principles that inform my choice of a community-based participatory research, specifically a participatory action research (PAR) approach. Deriving their base from post-positivist understandings, I illustrate how these principles align, to some extent, with poststructuralist thought in questioning the nature of 'truth' claims and by re-inserting the subject as an active participant in knowledge production. Subsequently, I examine the ways in which poststructuralist thought can contribute to strengthening further the critical stance of community-based participatory research, especially PAR, which has sometimes been criticized as being 'an archetypal modernist political project concerned with liberating marginalized and exploited subjects' (Cameron and Gibson, 2005:317), without paying sufficient attention to issues of diversity, historicity, identity and subjectivity among others (Gatenby and Humphries, 2000; Cameron and Gibson, 2005).

Community based participatory research (CBPR) in health has been defined as a collaborative approach to research that equitably involves all stakeholders in the research process (Israel et al., 1998; Green and Mercer 2001; Minkler and Wallerstein, 2003). Accordingly, CBPR begins with a research topic that is of interest to both the community and the researcher and aims to combine knowledge and action to produce social change and to improve community health and eliminate health disparities (Minkler and Wallerstein, 2003: 4). CBPR counters the dominant conventional applied research paradigm in which the outside researcher dominates the research process by determining the questions, the strategies, the interventions and how the outcomes are used, with little 
or no community involvement (Gaventa, 1993). The conventional research approach mostly draws on positivist perspectives that contend that the researcher is able to remain distant and value-free from what is being studied, and uses methods that tend to control for context (Guba and Lincoln, 1989). In contrast, CBPR affirms the value of communities' experiential knowledge, by working with people to strengthen their awareness of their own capabilities as researchers and change agents (Hagey, 1997). It consciously engages in methods that tend to blur the lines between the researcher and the researched (Gaventa, 1981).

CBPR draws on post-positivist theories such as critical social and constructivist theories. Critical theories allow for a questioning of 'truth' claims by drawing attention to the constructedness and situatedness of challenged and conflicted realities (Lee and Garvin, 2003: 450). They see social realities as being influenced by social, political, economic, cultural, ethnic and gender factors that change with changing circumstances. Similarly, people working from a constructivist perspective believe that there are multiple, socially constructed realities that are influenced by social, cultural, and historical contexts. The researcher and the researched are connected in such a way that the findings are inseparable from their relationship, and the methods used emphasize a continuous dialectic of iteration, analysis, assessment, reiteration and reanalysis (Guba and Lincoln, 1989).

In the context of political ecology then, Hannigan (1995:30) asserts that: 'social constructionism does not uncritically accept the existence of an environmental crisis brought on by unchecked population growth, over-production, dangerous technologies, among others. Instead, it focuses on the social, political and cultural processes by which 
environmental conditions are defined as being unacceptably risky and therefore actionable.' Political ecologists applying a poststructuralist perspective have exposed the partial and self-interested nature of what has been deemed 'acceptable' environmental knowledge and practices, and have called for the need to reconcile multiple ways of seeing and knowing (Escobar, 1995; Peet and Watts, 1996).

Within the health field, the notion of causality of ill health consists of more than just observable and verifiable phenomena. The identification of causation and explanation of health patterns seeks to uncover those processes and structures that underlie a particular pattern, and how the pattern produces and is reproduced by these processes (Mayer, 1992). Also central is the notion of social structure as an oppressive mechanism of some sort. This oppression is partly legitimated through dominant ideology (Eyles, 1993). Thus, like poststructuralist political ecology, critical analysis carries an injunction to examine taken-for-granted concepts underlying health knowledge and practices, and to clarify who is defining the problem, whose needs are being served, and whose knowledge gets marginalized and whose previledged (Lupton, 1998). It is also important to evaluate how these positions relate to wider oppressive structures and historical manifestations, and how these structures legitimate and conceal their oppressive mechanisms (Harvey, 1990).

CBPR is often used as an umbrella term for a variety of research approaches, such as participatory action research (PAR), which I use in this study and will discuss in the next chapter; feminist participatory research, action learning, among others. Although these approaches vary in their goals and change strategies, they tend to share a set of core principles and values (Minkler and Wallerstein, 2003; Wallerstein, 1999). Israel and her 
colleagues (1998) identify these as including: a participatory, co-operative, and colearning process; one that develops and builds local capacity as well as empowers people to increase control over their lives; and finally a process that achieves balance between research and action.

Leung et al., 2004 describe CBPR as composed of three overlapping components: participatory research, education, and social action. Participatory research provides space for beneficiaries of the study to participate in collectively analysing their community and the issues to be investigated (Israel et al., 1998). This ensures that the issues addressed reflect community needs and not solely those of the researcher. In the process, researchers tend to lose some power, while at the same time also learn about community networks and concerns that may reshape their thoughts and data collection procedures (O'Fallon and Dearry, 2002). Participants also acquire new skills with respect to conducting research and solving community problems which may enhance community competence (Israel et al., 1998)

By participating in the research process, participants acquire knowledge that is locally relevant. This knowledge becomes democratized such that it is available both intellectually and physically. Participants take equal ownership of the research process, making the research outcomes accessible, understandable, and relevant to their specific interests and needs. Also, through education, participants engage in dialogues that develop critical awareness about their problems and how these relate to the larger social structure (Yeich and Levine, 1992).

The third component of CBPR, action, is the most important attribute that distinguishes the approach from conventional research. Most conventional research 
findings end up in scholarly publications, and the implications of the study rarely translated to inform action or social change. In contrast, CBPR views action as an integral component of the research process itself. The specific course of action to be taken is decided collaboratively between the community and its outside research partners (Leung et al., 2004).

In the following section, I examine how critical thought, including poststructuralist ideas might contribute to strengthening the critical stance of some key constructs in community-based participatory research for health including concepts like health, community participation and community empowerment.

\subsection{Re-visiting Some Key Constructs in CBPR for Health}

While participatory research approaches have gained prominence among academics over the years, there have also been on-going tensions and critiques about their techniques and the use of uncritical concepts such as participation, community, health and empowerment (Kothari, 2001; Cameron and Gibson, 2005). Apparently, while participatory research has its paradigmatic base in post-positivist approaches, it overly emphasizes personal reform over political struggle, obscures local power differences by uncritically celebrating 'the community', and employs a language of emancipation to incorporate marginalized populations (e.g. of the South) within an unreconstructed project of capitalist modernization or exploitation (Williams, 2004:558). Recently there have been attempts to infuse participatory research with poststructuralist thoughts (Reason and Bradbury, 2001; Cameron and Gibson, 2005). For example, in the book 'Handbook of Action Research', 
edited by Reason and Bradbury (2001), they draw parallels between participatory action research and poststructuralism. They argue that poststructuralism through its questioning of grand knowledge claims, paradigms and truth regimes, recognizes multiple knowledges, just as PAR embraces subjective views and local and indigenous knowledges. Poststructuralism points to the political nature of all knowledge construction, just as PAR recognizes that underlying political connotations of seemingly objective and expert knowledges. Poststructuralism underscores the role of language in constructing the world, just as PAR seeks to ensure that everyday knowledges are used to inform the lives and experiences of ordinary peoples (Cameron and Gibson, 2005:317). In the next sections, I go beyond the similarities between PAR and poststructuralism on knowledge production to examine how other poststructuralist thoughts and critical theory, in general, are used to streamline concepts like health, community participation and empowerment.

\subsubsection{A Broad and Positive View of Health}

Community-based participatory research to health and the ecosystem approach consider health from a broad and positive view (Antonovsky, 1985). From this perspective, health is viewed as:

... [T] he extent to which an individual or group is able, on the one hand, to realise aspirations and satisfy needs; and, on the other hand, to change or cope with the environment. Health is, therefore, seen as a resource for everyday life, not the objective of living; it is a positive concept emphasizing social and personal resources, as well as physical capacities (WHO, 1986a: 73). 
By conceiving health this way, health is seen as instrumental, a means rather than an end. Health is what one must have to accomplish other things in life. The Ottawa Charter for Health Promotion (WHO, 1986) describes the pre-requisites for achieving health to include peace, shelter, adequate education, basic nutrition, sufficient income, a stable environment, sustainable resources, social justice and equity. Achieving health therefore becomes a shared responsibility between society and the individual, with health promotion being defined as 'the process of enabling people to increase control over, and to improve their health' (WHO, 1986:1). Such views of health reflect a change from viewing the individual as a passive victim of health to an active participant in matters concerning one's own health (Lincoln, 1992).

This conceptualization of health differs from the individualistic ethic that dominated many health and health care settings for the past several decades. As has been discussed previously, this tendency to ascribe poor health status to individual characteristics, lifestyles, and choices without regard for structural imperatives that may affect, produce, and shape health, denies alternative views of human agency (Lee and Garvin, 2003). It also objectifies the human body as a machine to be 'fixed' by medical experts, and idealizes the 'normal' human body as one in a perfect state of health (ibid). Such objectification of the human body, according to Haraway (1991), denies the individual's context and life situation. The production of such notions of health is also linked to the production and elevation of medical, 'expert' knowledges over indigenous ones (Jasanoff and Wynne, 1998). Such expert authority is maintained through control over discourse and the use of expert languages, which further reinforces the lay/expert divide (ibid). But as it turns out, and as I shall demonstrate in Chapter V, many local 
people are able to challenge these dominant medical discourses by drawing on their own conceptions and experiences of health, as well as through non-compliance behaviours with health promotion guidelines.

Researchers adopting a positive view of health and a critical stance argue that, unlike traditional models of health which are built on the assumption that a system is open to systematic scientific investigation and explanation, positive health is not amenable to conventional scientific investigation (Charlton and Kelly, 1992). It is based on a postmodern approach that sees physical and social life as fluid. From this perspective, health has no stable meaning; it changes with changing circumstances, and with the uniqueness of individual situations. The postmodern view does not seek ultimate truths about health; it simply acknowledges that positive health is a quality of individuals and social groups that is self-defined, and not externally imposed (Kelly et al., 1993). Similarly, political ecologists investigating health problems go beyond the individualistic ethic and seek explanations for health inequalities and patterns that are based on unequal power relations surrounding the use of environmental resources that are vital for human well-being and survival (Turshen, 1984; Mayer, 2000).

Although this broader conceptualization of health captures more accurately the complex dimensions of health, it also presents a number of problems. There is caution that by redefining health more broadly as a resource, we risk commodifying the notion of health as was done by the lifestyle approach through exercise clubs, health food stores and stress management programs (Robertson and Minkler, 1994). The fact that health has been reconceptualized as something that resides outside us, and determined by the entire social context, makes people feel less control over their health than before. Further, 
advocates for a socialized version of health may inadvertently make of health a moral value, a monolithic concept that tries to explain everything and ends up explaining nothing. As enunciated by Stevenson and Burke (1992), if health becomes the analytic lens through which all social issues are seen, it may dilute and obfuscate not only healthrelated efforts, but other social and political efforts as well.

Robertson and Minkler (1994) argue that much of this difficulty with the definition of health can be resolved if we realize that health has both a micro-level individual dimension and a macro-level dimension that interact closely. A good understanding of such interaction can then allow interventions to be deployed targeting 'high leverage' areas; be it the individual, community, policy makers, or institutional arrangements.

\subsubsection{Community Participation}

Within the new public health discourse, community participation is viewed as one of the defining features that sets it apart from other conventional individualized approaches. Community participation is seen as a strategy that provides people with the opportunity to self-define their needs and through careful reflection, contribute to solving them (McKnight, 1987; Hawe, 1994). Zakus and Lysack (1998:2) define community participation as the process by which members of a community, either individually or collectively and with varying levels of commitment: first, develop the capability to assume greater responsibility for assessing their needs and problems; second, plan and then act to implement their solutions; third, create and maintain organizations in support 
of these efforts; and finally, evaluate the effects and bring about necessary adjustments in goals and programs on an ongoing basis.

Despite the centrality of community participation in implementing successful health interventions, the concept and the means through which participation is achieved remains contested in the literature, partly because of the varying meanings and ways in which both 'community' and 'participation' have been deployed. For example, in the health literature, although there is no consensus about how community should be defined, an implicit definition can be derived from injunctions contained in health promotion documents such as the Ottawa Charter and the Alma-Ata Declaration. The Alma-Ata Declaration treats a community as a locality-bound aggregation of people who share economic, socio-cultural and political characteristics, as well as problems and needs.

Other conceptions see community to be a coherent unit, whose members work together to achieve shared goals (Jewkes and Murcott, 1996); or a social system, in which the focus is on social interaction, social institutions and social control (Haglund et al., 1990); or viewed as a group of people sharing norms and values (Thompson and Kinne, 1990).

Most of these conceptions of community are based on the sociological tradition of community research, where community is conceptualized as a spatial or social unit (Dickens, 1990). However, according to recent theoretical developments, instead of focusing on community as a spatial unit, with rural/urban, micro/macro and local/global distinctions, we should emphasize the contextual, explicating 'how external influences are shaping the defense, reconstructions or constructions of local identities, and creating new potentials for collective action and local enthusiasm' (Nilsen, 1996:170). 
In many participatory research projects the subject is seen as having a pre-existing and unalienated identity that is repressed by social structures, like patriarchy and capitalism (Cameron and Gibson, 2005). However, in poststructuralist thought the subject has no true essence or identity; rather the subject is understood as always in the process of becoming, of shaping and being shaped in a multitude of ways by various discourses, actions and practices (Foucault, 1979). Thus, there is no single identity associated with a 'community' or its membership. Instead, there are various discourses and practices that produce certain types of communities: communities as 'victims' of national economic restructuring, or communities as 'dependent' on the state (Cameron and Gibson, 2005:318). Similarly, within that one community, there may be many representations and conflicting local knowledges that need to be contextualized. For example, individual subjects may hold different knowledge systems about their life experiences and about the broader social, economic and environmental factors affecting their lives that may not necessarily be transformative (ibid). Thus in celebrating local knowledges, we need to exercise caution on the authenticity, representation and transformative potential of such knowledge systems.

In the context of development projects, Williams (2004) notes that all too often 'the village', 'the community' and 'the people' are mostly perceived as spatially-bound entities with clear and uncontested membership. This view is oblivious of the fact that 'the community' is often an object of development projects' own making, such as in the case of how Joint Forest Management committees create 'communities of forest users' in which, hitherto, none of the participants would have described themselves in such terms. Thus the process of acquiring such an identity was constituted, in part, through the 
subjection of community members to particular norms, rules and governing modes that produced this subject position.

Also, Williams (2004) cautions that communities are bounded by social norms which are part of a local culture. The failure for development programs to recognize this local culture as a product of internalized local power relationships risks the danger of working with an uncritical notion of 'community'. This uncritical notion of 'community' masks existing divisions, and power structures and privileges 'the local' as the site for 'authentic' knowledge (Kothari, 2001; Mohan, 2001). As Fine (1999), cited in (Williams 2004) argues, such homogenization of differences and the uncritical acceptance of 'the local' as the site for action, smoothens over 'repressive structures (of gender, class, caste and ethnicity) that operate at the micro-level but are reproduced beyond it, and also deflects attention from local power relationships that frame local development problems' (p.526)

Like the concept of 'community', participation has proven difficult to define, initiate and sustain in a research process (Brownlea, 1987). Most scholars tend to see participation as varying along a continuum. It ranges from manipulation or tokenistic forms of participation, where researchers attempt to get people in the community to take ownership of an externally defined health agenda, to full community control (Rifkin, 1996). Full community participation takes place at the level where both community and researcher are said to have equal control of the research process (Robertson and Minkler, 1994). At such a level, the community is involved in all aspects of the research process, including the identification of research questions, project design, data collection, analysis and interpretation of findings. The role of the researcher is then recast from an expert 
who defines community needs to a facilitator who mobilizes the community by providing technical and informational support. The capacity of communities' say in health promotion is then enhanced through such efforts.

The claims of openness and transparency of participatory approaches and development have led critics to question their emancipatory potential. For example, Kothari (2001) suggests that participatory development programs emphasising social exclusion bring previously marginalized groups and individuals into the development process, but do so in ways that bind them to power structures (internally and externally to development agencies) they are unable to question. In other words, participation is simply another way of executing top-down development programs, while portraying the impression of implementing a more inclusive project of empowering the marginalised. Mosse (2001) also argues that the outcomes generated by techniques such as Participatory Rural Appraisal (PRA), and couched as authentic expressions of the community's will, fail to realize that the knowledge generated, are mediated by the interplay of intra- and extra-community power relations.

Finally, for participation to be beneficial, Parfitt (2004) argues that, it is important to first understand how participation is executed; either as a means or as an end in itself. He argues that to the extent that participation is a means, then the unequal power relations between the 'uppers' and the 'lowers' would be eminent. In such situations, community members are mobilized to participate in the predetermined goals of the professional uppers or development agencies. Participation as a means is a short-term exercise and so puts less emphasis on understanding and critically analysing 'the community' (Oakley et al., 1991). In the case where participation is an end in itself, the goal is to blur those 
unequal power relations between the 'uppers' and the 'lowers' and to provide space for political engagement and action by the lowers. In this sense, empowerment is a key outcome, and a process in which a critical analysis of the community is necessary. Questions such as who, why, and to what degree they are participating and, who is defining, planning and solving community problems become important (Rifkins, 1996; Cornwall and Jewkes, 1995).

\subsubsection{Community Empowerment}

Community empowerment is seen as a primary strategy for health promotion (Laverack and Labonte, 2001; Labonte, 1996; Wallerstein, 2002). Like community participation, various scholars have interpreted the concept of 'community empowerment' differently. Underlying all the variants is the agreement that empowerment is a process through which individuals, groups, communities and populations become more involved and able to take control of and make decisions about their own health and well-being (Scriven and Stiddard, 2003; Laverack and Labonte, 2000). In the context of health promotion, this would mean increasing control over personal health behaviour, or urging for reforms pertaining to underlying health determinants such as water and sanitation, poverty, housing or environmental threats (Laverack and Labonte, 2000).

Like participation, the means to achieving empowerment is fraught with difficulties. According to Rappaport (1985), empowerment occurs not when power is given, but when power is taken by individuals and communities to enable them to identify and achieve their own goals. The role of researchers and health promotion professionals is, therefore, to provide the conditions that will make empowerment occur 
and also nurture the process by resisting the urge to lead and take responsibility (Labonte, 1989:87). What this means is that health promotion practitioners who truly facilitate empowerment do so by assisting individuals and communities in articulating both their health problems and the solutions to address those problems. True empowerment occurs when attributes like self-esteem, individual and community competence, self-confidence, self-awareness, self-development and quality of life are improved (Wallerstein and Bernstein, 1988). Also, it is often assessed that authentic participation leads to empowerment. This line of thinking is grounded in Paulo Freire's $(1972,1973)$ principles of critical consciousness that community empowerment starts when people are able to engage in participatory dialogue, name their problems, identify their commonalities, and construct new strategies to transform oppressive circumstances.

However, related to my earlier discussion on the ambiguities associated with 'participation' and 'collective community voices', Wallerstein (1992) cautions that in our attempt to empower, it is important to ask: Who exactly is being empowered? Does empowerment mean that some individuals or groups gain at the expense of others? Does empowerment and health promotion sufficiently challenge power structures that systematically operate to leave some people in poorer health than others? She cautions that the very understanding of research as participatory and emancipatory may in fact serve to induce individual participants to collaborate in their own oppression by taking on and internalizing the goals and projects of elite voices in the community (Robertson and Minkler, 1994; Hart, 1996). This concern over 'the tyranny of the community' (Robertson and Minkler, 1994:306) is rooted in the ongoing tension between the 
community and the individual, the public and the private, that marks so many of the practices that shape our day-to-day lives (Baker et al., 1998).

Also many participatory research projects often assume that through participation, the stifled thoughts and voices of the marginalized will be released, thus allowing them to confront the structural barriers affecting them and place them on the road of emancipation, liberation and empowerment (de Roux, 1991; Park, 1993). Related to this mode of thinking is the assumption that there is a pre-existing subject identity that is repressed and in need of liberation. However, along the lines of poststructuralist thought, there are no subjects to be empowered and subsequently liberated. Instead there are various forms of subjection including that of empowerment and liberation (Cruikshank, 1999).

Finally, critical theorists are skeptical about empowerment as a process of transferring skills to people, as this assumes that professionals or development agencies, occupying the high ground, have superior skills and knowledge, compared to local grassroot actors. Both poststructuralist political ecologists and medical sociologists are cautious about how knowledge claims about ecological actions and 'appropriate' health behaviour are deployed to the detriment of other actors, and are linked to reinforcing social inequities (Poland, 1992; Peet and Watts, 1996).

\subsection{Conclusion}

This chapter has reviewed the theoretical elements guiding the study. I began by situating the emergence of the ecosystem approach within its historical antecedents. The approach 
evolved based on the logic that conventional, biomedical interventions alone are insufficient to curb the changing pattern of health problems facing today's society. These health problems are increasingly being influenced by a complex web of ecological, social and political determinants, requiring that we adopt a broad, transdisciplinary, integrated, and holistic approach to public health research and intervention. The ecosystem approach is then complemented by drawing on political ecology theorizing to explicate the political situatedness of community health concerns, especially those mediated by environmental factors. Additionally, I argue that the conventional, positivist approaches to investigating and intervening upon health concerns have to be complemented with newer communitybased approaches that embrace human subjectivities and make community empowerment a goal to eliminating health disparities. Finally, drawing on recent theoretical developments, I examined the ambiguities associated with constructs such as health, community participation and empowerment. I illustrated how the critical stance of these constructs can be strengthened through poststructuralist ideas and complemented with those of community-based participatory research. In the next chapter, I take these discussions further in my discussion of the methodological processes guiding this study. 


\section{CHAPTER IV}

\section{RESEARCH METHODOLOGY}

To be a good participatory researcher means above all to have faith in people; to believe in the possibility that they can create and change things [Freire, 1971:62]

\subsection{Introduction}

In this chapter, I describe the methodological procedures that inform this study. In my quest to guide community members through a research and planning process in which we would jointly identify, analyze and intervene upon the health problems facing Charia, I chose a Participatory Action Research (PAR) approach. PAR is guided by the principles and assumptions of community-based participatory research (CBPR) described in the previous chapter. Thus, in this chapter, I begin by recapping some elements that are central to PAR. Subsequently, I examine issues of diversity and multiple subjectivities, and reflexivity in the research process, drawing on poststructuralist and feminist theorizing. This is followed by a description of the research process, beginning with a discussion of my anxiety of entering the field the second time around, data collection procedures, the strategic planning process and focus group procedures. I conclude the chapter by reflecting on the dynamic and political nature of the 'field' and 'fieldwork', elucidating the constant negotiation of my multiple positionalities with the research team and the research participants. I also shed some light on the challenges and ethical dilemmas associated with my choice of a PAR approach. 


\subsection{Participatory Action Research}

Participatory action research (PAR), sometimes used interchangeably with participatory research, is a structured process of inquiry in which those experiencing a problem collaborate with the researcher(s) as partners to identify and address mutually conceived problems and concerns through a process of research, action and reflection (Fals-Borda and Rahman, 1991; McTaggart, 1991; Whyte, 1991; Israel et al., 1998; Parkes and Panelli, 2001). PAR emerged among a plethora of research alternatives aimed at responding to the failure of conventional applied social science methods to understand and address complex human problems and implement successful interventions (Brown and Tandon, 1983; Maguire, 1987; Corcega, 1992; Park et al., 1993). The emphasis on both participation and action in PAR reflects in part the roots of this approach in both the 'action research' school developed by Kurt Lewin $(1946 ; 1997)$ in the 1940 s and the emancipatory research school developed by Paulo Freire (Freire, 1982) and other third world scholars in the 1970s (Park et al., 1993; Tandon, 1996). In Lewin's action research tradition, sometimes referred to as the Northern tradition, beneficiaries of a study are involved in a cyclical, iterative process of fact finding, analysis, implementation and monitoring. The results of monitoring are cycled back to problem identification and information gathering (Mc'Taggart, 1991, 1997; Reason, 1994; Hart, 1996). Through this process action research is not only linked to action and research but also assumes an educational stance as part of the problem solving process (Peters and Robinson, 1984).

On the other hand, Paulo Freire's tradition emerged as a counter discourse to the often 'colonizing' nature of the research to which oppressed people in Latin America, 
Asia, and Africa were subjected (Freire, 1982; Brown and Tandon, 1983; Fals-Borda and Rahman, 1991). This tradition, also referred to as the Southern tradition, considers collective participation as critical to challenging inequities and ensuring social progress. According to Freire (1982), as people engage in dialogue with one another about their communities and the larger social context, they become more aware of the social world around them, their relationship between each other becomes strengthened, and so their ability to reflect on their own values and choices is influenced. To Freire (1982), the purpose of conscientization and education is human liberation, which means that people are the subjects of their own learning, not empty vessels to be filled by knowledge of the experts. As participatory researchers then, our duty is to facilitate this educational process by fostering a research environment in which participants can take not only greater control of the research process, but take sole responsibility for social change (Hall et al., 1982; Maguire, 1987; Cornwall and Jewkes, 1995; Hagey, 1997).

As discussed previously, there are a number of assumptions that are central to PAR. Baker et al., (1998) discuss the following. First is the recognition that knowledge formations, as well as the practices they engender, are always political and never neutral (Apple, 1993; Gitlin, 1994). Second, is the need for participatory action researchers to understand that the interests and goals of social groups can be distorted, repressed, or controlled through formations of power (Stevens, 1992; Wuest, 1993). Third, by drawing on concrete social experience, social groups can counter and resist the representations that tend to serve the interests of the powerful, thus challenging their power (Freire, 1972; LeCompte and McLaughlin, 1994). Related to earlier discussions in the theory chapter, these assumptions stem from poststructuralist critiques of 'truth' claims and how these 
are linked to the partial and self-interests of the producers of such knowledge claims (Haraway, 1991; Lupton, 1998). As critical theorists point out, such modes of knowledge production are intimately linked to the exercise of power, as the exercise of power is also linked to the production of certain types of knowledge (Aviles, 2001). Through the control of discourse, practices and actions, dominant discourses get privileged over lay perspectives (Jasanoff and Wynne, 1998). The use of critical approaches including PAR and poststructuralist political ecology therefore, encourages researchers to interrogate the taken-for-granted assumptions in these knowledge claims and to reveal the power structures embedded in them, and how these are linked to the control of material resources (Peet and Watts, 1996). Critical approaches also draw attention to the agency of subjects and the social relations of power in which they are embedded as well as encourage the need to reconcile multiple forms of knowledge and multiple views of reality. These multiple views of reality also serve to challenge and resist the objective and legitimate notions of dominant discourses (Lee and Garvin, 2003).

PAR has been criticized both from within and from without. From without, there is the concern of the lack of clear articulation about the nature of this research tradition and the existence of numerous variants of definitions (Greenwood, 1994; Hart, 1996). While PAR shares characteristics with a number of approaches such as community organizing, organizational development, among others, what distinguishes PAR from other approaches is its ability to combine research, education and action, and also empphasize generating and validating local knowledges (Greenwood, 1994). Also, PAR has been criticized as blurring the line between research and practice (Meyer, 1993; Hitchcock and Hughes, 1995). But, as scholars such as Fine (1994:30) explains such 
blurring of boundaries within our research helps us to negotiate the 'messy nexus of theory, research and organizing'. Instead of viewing it as an obstacle to rigorous inquiry, such blurring reminds the researcher of the importance of being a reflective practitioner (Reason, 1994). As this same reflexive gaze may serve to illuminate tensions and tendencies arising within a PAR project.

From within, there are questions about how problems get defined, by whom and for whom (Eisen, 1994; Wallerstein and Bernstein, 1994). When a problem is named externally, it may lead to a solution that would not be suitable for addressing the real concerns of the community. However, many rural communities lack that initial drive to start a PAR project. It is the outside researcher who normally has the time and resources, and so initiates and facilitates the process. Care has to be taken, however, not to impose external agendas on the community.

In the next section, I draw on feminist and poststructuralist theory to examine two things: first, the need to create space for difference, dissensus, diversity and complexity among and between research participants, and secondly, the need for reflexive practice within the context of public health research.

\subsubsection{Capturing lived experiences as different, diverse and complex}

Poststructuralist and critical theorists have written against generalizations, arguing that the process of generalization reduces different, diverse, and unique experiences into coherent and homogenous entities, eliminating the influence of identity, history, time and place from their analyses (Flax, 1990; Abu-Lughod, 1993; Fox, 1994). In women's health research, for example, critical feminist writers have challenged totalizing discourses used 
by biomedicine to describe women's health experiences and needs. They argue that the subject positions of men and women are discursive categories created through the use of binary logic (Fox, 1994). Binary conceptualization 'creates a false appearance of unity by reducing the flux and heterogeneity of experience into supposedly natural or essentialist oppositions' (Flax, 1990: 36). By dividing events into two opposing categories, we then continue to build a series of other characteristics on the previous categories. For example, women are unhealthy, men are healthy; women are irrational, men are rational, and so on. It is through the use of such binary logic that we privilege one category and marginalize the other; we privilege the male body as healthy, and the female as sick (Annandale and Clarke, 1996). Poststructuralist feminists argue that attributes like being healthy, or sick, cross-cut gender and are not the domain of men or women as a group.

An example in point is how 'rural women', regardless of the differing child birth, cultural, and religious needs, are often seen as part of the problem of 'over-population' and encouraged to adopt family planning programs. As Abu-Lughod (1993) points out, generalizations risk smoothing over conflicts of interests, and contradictions inherent in people's lives, and as researchers we should acknowledge that generalization, textual or otherwise, is inevitably a language of power. It is a language of those who seem to stand apart from, and outside of what they are describing, making the 'other' seem more coherent, self-contained and different from 'us'. Radcliffe (1994:28) also points out that: 'in producing representations of Third World women, we are inextricably bound up with questions of authority, communication and representations, and the positions generated by such questions are inherently political'. 
In my study then, and in many participatory research projects, where the intent is to work on communally defined problems and to move on to take action as a community, it is difficult on the one hand to acknowledge particularities and on the other consensus. There is the danger that consensus might elide those voices that we need to elevate. Thus within the communal voices, it is still important to pay attention to particularities through follow-up, individual discussions and interviews.

\subsubsection{Reflexive Practice in Public Health}

For public health professionals and researchers, reflexive practice involves the ability critically to interrogate our use of knowledge and to be cautious of the interests we serve and reproduce as part of our working lives. As no discourse or knowledge is value-free, there is no way of escaping this position, but it is important to be aware of one's position as producer and reproducer of certain discourses and practices, and the personal commitments and values inherent in the use of such discourses and practices (Fox, 1991). Smith (1990:4) asserts that, reflexive inquiry involves 'explicating the conditions of one's own existence and ideological practice so as to expose one's participation in power relations.' Reflexivity requires being sensitive to the manner in which knowledge claims are generally accepted as common-sense and taken-for-granted, and questioning the way through which notions such as 'health', 'empowerment', 'risk' and 'participation' are deployed in public health practice. Thus, attention to language and discourse is central to any activity seeking reflexivity.

Foucault's theory of how knowledge is produced and how power operates is useful for looking at the process of changing social realities. According to Foucault 
(1980), knowledge production is not the result of simple bipolar relations of who has power and who does not have power. Relations of power take specific forms in different cultures, and are organized through, for example, class, age, religion, marital status, and education. Foucault posits that there is a direct relationship between the production of knowledge, social practices, and ways of being. Dominant knowledge systems can be resisted, consciously or subconsciously, by alternative perceptions and forms of knowledge. Alternative forms of knowledge exist, or are produced, at individual and group levels and their social power is increased through sharing and getting others to accept these forms of knowledge (Weedon, 1987).

In the field of health, the biomedical model and medical practitioners are perceived to have a dominant position regarding what is seen as healthy, what services should be provided, and what policies developed (Rifkin, 1996). The commonly accepted view is that the health worker holds power and that the local people are powerless. From a Foucauldian perspective, it is important to examine how each has the potential to accept, challenge or ignore the perspectives of the other. Even if one ignores the views of the other, the other's perspective still exists to influence what types of information are acceptable.

This perspective is useful for thinking about why health promotion and public health initiatives fail in developing countries. Often there is a gap between indigenous conceptions of health and healing, and those of medical practitioners. Going to a village to assemble people, and 'educate' them does not necessarily mean that people will adopt and implement what has been prescribed. Participatory research, thus, can be used to 
acknowledge and help differing perspectives emerge and to strengthen participants' confidence to explore their own views (de Koning and Martin, 1996).

\subsection{The Research Process}

I set off for Ghana in the Spring of 2001 to conduct my fieldwork with mixed emotions: first, I was happy to be returning home to see my family; second I was concerned about the health status of family members since the last time I was home for fieldwork, I found my dad on his death bed, passing away just eight days after my arrival; third, I was emotionally distraught for leaving behind my two-year old son for three months, and finally, I was anxious to know how I would be received by community members the second time around and how the community has fared since my last visit. My first encounter with this community was in 1996 when I went to conduct fieldwork for my master's dissertation on a community-based natural resource management project. As such, I was interested in assessing the impact of my first encounter, learn from any successes and failures, and extrapolate the earlier project to the present, by examining the impact of current environmental practices and conditions on the health status of community members.

The fieldwork was conducted in a number of steps. In the first step, a transdisciplinary research team was formed comprising of a variety of government departments including health, adult education, forestry, and agriculture. The second step involved a series of focus group discussions which were held separately with men and women. The issues discussed in these focus groups included participants' conceptions 
and understanding of health and ill health, what they perceived to be the major health problems in the community, the underlying factors responsible for those health problems and what they perceive as possible solutions or intervention strategies. Thirdly, I used a strategic planning process to guide participants in articulating their vision for a healthy community, assessing the obstacles standing in their way to achieving that vision, developing strategic directions to overcome those obstacles, and finally in outlining a plan of action to achieve that vision. I organized feed-back sessions at the end of each step to allow for reflections on the issues discussed. The research team facilitated the various sessions. The activity profile for the research is outlined in Table 4.1.

Table 4.1

The Fieldwork Activity Profile

\begin{tabular}{ll}
\hline Week \# & \multicolumn{1}{c}{ Activity } \\
\hline 1 & Meeting with the Director of the Institute of Adult Education \\
1 & Meeting with Community Representatives \\
2 & Individual Consultations with Research Team \\
3 & Orientation Workshop with Members of the Research Team \\
3 & Research Team Meets with the Chief \\
4 & Research Team meets with Men's Group \\
4 & Research Team meets with Women's Group \\
$5-7$ & Focus Group Discussions with Men and Women, field visits \\
$8-10$ & Strategic Planning Workshops with Men and Women \\
11 & Follow-up interviews and field visits \\
12 & Action planning and Implementation \\
\hline
\end{tabular}




\subsubsection{Entering the Community the Second Time Around}

Upon my arrival in Wa, the regional capital of the Upper West Region, I met with the Regional Director for Adult Education to discuss the subject of my research and to seek his help in forming a research team. He is the coordinator for CIDA-sponsored projects in the community and has a long-standing relationship with community members. He was my principal contact during the first visit and proved very helpful. The director and I met with two representatives from the community: the head teacher for the village Primary school, who is also the community leader, and the headmistress for the village Junior Secondary School. These two individuals have been instrumental in mobilizing community members to participate in research and community development projects. They are highly respected in the community and have received widespread recognition for their dedication in promoting community development. I invited them to be part of the research team and to help identify local government departments currently working in the community. In addition to the Institute of Adult Education, other departments identified included the Ministry of Food and Agriculture, Ministry of Health, the Department of Forestry, and representatives from on-going international development projects (CIDA-sponsored projects and World Bank-sponsored Northern Agriculture and Savannah Research Project).

I met individually with representatives from these government departments to explain the purpose of my research and to invite them to participate as co-researchers. Upon their consent to participate in the study, a research team of seven was formed. This included two representatives from the community (Primary School Head teacher and the Junior Secondary School Headmistress), a representative each from the Ministry for Food 
and Agriculture, Department of Forestry, Institute of Adult Education and the Ministry of Health, and myself as the principal investigator. A day was chosen for an orientation workshop with the research team. The purpose of this workshop was to learn about the activities of various departments in the community, their goals and vision for the community, the type of extension strategies used, the extent to which they involved local people in project planning and implementation, the availability of government reports and also to identify other key players for follow-up interviews. I also used this opportunity to explain to the research team some community data gathering processes and tools such as the strategic planning process and focus group discussions. I emphasized the democratic nature of the study and their role as facilitators and not 'experts'. I reiterated the need to see community members as equal partners in finding solutions to their own problems.

Members of the research team were motivated to participate in the study for a number of reasons. First, they felt an obligation to help provide solutions to problems facing the community, since it was part of their work schedule and there was also the opportunity to work intimately with community members to try to understand some of the constraining factors. Secondly, the opportunity to work with colleagues from other government departments in a joint effort to achieve a mutually desired goal created space to learn about their challenges and successes and to explore the prospects of coordinated project planning. Finally, the prospect of working as equal partners with community members seemed daunting and exciting at the same time. It appeared daunting in that they had to rid themselves that 'expert' status, and be receptive and willing to learn from community members. 
The research team then met with the village chief to request his permission to conduct the study. According to custom and as a sign of respect, we presented the chief with a bottle of whisky and an envelope containing some money. He granted us permission to conduct the research, and asked the community leader to encourage people to participate in the study and pledged his support throughout the research process.

\subsubsection{Meeting the Research Participants}

Using the community representatives as primary contacts, the research team developed a snowball sampling strategy to recruit participants for the study. This was done through initial contacts with clan heads, the village clinic, youth groups, and women's groups, and through public and church announcements. Eventually, two groups of diverse community participants, men $(n=20)$, aged between 17 and 65 , and women $(n=24)$, aged between 18 and 63 were recruited. Although this was the main group for the study, other community members stopped by from day to day to listen to the discussions. We (the research team) met separately with the men and women's groups to explain to them the purpose of the study, seek their consent to participate, explain the duration of the study and the time commitment required.

I chose to work with separate groups of men and women, not only because of my interest in understanding how gender and other social identities mediate health outcomes, risk exposures and coping responses in the community, but also to create a 'conducive' environment for women to speak up freely without any worry of being reprimanded by their husbands. Thus, while gender analysis is part of my analysis, my overriding emphasis is on the community as a whole. 
My first meeting with the research participants was characterized by great anxiety and anticipation. First, I was anxious to see which and how many old faces would return, as I thought this would facilitate trust building. Also, based on events during my last visit, I thought I had developed a good rapport with them, since at the end of my stay, the research team was given a grand 'send-off' party at the chief's palace, amidst dancing and singing. They even presented us with a goat as a sign of appreciation. So while I was hopeful that, this time around, residents would show their usual enthusiasm, I was also concerned about their reaction to my lack of contact with them for the past four years. On the one hand, I could imagine their sense of disappointment as being victims of one of those studies; on the other hand, if my intervention generated some useful outcome or learning, then they might be receptive to working with me again.

We met with the women's group first, and at this encounter I was introduced by one of the community representative in the research team in the following manner:

'some of you probably remember this woman; our friend, who came and worked with us some years back. As you remember she was a student at the time and so when she got back, she wrote about her work with us, and her people liked it and were very pleased with her. She received lots of praises for it, and so she has been asked to come and work with us again. I hope you will all do your best to help our friend this time around'.

This introduction spoke volumes to me, and increased my apprehension and vulnerability as a researcher. What I understood, or at least tried to understand was that, first, the benefits of the first intervention were one-sided, accruing only to me as the researcher; second, despite all attempts to make the research participatory, egalitarian, and collaborative, it was portrayed as 'her work'; and third, who did she mean by her people: academic committee or CIDA, with whom part of the project was affiliated. So if the 
benefits of the research accrued to a friend who never monitored the progress of her research to determine its impact on the community, how can we continue to help such a friend?

In the men's group, the old faces could barely wait for me to be introduced when they accused me of deserting them, and never bothering to 'send us shirts from abroad'. I used the first few minutes after each of the introductions to thank participants for coming and to explain that after my last visit I continued to study, rarely visited home (Ghana), and given the resources I had to conduct the first study, I was not able to do any followup studies, and so this second phase should be considered as building upon our initial experience.

I also reflected on the prospects of this next project and on what I could do differently this time around to make it a success. First, I thought it was important to spell out clearly the purpose of the project, my sole role as the initiator vis-à-vis mutual interests with the community, and what I perceived to be the long-term benefits and the beneficiaries of the project. As is expected of most PAR projects, both the researcher and the community are mutually to agree on the topic of research and the procedures for investigation. However in this case, the broader issues of the study were determined by me in consultation with my academic team and taken down to the community for refining, approval and partial ownership. Also in terms of benefits, I perceived it as a win-win situation; while community members stood to benefit in a variety of ways including learning problem-solving skills, strengthening community capacity, and using the results to draw government support, I, as the researcher, stood to acquire a postgraduate degree and develop my professional skills. In the long-term though, being 
able to sustain these benefits on the part of the community would depend on a number of factors including continuous commitment and ownership of the results, continuous support from government and availability of financial and human resources. Secondly, I also felt it was important to dispel any financial, international development-related aid and/or infrastructure-related expectations from the study. Although my first project was affiliated with a CIDA project, I failed to indicate clearly that I, personally, did not work with CIDA and so could not guarantee any international development assistance. Finally, I sought to encourage ownership of all discussions, opinions, and ideas from the study, urging them to perceive me as a facilitator and energizer in a community development research. As has been pointed out by many PAR researchers, while communities are quite aware of the problems facing them, they usually lack the initial drive to begin to look for solutions to their problems. The outside researcher seems to be the one with the necessary time, drive and resources to initiate such projects.

I also used this first meeting to collect basic demographic data from participants including age, marital status, level of education, religion, occupation, number of children and approximate family income. These characteristics of community participants are presented in Table 4.2. Participants also used this first meeting to outline the days, venues and times for focus group discussions and field visits. While the women's group decided to meet every Sunday after Church at the West end, the men decided to meet on village market days at the East side. The days chosen by each group were days they stayed away from farm work. 
Table 4.2 Characteristics of Community Participants

\begin{tabular}{llll}
\hline Characteristic & Male & Female & Total \\
\hline Sample Size & 20 & 24 & 44 \\
Mean Age & 29.6 & 32.4 & 31 \\
Marital Status & & & \\
$\quad$ Married/Partner & 12 & 14 & 26 \\
$\quad$ Widowed/Separated/Never Married & 8 & 10 & 18 \\
Education & & & \\
$\quad$ No Formal Education & 6 & 13 & 19 \\
$\quad$ Completed/Some Primary School & 8 & 7 & 15 \\
$\quad$ Completed/Some Middle/Junior Secondary School & 4 & 3 & 7 \\
$\quad$ Completed/Some College/Post-Secondary Training & 2 & 1 & 3 \\
Primary Occupation & & & \\
$\quad$ Farming & 11 & 10 & 21 \\
Trading & 3 & 3 & 6 \\
Pottery & - & 4 & 4 \\
Charcoal Making & - & 6 & 6 \\
Carving & 3 & - & 3 \\
$\quad$ Teaching & 2 & 1 & 3 \\
$\quad$ Other & 1 & - & 1 \\
Mean Annual Household Income in Cedis (1000s) & 250.3 & 140.5 & 195.4 \\
\hline
\end{tabular}

\subsubsection{Data Gathering Tools}

I decided to use a combination of group and individual methods for data collection. The group methods I used included Focus Group Discussions and Strategic Planning Workshops. I conducted three focus group discussions to understand how men and women conceptualized health and ill health and how they related this to their day-to-day activities. I also used focus groups discussions to ascertain what participants considered to be indicators of good health and ill health. I then contrasted participants' responses with 'expert' constructions to determine the congruence and differences between such conceptions, and the implications for health intervention in the community. Finally, I used focus group discussions to identify what participants considered to be the major 
health problems in the community and factors responsible for these health problems. These focus group discussions then laid the foundation for the strategic planning process, which was used to envision and plan a 'healthy community'. The strategic planning process helped community members to envision a healthy community, identify the factors inhibiting the realization of that vision, and the possible actions needed to achieve that healthy community.

Since some of the issues discussed were not amenable to group fora, I conducted a number of follow up interviews with key community members, health professionals and heads of other local government departments such as the Environmental Protection Agency, Water and Sewerage Cooperation and the Department of Town and Country Planning. In addition, I collected available secondary data on health and environment issues from local governmental departments. For example, regional data on the top ten diseases for the past five years (1995-2000) were collected from the Ministry of Health and climate variability reports and food production trends from the Ministry of Food and Agriculture. Secondary data proved useful during data analyses, where findings from group discussions were compared to secondary data. This comparison generated interesting discussions between the 'experts' and 'lay' participants, as they sought to explain disparities and congruence.

On free days, I scheduled visits with women and men either on their farms or on individual income generating projects such as pottery, charcoal burning and carving. The purpose of this was to assess how much time and energy was spent on these activities, as well as the associated occupational health risks. 


\subsubsection{Focus Group Discussions}

I chose focus group discussions because of their ability to generate a considerable amount of information and interaction between people within a limited time period (Kidd and Parshall, 2000). Lunt and Livingstone (1996) describe focus groups as effective processes through which social norms are collectively shaped through debate and argument. Compared to individual interviews, which highlight the views and attitudes of single individuals, focus groups reveal the way in which a particular individual's opinions are accommodated or assimilated within an evolving group process (Kidd and Parshall, 2000). Through argument and dialogue, participants confront one another's views and opinions, thus serving as an indirect means of education and validation of opinions (Kidd and Parshall, 2000; MacPhail and Campbell, 2001). A focus group setting provides space for participants to assess a range of behavioural possibilities, generate their own questions, and answer these questions in light of their own priorities (MacPhail and Campbell, 2001). Also, Kitzinger (1995) argues that focus groups are particularly appropriate for facilitating the discussion of topics that would otherwise not be discussed in public, as people who are more comfortable with the topic tend to break the ice for shyer ones. In this study participants used the forum to confront one another's ideas, and those of the research team, and offered their own understanding of situations. This would normally not have taken place in the traditional 'farmer-extension worker' encounter.

Members of the research team facilitated focus group discussions. Since not all the participants were fluent in English, we conducted the discussions in Dagaare, the local dialect, which I later translated and transcribed to English. The research team developed a focus group guide. This comprised a set of semi-structured questions that 
probed topics including: how participants conceived health and ill health, what they considered to be indicators of health and ill health, what they perceived to be major community health problems, and the environmental and societal factors responsible for these health problems. Focus group questions were also developed for the various steps of the strategic planning process (to be discussed next), and these probed topics including: participants' vision for a healthy community, factors inhibiting the realization of that vision, strategic directions to move toward that vision, and systematic actions that can be implemented to achieve their desired future. The questions were designed to be flexible in allowing new questions to be added during the data collection process.

Women and men met separately for discussions. All focus group discussions were conducted outdoors under trees at two locations in the community: the western and eastern corridors. Each group discussion ran for approximately two to three hours. Each focus group included a short feed-back session. All focus group discussions were taped with the permission of the respondents, listened to at the end of every discussion by the research team, and those issues that were not well understood were clarified with participants at the next group session. Refreshments were provided during a twentyminute recess and at the end of each discussion.

\subsection{The Strategic Planning Process}

The Strategic Planning Process (SPP) provides a good structure for planning group projects. It allows participants to look beyond their immediate problems and obstacles and to plan for a better future, making use of their unique abilities, resources and 
strengths. The process leads discussions through a series of logical processes and allows participants to come to a common resolve on problems facing the community and to search for a desirable future. The strategic planning process helps groups of people to develop strategic planning capacities and meet community goals among diverse stakeholders (Martin et al., 1995). This facilitative process is designed to tap the knowledge base of participants in a way that capitalizes on group dynamics and group learning (Spencer, 1989). The strategic planning process consists of five cyclical steps. The first step involves mapping out a community's vision and aspirations for a desired future (e.g. a healthy community); the second identifies the underlying obstacles preventing the realization of that desired vision; the third step identifies broad strategic directions that can be implemented to overcome the identified obstacles; the fourth step follows through with the identification of specific systematic actions to implement the broad strategic directions; and finally, an implementation timeline for the activities is developed. Focus group discussions on specific themes are then facilitated by the research team for each of the five steps of the strategic planning process. In chapter VII, I present a detailed account and analysis of the outcome of the strategic planning process. But first, I describe what each step entails.

\section{Mapping Out a Vision for a Healthy Community}

After the initial focus group discussions, the research team met separately with both the men and women's groups to plan for a healthy community. This began with the first step of the strategic planning process. In this step participants identify their aspirations for the 
future, their dreams and vision for a healthy community. The research team asked participants to respond to the following focus question:

Imagine that we are five years into the future, and all the health problems and their underlying causes identified in our previous discussions have been solved. What noticeable features and conditions would you want to see in Charia and in the people of Charia?

In response to this question, both men and women's groups identified the desirable health and environmental conditions they would want to experience in their community. They first brainstormed their ideas, categorized them into groups, discussed them and explored relationships between and within those groups. During analyses, the research team identified commonalities and differences between the men and women's groups.

\section{Analysing the Underlying Contradictions}

The second step of the strategic planning process allows participants to identify those blocks and obstacles preventing them from realizing the desired future envisioned above. Having mapped out their vision for a healthy community, participants were asked the following focus question:

What obstacles or roadblocks obstruct the realization of the vision we mapped out during our last meeting?

In response to this question, participants identified possible factors obstructing the realization of a healthy future for the community and its residents. They explored how these factors may be enabled and/or constrained by societal structures and policies, 
cultural practices and behaviours and their everyday interactions with the biophysical environment.

\section{Identifying Appropriate Strategic Directions}

The third step of the strategic planning process identifies bold and creative proposals and programs to overcome the obstacles identified in the previous step. This step also requires that community members assess their strengths, weaknesses and the resources available to them for the implementation of any programs and/or projects they might propose. Participants were asked to respond to the following focus question:

What new activities must we undertake to overcome the barriers and roadblocks identified in our previous discussion?

In response to this question, both the women and men's groups drew on the significance of local knowledge systems and their ability to contribute to mitigating health and environmental problems. They also identified major weaknesses relating to apathy in the community, as well as ongoing community conflicts which prohibited unified communal efforts. New directions for community-extension worker partnerships were also proposed.

\section{Identifying Systematic Actions}

The fourth step of the strategic planning process calls for the identification of practical and attainable actions which when implemented would fulfil the strategic directions set out in the previous step. Participants began to show great enthusiasm during this stage of 
the process as they gained confidence in their own capabilities of identifying possible solutions for their problems. Until then, they had always perceived themselves as helpless victims at the mercy of the government and international organizations. The focus question preceding this discussion was as follows:

What practical and attainable actions can we begin to implement so as to achieve the strategic directions (proposals, programs, etc.) that we mapped out during our last meeting?

In response to this question, participants identified specific activities to implement the strategies identified. The actions identified were then discussed to assess their feasibility and resource requirements. Activities perceived to be of immediate importance were ranked high on the list of priorities.

\section{Drawing up Implementation Timelines}

The strategic planning process concludes with an implementation timeline, which is followed by the actual implementation of activities. An implementation timeline outlines specific duties, meeting days, workdays, materials needed and other resources for implementing specific actions.

\subsection{In-depth Follow-up Interviews}

As a result of issues emerging from the group sessions, a number of key people were suggested by participants and members of the research team for follow-up in-depth interviews. These individuals included traditional healers, youth leaders and some government officials from the Regional Town and Country Planning Department, the 
Environmental Protection Agency, and the Ministry of Health. Participants also identified a few affluent people in the community who had sold portions of community lands, or had accepted building materials (cement, roofing sheets and boards) in exchange for allowing access to their family farms by a private contractor. This contractor was awarded a contract to upgrade the Wa (the regional capital) air strip to an airport. Most community lands were substantially degraded as a result of gravel mining by the contractor, leaving dugouts filled with water throughout the community. This posed health risks both to humans and livestock, not to mention the loss of farmlands. Although I was successful in interviewing a few landowners, efforts to interview the contractor or his affiliates proved futile. However, a few insiders like the regional officer for the Environmental Protection Agency provided some insights into this problem, especially with respect to the futility of saving community lands given the political embeddedness of the airport, and the political clout of the contractor. The follow-up interviews complemented the group discussions and clarified issues that would not otherwise have been understood if only participants' views had been relied upon.

\subsection{Data Management and Analysis}

I used a number of tools to keep track of activities and information in the field. These included photographs, tape recordings of group discussions, participation in activities such as pot making, charcoal making, tree planting, and farm visits. I also kept a journal on my field experiences. 
The analysis of information at the end of group sessions was a collaborative effort between community members, government officials (i.e. members of the research team) and myself. The constant comparative method was used to guide analysis of group discussions (Strauss and Corbin, 1990). At the end of each focus group discussion, key issues of the discussion were recapped, and themes and constructs around which questions were asked were identified and categorized. Broad areas of consensus and differences were identified in both the men's group and the women's group. The analysis of data was dynamic and cyclical, as insights from previous stages were used to inform subsequent stages. Participants clarified and checked with other members to ensure that the actual meaning of statements was well captured, hence lending credibility to the information generated. Overall, the process seemed to provide an opportunity for participants to learn from one another, and to confront and challenge one another's views.

Documenting participants' analysis in text form, unfortunately, is my sole responsibility as the principal investigator, and all efforts are being made to represent participants' perspectives, while recognizing my own limitations as a researcher. This thesis upon completion will be made available to the Department of Geography and Environmental Studies, the Carleton University library, and a summarized version with recommendations presented to the community, as well as other interested parties.

\subsection{Reflecting on the Research Process: Challenges and Ethical Dilemmas}

Fieldwork does not always fit in exactly with what we plan. It is filled with surprises and emotions including feelings of vulnerability and powerlessness. Prior to the onset of my 
fieldwork, I had questions about how I would be received, how cooperative the participants would be, and how my privileged status would mediate the research process and outcome. As Cotterill (1992:602) explains, some experiences, events and feelings are unpredictable at the planning phase of the research and will only emerge as the fieldwork progresses. Standing outside and reflecting on the research process allows me to see and evaluate the political situatedness of my research activities and my relationships with the research team and participants, and also assess some of the challenges and ethical dilemmas of participatory action research. In particular I will raise and problematize issues relating to: participatory research as transformative and empowering; identity and the politics of representation; dealing with vulnerability; understanding the changing community political landscape; establishing equal partnerships, and capturing knowledges through group processes.

\subsubsection{Participatory Research as Transformative and Empowering}

In general, participatory research aims to combine research, education and action (Hall, 1992). This is based on the notion that knowledge that is not used to stimulate social change is knowledge wasted (Maguire, 1987; Israel et al., 1998). Thus, participatory and emancipatory research approaches aim to produce knowledge from the perspectives of the marginalized, deprived, and oppressed groups of people, and then use that knowledge to undertake collective actions to reduce inequalities and transform social realities (Maguire, 1996). It is an attempt to give the silenced voices the opportunity to name their problems and participate in decision making towards their resolution. But, often, as outside researchers going into a community, we are faced with the challenge of 
identifying the 'silenced', 'oppressed', and 'marginalized'. Besides, we gain entry into the community through local leaders and gatekeepers who are in a position of power and also hold the ability to mobilize people and resources.

During my fieldwork, the community representatives I worked with still influenced which groups we asked to participate in the study. To some extent I felt powerless in controlling who participated, their reasons for participating and their relationships with community representatives. While I was interested in reaching the poor and voiceless, they probably could not become involved because they were either too busy securing the basic necessities of life (Rifkin, 1994), did not belong to any community organization, or did not want to participate because they had no clean clothes to join their friends in discussions, or were not on good terms with those handing out the invitations. As Cornwall and Jewkes (1995:1673) point out, 'unless a definite political commitment to working with the powerless is part of the process, those who are relatively inaccessible, unorganized and fragmented can easily be left out'. The dilemma this situation presents is that by working through local power structures, there is the tendency for the research to be manipulated towards the agendas of the powerful. On the other hand, working against local power structures can weaken both the potential impact of the research outcome and intensify marginalization and alienation after the research is completed (ibid).

Participatory research asserts that the problem to be investigated and the transformative actions that emanate from the research are meaningful when they are locally determined. Thus, the role of the researcher is one of a facilitator, a catalyst and a co-learner, who initiates the process and collectively works with the ideas of participants 
to achieve a new level of critical consciousness about participants' lived experiences and the broader social, economic, and political factors influencing those experiences, and to transform this knowledge into action. But as discussed previously, most deprived communities lack the resources, drive and commitment to initiate the process or take the necessary steps to change their situation. They rely on someone with the time, skills and commitment, someone who will almost inevitably be an outsider, and a member of a privileged and educated group. So to what extent should a student researcher, with limited resources specify action as an objective? This is a dilemma I faced in my decision to undertake a PAR project. Recognizing that the decision to initiate a transformative action must be locally determined, and might not be implemented due to lack of resources, I decided to work with the decision makers and the resource providers representatives from government departments. Being part of the research team, they were more likely to gain first-hand knowledge of the constraints and resource needs of community members and would likely assist with implementation plans, compared to having requests for resources dropped on their desks by community groups. Thus, in this study, while I specified action as an important component, I focused on fostering mutual learning, increasing a better understanding of participants' circumstances, building problem-solving skills and capacities as well as community competence. These are lifelong lessons that, if acquired, can be drawn upon to make decisions about particular circumstances, including appropriate health behavior and practices. 


\subsubsection{Identity and the Politics of Representation}

A number of feminist and poststructuralist writings have drawn attention to the ways in which our identities and changing positionalities affect the way we conduct research and the subjectivities that are inscribed in our work (Haraway, 1991; Harding, 1991; Rose, 1997). These writings question claims to objective and value-free research and explore how relations of power between researchers and the research influence the interpretation and representation of the knowledge we seek to create. Haraway (1991) for example, argues that, as academics, we embark upon our research with 'maps of consciousness' that are influenced by our identities of gender, race, ethnicity, nationality and class. These multiple identities, at any one time, are changing, conflicting and overlapping with one another (Butler, 1992; Mbilinyi, 1992). Thus, our accounts of reality and experience are filtered, or mediated, by the multiple, complex, varying, and contradictory nature of our positions, to produce myriad ways of seeing, experiencing, interpreting and understanding the social world. As such, a researcher's knowledge is never pure, but always partial and located and, hence, cannot claim universal application (Harding, 1986; Haraway, 1991; Mattingly and Falconer-Al-Hindi, 1995). Consequently, some critical theorists, including feminist geographers have argued for the need to use methodologies and reflexive strategies that recognize the partiality of our claims and allow for alternative ways of knowing and interpreting the world (Eyles, 1988; McDowell, 1992; England, 1994; Gilbert 1994). I shall return to these issues later.

In this section, I reflect on how my multiple identities and positionalities influenced the research process, the information given by participants and my 
interpretations of these accounts. I reflect on how my status as a Dagaati ${ }^{13}$ woman from the Upper West Region of Ghana, a doctoral candidate studying in Canada, and a second time researcher in the community influenced my working relationship with informants and members of the research team. I find the debates on insider/outsider relationships in research settings pertinent to my experiences in the field. On the one hand, writers such as Abu-Lughod (1988) and Hill-Collins (1990) argue that 'insiders', researchers who study a group to which they belong or share common identities have an advantage over 'outside' researchers because 'insiders' tend to draw on their knowledge of the group to gain more indepth understanding of informants' opinions. On the other hand, 'outsiders' argue that by not belonging to the group under study, they are likely to be perceived as neutral and confided in on issues that would normally not be given to 'insiders' (Fonow and Cook, 1991). They also argue that they are more likely to be objective in observing and interpreting people's behaviours without distorting their meanings (Mullings, 1999). What both arguments assume is that being an 'insider' or an 'outsider' is a fixed attribute and ignores the dynamism of positionalities (ibid). But as many researchers point out, the insider/outsider status is better perceived as 'a site of betweenness' (Nast, 1994;

Kobayashi, 1994; England, 1994), or 'a positional space' with unstable boundaries (Mullings, 1999). As Nast (1994: 57) explains ‘... because we are positioned simultaneously in a number of fields we are always, at some level, somewhere, in a state of betweenness, negotiating various degrees and kinds of difference - be they based on gender, class, ethnicity, race, sexuality and so on ... as such we are never 'outsiders' or 'insiders' in any complete sense.'

${ }^{13}$ Ethnic group of people in the Wa District of the Upper West Region of Ghana. 
Drawing on my experiences then, I never perceived myself as an insider or a complete outsider. I understood quite well that the differences between the research participants and myself, based on my education, age, place of residence, class and mobility outweighed our commonalities of language and place of origin. So I did not perceive myself to be in any privileged position compared to a complete 'outsider'. I also understood that my status as a student, and not any 'person of substance' (one who might be able to make financial or project commitments) might restrain informants from confiding in me. On the other hand, my status as a Dagao, a clan member, and a second time researcher in the community, put me in a 'somewhat' privileged position to better understand some community and cultural issues.

I chose to deploy or rather agreed to be deployed as an insider or outsider strategically; on the one hand, striving to be an 'insider' when I thought this might build trust and, on the other, striving for the 'outsider' status when I thought this would alleviate me being perceived as a threat. For example, during my interviews with women, I was referred to as 'our sister', 'daughter' and 'friend', and I strove to be these attributes based on our shared gender. By contrast, with members of the research team and community elders, I was the 'daughter' who studied abroad, needed to be guided into the community, and needed assistance in completing her research. In these instances, being perceived as an 'outsider' facilitated my entry into the community and accorded me the cooperation and respect normally bestowed to 'foreigners' or 'visitors'. My experiences illustrate that the choice to be an 'outsider' or 'insider' is partly out of the control of the researcher, and may be constituted differently by different community members at different times. This further destabilizes the insider/outsider argument that accords the 
researcher the control to choose and deploy his/her status as either an 'outsider' or an 'insider'.

Also of concern is the role positionality and power plays in shaping and interpreting research findings. Compared to research subjects, researchers are always perceived to be in privileged and powerful positions due to our greater access to material resources, middle-class luxuries such as education, and the power inherent in the production of knowledges about others (Kobayashi, 1994; Gilbert, 1994). These privileged positions are inextricably bound up with issues of communication and representation, and are inherently political. As such, some feminist geographers have emphasized the need to make transparent the process by which information is collected and interpreted (Pile, 1991; McDowell, 1992; Kobashayi, 1994; Gilbert, 1994; Rose, 1997). They call for researchers to situate their knowledge through reflexive examination of the relations of power that transpire during fieldwork. Reflexivity then becomes a process through which researchers critically self-examine their positionality regarding the research (Mullings, 1999). It also requires researchers to render visible their position through their writing, indicating the circumstances that surrounded data collection and analysis (Nast, 1994; Staeheli and Lawson, 1994). Rose (1997), however, argues that this type of (transparent) reflexivity fails to comprehend the complexity of power: 'it produces feminist geographers who claim to know how power works, but who are also themselves powerful, able to see and know both themselves and the world in which they work' (p.311). As researchers then, we are unable to occupy the same positionalities as our subjects. Instead, Rose (1997) calls for geographers to develop other forms of reflexivity, those that allow researchers to point out the uncertainties, failures and gaps in 
the interpretation of accounts from the field, as well as show the extent to which the research process allows both the researcher and researched to 'create versions of themselves that are re-interpreted and re-presented in different ways' (Mullings, 1999:348). In my research, there were moments when I failed to understand the responses that were given during group discussions. As I recount later on, the first set of discussions in the men's group were very evasive and cynical that I could not make any meaning out of them. I wondered why they were so different from those in the women's group and questioned my methodological strategy of conducting gender-disaggregated group discussions. I also wondered how my multiple identities might be influencing these responses. As it turned out, it was neither of my concerns, but instead, related to an ongoing community dispute which I later discovered.

\subsubsection{Dealing with Vulnerability}

In this section, I continue with my reflection by drawing attention to the fragility of the research process and how this sometimes augments the vulnerability of the researcher. I became vulnerable on a number of occasions. On one occasion, a brawl broke out during a discussion with the men's group. I posed a question relating to chieftaincy issues in the community and a young man attempted to respond but was admonished by an elderly man not to 'say a word' because the young participant was not born in the community, had just returned from the 'South' and was too young to speak about chieftaincy matters. In response, the young man argued that, despite these shortcomings, he had the right to respond to the question since he was part of the focus group. He was further admonished 
by his peers for challenging and not showing respect to an elder, thus confirming his 'outsider' status and his lack of understanding of community values. The exchange got out of hand and turned to a fist-fight between the two young men. During the encounter, a series of questions rushed through me. What had I done wrong? Should I have known better because chieftaincy was a sensitive topic in this region? Was there an on-going chieftaincy dispute? Was there an old grudge between the two young fighters? How was I to respond? I was left powerless and wondering how to restore order to the discussion. The situation was amicably resolved by other members of the research team.

Besides exposing my vulnerability as a researcher, this incident has other implications and lessons for participatory researchers. The first relates to the tendency to see communities or the 'field' as a homogenous, place-based entity. With respect to this situation, factors such as where one is born and length of residency dictate who belongs or does not belong to the community and what can and cannot be said by such a person. The second implication relates to the structure and composition of focus groups. Most focus groups are formed to capture diverse opinions, but from this incident I now see focus groups as sites of power struggles among various individuals based on age, ethnicity, gender among others. Given the cultural value not to challenge the 'received wisdom' of the elderly, how might we interpret the data we collect from group processes? As Mosse (1994) points out, data from such group processes obscure power relations and other group dynamics and tend to reflect the voices of those culturally sanctioned to speak in public, while silencing the rest. These concerns challenge the view that group processes provide avenues for the marginalized to articulate their views, be heard and build confidence to participate in decision making processes. If not careful, such 
processes redistribute, consolidate and reconfigure power in some individuals (Maguire, 1996). Finally, what is the implication for participatory processes that tend to strive for consensus and communal goals on which collective action is taken? Would such goals simply reflect those of the powerful and the elderly? How would youth interests come in? Thus, it might be important for focus groups to be formed taking into considerations other issues such as age, religion, ethnicity among others. But even then, is there such thing as 'absolute commonalities'? I believe group processes should be deployed strategically, weighing the magnitude of the problem, how widespread it is and the benefits associated with mobilizing communal responses. In my study for example, while I recognize the diverse needs of various groups, the stark reality of the poor health conditions confronting over $80 \%$ of the population and the social context of the underlying causes of these poor health inequalities required the adoption of the Freire approach of mass participation to internalize and respond effectively to the inequities.

\subsubsection{Understanding the Changing Socio-political Landscape}

During the four years following my last project in the study community, conflict had been brewing between two sections of the community over the location and distribution of proceeds from on-going international development projects. Most of the activities (woodlots, tree nurseries, hand-pumps) and personnel of the 'development' project were located in one section of the community. Members of the other section felt marginalized and angry, and protested this for quite a while. The research team for this study included the community leader, who belonged to the resource-rich section of the community. In our (the research team) attempt to be representative with the venue for group discussions, 
we decided to hold the men's group discussions in this marginalized section of the community and the women's at the other section. After the first two group discussions with both groups, I noticed a difference in the attitude and responses between the men and women's groups. While discussions in the women's group were lively and more responsive to the questions, the men's group was evasive, proverbial, cynical and antagonistic, as if to say 'don't waste our time, we have learned our lesson.' On our third visit to the men's group, the community leader and member of the research team failed to come. Participants took this opportunity to express their real concerns about how they had been marginalized and their lack of enthusiasm for community development activities. The focus for that group discussion was completely thrown overboard, while we followed their agenda and listened to their concerns. The discussion ended with both participants and the research team relishing a new spirit of enthusiasm. While we drove home, I had a number of unanswered questions: How did the men's resentment affect our last two group discussions? Were their responses reflective of the questions asked? And if they were not, how were we to ever find out their 'actual' responses? Or is there anything like an 'actual' response? How about the representation of the participants, could they all have come from that section of the community? Or were there members from other sections of the community who remained silent throughout these discussions? In relation to whether informants' accounts were 'factual', Foucault (1980) points out that, accounts (be they historical or otherwise) are problematic representations of life as they are constituted by heterogeneous cultural codes and complex social networks that entail shifting power differentials. They entail conflicting ideologies and political 
interests that need to be contextualized and assessed for their historical contingent validity.

In collaboration with the men's group, the research team decided to re-run the previous two discussions without the community leader. The discussions were livelier and much more informative than the women's group. Follow-up interviews were also conducted separately with the community leader and head of the marginalized section of the community to gain in-depth understanding of the situation and to complement discussions from the men's group.

Thus, political and social dynamics within the community can be problematic to the research process. Initial awareness of on-going conflicts between community groups, especially ethnic and clan groups, and reasons for conflict is important. Knowledge of previous chieftaincy disputes in the community is also important. Spending some time to learn, re-learn, or get an update on the socio-political landscape of the community before starting my next project would have been helpful.

\subsubsection{Establishing Equal Partnerships}

Although PAR calls for equal partnership between community members and researchers, achieving this goal is fraught with difficulties given the relative privileges that accrue to the researcher in terms of education, age, time, and resources. In my quest to form an equal partnership with members of the research team and community members, I wondered how my multiple identities as a young, female, doctoral student studying in Canada might affect this partnership as well as the research process and outcome. I wondered how government officials who mostly worked through vertical systems would 
relinquish their power and spend valuable time participating in a study that seemed to be of little benefit to them.

As discussed above, my relationship with members of the research team was dynamic and shifted with changing circumstances. For example, given their relation with the community and its members, they played a lead role in making sure I was accepted in the community. From a cultural perspective, they perceived me as an 'outsider' who needed to be guided through the process of gaining entry to the study community and to successfully complete my research. Also by calling me their 'daughter' I was expected to play a submissive role and respond in ways that a daughter would normally respond to her father. Thus, from the cultural point of view, I played a submissive role. However, this relationship changed when I had to outline the conceptual issues of my research and share with them some data gathering methods such as the Strategic Planning Process. Although I was open to their opinions, I still played a dominant role in specifying, to some extent, how the research should proceed and what we should aim for. Power therefore seemed dynamic, on the one hand concentrating in me to make academic decisions and, on the other, concentrating in members of the research team based on their elderly status, their ability to network with the local power structures, and their ability to command departmental resources.

There were some challenges in attempts to form equitable relationships between participants and the research team. Members of the research team occasionally worked with community members, either by providing them with technical information, educational materials or even working with them on their farms. Most disciplinary training, especially in the medical field, instils a notion of 'objectivity' in their 
professionals, making it difficult for them to embrace local subjectivities and give up their 'expert' status (Cornwall and Jewkes, 1995). The top-down fashion in which most departmental programming is implemented has impacted local people's sense of confidence in their abilities. For example, during group discussions, I noticed how some participants withheld information because they thought it might not be correct from the viewpoint of the 'experts' who were facilitating these discussions. Those who responded, especially to technical questions, looked to the facilitators for approval. Thus, the notion of equal partnership is always far from being a reality, developing sometimes during the latter stages of the research when participants sense the validation of their own knowledge systems.

Notwithstanding these limitations, local people still exercise some form of power based on their responses to questions or even refusal to respond to questions. During discussions with the men's group, I found it difficult to understand or interpret the responses of one elderly man. They were always proverbial and cynical; so after his response I would ask the group for clarification. In some instances they explained, while in others, they just laughed. As a researcher, what are you to make of such information?

\subsubsection{Group Processes: Are All Knowledges Captured?}

The literature on participatory processes suggests that the open, group and informal settings of discussions promote lively debates and arguments among participants, break the ice for shyer participants to discuss issues they would normally not discuss in public and also provide an opportunity to confront one another's views and opinions. While this 
may be true, for the same reasons, information collected through such group processes, if not enhanced through member checking, can be evasive, codified and misleading.

Mosse (1994) argues that, the social context in which participatory data are produced is problematic. It elides the influence of power, authority and gender inequality and presents the position of the dominant as that of the community. In particular, the subordinate role of women and the cultural norms about what they should say in public restrict them in their ability to articulate their concerns in public arenas, and so they are forced to go with the dominant position or only voice concerns that are culturally accepted within a woman's domain. This sentiment also can be said to be true for youth, as well as people perceived as 'not belonging' to the community. Despite separate group discussions, there were still internal power struggles within the men and women's groups.

In the women's group for example, socioeconomic status and material wealth played a key role in excluding people from group discussions. The women agreed to hold their group discussions on Sundays after church. In a community where most of the population is Christian, and going to church means wearing your best clothes, some women did not feel comfortable participating in the discussions simply because they did not have any fashionable clothes and did not want to be the odd ones out. It is also fair to assert that wearing good clothes gives one some amount of confidence and self-esteem to dominate group discussions, and those who were not in their best, Muslims and traditional worshippers, just had to watch, listen and wish. In a discussion on factors inhibiting participation in community health promotion programs, one female participant identified the lack of clean clothes as the major obstacle stopping her from participating in such programs. In a rather subtle way, she had made an important point. We (team) 
decided to change group discussions from Sundays after church to late Sunday afternoons. Although it was not a democratic move and conflicted a bit with the time women began preparing supper, it was the best choice, as no woman would wear her best clothes sitting around the house and waiting till late afternoon. The atmosphere during group discussions thereafter was much more egalitarian and everybody laughed equally hard when there was reason to.

Another assumption of participatory research is that knowledge is an undifferentiated product and, using the right procedures, people's knowledge can be recognized and accessed, and even used for developing effective and acceptable interventions. Mosse (1994:502) cautions against this assumption, arguing that knowledge is not self-evident. The information generated through participatory approaches is 'often of very different kinds, involving mixed combinations of fact and value, consensus and difference, openness and sensitivity, as well as public and private accounts'. Caution has to be taken when interpreting such information, taking into consideration detailed knowledge of the local socio-political situation.

\subsection{Conclusion}

This chapter outlined the methodological procedures guiding the study. Using a PAR approach, I worked with an interdepartmental team of co-researchers and two groups of community participants (men and women) to examine the health problems facing Charia. Taking the knowledge further, we engaged in a planning process, mapping out an envisioned healthy community. I also reflected on the research process, discussing how 
my privileged and multiple positions influenced the research process and relationships. Finally, I recounted the challenges associated with using participatory processes, including its failure to capture all voices.

Notwithstanding the difficulties encountered, the research process itself proved to be a powerful means of not only uncovering a breadth of opinions about community health concerns but also contributed to individual and community capacity building. The process provided an opportunity for the research team to gain first hand experience of issues community members felt passionate about and to listen to their own definitions of their problems and their underlying causes. Community members on the other hand felt empowered by the opportunity to confront the 'truth claims' of extension/field workers and to propose their own strategies based on lived experience and local knowledge systems.

In the next three chapters, I present and discuss the findings of the study. In the first, I discuss participants' understanding of concepts like health and ill health, what they perceive to be indicators of good and poor health, and their assessment of the major health problems in the community. In the following chapter, I recount participants' discussions on the underlying causes of major community health problems and how they cope with and respond to such factors. Drawing on these two chapters, the final chapter articulates participants' vision for a healthy community and how they hope to make this a reality. 


\section{CHAPTER V}

\section{HEALTH AND HEALTH PROBLEMS FROM THE COMMUNITY'S PERSPECTIVE}

\subsection{Introduction}

In this chapter, I present and discuss the findings of my first set of focus group discussions. These discussions were aimed at finding out how men and women conceptualized health and ill health, what they perceived to be indicators of good health and poor health, as well as their major health concerns. I locate my discussions in this chapter and the next within a political ecology of health framework, examining the ways in which community members' conceptualization of health and their health experiences shape and are shaped by their changing subjectivities and locations within social relations of power. I also draw on poststructuralist ideas to examine the ways in which the common-sense knowledge which sustains the community is generated and reproduced, and how local people are able to resist dominant environmental health discourses through the articulation of their own definitions based on their cultural values, experiences and knowledge systems.

As discussed in chapter III, the application of a political ecology approach to the study of health (or disease/ill health) provides a comprehensive analytical framework with which to understand spatial and social disparities in health and how these are constituted through a complex interplay of socio-ecological factors (Mayer, 2000; Harper, 2004). Of central importance to a political ecology framework is the concept of a 'politicized environment' (Bryant and Bailey, 1997; Bryant, 1998) which focuses 
explicitly on the role of power relations, and political and economic systems in mediating access to environmental resources and the resulting marginalization of weaker actors. Power, in this context, is theorized as the ability of one actor to exert control, both materially and discursively, over the environment of another (Bryant, 1998). Such control may take place in various forms, including the ability of one actor to control the use of, and access to, vital environmental resources by other actors; control the selective identification, prioritization and representation of environmental problems, and thus prevent the concerns of other actors from entering public policies; and also through the inequitable distribution of the costs and benefits associated with environmental activities (ibid). I will develop these issues further in the next chapter.

In the health sector, power may be exercised through the ability of one actor to name, define, and solve the health problems of other actors; define the values, beliefs and behaviours other actors ought to hold; and selectively control access to and use of health care services (Lupton, 1998). The exercise of power is maintained through the circulation of particular discourses (e.g. public health, environmental sciences) which have implicit rules on 'who is allowed to speak, from what point of view, what is allowed and not allowed to be said, and in which form' (Aviles, 2001:164). These implicit rules are also based on the notion that knowledge and power implicate each other. The exercise of power requires the production of certain knowledge types, while the production of knowledge requires the exercise of power to validate them (ibid). Usually, the validation of such specialized knowledge systems is achieved partly through the use of expert languages, labelling and the creation of abnormalities (Lee and Garvin, 2003). Labels such as 'rural women' and 'at risk groups' are constructed based on abnormalities. 
Constructed as deviating from the norm, these labels of abnormalities then require professional interventions. These interventions often appeal to the 'social' good, such as community health and well-being, while denying and concealing any political or economic interests. Validation is also achieved through the privileging of medical/health knowledge systems over lay perspectives (Lee and Garvin, 2003). The health practices and beliefs of local people are sometimes considered 'out-moded', 'primitive' and 'health deteriorating'. Local people's understanding of health or disease phenomena is seen to be inferior to professional knowledge which claims scientific accuracy. Based on such understandings, 'packaged' health promotion practices are then recommended to local people, with the assumption that they would accept these uncritically (Lupton, 1994; 1995, Lee and Garvin, 2003). But as it turns out, lay people are able to resist dominant discourses and practices by reconstructing them in light of their own social realities. They also are able to resist dominant knowledge systems through avoidance behaviours and non-participation in health programs. These resistance activities highlight the agency and adaptive powers of lay people.

In the sections that follow, I present and discuss participants' accounts of their health and health experiences. These accounts suggest that local people do not necessarily respond passively to dominant biomedical discourses to understand the origins of, and responses to their health problems; rather, through historicity, and their daily interaction with one another and their social and ecological environments, they are able to articulate alternative understandings of their health experiences, the underlying determinants of their health problems, and what it will take to resolve them. Both men and women drew on their respective societal roles, changing identities and positions to 
articulate what they understood as health and indicators of good and ill health. They were also able to make linkages among major community health problems, their existing social, economic and political marginalization, and how these influence their interactions with the environment. This understanding further gave meaning to why certain health problems such as tuberculosis are prevalent among men and psychosocial health concerns among women. Tuberculosis was linked to male labour migration to work in the mines in Southern Ghana, whilst women's psychosocial health problems resulted predominantly from constantly 'worrying' about meeting familial and community obligations.

The articulation of these accounts by participants differs from the dominant individualist notions of health that often deny the role of human agency, historicity, heterogeneity of populations, and the influence of other structural factors. In presenting participants' accounts, I make use of direct quotations from transcripts of our group discussions in an attempt to reflect participants' own points of view. For each quotation, the respondent's sex $(\mathrm{M}=$ men and $\mathrm{W}=$ women) and age (when known) are indicated.

\subsection{Men's and Women's Conceptions of Health and III Health}

During focus group discussions, $\mathrm{I}^{14}$ asked participants to explain what they understood by health and ill health. The purpose of this exercise was to ascertain how local people conceptualized health and the lack of it based on their specific situations. The research team was careful not to impose their conceptualization of health on participants. This exercise generated quite a lively discussion within both men's and women's groups. In

\footnotetext{
${ }^{14} \mathrm{My}$ use of ' $\mathrm{I}$ ' in reporting and analyzing the responses does not elide the role of other members of the research team. It acknowledges my lead role in facilitating these discussions and in taking ownership of these accounts.
} 
general, both groups shared similar ideas about what constitutes health and ill health. Various dimensions of health were expressed including: psychological, emotional, physical, spiritual, the ability to fulfill one's role in society, availability of social support networks, and health as a precondition to achieving other goals in life. Health was closely associated with ideas of 'well-being' and the ability to have access to a decent meal and a 'roof over one's head'. Ill health, on the other hand, was conceived as the inability to fulfill one's societal roles in the family and in the community, the constant worrying about how to meet daily needs, and feelings of being sick. Many participants' conception of health differed significantly from the biomedical conception of health. For example, very few people referred to health or ill health in terms of disease; instead, most conceptualizations were grounded in peoples' lived experiences and societal roles. As participants conceptualized health in relation to their everyday activities, the seemingly similar abstract conceptualization of health and ill health between men and women became differentiated into specific representations influenced by gender, age, education, religious orientation, and socioeconomic status.

Specifically, most men related health to their role as household heads. They saw health as the ability to achieve goals, meet personal and family needs, as well as meet the social demands of being a man within the community. They considered health as the ability to provide food and shelter for the family:

Health is the ability to be industrious and put laziness aside. Healthy men pick up their hoes at dawn, go to the farm, come home at dusk with food for their families. If a man is lazy and is unable to provide for himself and his family, then he is not healthy. (Man, 35 years). 
As the head of the household and the main provider, I am responsible for the health and well being of every single member in my house. If I fail to provide food and a good place for us to lay our heads, then I am subjecting everyone to ill health. It is my responsibility to keep the whole family healthy. (Man, 46 years).

Men's conceptualization of health was rather interesting, and linked to the cultural belief that 'ill health is not a man's domain'. Most men's responses suggested that men's health was given; men had no right to be sick; and men must stay healthy to provide for their families. In their opinion, ill health and flimsy excuses belonged to women. As put by one elderly man, 'a man only becomes sick when he is about to die. Our blood is too strong for any infection'.

The implications of such conceptualizations by men are myriad. In the first instance, in a patriarchal society where men are seen to be the bread-winners, the decision-makers, and the custodians of the community, any sign of weakness questions their 'manly' abilities. So just like women, there is some undue pressure from society for men to stay healthy so as to conform with societal roles. Secondly, most health care programs emphasize children and women's health (e.g. maternal/child health). Even though programs such as family planning are supposed to be for both males and females, women are mostly the targets. Such orientation reinforces what men believe about themselves: they are not supposed to be sick. Third, very little is written about rural men's health in developing countries, compared to rural women's health (Avotri and Walters, 1999). This is often because most researchers studying women's health issues assume that women have more in common with each other than they do with men. Thus 
little is done to make comparisons between men and women's health. Instead we focus on the search for a 'universal women's experience'.

Most women conceptualized health in terms of their roles as mothers, wives and primary caregivers in the family and in the community:

Health for me is the ability to take good care of my children and be able to meet their day-to-day needs. When this is done, then I worry less, I am able to sleep and I am also healthy. (Woman, 26 years).

In their conceptualization of health, older women conceived of health in terms of having security during old age. In the words of one woman in her sixties:

Health is having responsible children to take care of you when you are old. Had it not been for my children, I would have been dead long ago. I sleep without ever worrying about anything. They send me money, buy me clothes and make sure I never run out of food.

In a society where women are looked upon as primary caregivers, women, just like men felt an additional pressure to stay healthy or keep silent about their health problems in order to fulfill those expectations of caregivers. This was reflected in their conceptualization of ill health:

Health! [laughing] Why are we even talking about health when we women can never say 'I am not feeling well.' Technically speaking, I have never experienced ill health and so cannot even describe what it feels like. I continue with my daily chores even when I don't feel well. If I allow the sickness to put me down, who will take care of my family? As a woman, I have no right to become sick. (Woman, 42 years) 
This response is consistent with the literature on women's health in developing countries. Okojie (1994) observes that the threshold of illness is so high for women that they endure so much in order not to disrupt household organization. Thus, women prefer to keep silent about their health problems and to bear the pains and aches associated with their heavy workload and multi-tasking daily chores:

Madame! Listen to me. My day starts with the first cockcrow when I leave for the borehole to get some water. I make six rounds before the children wake up. Then I sweep the compound, bathe the children, make some breakfast and leave for the farm. I return at dusk, go to the grinding mill, draw some water again and prepare supper. After supper, I wash the bowls and when I eventually sit down, I shell my groundnuts for sowing the next day. By the time I go to bed, all I experience is bodily aches, especially my waist, knees and back. But I don't consider this as dangerous to my health. I consider myself lucky to be able to do all this work for my children. If I don't work this way, who do I expect to take care of my children? (Woman, 32 years).

To some extent, women have come to understand that ill health is only associated with pregnancy-related complications, hospitalization for child-birth and postpartum complications. Any other health problems are deemed minor, non-legitimate, or considered as signs of laziness. This perception originates partly from the community's expectations of women as child bearers and child caretakers, and so their only legitimate health problem must be associated with childbirth or childcare. It also relates in part to the early missionary health policy that placed emphasis on family planning, maternal and child health in rural areas as a way of gaining more converts (Twumasi, 1975; Randall, 
1998). This emphasis seems to have persisted until today and leads many women to perceive their health strictly in terms of maternal and child health. Women's health issues are, therefore, defined in terms of reproduction, with an undue emphasis on only women within childbearing ages. Other health issues, such as psychological, occupational and environmental health problems, rarely feature prominently in health-care organization and delivery. Ironically, however, despite the biomedical emphasis on this issue, rural maternal mortality rate remains the only health indicator that has failed to decline in recent years (GSS/MI, 1998; WHO, 2001).

Also, rural women's health concerns have to be examined within the broader societal context. Many rural women lack the autonomy, independent decision-making powers, and financial resources to make regular antenatal visits, despite the availability of these services in some communities. Any health problems encountered during pregnancy are silenced and considered non-life threatening, until complications become severe. Severe complications are then referred to the major hospital, which is sometimes located at a distance from the community. However, due to concerns of interrupting household organization, financial, and transportation problems, women arrive at the hospital just when it is too late, or never make it at all. As has been pointed out earlier, the introduction of user fees through SAPs, has been the major reason preventing many women from utilizing hospital-based services. Despite the fact that some village women have been trained as traditional birth assistants, their training stops with handling only normal deliveries and not with complications. 
Interestingly enough, during my group discussions with women, very little was said about reproductive health issues. Most women tended to conceive of ill health in terms of psychosocial health, relating it to 'worrying' and the 'inability to sleep':

Headaches and stomach-aches are not what constitute ill health. Health for me (as a woman) means more than just being physically fit. I am continuously worried about the health of my children, how to get money to send them to the clinic, to school and even to provide food for them. Although I may look physically fit, the continuous worrying throughout the day and night wears me down and I don't see myself as healthy even though I may look so. This is the biggest health problem for women. When we take these complaints to the clinic the nurse tells us it is not sickness, we are only being lazy. (Woman, 46 years).

In the men's group, conceptions relating to psychosocial health were often expressed in terms of 'worrying to provide for my family' and 'concerns about standing up to their roles as men'. In another study on how men and women coped with mental stress, it was observed that alcohol played a significant role in alleviating men's psychosocial health concerns (Luginaah and Dakubo, 2003: 1752). Most men admitted to taking akpeteshi (a locally brewed gin) for the purpose of not 'thinking too much about the house problems'. For most men, alcohol served as a coping strategy to their daily problems, serving an escapist function of taking them away from the realms of their daily struggles. It is not common for women to drink akpetheshi in this community, but the very few who indulge do this primarily for the purpose of 'rebelling', 'protesting', 'resisting' or 'facing' up to their drunk husbands. While akpetheshi serves a temporary escapist function from daily struggles, it also results in household violence including spousal and child abuse. 
Level of education also played a key role in how health was conceptualized by both men and women. While those with no formal education conceived of health in terms of their ability to fulfill societal roles and functions, those with some formal education conceived of health in Western terms. For example one middle school graduate conceived health as:

..... taking care of one's self and adopting good health behaviours. By this I mean eating good food, exercising, abstaining from smoking cigarettes, abstaining from drinking alcohol and keeping our surroundings clean. (Man, 22 years)

Religious orientations also influenced how people conceptualized health. Traditional male worshippers, mainly the elderly, explained health in supernatural and spiritual terms. They alluded to the fact that health or healthiness is a transitory and evolving state, which is partly bestowed upon us or taken away from us by superior powers. Accordingly, ill health or illness is an inescapable fact of day-to-day life and deserves no explanation. For them, ill health is an inevitable part of living and:

we should learn to accommodate it and not question it. God made us and it is he who brings sickness. If it is stomachaches or headaches, it is God who brings them. We wake up and we find ourselves with one of these sicknesses. (Man, in his sixties)

Traditional worshippers believe in the efficacy of traditional healing and the use of spells to cast away demons. On the other hand, most Christians influenced by missionary thoughts seemed to believe in the efficacy of medical intervention. 


\subsection{Contrasting Participants' Concepts of Health with Other Notions of Health}

In this section, I contrast participants' conceptions of health with those espoused by biomedical orientations, to examine how these influence health-related activities and interventions. Currently, three health models co-exist: the biomedical, social, and salutogenic models (Kelly et al., 1993). The biomedical model is the predominant model of health across many places in the world. It assumes that health and disease are natural phenomena which exist in the individual body, rather than in the interaction between the individual and the social world (Gordon, 1988). It also assumes that diseases are generic; they have common symptoms and outcomes across social circumstances (Bird and Rieker, 1999). The biomedical model claims scientific neutrality, rationality, and objectivity, and claims to be value free (Mishler, 1981).

As discussed in Chapter III, the biomedical model has been criticized for focusing on the individual and its component parts, as well as placing emphasis on measurable physiological and chemical data, to the detriment of social, cultural, and environmental factors (Doyal, 1979; Navarro, 1986). These criticisms led to conceptions of social models of health including, the 'holistic/socio-ecological', and behavioural models of health. Social health models focus on the individual as a whole, and not just a sum of its component parts (Wohl, 1983). It broadens the biomedical model to include social, cultural and environmental influences (ibid). Health from this perspective is reflected in the definition offered by the World Health Organization: 'Health is a state of complete physical, mental and social well-being and not merely the absence of disease or infirmity' (WHO, 1948:1). However, from this perspective, critics argue that health is presented as 
an ideal goal that can only be approached but never achieved. Others argue that health is not a state but a task; health is a means to an end, and not an end in itself (Seedhouse, 1986; Duhl, 1986). Following these criticisms, health has been conceived in positive terms (salutogenic) (Antonovsky, 1985); a resource for everyday living, that allows individuals to manage, cope with, and change their environments (WHO, 1986:1).

Most participants conceived of health in positive terms. Their conceptualization of health was very much in tune with that put forward by the new health promotion movement. Except for a handful of formally educated individuals, health and ill health were never conceived in terms of the absence or presence of disease or infirmity, but rather in terms of the ability of men and women to achieve goals, meet personal and societal needs, and cope with everyday life circumstances. Participants' conceptualization of health also illuminated the differing needs, beliefs and concerns of people differentiated by gender, age, religion and socio-economic status. This captured the complex, socialized dimensions of health and points to the fact that health promotion and interventions go beyond efforts of the health sector alone. They include a broad range of social, cultural and economic factors and require the cooperation of various sectors.

In contrast, health and health programs in Ghana are still shaped around Western biomedical concepts and practices, emphasizing curative and technological solutions that focus on isolated diseases to the neglect of broad-based health promotion. From the preceding, it is apparent that psychosocial health concerns have become prominent in the community; a problem for both men and women. The underlying causes of such psychosocial stress have to be located within the broad view of problems confronting 
many rural communities, including the lack of economic opportunities and the basic necessities of life. Such difficult situations have, over the years, dismantled the social system that provided for everyone. As one woman put it, 'I can no longer take my bowl to my neighbour and borrow flour, with the promise to replace it next week, since I might never be able to do so'. The falling apart of the social system and social support networks has only begun to augment inequalities within the community, inequalities that are shaped by broader national and international ones. I will illuminate these factors in the next chapter.

Also because the health systems in many developing countries fail to accommodate psychosocial health problems, they are often dismissed as petty complaints of no significance, or as signs of a 'lazy' woman. This puts additional pressure on women to keep silent about such health concerns or even to doubt themselves as being 'a proper Dagaarti woman'. In a similar study conducted in the Volta region of Ghana, Avotri and Walters (1999) point to the increased psychosocial health concerns of women in the study community and the need to make room for addressing such health concerns as legitimate.

\section{$5.4 \quad$ Indicators of Good and III Health}

In order to move the conceptualization of health and ill health beyond abstract dimensions, we asked participants to identify features and/or conditions that they thought signified 'good' health and 'poor' or ill health. Indicators identified by both men (M) and women (W) were quite similar and are summarized randomly in Table 5.1. For the most part, participants identified indicators of good health to include factors such as peace, 
unity, love among family members, social and community cohesion, family unity, material and financial resources. On the other hand, indicators of ill health focused on social dysfunction, household food insecurity, pride, lack of social support, among others:

A healthy family is one where there is unity and love among family members.

Family members support one another in whatever they do, and you can never hear them shouting at each other or fighting over things. They are always happy and healthy (Woman, 41years).

Table 5.1. Participants' Subjective Indicators of Good and III Health

\begin{tabular}{|c|c|}
\hline Indicators of good health & Indicators of ill health \\
\hline Love, unity and peace among family members (W) & Lack of unity, love, and peace among family \\
\hline Healthy-looking (plump) family members (M) & members (W) \\
\hline Participation in community activities (M/W) & Household food insecurity (M/W) \\
\hline Low child morbidity and mortality (W) & Pride and social isolation (M) \\
\hline Access to education $(M / W)$ & Frequent visits to the clinic $(\mathrm{W})$ \\
\hline Well-educated children $(\mathrm{M})$ & Ignorance $(M / W)$ \\
\hline Access to, and control of land resources (W) & Childlessness, insecure old age (W) \\
\hline Access to, and control of proceeds of labour (financial & Lack of access to farmlands $(M / W)$ \\
\hline self-sufficiency) (W) & Lack of access to income opportunities (M/W) \\
\hline $\begin{array}{l}\text { Happy, cheerful and never worried about food, money, } \\
\text { or shelter }(M / W)\end{array}$ & $\begin{array}{l}\text { Continuously worried about how to meet life's basic } \\
\text { needs }(M / W)\end{array}$ \\
\hline
\end{tabular}

In the men's group there were clashing perspectives on whether health was a commodifiable outcome, one that could be achieved once an individual or family is financially self-sufficient, versus health as a social product: 
In my opinion health can be bought with money. If you have enough money to buy food, clothing and go to the clinic, you can never fall sick. People with money look healthy, their children are plump (i.e. fat), and they are always happy with nothing to worry about. (Man, 28years)

I do not think health can be bought with money. One may have all the money, food, and clothes, but if the person does not participate in community activities, does not socialize with his peers or does not help other members in the community, he becomes a social outcast. Being a social outcast with no community support is the worst thing that could possibly happen to you in this community and such people, although healthy looking, are frightened, isolated and, therefore, not healthy. (Man 52 years).

Such exchanges are reminiscent of the on-going debate within the health literature whereby, on the one hand, the achievement of good health is considered a shared responsibility between society and the individual (WHO, 1998), and on the other hand, it is seen as dependent on individual choices. As has been pointed out by those advocating an ecological approach, the choices that individuals make should not be examined in isolation but situated within the broader lens of the social and political contexts, and how these influence and are influenced by individual-society interactions (Robertson and Minkler, 1994).

Also, compared to the predominant use of quantitative health indicators such as mortality and morbidity rates, frequencies of disease occurrence, and average life expectancy within many health sectors, community members referred mostly to 
qualitative indicators. While quantitative indicators may serve the purpose of identifying at-risk-groups and health issues requiring immediate attention, they do not reflect the subjective indicators community members use to measure their health status. A focus on numbers reflects the biomedical orientation to treat and cure, with minimal attention to preventive measures or overall well-being. Some scholars argue that the use of quantitative indicators vis-à-vis qualitative indicators risks translating peoples' health experiences into predetermined, static categories, which can result in distorting or silencing people's experiences (Mies, 1983). They also argue that quantitative indicators assume some level of false objectivity, neutrality and impartiality, creating what Haraway (1991) calls a 'false vision'. Additionally, in many rural communities, there are problems associated with accessing accurate and reliable quantitative health data as most fatalities that occur in the home environment fail to make it to the clinic or hospital. Thus, quantitative health indicators may fail to capture the true figures, while also failing to capture the underlying reasons for poor health.

\subsection{Perceptions of Major Health Problems in the Community}

After having understood how local people conceptualized and measured health and ill health, we moved on to identify what they perceived to be the major health problems in the community. Again, in line with PAR, we did not want to impose our ideas or agenda on the community, but instead guided participants to determine what they perceived to be their major health challenges. We asked both the men's and women's groups to identify and rank the top ten health problems in the community. With a few deliberations and 
arguments, both groups indicated malaria and childhood diarrhoeal diseases as their first and second health problems respectively. To further clarify, I probed how participants identified and diagnosed specific health conditions. In the case of malaria, for example, participants described the symptoms to include ngan-orung (bodily pains/weakness), marung (cold/fever), and zuubaare (headache), which according to health workers, are the typical symptoms of malaria. The health problems identified by both the men's and women's groups are presented in Table 5.2. These are contrasted with the top ten health problems recorded by the community clinic for a one year period (June 2000-June 2001).

Although participants' lists and that from the community clinic were quite congruent, health workers at the clinic ranked Acute Respiratory Illnesses (ARI) as the third major health problem in the community. Acute respiratory illnesses were not included in the men's list partly because of their inability to accurately distinguish it from malaria. During the focus group discussions, it was observed that men categorized symptoms associated with acute respiratory illnesses as malaria. In the women's group, however, mothers were able to isolate respiratory illnesses from malaria. They described symptoms of acute respiratory infections to include maarung (cold/fever), corrung (cough), and short rapid breathing. These descriptions are congruent with the literature (Dakubo and Commey, 1996) and confirmed by health professionals to typify clinically diagnosed pneumonia. Mothers were also able to indicate that acute respiratory infections affected children mostly under the age of five. 
Table 5.2. Top Ten Community Health Problems Identified by Participants and Compared to Community Health Data

\begin{tabular}{|c|c|c|c|}
\hline Ranking & Men & Women & $\begin{array}{l}\text { Community Health Data* } \\
\text { (June 2000-June 2001) }\end{array}$ \\
\hline 1 & Malaria & Malaria & Malaria \\
\hline 2 & Diarrhoeal diseases & Diarrhoeal diseases & Diarrhoeal Diseases \\
\hline 3 & Measles & "Unknown illnesses" & Upper Respiratory Illnesses \\
\hline 4 & Cerebrospinal meningitis & Hernia & Skin Diseases \\
\hline 5 & Hernia & Sight problems & Pneumonia \\
\hline 6 & Eye infections & Epilepsy & Acute Eye Infection \\
\hline 7 & Farm-related accidents & Cerebrospinal meningitis & Accidents (Farm and Non-Farm) \\
\hline 8 & Tuberculosis & Respiratory diseases & Chicken Pox \\
\hline 9 & Kwashiorkor & Work-related injuries & Rheumatism \\
\hline 10 & Guinea worms & Rheumatism & Snake Bites \\
\hline
\end{tabular}

* Source: Charia Community Health Clinic

Malaria according to most participants was the main health problem in the community. As one man cynically put it:

We do not consider malaria as a foe anymore; we see it as our friend and have opened our doors to it. We can never get rid of malaria; we only have to learn to live with it. Malaria has killed many of our children, particularly in the rainy season. We have done all we can but it continues to be our number one enemy. Our blood is gotten used to the drugs and they do not seem to protect us anymore. (Man, 32 years)

Similarly, diarrhoeal diseases (binkuo) were said to be very common with children and responsible for the deaths of many children: 
Binkuo (diarrhoea) has been one of the major health problems in this community, particularly during the harvesting season when children eat fresh groundnuts and roasted maize. We have our own local way of stopping diarrhoea. We try to treat it with herbs such as mwanbehe, nyelimanyuu and pawpaw leaves, but when this fails we take them to the clinic. If we are lucky they survive, but most often it is too late. (Woman, 28 years).

Other health problems identified by male participants as peculiar to men included tuberculosis, hernia and farm-related accidents. According to most male respondents, tuberculosis is a disease contracted and spread by migrant workers who returned from mining communities in southern Ghana. As discussed in an earlier chapter, male migration to urban centres of development in southern Ghana has persisted since colonial times. Accordingly, after years of working in the mines, many ex-miners return home to settle down. As a result of the poor working and living conditions, most of these exminers return with tuberculosis, which is quickly spread due to overcrowding in poorly ventilated houses. Another common health problem identified by both men and women was hernia (gyira), which apparently results from engaging in hard work and lifting heavy loads. Some men also associated it with eating certain western foods such as Maggi (type of seasoning) and canned tomatoes. Farm-related accidents, including snake bites, were the other health problems identified by male participants.

Apart from childhood diseases, most of the discussion in the women's group centred on a cluster of symptoms categorized as 'unknown' illnesses, a category which was ranked third in their list of top ten health problems. Some of the symptoms described included a combination of bodily pains, shortness of breath, and dizziness. According to 
most female participants, these health problems cannot be clearly categorized, but can only be described:

One day I was coming home from the farm and carrying a basin full of sheanuts, just as I got close to my house, I suddenly felt stiff, my heart stopped beating, I began to run out of breath and suddenly my knees collapsed. I fell to the ground and my senior son came to help me. When I went to the clinic the next day, the nurse told me there was nothing wrong with me. Meanwhile this has been going on from time to time. (Woman, 44 years)

These 'unknown' illnesses described by women might be associated with their arduous and load-related duties (Messing, 1991). For example, carrying heavy loads over long distances is exhausting and physically demanding. Heavy weights are said to cause back strains, lower back pains, fractures, chronic and debilitating back and leg problems (International Labour Organization, 1989; Haile, 1994), and could also lead to prolapse of the uterus (Labour Resource Centre, 1995), a major cause of maternal death in many developing countries.

Also, standing long hours in the fields weeding, picking and sorting puts women at high risks of suffering severe back aches, arthritic pains, postural defects and leg problems. According to Kitts and Hatcher (1996), the heavy and repetitive physical activities required in the fields are also associated with musculoskeletal and soft tissue disorders and degenerative joint diseases of the hands, knees and hips. Such health problems might not be well-articulated by many rural women.

In the women's group they identified other health problems to include sight problems, rheumatism, and work-related injuries and accidents. Pottery and charcoal- 
making are the two main income-generating activities undertaken by women in this community. According to some female respondents, these activities expose them to intense fires and heat, thus affecting their eyesight. During our group discussion on workrelated illnesses, members of the research team took the opportunity to explain to women some unacknowledged health risks. Many women could not associate indoor air pollution resulting from cooking with biomass fuels and poor ventilation with the incidence of acute respiratory illnesses. They did not also realize that ingesting small amounts of agrochemicals as a result of failing to wash their hands properly after applying fertilizer and pesticides to their crops could be harmful to their health. Some women, upon completing their field work, even harvest vegetables and store them in used fertilizer bags, oblivious of the health risks. According to literature on women's occupational health, exposure to some agrochemicals can result in effects such as dizziness, muscular pains, difficulty in breathing, impaired eyesight and nausea (Labour Resource Centre, 1995). Sadly, some pesticides that find their way to rural communities are banned in most industrialized countries because of their health risks (Puta, 1994). Given the desperate attempts by rural communities to boost agricultural production, they seem to be more than grateful to receive these fertilizer and pesticides, perhaps for free.

\subsection{Conclusion}

In this chapter, I presented and discussed participants' conceptions of health and ill health, their perceptions of indicators of health and ill health, as well as their perceptions of the major health problems facing them. For the most part, both men and women 
conceptualized health from a social, ecological and holistic perspective, situating their health experiences within their respective societal roles. They also considered the means to achieving individual and community health as linked to, and located within the broader social, political and economic contexts. Similarly, participants identified health indicators that were culturally bound and also derivative of their social values and norms as well as community functioning. The nagging question that arises is, to what extent does the health care system in the study community, and in Ghana as a whole, take such lay and local perceptions into health care programming and delivery?

As discussed in preceding chapters, there are a number of reasons that prevent lay perspectives form being privileged or taken seriously in mainstream health systems. One of the reasons lies in the dominance of the biomedical approach and the top-down approach that characterizes current health care delivery systems. Much of the material presented is in a biomedical framework, with health educators perceived as those with the 'appropriate' knowledge to educate lay people about their health problems. Biomedical interpretations of health problems situate the problems and those affected vis-à-vis dominant norms of conduct, morality, and social order. Lay views are considered primitive and their practices health-deteriorating. Lay people are also perceived as passive, empty vessels waiting to uncritically accept dominant biomedical views as 'truth' (Lee and Garvin, 2003). As it turns out, lay people are able to challenge these dominant discourses by drawing on their own local social realities. Health problems within this perspective emerge as more than the sum of their symptoms; they are always seen as cultural products being shaped by political economies and historical contingencies. The application of poststructuralist ideas to health, thus allows us to 
recognize the precise ways in which health problems, and the people they affect, are culturally constructed and socially deployed, and providing another layer of meaning and understanding of health/ill health.

It also allows for understanding how the construction of social identities within medical discourses risks masking power relations. Medical constructions of identity are highly abstracted because they reduce a complex and varied set of practices to narrowly defined issues (Miles, 1993). For example, are rural people, by virtue of their place of inhabitance, more disempowered to negotiate for better health care than their counterparts living in other places? In what ways does social identity interact with economic need and other structures to shape health risks and inequalities? The emphasis on narrowly defined identities prevents any thorough contextualization of the health experiences of the marginalized. What is required is a closer examination of how socially ascribed identities impact upon configurations of power. In the next chapter, I develop these issues further, examining the underlying factors responsible for poor health in the community. 


\section{CHAPTER VI}

\section{UNDERSTANDING THE FACTORS AFFECTING HEALTH IN THE COMMUNITY}

\subsection{Introduction}

In this chapter I discuss participants' perceptions of the factors influencing their health. I analyse these responses in light of a political ecology of health framework, illustrating the complex links amongst health, environment and socio-political and economic factors. I also develop further the concept of a politicized environment to illustrate how marginalization, vulnerability and poor health outcomes of certain community groups occur as a result of unequal power relations surrounding the use of, and access to, ecological and health resources.

The application of a political ecology of health framework allows for an understanding of the mechanisms through which political and economic processes shape human-environment interactions and how these contribute to disparate environmental exposures and health experiences (Turshen, 1977, 1984; Mayer, 1996, 2000; Kalipeni and Oppong, 1998). Political ecology of health draws our attention to how actions by local elites, the state and global processes differentially enhance the power of others while diminishing the coping ability of weaker actors. It also draws our attention to how weaker actors are able to resist powerful actors through avoidance behaviours, noncompliance, and acts of sabotage and arson. As discussed previously, power is a key concept in specifying the topography of a politicized environment, and it is important to 
understand the various ways in which power relations shape patterns of humanenvironment interactions and how these impact people's health.

Powerful actors, such as household heads, local elites, states, businesses, and multilateral institutions exert power over the environment of weaker actors (e.g. farmers, peasants, women, indigenous populations) through the control of, use and access to a diversity of environmental resources, including land, water, forests, and non-timber forest products (Bryant and Bailey, 1997). In many parts of Africa, for example, colonial policies regulated access to vital natural resources through policies of total and partial exclusion, and through the establishment of game and forest reserves (Peluso, 1992; Bryant, 1997). Some of these policies have persisted until today in certain parts of Africa, including Ghana. At the household level, power relations between men and women are reflected in the inequitable distribution of environmental rights and responsibilities, of income-earning opportunities within households, and the failure to recognize women's household activities as 'work' (Joekes et al., 1995; Carney, 1996; Rocheleau et al., 1996; Agarwal, 1997). Power exercised as control over access to environmental resources is normally done with the intent to monopolize the economic benefits associated with that resource to the detriment of weaker actors. In situations whereby accessing environmental resources is for livelihood purposes, weaker actors are unable to obtain basic necessities such as food, game, medicine and fuelwood which are all vital for human health.

Power manifested as control over access to environmental resources is linked to the marginalization of weaker actors which often leaves them vulnerable to environmental calamities such as drought, low soil fertility and low crop productivity. By 
virtue of their marginal political and economic status, weaker actors such as farmers and peasants are pushed onto economically marginal lands. However, in order to eke out a living on these lands, they intensify their production and employ unsustainable land practices and in the process render the land ecologically fragile and less productive. Low crop productivity translates into undernutrition and increased morbidity and mortality, especially for children. This vicious trend continues since the prospect of weaker actors deriving livelihood from their lands becomes diminished. As Blaikie and Brookfield (1987) note, environmental and/or land degradation then becomes both a result of and a cause of social marginalization.

Power manifested as control over access to environmental resources is also closely linked to a highly unequal distribution of the costs and benefits associated with environmental problems. In most cases, weaker actors bear the disproportionate burden of environmental costs associated with the economic activities of powerful actors. They are doubly disadvantaged as they receive little to nothing of the benefits and also have the least amount of resources to cope with or escape the associated environmental costs/problems (Bryant and Bailey, 1997). In this study for example, participants reported on the activities of the building contractor and how these destroyed their farmlands and created breeding grounds for disease vectors. They also recounted how cotton plantations, set up by state corporations, depleted their soils and affected food productivity.

In other instances, power is exerted through the control of societal prioritization of environmental projects and resources. In these circumstances, the state and other external organizations are able to allocate substantial amounts of resources favouring 
certain geographical locations and people. This unequal allocation of resources is closely linked to the economic and political benefits of the allocators, although this might not be that evident. In this study, for example, participants drew attention to the unequal prioritization and allocation of resources including infrastructure and services between northern and southern Ghana during both colonial and post-independence eras. They argued that these uneven development trends have been the backdrop for north-south migration and the resulting labour shortage in rural northern households.

Finally, control over another's environment takes place through the delineation of what is accepted as 'appropriate' environmental discourse and/or practice and through the construction of environmental problems/crises and their associated interventions. Just like the discursive constructions of health discussed in the previous chapter, the selective identification and representation of environmental problems and crises is itself a political process and may or may not be grounded in scientific 'fact' (Bryant, 1998:88). As Schmink and Wood (1987) point out, power is not only about the control over material resources, but also about the regulation of ideas, which is intimately connected to the production of environmental knowledge. This process of knowledge production often reinforces social and economic inequities in as far as such knowledge claims serve as the basis of socially divisive public policy or for the societal prioritization of environmental projects (Schmink and Wood, 1987; Guthman, 1997). For example, in many parts of Africa, the colonial administration's claim that local farming practices were inappropriate and caused soil erosion resulted in the implementation of a coercive system of soil 'conservation' in which farmers' land-use practices were closely regulated or the farmers were required to vacate the so-called 'threatened' areas (Neumann, 1996). These colonial 
discourses on soil erosion still persist today and have remained popular with mainstream scholars and policy makers (Bryant, 1998).

From the above discussions, it seems that powerful actors tend to prevail over weaker actors. However, as Scott (1990) points out, this is not necessarily the case as weaker actors are able to challenge and resist the activities of powerful actors through resistance behaviours, thereby undermining the dominance of powerful actors. For example, in this study, community members, particularly the youth, were able to challenge the activities of the building contractor and requested a restoration of their farmlands.

In the sections that follow I report on group discussions with participants on their perceptions of the underlying causes of poor health in Charia. In articulating these underlying factors, there seemed to be two trends of thought; those who owned or tended to blame themselves for their problems (e.g. citing issues of inappropriate environmental practices, ignorance); and those who articulated their problems in terms of structural and socio-economic causes including social and political marginalization, ecological uncertainties and poverty. For purposes of organization, I discuss participants' responses under separate categories of climatic variability and agricultural productivity, ecological disturbances, water and sanitation, poverty, access to health services and gender roles, while cognisant of the intricate links amongst them. Like the previous sessions, separate focus group discussions were organized for men and women. The group discussions were lively and challenging to facilitate, as participants confronted one another's views as well as those of the research team. In reporting participants' views, I make use of direct 
quotations from transcripts. Each quotation is followed by the respondent's sex and age (when known).

\subsection{Climatic Variability, Agricultural Productivity and Health}

The climate in most of northern Ghana is often described as harsh. Unlike southern

Ghana, the northern regions experience only one rainy season. Rainfall during this season is erratic, often making it difficult for farmers to predict accurate planting, harvesting and drying times. During group discussions, participants made explicit linkages between sustainable agricultural production, food security and human health. They pointed out that, over the years, gradual climatic and ecological changes have greatly affected agricultural activity and food production in the community. To obtain a better perspective of these changes, the research team decided to conduct a historical scan with community members to determine what specific ecological conditions had changed and how they had changed. Using timelines and important events, participants observed changes in weather events, soil fertility, vegetation, wildlife, and biodiversity, and how this had affected their farming practices. Although the observations by men and women were quite similar, men seemed to emphasize changes to the vegetation cover and livestock numbers, while women made observations about the changing availability of water bodies. Participants' responses are summarized in Table $6.1(\mathrm{M}=$ men; $\mathrm{W}=$ women $)$. 
Table 6.1 Major Community Changes Identified by Participants

\begin{tabular}{|c|c|}
\hline Feature & Type of Change \\
\hline Rainfall & $\begin{array}{l}\text { Amount gradually reducing, becoming more unpredictable, and } \\
\text { starts late and stops early }(\mathrm{M} / \mathrm{W})\end{array}$ \\
\hline Vegetation & Opened up and reduced cover except for reserved areas (M) \\
\hline Wildlife & $\begin{array}{l}\text { Reduced numbers and not common near settlements. Diversity } \\
\text { drastically reduced }(M)\end{array}$ \\
\hline Livestock population & Drastic decrease in numbers per household (M) \\
\hline Soil fertility & $\begin{array}{l}\text { Observed decrease in fertility, low crop yields, increasing use of } \\
\text { fertilizer }(M / W)\end{array}$ \\
\hline Water bodies & $\begin{array}{l}\text { Year-round water bodies are now seasonal, with some drying } \\
\text { out (W) }\end{array}$ \\
\hline Human population & $\begin{array}{l}\text { Gradually increasing. More built-up areas and settlements and } \\
\text { thus less land for agriculture }(M / W)\end{array}$ \\
\hline Ethnic groupings & People more mixed $(\mathrm{M} / \mathrm{W})$ \\
\hline Occupations & $\begin{array}{l}\text { Initially emphasis was on hunting and farming, but now many } \\
\text { people are beginning to turn to petty trading, irrigated farming, } \\
\text { fishing, and other income generating activities } \\
\text { Gradually losing traditional trades e.g. blacksmithing and } \\
\text { pottery }(M / W)\end{array}$ \\
\hline $\begin{array}{l}\text { Agriculture } \\
\text { Technology }\end{array}$ & $\begin{array}{l}\text { New crop varieties and livestock species, increased used of } \\
\text { mechanized farming }(M / W)\end{array}$ \\
\hline
\end{tabular}

During group discussions, elderly participants were particularly vivid in recapping their memories about how cropping patterns had changed as a result of climatic changes. One elderly man put it this way:

When I was a young man, everybody knew that the planting season began on April $15^{\text {th }}$. By April $15^{\text {th }}$ we had sufficient rains to begin sowing beans while 
clearing land for other crops like maize and groundnuts. These days what do we see? We wait sometimes, until July before the first rains come. By then our granaries are emptied and we have no food to eat and no harvest to look up to. We no longer have control over our farming practices. We are at the mercy of the weather.

Participants' accounts of historical trends also revealed some occasional periods of droughts. But since participants could not be exact with their dates, they made use of some major historical life events and folklore. For example, drawing on folklore, some elderly men explained that a catastrophic drought occurred during the early twentieth century:

In that year the drought was so severe that the local people ate all their grain including seed grain. When the planting season came, there was no seed to plant, so an old man sent his son to dig deeply into a termite nest to obtain seed for planting. (Man, 60 years)

While data on annual rainfall amounts in the region do not date back to the early twentieth century, data from 1950 to 1998 show few yearly variations, despite the fact that most participants seemed to be convinced that rainfall amounts have reduced over the years. The difference in the two accounts can be understood by distinguishing between inter-annual and intra-annual rainfall variability. Inter-annual variability, reported in the data, refers to a comparison of total annual amounts of rainfall in different years, while neglecting the year-to-year variation in the rainfall distribution (Schaik and Reitsma, 1992). Intra-annual variability, on the other hand, refers to the distribution of rainfall within a year, which seemed to be what participants referred to. Given that the 
Upper West Region has only one rainy season, intra-annual variability may pose problems to farmers, if during the rainy season they get too much rain in a short period while the rest of the year fails to yield sufficient rainfall for crops to fully mature (Geest 2002).

Also, one middle-aged woman remembered the 1983 drought, when she had to queue for long hours for rationed grain:

I remember that year when I needed strength the most. We queued for long hours to receive grain from the government, and eventually after receiving it, if not lucky, someone stronger than you will snatch it away from you. That was how bad hunger was that year. It made brothers turn on each other. The 1983 drought was one of the worst in the country's history; it was nationwide and affected agricultural productivity in the southern region as well. Ironically, this drought occurred in the early years of the structural adjustment programs, when the adverse impacts of SAPs were just beginning to unfold. ${ }^{15}$ The removal of food subsidies, compounded by the drought rendered many households food insecure. Food rationing was instituted to help curtail the crisis, but these rations failed to make it to many rural communities. As a result many northern households replaced nutrient-rich meals such as beans and millet with nutrient-poor diets such as 'konkonte' and 'gaari' (both cassavabased meals).

In recent times, changing ecological conditions and low agricultural productivity have been used as common excuses for the seasonal migration of young men to southern

\footnotetext{
${ }^{15}$ In a case study of how communities in the Eastern Region of Ghana survived this period, see Dei (1993) Learning in the time of Structural Adjustment: The Ghanaian Experience. Canadian and International Education 22 (1): 43-65.
} 
parts of the country. Whilst there, some work as wage-labourers on maize farms, whilst others follow colonial trends and work in mines. But as has been pointed out by Cleveland (1991), these seasonal migrations, over the years, tend to become permanent as expressed by a young man during the discussion:

I use to go to 'gyong' (down south) after the harvest season to do 'par' (sell labour) for some money for my Christmas shopping. Then, I came home for Christmas and went back until the farming season when I returned home to farm. These days I sometimes stay in 'gyong' the whole year, because there is no longer any farming season up north, it is all down south... and as a young man if I stay home (up north), where will I get money to marry and start life? (Man, 19 years). The implications of such long-term migration on female-headed households and widows are myriad. As discussed by women, not only have their work-loads increased, but they also risk losing their land due to their inability to cultivate it yearly. They are also forced to give up cultivating their 'personal' crops $^{16}$ :

Since Kwesi (referring to son) left for 'gyong' (down south) two years ago, I have not been able to cultivate my rice field. I have no man in my house. It was Kwesi who used to help me on the main farm and on the rice field. Now the rice field is lying empty and part of the farm uncultivated. I do not hear from him either and so I am left wondering when he will come home (Woman, 42 years).

Young women, on the other hand, do not migrate primarily because of the cultural belief that women stay home whilst men go out to fend for food and money. Instead, some

\footnotetext{
${ }^{16}$ Crops such as rice and vegetables are mostly cultivated by women and the proceeds accrue solely to women.
} 
women were concerned about young men returning to the community with sexually transmitted diseases such as HIV/AIDS. A young woman's fears were evident in her statement:

These young men return home eventually to marry. They come home with flashy clothes, money, bicycles and other material wealth. They ask our parents for our hand in marriage. Drawn to their material wealth and not knowing what 'secrets' they brought with them, our parents may accept a proposal and then we could end up contracting this dreadful disease (referring to HIV/AIDS). It is a scary situation. (Woman, 24 years).

While acknowledging the difficult agroecological conditions facing farmers in northern Ghana, it would be myopic to limit the explanation of the high food insecurity levels and malnutrition to only such factors. Instead, these should be examined within the broader context of a 'politicized environment' and the marginalization of the region in past and present times. For example, current human-environment interactions in rural northern Ghana has to be seen in the context of how colonial powers incorporated the rural agricultural economy into the global capitalist system of production, and in the process transformed the livelihoods of many rural communities for the worse (Songsore, 1983). The commodification of labour for mineral extraction and cash-cropping and building of railways in Southern Ghana negatively impacted subsistence farming and productivity. The role of the IMF/World Bank-led structural adjustment policies and present-day globalization techniques are reflected in current environment crises as local people intensify agricultural production on ecologically fragile areas. 
Among other things, participants pointed out additional concerns such as: lack of good preservation methods, value-added processing systems, poor markets, outdated farm equipment, inaccessibility to wider markets, and lack of farmer-centred agricultural policies:

I farm a lot of tomatoes and okro (also referred to as okra) on my vegetable farm. In some years when the harvest is good, I am thankful to God. But what do I do with all those tomatoes when there are no markets for them? They (tomatoes) all get rotten in a few days and my labour is wasted. We do not have those cold things (refrigerators) that the agricultural officers have nor do we have the facilities for turning it into the 'Whiteman's' tomato (referring to tomato paste). Those your people (referring to a group of international development workers) promised to help us, but we have not heard from them yet. (Woman, 44 years) The dire need for liquid cash by rural inhabitants also compels farmers to sell their farm products at relatively cheap prices at farm gates to urban dwellers and middlemen. In one farmer's words:

Yams cannot cure my children when they fall sick. I need money to take them to the clinic, so although I cultivate yams and rear guinea fowls, I do not eat them. They are just to provide money for incidentals. (Man, 32 years) The majority of agricultural produce is sold through local periodic markets, usually organized on a six-day cycle. Wa, the regional capital, is the major urban market and functions as a relay market for the area attracting traders from southern Ghana, as well as within the region. However, there is no organized marketing system that enables farmers to sell at better prices, thereby reaping maximum profits. Some women expressed 
frustration at the fact that $\mathrm{Waala}^{17}$ trades women 'knock at our doors at dawn on market days just to give us 'peanuts' for our products, and then return to Wa to sell it for over a hundred percent profit.' Middlemen have usurped the economic power of the rural farmer. Middlemen purchase farm products at relatively cheap prices, store them until the lean season, and retail them back to rural people at relatively high prices. Many participants indicated they had no choice but to sell their produce at farm gates because they needed the money for 'more pressing issues.'

Food insecurity and the poor health status of most rural residents in the UWR can be seen as a result of the interaction of agro-ecological and political-economic forces. Problems associated with the already harsh agro-ecological condition of the region and its low agricultural potential were worsened with the implementation of structural adjustment programs (SAPs) in the 1980s. The SAP was implemented to increase tradables and so the cash-crop sector was promoted at the expense of rural subsistence (Cornia et al., 1987; Kanji et al. 1991; Woodward, 1992). The SAP favoured large-scale commercial farmers and landowners compared to small-scale subsistence farmers. In the Upper West Region, for example, large-scale cotton production was encouraged at the expense of food crop production. This made use of intensive farming practices, replacing the traditional hoe farming with mechanized farming and agrochemicals. Farmlands used for cotton production eventually became unsuitable for food crop production. SAPs also placed an extra burden of work upon women in smallholder households through pressure to produce more crops for sale. Heavy workloads combined with the inability to meet the family's consumption needs undermined the nutritional status of both women and

\footnotetext{
${ }^{17}$ Natives of Wa
} 
children, increasing their susceptibility to infectious disease and other maternal and child related morbidities and mortalities (Kanji et al., 1991). As Bradley (1993) explains, nutrition plays an important role in understanding the high incidence of infectious diseases in developing countries. Low nutritional status predisposes an individual to infection, and because the immunological status of a malnourished individual is impaired, the course of infection is more severe compared to a well-nourished person. In addition, not only are malnourished people more likely to contract and die from infectious diseases, but the infection itself causes further malnutrition - a synergistic relationship. The fragility of the region's ecosystems and its poor agricultural potential has drawn a number of international development organizations (Sasakawa Global 2000, Catholic Mission, Adventist Development Relief Association (ADRA), to help promote sustainable agricultural practices. While some of these projects have been successful in developing social awareness of implementing sustainable agricultural practices, others have failed to make any significant impact because of the non-coordination of efforts among projects resulting in duplication, and also because of the incompatibility of program objectives and recommendations with those of local people. This was evidenced in one elderly man's views:

Our ancestors had traditional methods of farming and storing the best seed-crops for the next planting season. They had their own ways of forecasting weather patterns and making informed decisions as to when to begin sowing their seeds. These days we are told that our seeds are not good. Instead we are given free seeds sealed in plastic bags, and told how, when and where to plant them. When we harvest these 'new' crops, particularly groundnuts, they no longer taste like 
the groundnuts we had before. We are no longer in control of our own farming practices (Man, 28 years).

Some scholars have written against the imposition of packaged technologies and ideologies based on western conceptualizations on southern environmental problems, arguing for the need to pay attention to specific cultural and historical contexts, and changing agrarian and socio-political events. In a similar vein, the discursive turn in political ecology draws our attention to how power relations may be reflected in conflicting perceptions, discourses and knowledge claims about ecological processes and how these might in turn reinforce social and economic inequities. By appealing to notions of 'common good' (e.g. increased food availability), and 'scientifically proven interventions' (e.g. pest-resistant seeds), powerful actors often seek to justify unequal patterns of human-environment interactions, while concealing or rendering natural their political and economic interests (Escobar, 1996; Guthman, 1997; Schmink and Wood, 1997). Local people, on the other hand, would have to discount their knowledge as inferior, resist these dominant discourses, or live with the consequences should they become part of public policy, as was done with soil conservation systems and game reserves (Neumann, 1997).

\subsection{Ecological Disturbances and Exposure to Disease Vectors}

In their conceptualization of health and its indicators, some participants made linkages between sustainable landuse practices, natural resource conservation and good health. During focus group discussions, we explored what land-use practices participants 
perceived as ecologically disruptive and how these posed threats to their health. One major activity identified by participants was the conversion of virgin or long fallow lands for farming and settlement purposes: 'As a young man of age and recently married, I need to step aside and build my own little place for my family.'

Extensive land clearing often involves clear cutting and bush burning, leaving behind a few economic and fruit trees. Such landscape modifications are associated with the emergence of both old and new diseases as was seen in the case of Lyme disease (e.g. Levins et al., 1994; Schrag and Wiener, 1995). Although participants acknowledged that such land-use practices were ecologically destructive and might adversely affect health in terms of curtailing the necessary life-support services, they could not make any direct association between virgin land conversion and the emergence of disease vectors. Drawing on prior knowledge and from the literature, I explained how extensive virgin land conversions sometimes eliminated disease vector predators and competitors, creating opportunities for new species to colonize the area, and so when people came into contact with these environments, they stood the chance of contracting both old and new diseases (Levins et al., 1994). Despite this short-sightedness, many participants were still able to make linkages between sustainable landuse practices, conservation and their health. Such thinking counters mainstream environmental thought that portrays rural dwellers as irrational users of land, who, because of their high population growth rate and povertystricken nature, are mostly responsible for environmental degradation (WECD, 1987). As Broad (1994:812) points out, this way of thinking is 'fairly deterministic', eliminating the need to search elsewhere for environmental culprits. 
For example, in the study community, the onslaught of land scarcity, and hence the cultivation of marginal lands can be seen as the result of the expansion of peri-urban areas, as village land is being sold to professionals looking to build their private homes. Until now the sale of land was seen as a practice that would incur the wrath of the earthgod; but growing economic hardship has forced rural landholders to break these customary rules, now seeing them as myths. Such trends have resulted in increased land fragmentation, intensive farming practices and commercial land use practices.

In a related incident, participants discussed how village land has become a site for gravel extraction for construction purposes in the nearby capital town, Wa. In particular, participants made reference to one wealthy building contractor who had destroyed community farmlands by using large earth-moving equipment to excavate gravel for the expansion of the Wa airstrip. Both men and women spoke angrily about this incident:

I woke up one morning and went to our bush farm to fetch some firewood. Upon my arrival, I noticed that the trees were uprooted, and there were large holes everywhere. This was no more a farm. I was in shock and wondered who might have done this. So I went home and told my diedoo (husband) about it. He was surprised too. We later found out that we were not alone and that other farms have also been destroyed. We are determined to find out who entered our farms without our permission and caused so much destruction. (Woman, 36 years).

During my discussions with the men's group, it was revealed that the building contractor negotiated with some community elites and pressured landlords to giving up portions of their land in exchange for building materials, such as roofing sheets, cement and boards. The activities of the contractor left behind large trenches of dugouts that collect water 
during the rainy season. This situation has since generated conflict among various community groups; women felt their husbands received bribes from the contractor without informing them; some family members felt betrayed by their elders; the youth became disappointed in the inability of community elders to stop such an invasion; while some elites exercised caution: 'let us not rush to judgement and blame others until we find out all the facts.' But given the complexity of the situation, the status of the actors involved, and the anguish it has caused among community members, it is unlikely that 'all the facts' will ever surface, since this transpired in a culture that abhors rebuking elders. What is certain, however, is the human health risks generated by such ecological destructions. The dugouts, for example, have since been used as defecating grounds for livestock, and swimming grounds for both humans and livestock, not to mention their role as breeding grounds for disease vectors, such as mosquitoes and snails. While there has not been any formal study linking this situation with water-related diseases reported at the community clinic, staff at the clinic certainly observed a rise in acute eye infections and skin diseases, partly resulting from contact with polluted water sources.

At the time of this study, the village youth had launched an inquiry seeking an explanation for how community farmlands and trees could be destroyed without any concern for people's livelihoods. Together with the chief and some community members, the project contractor was invited back to the village to fill up all the dugouts, and replace the top-soil on farmlands. Given the status, power and influence of the building contractor, and the lack of strict enforcement of environmental regulations, it is unlikely he will act according to the community's demand. At best, the community will be left to face the human health consequences of his actions. The youth have also asked all those 
who received bribes from the contractor to donate all such proceeds to community development projects.

\subsection{Water and Sanitation}

As in previous sessions, both groups acknowledged the centrality of water and sanitation to their health. Women discussed at length the difficulties and amount of time spent to access clean drinking water from the few boreholes in the village. Depending on the number of grown up daughters or helpers one had, a woman could cut down the time spent collecting water: 'If my daughters are home, we usually make about three trips and we have enough water for the whole family for a day. But if I am alone it could take up to five to six trips, said one middle-aged woman. The topic about getting help to fetch water eventually generated into an argument as to whether young boys should help with fetching water so as to lessen the workload on their mothers and sisters. Quite interestingly, I noticed that women who had spent most of their lifetime in the village argued that it was not right to involve young men in drawing water. 'Do you want their friends to laugh and make fun of them? Drawing water is not for a young man. They have their own duties which we do not do. Let us not pull them into this', observed one young woman. On the other hand, women who had spent a good part of their lives in southern Ghana, and had their children there, argued that boys do help their mothers to fetch water in the south; it is the northern culture that discourages boys from fetching water:

Supposing that you gave birth to only boys, should they sit and watch you draw water all day long for them to bath? Ever since we came from the South, my boys 
have always helped me to draw water from the borehole. Their friends made fun of them, gave them names, and yet they did not stop. Compared to these friends, my boys are now very responsible. They went to school, fetched water after school and now they have good jobs. It is our responsibility as parents to teach our boys what is right and not let society alone do it. (Woman, 42 years). While the question of whether boys should help with fetching water is a valid one, I believe the important point is that securing water should not be so arduous to interfere with the education and development of children, especially the girl-child. Some gender activists have argued that ' $i$ it is time to make the gender dimension of water and sanitation challenges the focus of politics' (Amenga-Etego, 2003:6). Amenga-Etego points out that many studies have reported on the impact of water scarcity on women and children, merely drawing sympathy to the situation and doing very little to change it.

Charia, like many rural communities, faces problems accessing clean and safe water supplies. This situation was made worse by decentralization policies and the restructuring of Ghana's water and sewerage system, initiated by the World Bank as part of its reform programs. In 1988, the Government of Ghana began to implement the decentralization policy which devolved to the district and local government levels, the responsibility for providing drinking water and sanitation services to rural communities. But most rural districts have since been unable to cope with this responsibility, largely due to difficulties in raising sufficient revenue to support water and sanitation projects. In 1993, the government also embarked on the separation of rural and urban water services, shifting responsibility for sanitation and wastewater management to local governments. Apparently, the main objective of this policy was to separate the potentially profitable 
urban water supply systems from the unprofitable rural water systems, so as to make the water sector attractive to foreign investors as part of the World Bank's effort to privatize public sector utilities in developing countries (Amenga-Etego, 2003). Such policies required communities to own and manage their water supply systems, contribute $5-7 \%$ to the capital costs, and become fully responsible for operation and maintenance. However, many rural communities have not been able to commit much investment to providing clean water and so are forced to resort to contaminated and polluted water sources. Some participants reported using rainwater, water from dams, wells, streams and dugouts for watering livestock, laundry, bathing and for irrigation purposes. These water sources are contaminated by waste material, such as human or animal waste and sewage and contain parasites, bacteria and viruses. With no capacity for water treatment, community members are left to face the potential health risks.

During group discussions, both men and women participants explored the various ways through which water sources became contaminated and how these affected their health. Most participants were able to make associations between the use of contaminated water sources and diseases such as diarrhoea, bilharzia, guinea worm, and skin and eye infections. Participants agreed that the lack of waste management and toilet infrastructure resulted in indiscriminate defecation and waste disposal around the compound. These unsanitary practices eventually pollute open water bodies such as that created by the community dam. Given that water from the dam is used for a number of activities including irrigation, laundry, fishing and bathing, this seems to be a great health hazard for residents. 
Sanitation and waste management at the district and regional level is the joint responsibility of the District Assemblies and the Environmental Health Protection Branch of the Ministry of Health. One of the underlying problems limiting the capacity of these two institutions to effectively manage liquid and solid wastes is the inherent weakness in the institutional structure for dealing with wastes. The existing limited personnel and equipment capacity depict the level of inadequacy in the sub-sector. Only a small fraction of the region's population has access to acceptable standards of sanitation. In several instances, households depend on overloaded and run-down public toilets, while others practice open defecation on the land. The public toilets are all operating below minimum acceptable standards. At the rural level, there are only a few Kumasi Ventilated Improved Pit Latrines (KVIPs) constructed through community initiatives with occasional assistance from donor agencies. Clearly, these limited facilities are unable to meet community needs.

With growing urbanization of the nearby regional capital, participants observed that community suburbs were increasingly being used as waste dumps and were concerned about the potential health hazards of such practices. While relatively few scientific studies have been conducted regarding adverse health effects of waste dumps and landfill sites (Vrijheid, 2000), a recent study in five European countries found out that living near a landfill can raise the risk of having a child with birth defects, such as Downs Syndrome, by as much as forty per cent (ibid).

While efforts are still being made to determine and confirm the health effects of waste damps, those associated with poor sanitation and the consumption of contaminated water are proven. Diarrhoeal diseases alone claim the lives of nearly two million children 
every year, worldwide; over 90 per cent of the cases reported are in developing countries (WHO, 1999). In Ghana, diarrhoeal diseases are the third most common cause of outpatient attendance in most health institutions. With an annual diarrhoeal incidence rate in children under five of 4.5 episodes per child per year, approximately 10 million episodes of diarrhoea per year in this age group occur in the country (GSS, 2003). Despite widespread health-education campaigns on the adoption of appropriate hygienic practices and the use of oral rehydration therapy, morbidity rates have not decreased significantly. This, accordingly, reaffirms the point made by scholars that technocentric-based treatments such as oral rehydration only alleviates symptoms and provides temporary relief. The underlying causes such as water privatization, and the declining role of the state, have completely eroded local peoples' democratic rights to water as a basic necessity (Shiva, 2002).

\subsection{Poverty as a Determinant of Ill-Health}

During group discussions on factors influencing ill health in the community, both men and women described poverty as 'the number one' cause of ill health. Given the emphasis placed on poverty as a health determinant, I followed through with probes to understand the various ways in which poverty or wealth was conceptualized by participants. Like the concept health, poverty was conceived by both groups to include: lack of social security, lack of access to social amenities, lack of employment and offfarm opportunities, lack of education, poor marketing opportunities and poor housing. As discussed below, there were slight variations in conceptions between men and women. In 
many instances though, poverty was conceived from the lack of sufficient cash, income or farmland:

In my opinion money is every thing! Money can buy you knowledge, food, shelter, clothes, health and even friends. We do not need plenty money to be healthy. We need just small money to see us through our daily needs. But there are not many income-generating activities to engage in. As a woman, my only source of income during the dry season is to brew pito, and sell charcoal and firewood. During the rainy season I depend on my vegetable farm for income. Usually, the money I earn is sufficient only for a few bowls of grain from the market, with nothing left to 'guard' the house. (Woman, 22 years).

My daughter! Land is all that we need to live in this village. The land is like our first-born son. It is our major source of livelihood. It gives us all that we need: food, water, air, medicine, and money. In the olden days, a man did not have to sell his goat or sheep when he needed money. All he had to do was go to the bush and he would find most of the things he needed including medicine. We lived off the land and earned enough from our farms. These days, things have changed. The land can no longer support our needs. The soils are dead and crop productivity is low, and so is our source of income. (Man, 54 years) When probed about what signified wealth, most women mentioned household assets such as the number of big basins, 'makola' (big pans), aluminium pots, half pieces of $\operatorname{cloth}^{18}$,

\footnotetext{
${ }^{18}$ Cloths are among the most valuable possessions of Ghanaian women. They are sold either as full or half pieces, vary in quality or grade and are often worn as cloths or used to make dresses. Most women pride themselves in the type/grade and quantity of cloths they own.
} 
and sewing machines owned. These items are very expensive and are the pride of a woman in this society. When a woman owns them, they are usually proudly displayed in her room and used on very special occasions like festivals and funerals. Some women choose to invest in these items as a way of preventing their husbands from sharing in their hard-earned money. Excessive items are then sold anytime a woman needs money urgently. This, according to one young woman, is 'our livestock.' 'Men can sell livestock at any time when they need money. But we cannot. We have to keep our money this way.' Men, on the other hand, identified indicators of wealth to include the number of livestock owned, particularly cattle, bicycles, amount of surplus grain in the granary, housing characteristics, whether aluminium or thatched-roofed, and the number of educated children one had. Most men prided themselves in their livestock, especially cattle, as this signified wealth for many generations and guaranteed bridewealth for the wives of their sons. In a community where cash is so scarce, people with educated children working in the government sector occasionally remit money to them, and so such families are able to meet their daily needs with little difficulty. But such families are few, with over 80 percent of communities in the Upper West Region living in extreme poverty.

The indicators identified by participants differed considerably from those used by the Ghana Statistical Services Division to assess household poverty (GSS, 2000a). For example, in a report on Poverty trends in Ghana in the 1990s (GSS, 2000a) ${ }^{19}$, one aspect of poverty assessment was based on the percentage of households owning 'assets' such as

\footnotetext{
${ }^{19}$ The report was prepared by the Ghana Statistical Services Division. It analysed and presented the findings of two rounds of the Ghana Living Standard Survey (a multi-topic household survey, designed to provide comprehensive information on the living standards of Ghanaian households) carried out in 12month periods in 1991/92 and 1998/99.
} 
cameras, television, refrigerators and other electrical appliances. But as can be seen from participants' discussions above, items they consider as assets include livestock and farmland for men and expensive large aluminum pots and cloths for women. Thus, the indicators used by this report failed to capture most of what rural northern communities perceive as 'assets', except for three items: sewing machines, radios and bicycles. In a sense, these 'assets' are not perceived as assets by rural (northern) communities, partly because of their limited utilisation due to lack of electricity. Poverty was also perceived in terms of lack of basic services and poor human development. Thus, poverty in such communities is more meaningful when characterized in terms of people's inability to meet the basic necessities of life, rather than solely in monetary terms. For example, the lack of access to land-based resources such as fuel, fodder and farmland has serious implications for health, although they are not reflected in income statistics. Similarly, social support networks and participation in economic, political and cultural activities within a community contribute to health enhancement, but are not reflected in incomebased poverty measures.

Poverty within the household is also meaningful when examined from the ongoing contestations and negotiations among household members over both material resources and the symbolic meaning of those resources. For example, during our group discussions, some women pointed out that, while it was acceptable for men to socialize with friends, drink and eat meat at market squares and other public places, this same act was forbidden for women:

Nobody is ever going to point fingers at a man eating meat in the market place.

But if a woman is seen eating meat at the market place, the whole village will 
hear about it. They will admonish you for being a shameless mother and wife. We women are supposed to spend our money 'wisely', where wisely means on things that will benefit the whole family.

Thus, through social constructions of a 'good wife' or a 'good mother', women are expected to spend their money wisely, where wisely means on their families.

Development scholars caution that while there is evidence that many rural African women act 'selflessly' to provide for their families, these acts should not be erroneously interpreted as being 'natural' or 'intrinsic' to women (Whitehead, 1981; Guyers and Peters, 1987). The fact that some women conceal their income in material goods such as half-pieces of cloth, aluminium pots, and grains, demonstrate their unwillingness to selflessly spend their money on household needs alone. They also caution that erroneous assumptions of women as being 'self-sacrificing' may lead to an undue focus on womencentred programs which, in turn, may reinforce existing household inequities. Poverty within the household thus has to be understood from the perspective of a household as a site of struggle, where resources including, land, labour and its proceeds are constantly being contested and negotiated among family members and in ways that are not readily discernable (Whitehead, 1981; Guyers and Peters, 1987; Carney and Watts, 1990). In the three sections that follow, I examine how poverty, reflected in environmental and natural resource degradation, in substandard housing, and in the lack of education, affects the health and well-being of local people. 


\subsubsection{Poverty, Environmental Degradation and III Health}

During group discussions, I observed that both men and women referred quite frequently to poverty as the main driver of environmental degradation. In an earlier quotation, one male participant suggested that many locals depend on their land (referred to as their first-born son) for their livelihood. But as a result of a complex interaction of political, economic and ecological factors, the growing inability of this land to provide and cater for their needs has resulted in further intensification of resource exploitation. This process Bernstein (1979:427) describes as the "simple reproduction squeeze.' Bernstein sees poverty in rural environments as one in which land and labour have been exhausted using the modern techniques of cultivation and market forces that introduce new means of ensuring that surplus is appropriated from rural farmers. The new means of production (seeds, machinery, fertilizers, insecticides) are usually too expensive for the poor farmer, and the farmer's returns to labour do not often match his or her investments. There is, thus, a tendency for the farmer to increase production through the use of intensive land use practices which deplete soil fertility over time. Cultivating less fertile soils requires a greater expenditure of labour and time to produce the same output of crop, thereby increasing the costs of production and reducing the returns to labour (Bernstein 1979:427-8). Although Bernstein does not provide a gender analysis, the differential access to and control of the means and resources of production by men and women means that women farmers, who undertake most of the activities associated with both food crops, and export crops stand to benefit less as they have little control over the proceeds of their labour (Staudt, 1987; Mackenzie, 1993). Besides, more labour is required on marginal lands to reap any benefits. 
How did such new means of production come to predominate in communities which had no access to capital in the first place? Redclift (1987) explains this through the process of internationalization of the environment. In his view, environmental change at the local level is a 'social process, inextricably linked with the expansion and contraction of the world economic system' (ibid: 3 ). He argues that through growth in the world trade, growing debt crisis, globalization of agriculture and the expansion of multinational strongholds, farmers are continuously being pushed to intensify land use and exploit their resource base (Redcliff, 1984).

Thus, the synergistic relationship between rural poverty and environmental degradation needs to move beyond the Brundtland report's assertion that 'poverty itself pollutes the environment' in as much as those 'who are poor and hungry will often destroy their immediate environment in order to survive' (WCED, 1987:28). Environmental degradation in developing countries has to be situated within the price changes and deflationary policies that augmented poverty and encouraged people to encroach onto marginal lands. The removal of subsidies on basic commodities such as food, agricultural products and fuel led to an increased burden on the poor, causing increased dependence on natural resources. Also, the promotion of cash cropping at the expense of landless labourers encouraged intensive agriculture, which is typically characterized by use of heavy machinery, monocropping, and the use of pesticides, resulting in further environmental depreciation. By promoting cash crops, many farmers abandoned the cultivation of food crops.

With respect to the promotion of cash cropping in the community, participants discussed at length how the introduction and cultivation of cotton for commercial 
purposes contributed substantially to soil degradation and low food crop production in their community. There were mixed views about the repercussions of the introduction of cotton cultivation between men and women, and amongst them.

Cotton cultivation can be described as both an enemy and a friend. When cotton cultivation was introduced, we thought all our financial problems had come to an end. With a good harvest we made a lot of money. But this did not last. When the boom was over, we were left wondering what to do next. Our lands were no more fertile because the cotton had eaten up the nutrients (Man, 55 years)

I do not know whether to say cotton was a blessing or not. Cotton was seen as a business for men. You know, my sister, any activity that comes with money, they always say it is a 'man's business.' Women can only help with the picking of cotton on our husbands' farms. But the money that came with cotton was so good that women left their husband's farms and picked cotton for the corporations to make money [laughing] (Woman 47 years).

The introduction of cotton in the Upper West region had dire ecological and nutritional consequences for farmers. Commercial cultivation of cotton was introduced in the region in the 1970s, by the Cotton Development Board of Ghana, after failed attempts to implement it during colonial times (Naylor, 1999). As a result, it was managed by the government. But in the 1980 s, as part of the push towards privatization, cotton production took on a new dimension involving private companies, such as the Plantation Development Limited (PDL), Agro Trade, and Cotton Development Company (Ministry of Food and Agriculture Report, 2000). These private companies paid farmers relatively 
good money, and so many rural farmers began to spend more time cultivating cotton. The ecological destruction was associated mainly with the cultivation process. Large-scale cotton production required that large tracts of land be cleared and stumped to facilitate ploughing and planting in rows. Heavy agricultural machinery, fertilizers and pesticides were then used to augment production. These activities resulted in the exposure of vast lands to soil erosion and exhaustion, as well as, chemical pollution of surrounding water bodies. Some male participants observed that not only was cotton cultivation labourintensive, but it also competed directly with food crop production for time, energy and land of the average family farm:

....a few years ago, cotton was the only thing that gave us good money. We worked on our cotton farms from dawn to dusk. We left the cultivation of food crops to the women because cotton is a crop that needs full attention. If you turn your back on the farm for just one day, all your labour would be wasted. So we toiled on these farms day by day, until the market for cotton fell. When the market fell, most of us stopped farming cotton and began to farm our food crops, but then the soil was no longer the same; it was all 'dead' (low in fertility) and food crop harvest have been very bad ever since. (Man, 43years)

In the women's group, many confirmed the impact of male labour shortage for family farms on household food insecurity. Most women observed that their workload tripled due to the promotion of cotton production in the community. Some indicated that they had to abandon all income-generating activities in order to give adequate attention to food crop farms and to the family's welfare: 
....it is good that the prices of cotton fell. Men left for their cotton farms by sunrise and we women had to finish our chores at home and go and work on the family farm. We had to clear and till the land ourselves, sow the seeds, weed and harvest food crops for the family. We also attended to the compound farm because that is where we got our soup from, and also helped our husbands to harvest the cotton. The bad thing about it all was that we never saw the proceeds from the cotton, nor could we ask what had been done with the proceeds from his cotton farm. (Woman, 40 years).

The introduction of cotton cultivation certainly generated some household struggles over the proceeds of cotton. While women wanted to know how much their husbands made from their cotton farms; men were also curious about their wives' earnings, made through wage labour.

The impact of cotton production on household food security and nutritional requirements is reflected in the overall health status of residents in the Upper West Region. According to the 1998 Demographic and Health Survey, the Upper West region ranks second to the bottom in terms of maternal and child nutrition, slightly surpassing the Upper East region. The data estimates that about $35 \%$ of children in the region are stunted, with about $28 \%$ under weight. The mean bodily mass index for women was recorded as $20.9 \mathrm{~kg} / \mathrm{m}^{2}$ (GSS/MI, 1998). Women seem to be worse affected as they tend to suffer disproportionately from iron-deficiency anemia, iodine-deficiency disorders, and stunting caused by protein-energy malnutrition (WHO, 1994).

In summary, poor health at the local community level cannot simply be explained by local people's lack of health consciousness or irrational use of environmental 
resources, but has to be situated within a broader political-economic framework, that examines how people's environmental actions and health choices are constrained by powerful actors at various levels.

\subsubsection{Poverty, Housing and Ill Health}

During group discussions, we explored the linkages between inadequate housing and poor health. It was evident to me that, despite their acknowledgement of the need for proper housing to protect health, many did not take the health implications too seriously. As put by a young woman, 'all we need is a roof over our heads'. As to the type of roof, that was not a priority. In a community where almost all income was spent on securing food, proper housing with screened doors and windows, piped water and sanitation facilities seemed to be luxurious and meant for a few in the community. One elderly man even questioned the logic of the association: 'Madam, our grandfathers have lived in these houses for decades, and have always been healthy. So to see how our houses can make us sick is difficult to explain'.

Similarly, when I asked women whether they considered smoke from burning firewood harmful to their health or that of their children, many laughed claiming: 'If smoke killed, then it would have killed our mothers and grandmothers long before we were born.' Some even claimed smoke was a therapy for certain ailments, such as a bad cold, and burning certain types of firewood would 'make you sneeze and get rid of the cold'. While the latter might be associated with traditional forms of healing, the research team felt it was important to let both men and women know about the associated health effects of living in poor housing conditions, including smoky indoor environments. From 
a personal perspective, I struggled with challenging local views, as I found it contradictory to the principles espoused by participatory action research. Yet, from my privileged academic perspective and those of the health professionals, we understood the implications of failing to alert participants to the health risks associated with indoor air pollution. Thus, through a dialogue that did not completely discount participants' views, members of the research team spent some time explaining the linkages among substandard housing, the immediate home environment and health problems such as respiratory illnesses, gastro-intestinal infections, and malaria to participants. For example, we explained how the use of inefficient energy sources, such as straw, cow dung, and crop residues, for cooking and heating can cause acute respiratory illnesses (WHO, 1992; von Schrinding and Bruce, 2000). This is necessary as studies indicate that measurements of indoor particle concentration in rural households of some developing countries exceeded the 1987 World Health Organization's recognized guideline values and air quality standards by a factor of about twenty (Bruce et al., 1998; 2000). In rural Ghana, acute respiratory illness (ARI), particularly pneumonia, has remained one of the leading causes of infant mortality despite continuous efforts by the health sector to curtail its occurrence. The home-based chores of many rural women and their children predispose them to greater risks (Dakubo and Commey, 1996; GSS/MI, 1998).

\subsubsection{Poverty, Education and Ill Health}

During group discussions, both men and women identified illiteracy as one of the major underlying causes of poor health in the community. In probing why adult literacy was so low in their community, some pointed to poverty and the need to attend to 'more pressing 
issues at home' as the main reasons that kept them away from school. For example, while most male participants indicated that they were removed from school to help with household activities such as taking care of the family cattle, helping with farm work or petty trading, some women said they were never enrolled and expressed the desire to have been educated:

Anytime I visit the clinic, I see lots of photographs (referring to health posters) on the wall, with writing on them. I know this is useful information about our health, but I have no way of understanding what is written. I can only imagine from the pictures I see. Had I gone to school, maybe, I would have been able to read and known exactly what they want us to do to protect ourselves from being sick. But I am not disappointed for not going to school, because I stayed home to help my mother, and that is all right. I am only hopeful that my children will have the chance to go to school (Woman, 20 years).

I attended school up to P4 (Primary Four) and was removed by my uncle to come home and take care of the family cattle. I really wanted to go to school and become a teacher some day... but it also important to take care of the family cattle, else they will all be stolen and when it gets to paying my bride price, there will be no cattle for me. I know the importance of education... it is just that there are always more pressing things to attend to at home. (Man, 25years).

As discussed in Chapter II, the reasons for low literacy rates in northern Ghana stem from colonial policies of uneven development. After independence, Dr. Kwame Nkrumah tried to reverse these inequalities through a policy of universalized free education for 
northerners. This resulted in the training of a large cadre of northern professionals (Ray, 1986). However, with the onslaught of Ghana's economic crisis, through to the implementation of structural adjustment programs, poorer communities have fallen behind in terms of school enrolment. Drop-out rates increased in rural communities as women's contribution to the household economy became critical. Women had to work longer hours in less skilled work in the informal sector for comparatively lower real wages. To keep up with the increasing workload, poor households withdrew their children from school, either to work in paid employment or to help care for younger siblings, resulting in high illiteracy rates for most young women (Kanji et al., 1991; Asthana, 1996).

Yet, a number of studies point to the importance of literacy and/or education in health promotion practices and behaviour. Accordingly, not only does education affect an individual's income-earning capacity, but also gives one the ability to act on the knowledge gained and become better informed about important health issues such as the disease process, prevention, and health promotion strategies in general (World Bank, 1993). Maternal education, in particular, has been shown to improve household health immensely. A World Bank study showed that the better educated a mother is, the more she is able to avoid health threats, deal with illness and act to reduce mortality rates (World Bank, 1993). The study also showed that educating mothers from poorer countries for 1 to 3 years could reduce child mortality by up to 15 percent, with such improvements continuing to increase with additional schooling (ibid). According to the Ghana Demographic and Health Survey (GSS/MI, 1998), whereas only 10 percent of 
children whose mothers have secondary or higher education are stunted, the average figure for less educated and/or illiterate mothers is around 33 percent.

In many rural communities, education is associated with the wealthy; those who can afford school fees, school supplies and also hired labour. Despite the policy of free elementary education in Ghana, access to basic supplies prevents many school-age children from enrolling in school. The old traditional norm that "when you educate a women, you have wasted your money' stands in contrast to the well-known quote that 'when you educate a man, you educate an individual, but when you educate a women, you educate a nation'.

Thus, enhanced education for women not only means health for their children, but it also means that women themselves will be healthier. They can become better informed about how their body functions and be able to make good use of health services.

Education also has the tendency to increase women's self-confidence and self-esteem, thus drawing some respect from health providers. This sentiment was clear in one woman's comment:

My sister, if you go to the clinic today, I don't think the nurse will talk to you the same way she talks to me. This is because you have been to school, just like she has, and so you can afford to dress nicely, thus, deserving some respect. You will be able to explain to her exactly what your health concerns are and so there is no way she can accuse or scold you. When I go to the clinic, I am not treated with any respect. I am only blamed, accused and scolded for not taking care of my children and myself, and that is why I am at the clinic. Yes, I may be doing certain things wrong, but the nurse should not speak to me as if I am her child. 
The only difference between the two of us is that she is educated and wearing a uniform. I am not educated and I am wearing tattered clothes...besides, I am supposed to be ignorant about everything concerning health. My sister, this is what not being educated can do to us (Woman, 30 years).

While women's status, confidence, decision-making powers, and health may be enhanced through better education, much more has to be done to overcome gender stereotypes, cultural dictates and other socioeconomic barriers that prevent women from receiving both formal and non-formal education. More importantly, special efforts are required to reverse the existing inequalities between regions, rural/urban areas, and men/women.

\subsection{Accessibility and Utilization of Health Services}

Group discussions revealed that lack of access to quality health care services has been a major underlying cause of poor health in the community. According to participants, factors such as distance to better health care facilities, transportation costs, high health care costs and some health belief systems restrain them from accessing quality health care. In addition to these factors, women also identified lack of autonomy and decisionmaking powers to seek health care, concerns about interrupting household organization, and lack of social and family support.

Charia has a community clinic which is situated within the sub-district level and has a staff of one community health nurse, a trained midwife, a public health nurse and a few paramedical staff. This staff is not responsible for attending to the health needs of the people of Charia alone, but they are also in-charge of seventeen other surrounding 
villages, often referred to as 'catchment areas'. Community health workers travel to these inaccessible villages on motorbikes to deliver health services. In an interview with the trained midwife, she said they often stop services to these remote areas during the rainy seasons, because the roads and paths leading to these communities become unmotorable. Ironically, this is precisely the season when health problems become very severe in those villages and when residents are very much in need of greater attention. The community health nurse also indicated that she and her colleagues have to work with very limited facilities and the provision of good services is hindered by the lack of available electricity. Thus, some cases that could be treated at the community clinic are referred to the district and regional hospitals.

The high costs of health services at district and regional hospitals leave many poor people worried and seeking alternative care. As put by one participant, a lot of 'thinking' goes into making a decision to go to the hospital in Wa:

I have to think paa (meaning a lot) before I decide to go to the hospital. On many occasions the nurses have asked me to go to Wa to get my hernia operated upon, but I have since refused because I cannot afford the cost. To visit Wa hospital means you must take along some fowls or some grain for sale. If you are lucky enough to get a good market for them then you can proceed to the hospital, if not you come back home. The fees and drugs are too expensive for us. Hospitals these days are for the rich. Poor people like me cannot afford to be sick and we cannot afford to be healthy either. (Man, 40 years). 
I pray everyday that I should never be sick and have to go to Wa. One trip to Wa hospital means one week of hunger. Why do I say so? Because you put all your farm work on hold and sell the little grain that you have left. When you come back from the hospital, what do you have left? Nothing! These days things are spoiled. You can no longer borrow money from a friend, because she hasn't also got it. Sometimes I agree with my diedoo (husband) when he says we should try local medicine, but not all sickness can be treated with local medicine. (Woman, 44 years).

In Ghana, high healthcare costs have been blamed mostly on structural adjustment programs and low government health spending. Cuts in health spending significantly affected the availability of health supplies and basic drugs. User fees were introduced for casualty and polyclinics, laboratory tests, drugs, medical examinations, and medical and surgical treatments (Anyinam, 1989). The high costs of drugs and the implementation of user fees have persisted until today and have greatly affected the utilization of health services, including child attendance and malnutrition clinics (Nyonator and Kutzin, 1999; Konadu-Agyemang and Takyi, 2001).

In addition to expensive health care costs, participants also identified distance and lack of transportation to and from major health service points. Charia is connected to Wa through a very deplorable feeder road. Except for market days, very few vehicles ply that route. On most occasions, women travel by foot, while men ride their bicycles and motorbikes to access health care services in the regional capital. According to participants, in situations where they have to transport emergency cases such as snake 
bites, convulsions, complicated deliveries, and serious home accidents to the hospital they often arrive there when it is too late.

A few elderly men also indicated lack of trust in the efficacy of modern medicine and said traditional medicine and healing worked better for them:

As for me I do not believe in those their hospitals. There is no medicine better than what we have in our bushes. In the past, when there were no clinics, no hospitals and no Whiteman's medicine, how did our grandfathers manage to stay healthy? They depended on the herbs in the bush. We have lots of local doctors and good medicine out there. Our youth are not willing to learn about them. All they know is the hospital and I do not sympathize with people who cannot afford to pay hospital fees. It is their choice. (Man, 59 years).

Trust and belief in the efficacy of traditional healing are common in many cultures. According to Vlassoff (1994), women in some cultures even prefer traditional healers as they provide meaningful explanations of their illness. In contrast, modern health care workers tend to give limited information, assume authoritative roles and dictate procedures to be followed, rather than explain the necessary precautions that would prevent ill health.

While factors such as cost, distance and transportation play an important role in determining whether people use health services or not, it is also important to realize that the utilization of health services by women goes beyond issues of distance and cost. The low status of women, coupled with their lack of access to resources, income-generating activities and decision-making powers, restrain them from seeking health care. Thus, the lack of access and non-utilization of health services by women should be understood and 
evaluated within the context of the organization of the traditional society of which they are part.

During group discussions, some women indicated that they rarely used the community clinic except for child health and pregnancy-related cases. Some women also indicated that they depended on traditional birth attendants for normal childbirth and were more comfortable with them compared to trained midwives. But in the event of obstetric complications, they are taken to the regional hospital. However, issues of immediate access to transportation and the poor condition of the road network make such moves risky.

\subsection{Gender Roles, Environment and Health}

According to Kettel (1996), the biophysical environment affects the health, social and economic lives of men and women differently. She advocates a careful attention to the actual spaces that women occupy and the activities that they carry out in those spaces so as to give a clearer analysis of the differences between men and women in relation to the type of space they occupy. Thus, in the process of socialization, men and women acquire different familiarization with their social and physical environments, which in turn, provide them with a view that is characteristic of the role they occupy (Kettel, 1996). For example, women-specific duties include rearing plants and animals for domestic use, production of agricultural goods for market, gathering fuelwood for cooking, and fetching water from streams and ponds. Men, on the other hand, till the land and harvest the crops. In their daily interaction with plants, animals, land and water, both men and 
women acquire specialized knowledges about these organisms and ecosystems, express different needs and aspirations, become exposed to different health risks and also differ in their approach to preventing and managing these risks. Such gendered views, opinions and knowledge systems underpin the conviction that health and health promotion research must systematically and purposefully recognize the gender-specific nature of health and respond to concerns, needs, and aspirations of both men and women appropriately and equitably.

During my discussions with the women's group, many indicated that their work, workloads, and role expectations from society adversely impacted their health. However, they were quick to point out that, this should not be perceived as a complaint. They are just fulfilling their 'normal' duties as mothers and wives:

My sister, this is my work. This is what I have to do to live and feed my children. If I think of the health effects of my work then I will stay home and who do I expect to do the work (Woman, 34 years).

As discussed before, the idea of 'fulfilling our duties as wives and mothers' emanates from the societal construction of a 'good wife'. Thus, a 'good wife' is not supposed to complain but puts all family members' needs and the community's well-being ahead of hers. Another reason, why rural women give little thought to their occupational health concerns is that, unlike reproductive health issues, occupational health has received very little attention from the health sector and so little is said about it in community health programming.

Yet, from working with women in the field and from my discussions in previous sections, women seem to face enormous environmental health risks. Take for example, 
the fact that over half of the women in Charia engage in either charcoal burning or pot making or both for a living. As pointed out by one old lady and showing me her fingers 'I have made pots all my life. Now I am beginning to slow down because my eyesight has become poor because of the intense fires and my fingers cannot mould very well due to pain at the joints'. Also, the exposure of women to smoky indoor environments as they prepare family meals, together with other productive work roles, disproportionately exposes them to health problems including, arthritis, backaches, and prolapse of the uterus (Enberg, 1993).

However, in order not to essentialize the category woman and create a false appearance of a coherent and homogenous rural women's experience, I am cautious of the influence of women's different and diverse identities, histories, and experiences in my analyses (Flax, 1990; Abu-Lughod, 1993; Fox, 1994). For example, rural women who are socioeconomically privileged perhaps as a result of higher education are able to afford less harmful fuels such as liquefied petroleum gas for cooking. Similarly, men who manually clear their lands are much prone to snake bites, farm injuries and other occupational health issues, compared to those who can afford tractors or hire labour.

While not all women share the same experiences of a gendered society in exactly the same way, women across various social strata share more in common with each other from a health perspective than they do with men. For example, in most developing countries, women on average suffer more chronic and debilitating diseases, earn significantly less, are less educated, have less access to life resources, and have differential rates and types of exposure to health risks and threats (WHO, 1999). These, 
in addition to gendered norms and relations in communities have prevented women from attaining optimal health outcomes.

\subsection{Conclusion}

In this chapter, I documented participants' perception of the underlying causes of their major health problems. I then analyzed these in light of broader socioeconomic, political and environmental contexts of the community. Throughout our discussions, participants linked their current predicament with their continuous marginalization and neglect by the government through its inequitable allocation of the national cake. As members of a rural community located in one of the most deprived regions in the country, participants felt they were doubly jeopardized. Compared to other areas, rural savannah communities receive very little of the national government's budget for education, health care, infrastructure and other social services. The effect of such neglect is evident in the general poor health and educational status of people in these communities. Spatial inequities as well as inequities across gender and socioeconomic groups were further compounded through the spin-offs of structural adjustment programs, as poorer households struggled to meet their nutritional needs and pay for health services. As a consequence, such difficult circumstances translated into unsustainable use of marginal environmental resources with devastating health consequences.

Thus, even though community members are able to articulate the causes of their ill health, the structure and organization of the health sector does not accommodate these ideas nor does it have the capacity to single-handedly respond to such a complex 
interplay of factors influencing health. As discussed before, attempts to provide comprehensive care have always reverted back to the narrow focus on selective cases and populations, partly because of the practical, financial and political implications of broadbased preventive health measures. As a step forward, I see it as important for communities to initiate the process, and work jointly with all relevant stakeholders in articulating their problems and devising joint strategies to solve them. This way the chances that local government departments will pitch in to help communities achieve their goals are greater than not acting at all. It is in this light, that I conducted the strategic planning process with community members. While such a process requires time, a facilitator and a community that is willing to put their common needs ahead of their differences, such a process has the tendency not only to improve rural livelihoods, but also to confront the inequities they encounter. In the next chapter, I describe how we used the strategic planning process to map out a plan for achieving a healthy Charia. 


\section{CHAPTER VII}

\section{PLANNING FOR A HEALTHY COMMUNITY}

\subsection{Introduction}

In this chapter, I present and discuss the findings of a strategic planning process (SPP) that was organized with both men's and women's groups. The process took the form of a series of community workshops in which the research team used focus group discussions to guide participants through the phases of the strategic planning process. As discussed in the methods chapter, the strategic planning process is a tool that allows participants to look beyond their immediate problems and to recast their abilities in achieving a desirable future. The process leads discussions through a series of logical steps that allow participants to first articulate a vision of what their perceptions of an ideal community are. Then, they proceed to identify the obstacles preventing them from achieving that vision. Next, they articulate what it would take (resources, abilities) to achieve it, and finally, they devise a plan of action and implement it. This process builds on the principles of participatory action research and helps communities develop planning capacities to meet their goals among diverse stakeholders (Martin et al., 1995).

To set the stage for the process, I took participants through a guided imagery exercise of their community five years into the future, a future that is rid of the major health problems and their associated environmental and social causes identified in earlier focus group discussions. Participants were then asked to respond to a focus question by identifying a number of attributes, features and conditions that they would want to 
experience in their new community. We devised similar focus questions for the other steps as well. Participants seemed enthusiastic throughout the process and were optimistic about their ability to build a healthy and sustainable community for themselves and for their children.

With this enthusiasm also came a number of challenges. One was that, achieving consensus among a group of people with diverse and different needs is a challenge. There is the tendency that only the louder voices might be heard, and those that need to be heard silenced. To what extent will the vision and plan accommodate the needs of both men and women, children and adults, young and old, employed and unemployed, the rich and poor? To what extent can these diverse groups work together? Who will make the final decision about how to distribute the proceeds of this collective exercise (e.g. locating a facility)? These are questions I grappled with, and I tried to use the strategic planning process as a tool for these diverse views to emerge and be thoroughly deliberated, before participants made a final resolve on how they wanted to proceed.

Another challenge was how to reorient community members from blaming the government and embracing a spirit of self-help, focusing primarily on the strengths and resources available to them: what can we do for ourselves versus what can be done for us. Such a perspective allows community members to plan and act based on immediacy and capability, while organizing to lobby the government to support their plans, and also confront issues of political marginalization and rural neglect. This approach involves critical self-examination and community competence, attributes that many rural communities initially lack until conscientized. 
Also, the SPP requires great expertise in facilitation skills; techniques that will lead discussions to accommodate and prioritize varied views without fist-fighting. As such, it was very challenging for members of the research team to hold back their own biases and suggestions, while allowing participants to piece together their views and needs. In presenting participants' responses, I have made use of direct quotations where necessary. In certain instances, however, I have summarized their responses into appropriate themes, and presented them in tabular forms.

\subsection{Creating a Vision for a Healthy Community}

The vision workshop is a process of mapping out a shared picture of that ideal place that participants want to live in, work and play. It requires participants to expand their thinking beyond current constraints and to come up with inspirational and far-reaching ideas for the future. The visionary attributes encompass their values, priorities, desired features and how they hope to function in the future. The process, if done properly, can provide participants with a common purpose, ensure sustained commitment to meet the goals articulated in the vision and inspire action. People will only own the outcome of a vision if it is a vision that they created and not one imposed on them.

I began the vision workshop by recapping the major themes that emerged in earlier focus group discussions, including their perceptions of health and its indicators, major community health problems and their perceived causes. Participants were encouraged to envision a healthy and sustainable community from a holistic perspective, as they had done before, taking into consideration aspects of the natural environment and 
ecosystems, the built environment, social, cultural and political systems, and aspects of the rural economy.

In order to illicit a wide range of views and to avoid dominance by a vocal few, participants in both the men's and women's groups were encouraged to work in subgroups of four. These groups were not permanent but changed randomly with every phase of the strategic planning process. For the vision exercise, sub-groups were asked to brainstorm a list of attributes, features and conditions that they would like to see in their desired community. The lists were then discussed and common themes identified. Each sub-group was also provided with drawing sheets on which participants could put their ideas into visual images. At the end of the session each group presented their list of themes to the plenary group. The plenary group further deliberated upon the themes.

The list of themes generated by men and women were quite similar, except for a few areas of emphasis (see Table 7.1). The vision elements identified by men emphasized issues of a vital biophysical environment (fertile soil, good grazing pastures, woodlands), equitable resource allocation by the local, regional, and national governments, equitable resource distribution between the two sections of the community (mainly resources from international development projects), access to basic infrastructure such as roads, electricity and waste management services and a better working relationship with local government departments. The desired elements of women, among other things, focused on peace and unity among family members, an increased sense of community and belonging, social support networks, especially for women, and access to better education for girls. These vision elements were not ranked. 
Table 7.1 Vision Elements Identified by Participants

\begin{tabular}{|c|c|}
\hline Vision Elements & $\begin{array}{l}\text { Men (M) / } \\
\text { Women (W) }\end{array}$ \\
\hline Clean and healthy physical environment and surrounding & $\mathrm{M} / \mathrm{W}$ \\
\hline Improved health status for all community members & $\mathrm{M} / \mathrm{W}$ \\
\hline Productive and sustainable agriculture & $\mathrm{M} / \mathrm{W}$ \\
\hline Peace and unity among family members & W \\
\hline High levels of school enrolment and education in the community & W \\
\hline Equitable and accessible distribution of health services for all & $\mathrm{M} / \mathrm{W}$ \\
\hline $\begin{array}{l}\text { Equitable resource distribution within the community and amongst } \\
\text { community members }\end{array}$ & $\mathrm{M} / \mathrm{W}$ \\
\hline $\begin{array}{l}\text { Ability to meet basic needs (food, water, sanitation, proper nutrition, shelter, } \\
\text { income) }\end{array}$ & $\mathrm{M} / \mathrm{W}$ \\
\hline $\begin{array}{l}\text { Access to basic infrastructure (roads, communication services, electricity, } \\
\text { waste management) }\end{array}$ & M \\
\hline $\begin{array}{l}\text { Access to markets, a growing community economy, and financial self- } \\
\text { sufficiency }\end{array}$ & $\mathrm{M} / \mathrm{W}$ \\
\hline $\begin{array}{l}\text { Active community involvement in all phases of community development } \\
\text { programs }\end{array}$ & $\mathrm{M} / \mathrm{W}$ \\
\hline $\begin{array}{l}\text { Healthy and sustainable ecosystems (farmlands, water bodies, rangelands, } \\
\text { woodlands) }\end{array}$ & $\mathrm{M} / \mathrm{W}$ \\
\hline Greater awareness of health promotion strategies and behaviours & $\mathrm{M} / \mathrm{W}$ \\
\hline A sense of community and belonging, and available social support networks & W \\
\hline Egalitarian relationship with local government departments & M \\
\hline Equitable distribution of government resources & M \\
\hline
\end{tabular}


The vision elements identified by both men and women were categorized into seven major vision themes:

D A viable natural environment with healthy ecosystems;

Improved health status and good quality of life for community members;

An equitable and supportive social environment;

A vital and sustainable economic environment;

Increased access to basic services and infrastructure;

Increased public participation in community activities; and

Development of human potential for the whole community.

Both men and women made strong linkages between environmental viability, ecosystem health and human health. According to most participants, a community with a sustainable natural resource base, productive farmlands, sustainable agriculture, grazing lands and water bodies, is much more likely to be able to support a healthy population than a community with depleted resources and a degraded environment. One middle-aged man put it this way:

From folklore and stories from our grandparents, we know that in the olden days the land was more productive than it is today. Our ancestors did not struggle to find food or meat. The land was productive and everything was plentiful. I understand people rarely became sick in those days, and even when they did they had all the medicine at their doorsteps. These days our lands are bare and nonproductive, food has become so scarce and we are faced with very strange health problems. The forestry and agricultural officers blame us for the current state of our land, but it is not our fault. We have no other alternative but to continue to 
live off the land. So for me, I think if we can find ways to take good care of our land, then we may be able to live as healthily as our ancestors.

Some women also expressed a desire for a community with a strong sense of togetherness, interconnectedness and unity (one-mouth); a community that provides social support and is able to cater for the varying needs of its members and embrace communal spirit. In one young woman's words '.. unity drives every successful event. If there is no unity among us, both at home and in the community, then all our efforts will be in vain'.

There were concerns among participants on how to reach beyond their differences to achieve communal goals. Most of these differences were augmented by the unequal allocation of 'development' projects in the community. Some women were hopeful that they could 'stand together as a community' to pursue their communal dreams. They expressed disappointment at the 'greed' and 'selfish' activities of some community members. They also referred to some individuals as 'saboteurs' who deliberately set fire to community woodlots. The men's group interpreted such acts of arson as acts of resistance based on the location of those woodlots. 'If we call ourselves a community and most of the resources that come from outside are put in only one section, what do you think the other section should do?' asked one elderly man. With respect to community functioning, both groups envisioned a community in which they would participate actively in the planning and decision-making of community development projects. According to participants, for so many decades they have played passive roles in activities influencing their lives, partly because they have always lacked' the trust in their ability to be influential, and most often they have not always been given the opportunity. 
They see a new community in which strong and collaborative partnerships would be established with local government, private and non-governmental organizations.

Participants envisioned a productive rural economy and improved socioeconomic conditions for all community members. With agriculture being the mainstay of the community, most men were optimistic that access to agricultural loans to purchase the necessary inputs and the use of sustainable agricultural practices could help bolster agricultural production again. They indicated that access to value-added processing machines, good marketing systems, storage facilities, and increased technical assistance from the agricultural department would help enhance food security in the community. Other income-generating activities, such as pot making by women and carving by men, could generate a considerable amount of income for community members if these industries were promoted and supported nationally and internationally. An improved socioeconomic status would then allow people to access basic human services such as food, water, good housing and education.

During the visioning exercise, the research team was mindful of raising unnecessary expectations among participants. So participants were often reminded to identify activities that were within their reach and resources. Activities that required external help were not discouraged but only placed at a lower priority level. We were also mindful of unnecessary promises, as these, if not fulfilled, could strain relations with the community after the research was over.

Despite a few disagreements, both men and women articulated a vision that depicted a holistic and ecological perspective of health giving equal importance to environmental, social and economic issues. From this perspective then, a healthy 
community comprises many different interrelated subsystems (individuals, households, community groups, social and political institutions) that work together and mutually reinforce one another for the well-being of the whole. The health of each subsystem is necessary for the health of the whole. For example, environmental management and resource conservation must take societal needs and values into account, and similarly economic development should be pursued in a way that is environmentally and socially sustainable.

The vision mapped out by participants brings to life some of the principles of a healthy community outlined by the WHO Healthy Cities/Communities Initiative. In a model by Hancock et al. (1999), six attributes of a healthy and sustainable community are depicted (see Figure 7.1). Environmental viability, the first attribute, refers to the quality of a community's local environment including soil, water, land, vegetation and air. A viable community takes care not to degrade or deplete its natural resource base. This leads to the second attribute, ecological sustainability, which requires that resources be used in such a way so as to meet the needs of today's population while preserving them for the needs of future generations. 


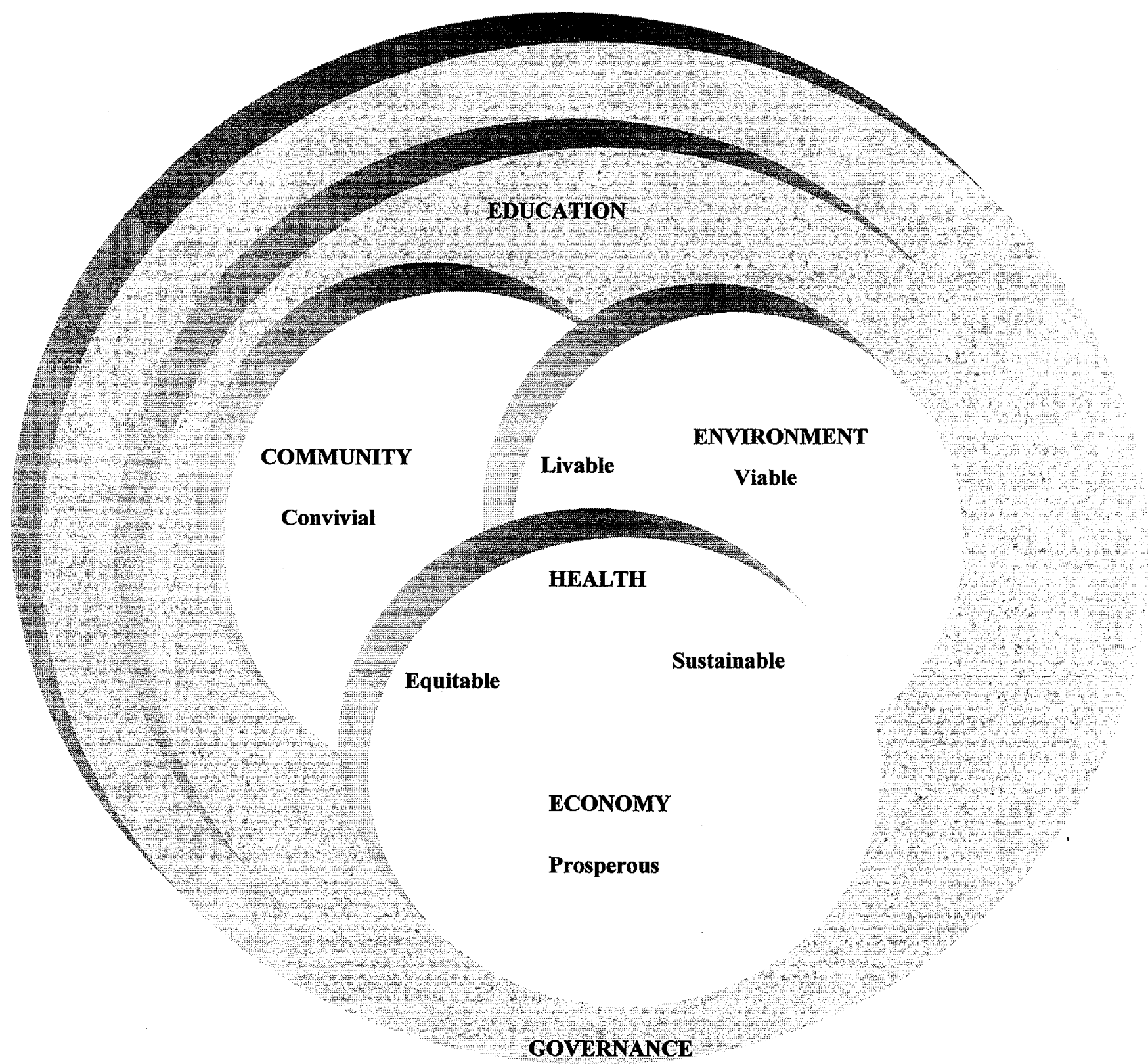

Figure 7.1 Healthy Community Model

[Adapted from Hancock et al., 1999] 
Liveability is an attribute concerned with the interplay between the social and physical settings of the community. A liveable community seeks to promote the health and wellbeing of its inhabitants by providing a safe and secure environment. A liveable community seeks to provide basic services such as adequate housing, water and sewerage services, good roads and transportation systems, and other infrastructure that will allow community members to live healthy lives. Meeting this feature is mostly beyond the reach of many poor communities, as they have to lobby governments for such services. Community conviviality is concerned with social cohesion, unity among community members, and a sense of togetherness. A convivial community has both formal and informal social support networks, and provides opportunities for residents to participate actively in community development efforts. This is a feature that was mostly discussed by women as very essential to their health and well-being. At the same time, both men and women saw it as the most difficult feature to nurture given the current faultlines and fractures in the community. Social equity is concerned with equitable distribution of resources, power, and benefits from the local economy and other development projects. This allows community members to meet their basic needs, as well as develop their full potential. Again, resources within this community have not been equitably distributed and such lack of equitable resource allocation stands to hamper community development. Finally, economic prosperity refers to the ability of a community to achieve some level of financial prosperity that would allow community members to meet the basic demands of everyday life (Hancock et al., 1999). This need resonated in every group discussion amongst both men and women. 
Hancock et al. (1999) observe that these attributes of a healthy and sustainable community cannot, however, be translated into action without two key drivers of the change process: education and governance. Thus the three spheres in figure 7.1 (community, environment and economy) and their overlaps are located within the broader spheres of education and governance. These two drivers of the change process include knowledge development, awareness creation, empowerment, participation, and performance by government. The effective functioning of these two elements increases the chances that the attributes associated with a healthy community will lead to improved human and environmental health.

While participants were delighted and inspired by the vision they had set out for themselves, they were also concerned about the roadblocks, barriers and obstacles that stood in their way to achieving a healthy and sustainable community. The next section discusses the findings of the barriers workshop.

\subsection{Identifying the Underlying Contradictions to a Healthy Community}

The second stage of the strategic planning process is the barriers/contradictions workshop. This step allows participants to identify and examine the obstacles preventing them from achieving their aspired future. The barriers workshop for both the men's and women's groups started with a review of the key vision elements that they identified previously. I divided participants again into sub-groups of four and asked them to identify and categorize what they perceived to be the major obstacles to achieving their vision of a healthy community. Participants identified the barriers to achieving each vision theme. 
This exercise was fraught with a lot of arguments in both groups. Commonly, the arguments followed two streams of thought, one being from the conventional school whereby victims' behaviour and practices are the culprits, with the second school taking a more social and political-economic approach. For example, while some male participants considered low agricultural productivity to have resulted from their poor farming practices, others viewed it as a neglect of the development of their agricultural sector and economic hardships, while some saw it to be a combination of both factors. Similarly, in the women's group, while most women identified obstacles to good health as related to gender roles and expectations of a 'good wife', others blamed themselves for engaging in poor health practices, while a few argued for a more nuanced understanding, asserting that it is the tight work schedule of women that forced them to compromise taking the necessary health precautions. Despite these constructive confrontations, a number of shared concerns emerged from both the men's and women's groups, as well as specific concerns relating to each group. I also encouraged members of both groups to accommodate all obstacles identified as we would later analyze them to see how they were linked. At the end of the various sub-sessions, the findings were discussed and categorized into four broad themes: geographic, institutional, socioeconomic, and behavioural barriers (see Table 7.2).

The geographic and climatic obstacles identified by participants were similar to those discussed in the previous chapter. These included the naturally harsh ecological conditions, low soil fertility, and gradual overall environmental deterioration. Participants acknowledged that while, in part, some of these ecological conditions were natural and could not be altered much, the deteriorating conditions were closely linked to their poor 
socioeconomic and political status, the lack of alternate income sources, a poor rural economy, poverty and rural marginalization. As such, these are the barriers to focus on in order to achieve a healthy environment, and not necessarily their farming practices alone.

Table 7.2 Barriers Inhibiting the Realization of a Healthy Community

\begin{tabular}{|c|c|c|}
\hline Major Theme & Examples of Barriers & $\begin{array}{l}\text { Men (M)/ } \\
\text { Women(W) } \\
\end{array}$ \\
\hline \multirow[t]{3}{*}{$\begin{array}{l}\text { Geographic/ } \\
\text { Climatic }\end{array}$} & $\begin{array}{l}\text { Unfavourable climatic conditions and their impact on } \\
\text { environmental quality }\end{array}$ & $\mathrm{M} / \mathrm{W}$ \\
\hline & Loss of restorative ability of natural environments & $\mathrm{M} / \mathrm{W}$ \\
\hline & Rural isolation, neglect and marginalization & M \\
\hline \multirow[t]{5}{*}{ Institutional } & $\begin{array}{l}\text { Lack of fit between community needs and health and } \\
\text { environment programs }\end{array}$ & $\mathrm{M} / \mathrm{W}$ \\
\hline & Poor intersectoral coordination & $\mathrm{M} / \mathrm{W}$ \\
\hline & Poor health and environmental communication strategies & $\mathrm{M} / \mathrm{W}$ \\
\hline & Lack of environmental protective legislation & W \\
\hline & Lack of health promotive legislation & $\mathrm{M}$ \\
\hline \multirow[t]{6}{*}{ Socioeconomic } & & \\
\hline & Poverty & $\mathrm{M} / \mathrm{W}$ \\
\hline & Poor social support networks & \\
\hline & Low status of women & W \\
\hline & Lack of community participation in health planning & $\mathrm{M} / \mathrm{W}$ \\
\hline & Lack of access to health care planning & $\mathrm{M} / \mathrm{W}$ \\
\hline \multirow[t]{6}{*}{ Behavioral } & Health damaging cultural and religious beliefs and practices & M \\
\hline & Lack of participation in health promotion programs & $\mathrm{M} / \mathrm{W}$ \\
\hline & Lack of personal initiative for preventive health care & $\mathrm{M} / \mathrm{W}$ \\
\hline & Non-utilization of community health services & W \\
\hline & Non-compliance to adopt sustainable environmental practices & $\mathrm{M} / \mathrm{W}$ \\
\hline & Ignorance of some health risks and causal pathways & $\mathrm{M} / \mathrm{W}$ \\
\hline
\end{tabular}

Participants also identified a number of institutional factors constraining the realization of their vision. Significant among them were the difficulty in ensuring that environment and health programming suited community needs, poor coordination among local government 
departments, ineffective extension and communication strategies, and lack of effective legislation in both the health and environment sectors. As discussed previously, most rural health services focus on externally designated health priorities and rarely address pressing health problems in the community. Although Ghana's Ministry of Health has pledged to pay more attention and devote more resources to rural areas, this has rarely been translated into action to the extent, for instance, of rural areas receiving the greater part of increases in health service budgetary allocation. Also, while community participation in health programs is in vogue, participants observed that they rarely had any voice in health planning and programming.

Given the holistic perspective of health articulated by participants in earlier discussions, achieving a healthy and sustainable community requires the integration of various sectors, including environmental, social, economic, health and land-use planning. The challenge therefore lies in creating new structures that will foster intersectoral collaboration among participating departments, who in turn would have to work with community members in planning for a healthy community. However, as expressed by government officials, intersectoral collaboration is often difficult because of the varying and sometimes competing departmental mandates and goals. Also in existence are questions such as, who will be responsible for providing resources for such joint ventures? How would departments justify the allocation of resources to such projects? And how would they protect their departmental interests while serving non-departmental ones? Some male participants expressed disappointment with such piece-meal approaches to intervention, observing that they are often ineffective, and also consume a 
lot of their time since they have to attend separate information sessions by the various departments.

Participants also observed that creating a healthy community goes beyond intersectoral collaboration, but also involves other stakeholders, such as individuals and private enterprises whose activities affect community health one way or another. They observed that while it may be relatively easy to bring local government departments together, it is difficult to bring to the table individuals and private businesses who perceive the community as a 'resource depot', and care very little about people's health or the damage they may cause to the environment. In the case of Charia, participants expressed the futility of getting the wealthy building contractor to take part in talks concerning the impact of his activities on community well-being, or getting other local businessmen, for example, commercial livestock owners, to participate in talks about how to restrain their animals from destroying community farmlands. Such issues, which were widely discussed in the women's group, led some participants to consider greed and disunity as major barriers to achieving a healthy community. In the men's group, however, disunity was discussed in relation to the current conflict between the two sections of the community concerning inequitable resource distribution. One man expressed this as follows:

How can we work together for a better community if some of us only work for the benefit of others? Some years back we thought we were working for a better community. Most of us left our farm work to go and work on community nurseries and woodlots. When the trees were ready for harvesting, they said it belonged to only one section of the community. They said they were the only 
people who worked on the woodlots. Since then, I have learned my lesson and will only participate in a community project because of respect for whoever is organizing it. Maybe, like you Madame, I am shy of you, and so if you ask me to come out and work, I will only do it because I respect you and not because I hope to benefit from the project. (Man, 34 years).

Some participants also observed that 'saboteurs', such as the contractor and other local businessmen, are able to avoid any serious consequences, partly due to the lack of environmental protective legislation or perhap's lack of enforcement of such legislation. However, other participants argued that, had there been any strict environmental protective legislation, 'individuals of their stature have so much power that they are considered above the law and can pay their way through the system.' This was also confirmed by an interview I conducted with the Director of the Environmental Protection Agency (EPA) in Wa, who indicated that the airport under construction by the contractor was not even approved by EPA. Rather, it had been approved 'from above,' and so EPA had little power to even stop the construction of the airport, let alone stop the contractor from extracting gravel from surrounding communities. Participants, therefore, saw the inability to enforce environmental protective legislation, among others, as major institutional obstacles standing in their way to achieving that viable natural environment they envision.

In the women's group, some female participants identified the erosion of social support networks as major barriers to improved community health. Most women saw support from families, friends and communities as necessary for good health. Such social support networks could be very important in helping people solve problems and deal with 
adversity, serve as pathways for informal learning, and help people maintain a sense of control over their life circumstances. Accordingly, these support networks in the community have begun to deteriorate as a result of economic hardships. In recent times, traditional support systems are being eroded as people tend to rely on community organizations, of which they are part, such as churches, youth groups, trade unions and other political bodies. In the event that one does not belong to any of these groups, then community social support is often lacking and people find themselves lonely and anxious. In one woman's view, 'we face problems everyday, and when there is no one to turn to for help, it not only affects you mentally, but it affects you physically and your ability to make good decisions.' Some women observed that because of time constraints, restrictions from husbands, and religious beliefs, not every one can belong to a community organization and so formal support groups could be organized to accommodate all women and provide them with peace of mind.

The inability of women to make decisions to join a community group depicts their status in the household and the power dynamics that play out in patriarchal societies like Charia. Women's low status limits their autonomy in making household decisions, including decisions concerning their own health. However, women's low status is not a generalizable concept, as many young women in the group discussions did not agree with their elderly counterparts that women occupied a low status in the community and in their households:

My sister, things are changing in this modern world and we women are becoming wise. Women used to depend on their husbands to make decisions for them because they (husbands) provided all the households needs. In this era, some of us 
(women) are the sole providers, and so it would be foolish on our part to sit down and act based on our husbands' decisions and wishes (Woman, 26 years).

Such radical perspectives are very common with young women and, accordingly, can be traced to their involvement in women's political organizations such as the $31^{\text {st }}$ December Women's Movement, which is presided over by the former first lady of Ghana, Nana Konadu-Agyemang Rawlings. Thus, consciousness raising and programs to empower women were considered necessary to achieving a healthy community.

Finally, in addition to the structural barriers outlined above, participants shifted the focus to themselves, examining how their attitudes, behaviours and beliefs constrain their ability to engage in appropriate health practices. People's behaviours are organized into recurring patterns of activity that take place within their daily life experiences and interactions with the environment. Within these recurring patterns and environmental contexts, certain behaviors, social roles, and situational conditions can exert a disproportionate influence on individual and collective well-being. In Charia, participants identified a number of personal behavioural barriers that inhibited the achievement of good health. The most common barrier identified by both men and women was the lack of personal initiative to engage in health-promotion practices. Most participants indicated that they were so preoccupied with securing basic needs such as food, water, shelter and income that they placed little value on protecting and promoting their health, or in participating in environment and health education programs. According to one young man 'rains do not come very often, and so with the few that we get, no man will leave his farm work and go about listening to karaches (learned folks). We leave that to the women.' However, most women argued that they were more pressed for time, and could 
not even take the necessary health precautions at home, let alone attend health education programs. They also explained how they compromised their health to maintain that of their children. 'Sometimes, it is not the lack of knowledge on our part to protect our own health, it is a rather a question of whose health matters. The children easily fall sick and so we do all we can to protect their health,' said one woman. Accordingly, women were very much concerned about protecting the health of their children, such that they placed low priority on their own health.

Another barrier that was identified in the men's group was the continuous denial of men as vulnerable to ill health. According to some male participants, men see illness as a sign of weakness, and so they tend to ignore any potential signs and symptoms of ill health. They find it difficult to discuss health problems with female community health nurses and are often apprehensive about how others will see them. According to the community health nurse, this attitude by men is reflected in the low attendance of male patients at the village clinic.

If you are the man of the house and you fall sick almost every now and then, who then do you expect to take care of the family. As men, we have to be strong and not complain about little things like headache and back pains. Which man returns from the farm and does not expect to experience back pains? If our wives do not complain of back pains, why should we? It only makes you look weak before your children. (Man, 34 years).

Both men and women also identified ignorance of some health risks as a major barrier to undertaking protective health behaviours. Examples included both men and women's ignorance about the possible health effects associated with the consumption of small 
amounts of agro-chemicals. Despite occasional disagreements, participants observed that adopting positive health promotion behaviours, attitudes and practices would move them a step closer to enjoying good health. They also emphasized the need to intensify environmental health education using culturally appropriate communication strategies.

\subsection{Assessing Our Strengths and Resources}

Having identified the obstacles constraining the realization of their vision, participants then turned their attention to the identification of their strengths, resources and assets that might help overcome or circumvent some of these barriers, and make their dream a reality.

Contrary to seeing communities as passive victims needing professional attention, there is now growing emphasis to look at communities as having assets, strengths, resources and capabilities that can be harnessed to improve their living conditions (McKnight, 1985; Kretzmann and Mcknight, 1993). Communities possess a wealth of knowledge and experience, values, norms, and other locally available assets that can play a major role in efforts aimed at improving their livelihood.

During group discussions I asked participants to list what they perceived to be their strengths and the resources that could facilitate the achievement of their ideal community. This was a challenging exercise for the research team in that we had to work with participants to focus on their strengths and resources before counting on external assistance. This was important because, since I did not have the ability to support or finance the implementation of any project, I did not want to raise any false expectations 
and later disappointment in the community. Members of the research team were also careful not to make undue promises or implicate their departments in any way, thus the need for caution. Additionally, the primary goal was for community members to discover their own unique abilities to facilitate their own development with minimal external help. The issues identified during this exercise are presented in Table 7.3.

Table 7.3 Perceived Strengths of Community Participants

- A strong sense of community coherence

$\mathrm{M} / \mathrm{W}$

- Possession of valuable traditional environmental and $\mathrm{M} / \mathrm{W}$ health knowledge systems

- Well-organized community groups (women, youth and religious organizations)

- On-going international development projects

$\mathrm{M} / \mathrm{W}$

- Dynamic chief and community leader

M

- Receptive to external development programs

W

- Good working relationship with extension workers

M

- Enthusiastic and hardworking community members

$\mathrm{M} / \mathrm{W}$

- Increasing number of highly educated and enthusiastic youth

$\mathbf{M}$

- Strong ability to mobilize and work on community projects

$\mathrm{M} / \mathrm{W}$ 
Participants believed most of their strengths fell within good community organizing. Both men and women thought there existed a strong potential for unity, coherence, caring and 'brotherliness' among many community members that would allow them to reach common goals and effectively mobilize themselves to undertake community projects. Some men believed that this sense of community could be strengthened if equity in resource allocation became central to project planning. Some men also thought that the community had a dynamic chief, who was backed by able elders, and who had always been supportive of most community development projects. Over the years, he had committed resources, such as land, to community projects and had also been keen on the activities of researchers. He was very supportive of my team, welcoming and sending us off in grand style. In addition, both the men's and women's groups felt that the people of Charia possessed valuable traditional environmental and health knowledge that could be harnessed by extension and other local government workers through the development of professional/lay knowledge synergies, rather than the 'expert-know-all' mentality that elides local people's knowledge and creativity. Most extension workers I spoke with indicated that they enjoyed working with the people of Charia, and that the people were very enthusiastic and supportive of community development projects. Most community members also believed that they had established good relationships with extension workers, and hoped such amicable relationships would continue. One forestry technical officer observed that any time he wanted meat for soup, he would visit Charia for 'duty' and would be sure of 'at least one guinea fowl on his way back home.'

Most important among the strengths identified by participants was the slowly growing number of highly educated youth from Charia and the important positions they 
occupied. Accordingly, in recent years, Charia can boast of a few high profile government officials, most of whom occupy top positions at the regional, national and even at the parliamentary levels. These highly educated youth have always taken keen interest in the development of their community, supporting it financially and otherwise to undertake development projects. They were also in key positions to lobby the government to allocate resources for the establishment of some basic infrastructure and services. During my research, there were efforts to connect Charia to the national electricity grid, a move seen by community members as a big leap toward initiating the establishment of small-scale industries and agricultural processing activities.

The ability to harness these assets to inform the creation of a healthy and sustainable community depends to a great extent on nurturing the right climate and empowering community members to use these strengths and resources to improve their own livelihoods.

\subsection{Strategic Directions and Systematic Actions for a Healthy Community}

After identifying the barriers, strengths and resources to achieving a healthy and sustainable community, participants began to explore some strategies followed by systematic actions that could lead them to their desired future. Prior to the onset of each workshop, participants reviewed charts of their vision elements and obstacles, and, with the help of the research team, recapped some of the key points during those discussions. This section combined two stages of the strategic planning process: the strategic directions and the systematic actions. First, participants worked in sub-groups of four to 
identify possible strategies to achieve a healthy community. These strategies were then categorized into broader themes for which specific actions were identified. The research team urged participants to be creative and bold in identifying their strategies and actions. We encouraged participants to set strategies and actions that were practical and attainable, and within the means and capabilities of the community. This was done to encourage participants to develop some confidence in their own capabilities of finding solutions to community problems, and also to develop a sense of community competence. It has been observed that most local communities tend to suggest strategies that cannot easily be achieved by the community and the resources available to them, thus, forcing them to become dependent on the assistance of government and non-governmental organizations (Bergdall, 1993). However, research shows that, except for actions requiring policy backing, most actions needed to improve human health through primary environmental care can be achieved through local efforts (WHO, 1994). Thus, both men and women were encouraged to see the realization of their ideal community as mostly dependent on them and the successful partnerships they form with workers from the local and regional governments.

At the end of the session, we categorized the issues raised into six broad strategic directions. As I elaborate on these strategic directions, I will also specify the different emphasis placed on particular issues by men and women, and the actions suggested by participants. The six strategic directions identified are as follows:

Build community capacity to sustainably manage local environments to prevent major community health problems;

Develop intersectoral approaches to community planning and intervention; 
Use community participatory approaches that are inclusive of a broad range of skills and experiences of local people;

$>$ Strengthen environment and health education and communication;

$>$ Build on local knowledge systems; and

Build community capital.

\subsubsection{Building Community Capacity to Sustainably Manage Local Environments}

Participants observed that since major community health problems such as malaria, diarrhoea and acute respiratory infections are environment-related, it was important for community members to pay greater attention to managing local environmental resources, as well as dealing effectively with problems in the home environment such as poor water quality, food contamination, unsanitary excreta and waste disposal, crowded and poorly ventilated living spaces, and smoky indoor air pollution, to reduce the occurrence of these health problems.

While participants indicated that they had very little control over climatic conditions and natural environmental phenomena, there were certain practices they could begin to undertake that could prevent further environmental degradation. Some of these practices identified in the men's group included the need to establish local legislation and community by-laws, form enforcement committees to prevent the use of bush fires for trapping game animals during the hunting season, and to levy fines on people felling trees indiscriminately, especially on fragile landscapes. Both men's and women's groups expressed interests in working with local non-governmental organizations and extension officers to undertake activities such as tree planting, watershed and rangeland management, vegetable gardening, recycling and composting domestic wastes, and the 
construction of more KVIPs in the community. Participants thought that Charia already had a head-start on such projects as a result of on-going CIDA activities in the community. The only problem they observed was the waning support and participation in the project, especially from the men and the section of the community that benefited least from initial development projects because of the distant location of these projects. Thus, some participants identified the need to find amicable ways of solving the existing conflicts about inequitable community resource allocation so as to regain the trust of the whole community. Some women also discussed the importance of encouraging all community members to participate in community development projects. In their view, some 'lazy' community members ridiculed them for not making good use of their time and labour, failing to recognize the indirect benefits they reaped from tree plantations.

Concerning how to reduce the incidence of the major health problems facing the community, participants suggested some practical actions that could be implemented at the community- and household-levels to prevent and/or reduce the incidence of malaria, diarrhoea and acute respiratory infections (ARIs). These actions, listed in Table 7.4, ranged from taking basic precautions to avoid mosquito bites to building well-ventilated houses. Some women cautioned that identifying these actions without making the conscious effort to find time to implement them was meaningless. Members of the research team also pointed out that, in addition to these actions, it was important to continue to send children to the community clinic for regular growth monitoring and immunization exercises, attend environmental and health education campaigns, and seek immediate medical care should health problems become severe. 


\section{Table 7.4 Community-and Household-Level Activities to Reduce the Incidence of Malaria, Diarrhoea and ARIs}

\begin{tabular}{ll}
\hline Health Problem & Intervention Actions \\
\hline Malaria & $\begin{array}{l}\text { Reduce/eliminate breeding sites for mosquitoes } \\
\text { Use appropriate farming practices } \\
\text { Proper maintenance of water supplies } \\
\text { Screen doors and windows } \\
\text { Self-protection from mosquitoes }\end{array}$ \\
& $\begin{array}{l}\text { Proper maintenance of water supplies } \\
\text { Practice good hygiene and sanitation } \\
\text { Reduce breeding sites for flies } \\
\text { Protect food and drinking water from "dirt" } \\
\text { Reduce waste production } \\
\text { Cook meals thoroughly }\end{array}$ \\
& Build highly ventilated houses \\
& Use efficient household stoves \\
Keep children away from smoky kitchens \\
Cook in yards (open areas)
\end{tabular}

\subsubsection{Strengthening Intersectoral Collaboration}

Participants expressed the need for government, private, public, international and nongovernmental organizations working to promote community well-being to coordinate their activities and interventions so as to increase their efficacy.

Such sentiments have been expressed in the environment and health literature. For example, the ecosystem approach to human health recognizes that single-sector and disciplinary approaches to human health and environmental management are ultimately not effective. The complexity of factors, actions and decisions influencing health are not amenable to solutions from only the health sector. Thus, an intersectoral approach 
requires that problems facing communities be 'unpacked', and their component parts be attributed to all sectors of government, society and people's daily life events. An intersectoral approach emphasizes the importance of integrating all these perspectives to develop solutions that extend beyond the scope of a single discipline and department, and embrace ecosystem health and human health. It also advocates a coordinated approach in which various intervention activities (such as, educational activities, regulations) are not only complementary, but aligned with each other, thus covering the whole of the feasible intervention spectrum.

Intersectoral approaches do not only require commitment from participating departments, but also the active involvement of community members. In this regard, participants in the men's group suggested regular monthly meetings with extension workers of various departments and the need to involve community members in the planning phases of project development. Some women also expressed the importance of including women in these meetings, as these have a high tendency of being only male affairs. In general, participants expressed the need for interventions to be broad-based, taking into consideration the varying needs of all social groups and not just the so-called at-risk groups.

Participants also identified the need to form partnerships with the private sector. They observed that some of the conditions that facilitate environmental risks and ill health resulted from the activities of the private sector (e.g. gravel extraction for construction purposes). They observed that, to counter their contribution to ill health, the private sector could be asked to contribute positively (e.g. donations) to community health development. The challenge, as noted earlier, is how to establish partnerships with a 
sector that maximizes profit at the expense of community and ecosystem health. One approach, according to participants, is to set up a village welfare committee. The committee would develop avenues of engaging the private sector in discussions about how to go about their activities with minimal environment and human health consequences, and about how to contribute to community-development efforts.

\subsubsection{Broaden the Concept of Community Participation}

Some participants pointed out that although many environment and health programs have sought to be 'participatory', they have involved community members only as providers of information and as 'labourers' in the field. As one woman put it, 'participation to them means bringing us together, talking to us about the benefits of a particular project and asking us to cooperate with them.' 'Cooperation' here, according to one young man, means 'doing whatever is requested of us (attending meetings, providing information, and working on the fields) without questioning.' Some participants pointed out that such narrow conceptualization of participation failed to make use of the diverse skills, knowledge and human resource potential of community members. According to one elderly man:

I may not be able to contribute physically to a community project, but I could certainly give out a portion of my land for the establishment of a community woodlot, or help in the planning process, which is a good way of being involved. But most at times, they never ask as to participate in that way. Instead they require me to contribute my labour to a project I might not even approve of or benefit from. (Man, 62 years). 
A community is usually perceived as home to a wide variety of people with diverse backgrounds and views. Community efforts are beneficial when everyone has a voice, when all voices are encouraged, and when community members have the choice to express their views and contribute to the community in different ways. With respect to this, Rifkin (1990) distinguishes between five 'levels' of participation. At the first and most passive level, people may participate in the benefits of a project by receiving services or education of some sort. At the second level, people may participate by contributing resources such as labour, money or volunteering to help in one way or another with the community project. The third level involves implementation, where local people assume some managerial responsibilities and decide how certain activities should be implemented. The fourth level deals with monitoring and evaluation. The fifth and most important level is when local people are involved as active participants in program planning and/or in translating their own felt needs and interests into true 'grassroots' development, a level that is very rarely achieved.

Thus, in identifying possible strategic directions, participants expressed the need for organizations working with them to use effective participatory processes that would not only use them as sources of information, but also embrace the principles of grassroot democracy and empowerment and make use of local knowledge systems and skills. Some of the actions suggested included the formation of partnerships with extension workers, information-sharing sessions between the two parties and active involvement of community members in all phases of projects. 


\subsubsection{Strengthen Environment and Health Education and Communication}

Participants expressed the need for the use of appropriate and effective education and communication strategies for the dissemination of environment and health information. According to some participants, educational activities and messages are delivered as flat statements whose truth is beyond question, and make no attempt to integrate the content of the messages with indigenous knowledge or concepts. Cultural dynamics, such as communication codes, meaning and context between educators and learners, are often ignored despite their relevance in the production and acquisition of knowledge.

In commenting on the delivery of health information, Airhihenbuwa (1994) asserts that health communication projects in Africa have operated under three key assumptions: first, health information can reach a population through the media; second, health information can change negative health practices if the population has the requisite health knowledge; and third, if relevant health information is not acquired by the people, then the skill in acquiring health messages must be developed through literacy programs. He argues that the problem with such operational assumptions is that, should local people fail to acquire and practice the required health knowledge, then the responsibility for program failure is mostly placed on the inaction of community members; the victimblaming approach that has always been adopted by health education. So, when the program fails, it is always reasoned that the people lack the required knowledge and/or motivation to initiate the necessary health actions that would lead to positive health outcomes. The health interventionist is freed of any responsibility or accountability for the failure of participants to attain the expected health outcome. What is not examined, he 
argues, is the method of health communication used, and whether this is in compliance with the traditional mode of learning of the target community and the cultural practices relating to knowledge production and acquisition. For example, it has been demonstrated that in many African countries, person-to-person or home-visit communication is more effective in changing negative health behaviours than mass media campaigns. Such practice is based on oral tradition as the customary mechanism for the production and acquisition of knowledge and the construction of reality (Airhihenbuwa, 1994). Demonstration, which combines all the senses - sight, hearing, vision, taste, touch and intuition - is said to be the most effective learning method (Fuglesang, 1973). Unfortunately, most of the health communication programs that have been implemented in African countries emphasize visual learning (mainly posters), which is in tune with Western culture and often requires adult literacy. Although the use of media, especially radio (local FM stations), has been instrumental in health education for the past few decades, not many rural communities had access to electricity nor could rural folks buy radios, and so have not benefited much from such education programs. With the recent commitment of the Ghanaian government to expand electricity supply to all rural communities, I see the radio as being an indispensable tool for health education, especially on HIV/AIDS awareness campaigns.

Another problem with implementing educational programs in rural Africa is the fallacy of assuming a rural community to be homogenous, with people sharing common interests and problems and, thus, the preoccupation to seek universal solutions. According to Airhihenbuwa (1994:350), 'this fixation on universality has resulted in the promotion of a common denominator for global health, education and development when 
the numerators are central to cultural production and thus, affirmation of differences.' This, he argues, has negatively influenced the learning possibilities that underlie and affirm different cultural expressions throughout the world.

Participants in both the men's and women's groups urged members of the research team to deliver educational programs that considered their cultural values and traditional modes of learning. Educational programs should also strengthen their understanding and knowledge base of the social and environmental determinants of health, and not focus solely on behaviour change and modification. Some women urged the use of events such as village festivals and fairs to disseminate health information. This, they suggested, could take the form of drama or specially composed songs by community groups. The men's group requested the organization of formal reward ceremonies for families, such as 'healthy family of the month', for families who make the necessary effort to keep their home environments free from health hazards. They also suggested introducing such concepts earlier on to school children and organizing formal debates between various community organizations. A list of some of the activities identified by participants is presented in Table 7.5 . 
Table 7.5. Actions for Environmental and Health Education and Communication

\begin{tabular}{|c|c|}
\hline Specific Actions & $\begin{array}{l}\text { Men (M)/ } \\
\text { Women (W) }\end{array}$ \\
\hline $\begin{array}{l}\text { - Hold awareness-raising activities in community } \\
\text { - Hold exhibitions on the impacts of environmental } \\
\text { degradation on health }\end{array}$ & $\begin{array}{l}M / W \\
M / W\end{array}$ \\
\hline $\begin{array}{l}\text { - Encourage local drama groups to perform plays on } \\
\text { environmental health problems }\end{array}$ & W \\
\hline $\begin{array}{l}\text { - Hold community-wide fairs and festivals } \\
\text { - Organize local campaigns using community and folk media } \\
\text { - Organize debates on occupational health issues between } \\
\text { men and women }\end{array}$ & $\begin{array}{l}\mathrm{W} \\
\mathrm{M} / \mathrm{W} \\
\mathrm{M}\end{array}$ \\
\hline $\begin{array}{l}\text { - Encourage sharing of culturally appropriate knowledge about } \\
\text { the causes and treatment of environmental health problems }\end{array}$ & $\mathrm{M} / \mathrm{W}$ \\
\hline $\begin{array}{l}\text { - Encourage information events at community gatherings } \\
\text { - Hold awards ceremonies to honour community members who } \\
\text { keep their surroundings clean }\end{array}$ & $\begin{array}{l}\mathrm{M} / \mathrm{W} \\
\mathrm{M}\end{array}$ \\
\hline
\end{tabular}

\subsubsection{Building on Local Knowledge Systems}

Local/indigenous knowledge systems are often crucial in designing interventions to benefit local communities. Rajasekaran (1993) describes indigenous knowledge as a systemic body of knowledge acquired by local people through the accumulation of experiences, informal experiments, and intimate understanding of the circumstances in their culture. This collective wisdom is a rich repository of cultural norms, values and beliefs. It influences every aspect of life, including people's acceptance or rejection of messages from extension workers and change agents (ibid). 
Participants observed the usefulness of this rich repository of knowledge in identifying and managing environmental problems, as well as in improving human health. For example, understanding the ecological and cultural features of traditional agriculture and the ability to use local plants to control pest and repel mosquitoes are crucial for obtaining useful and relevant information to guide the development of appropriate agricultural and health strategies.

Despite the growing realization of the usefulness of indigenous knowledge systems, some extension workers and researchers still consider local knowledge as primitive, non-scientific and backward (Thurston, 1992). Most environmental health problems are still informed by scientific understandings and western solutions. Scientific knowledge is elevated above local knowledge, and essentially fails to accommodate any local views. But, as Chambers (1993) argues, local knowledge is the basis for local-level decision making in agriculture, health care, natural resource management and a host of other endeavors in rural communities. Incorporating these varied perceptions and knowledges into programs can result in successful interventions, since the outcome often reflects the felt needs and aspirations of the people being assisted. Participants observed that the lack of incorporation of local knowledge into community development interventions has resulted in a gradual decline of certain knowledge systems among the youth. As expressed by one woman:

Our children are like turkeys these days. They know absolutely nothing about medicinal plants or which grass types indicate a potential good bean harvest. When I was young I knew all these plants...I knew what plant to use for scorpion bites. These days when a scorpion stings a child on the farm, he/she just stands there 
crying for help. We try to teach them about the medicinal uses of various plants but they do not listen because they think there is better medication at the clinic (Woman, 36 years)

Some male participants, however, attributed the lack of knowledge about some important plants among the youth to the growing decline of those plant species, and suggested occasional exhibitions of important plant species for the youth. I followed through with this suggestion by organizing a field trip with some participants to community outskirts to collect various medicinal plants and identify their uses. Two specialists, one from the Ministry of Health and the other from the Ministry of Forest Services, joined the team to help identify the botanical names of the plants. Upon our return from the trip, participants displayed and grouped the plants according to their various medicinal uses. Both the research team and the participants were amazed at the number of ailments that could be treated with the plants collected (see Table 7.6). After taking notes on all the plant species gathered, I asked participants to take the plants home and teach their children about the medicinal uses.

During this exercise, it was interesting to see how the gendered knowledge systems on these plants played out between men and women. While most women were able to identify medicinal plants immediately at their backyards and all the way through to their bush farms, the men argued that 'the proper medicinal plants were far away in the bush and not easily obtainable.' Upon our arrival at the farm, women readily picked up their plants, mainly leaves and branches, while the men dug deep into the soil to cut off plant roots. It was obvious that the men were very knowledgeable about the medicinal uses of roots, and the women mainly the leaves and branches. Similarly, the men 
demonstrated a sophisticated knowledge about 'concoctions' or combinations of various medicinal plants to cure certain ailments, while the women knew about the uses of single plants. Compared to men, women showed good knowledge about plants used to cure children's ailments including diarrhoea, malaria, colds and stomachaches. Men were concerned about how to stop bleeding wounds, treat scorpion and snake bites, and how some plants could be used as pesticides and for grain preservation. In general, both men and women were very knowledgeable about these plants.

To be able to build upon this rich knowledge base of local people, participants called for fundamental changes in the way extension and community development agents worked with them. Instead of perceiving them as passive and non-knowledgeable about many events, they wanted extension workers to develop clear-cut methods for uncovering and incorporating local knowledge into intervention strategies. Participants also urged one another to continue to transmit this knowledge to future generations through oral history and folklore, and also teach their children about the importance of conserving biodiversity, as well as, the consequences of biodiversity loss for human health and wellbeing. This, they suggested could also be incorporated into environment and health education programs. 
Table 7.6 Medicinal Plants Identified by Participants

\begin{tabular}{|c|c|c|}
\hline Disease & Medicinal Plant & Mode of use \\
\hline \multirow[t]{2}{*}{ Malaria } & $\begin{array}{l}\text { Lingbera (Hymenocardia acida) } \\
\text { Zimbrima (Zizyphus mouritiana) } \\
\text { Neem (Azodriachia indica) } \\
\text { Mango (Magnifera indica) }\end{array}$ & $\begin{array}{l}\text { For the first four plants, the leaves are } \\
\text { boiled, and the water used for bathing } \\
\text { and/or drinking }\end{array}$ \\
\hline & Dungkara & $\begin{array}{l}\text { Leaves are burnt in rooms to dispel } \\
\text { mosquitoes }\end{array}$ \\
\hline \multirow[t]{2}{*}{ Diarrhoea } & Mwanbehe & $\begin{array}{l}\text { Leaves and roots are boiled, and the } \\
\text { water used for bathing and/or drinking }\end{array}$ \\
\hline & $\begin{array}{l}\text { Nyelimanyuu } \\
\text { Pawpaw (carica papaya) }\end{array}$ & $\begin{array}{l}\text { Leaves are eaten to prevent diarrhoea } \\
\text { Fresh leaves are boiled and drunk. }\end{array}$ \\
\hline Stomach aches & $\begin{array}{l}\text { Damui } \\
\text { Sunkpiili } \\
\text { Dabilituo }\end{array}$ & $\begin{array}{l}\text { Leaves are boiled and drunk } \\
\text { Leaves are boiled and drunk } \\
\text { Roots are chewed and juice extracted } \\
\text { and swallowed }\end{array}$ \\
\hline \multirow[t]{2}{*}{ Colds and flu } & Lingbera (Hymenocardia acida) & Leaves are boiled and drunk \\
\hline & $\begin{array}{l}\text { Pileemazinti } \\
\text { Gbaganyuu } \\
\text { Naahunyakobiri }\end{array}$ & $\begin{array}{l}\text { For the last three, leaves are boiled, and } \\
\text { the water used for bathing and/or } \\
\text { drinking }\end{array}$ \\
\hline \multirow[t]{2}{*}{$\begin{array}{l}\text { Wounds, boils, } \\
\text { scorpion bites }\end{array}$} & Siira (Amogeissus leiocarpus) & $\begin{array}{l}\text { Boil fresh leaves and use to scald fresh } \\
\text { wounds. Pound dry leaves and apply to } \\
\text { old and burns wounds. }\end{array}$ \\
\hline & Baataanga (Annona senegalensis) & $\begin{array}{l}\text { Roots are chewed and applied to areas } \\
\text { of scorpion bites }\end{array}$ \\
\hline Dewormer & $\begin{array}{l}\text { Waahudunkye (Phallantus } \\
\text { auraanus) }\end{array}$ & $\begin{array}{l}\text { Pound leaves, soak in water, decant and } \\
\text { use with millet flour for a meal }\end{array}$ \\
\hline Toothaches & $\begin{array}{l}\text { A mixture of Kpaangukpantoli and } \\
\text { lungburi (Citrus aurantifolia) }\end{array}$ & $\begin{array}{l}\text { Boil slices of lime with the leaves of } \\
\text { Kpaangukpantoli, gurgle and keep in } \\
\text { mouth for some time. Repeat daily until } \\
\text { toothache disappears }\end{array}$ \\
\hline
\end{tabular}




\subsubsection{Building Community Capital: Integrating the Strategic Directions}

Participants identified and discussed a plethora of strategies that can be classified as the need to build community capital. Community capital is often described as comprising four forms: natural capital, which comprises the natural resources that sustain our economies and health; economic capital, which constitutes the means by which we attain a certain level of prosperity that is sufficient to meet our basic needs; social capital deals with the social networks and systems that constitute our civic society, and finally, human capital, which is reflected in our health status, skill, level of education, innovativeness and creativity (Ekins et al., 1992; World Bank, 1995; Hancock, 2000). In most cases, communities tend to focus on increasing one form of capital, mostly economic capital, to the neglect of others. Such communities, Hancock (2000) argues, cannot be described as healthy or sustainable. In his view, a healthy and sustainable community is one that is able to increase all four forms of capital simultaneously, without hindering the development of any one capital.

In their first strategic direction, participants identified ways to improve the quality of their local environment in order to protect their ecosystems and also reduce the occurrence of diseases. In subsequent discussions, participants identified strategies meant to improve social capital. For example, they identified the need to preserve informal social networks and to create formal ones that would help community members, especially the vulnerable to meet their day-to-day needs. Participants also discussed the need to form village committees that would act as mediators between the community and the local government. These committees would then lobby the government for the 
extension of services such as electricity, water supply and sanitation services to the community. They would also work with other government departments to influence the development of healthy public policy that would cut across a number of departments, and deal with a shared interest in social equity, ecosystem health and community health. On strategies to increase economic capital, participants discussed the need to explore and implement poverty reduction strategies involving activities such as the establishment of small-scale loan programs for farmers and petty-traders, and diversification of the rural economy through the establishment of vocational training institutes, small-scale industries and skill development workshops for local artisans, as well as the exploration of alternative well-organized market systems for community products. Strategies to improve human capital included the empowerment of women through increased enrolment of the girl-child in school, and occasional workshops by the Department of Social Welfare to enhance women's confidence and self-esteem. Some women were, however, concerned that their husbands might see such workshops as 'coaching grounds' for women to rebel against their husbands, and so might prevent the women from attending. Mechanisms for ensuring social equity and conflict resolution were also suggested as ways of promoting harmony in the community, which participants saw as precursors for their community to work together to achieve a shared vision. To move these broad strategies a step closer to implementation, participants devised a plan of action. 


\subsection{Drawing up a Plan of Action}

During this last phase of the strategic planning process, participants outlined tentative plans to implement the strategies and actions they identified in the previous session. They outlined specific duties, meeting days, workdays, and materials needed and other resources for implementing these activities.

During this process, participants identified a series of activities to be undertaken in the coming weeks. Since we had not secured any financial assistance for projects, I encouraged participants to identify projects that could easily be implemented without any financial and/or material resources, such as the formation of lobbying groups and steering committees to lead the process. Extension workers also pledged to continue to provide technical assistance to the community and work closely with community members.

I had many mixed emotions during this last stage of the strategic planning process for a number of reasons. First, I knew I could not stay long enough to see the culmination of this exercise, and so I wondered what the outcome might be. Would people follow through with their plans? Would they be disappointed with me once again for coming to lead them this far and disappear? Would subsequent issues regarding implementation generate conflict as did the other international development project? I also reflected on my use of the PAR approach. Does a PAR study constitute failure, when it fails to be carried through to actual implementation? The questions for me at this stage were endless.

In my attempt to find answers to some of these questions, I held a feedback/reflection session with participants to hear their comments about the process 
and what they had learned. One comment seemed to suggest that it was not a fruitless exercise:

We did not realize we could participate in solving our own problems. For years, we have always depended on the big people in Wa (the Regional capital) and always extended our arms to your people (referring to the international community) for assistance. I guess what we needed was someone to hold our hands and show us how to go about understanding and solving our own problems. This experience has been an eye-opener and we have learned a lot from you (Man, 42 years).

In general, participants seemed to have enjoyed the discussions that took place during the workshops. They found the discussions interesting and informative. Some were particularly happy with the opportunity to dialogue freely with members of the research team, who, until now, were seen as holding onto some powerful knowledge that could not be challenged. Members of the research team seemed delighted with the process thus far. They thought they had come to understand community concerns better as well as to understand and learn from one another about how they each worked with communities. In addition, they hoped to build on the experience by continuing to work together as a team and with community members, even when the study was over. Some participants also used the occasion to caution me not to abandon them as I did during my first fieldwork with them. I found this caution very disturbing and it reiterated my ethical dilemmas about participatory research in general. While I use their words for my academic advancement, I reflect on what I have given back. I can only hope that they have been conscientized by articulating their problems in ways that they have not done previously, 
re-evaluating their individual actions and practices in light of their social environments, and acquiring some confidence that they can help improve their own lives.

\subsection{Conclusion}

In this chapter, I presented and discussed the findings of a strategic planning exercise that was undertaken by community members and facilitated by the research team. The process outlined the community's vision for a healthy community, identified the barriers to achieving that vision and possible strategies to achieving this vision. We also took stock of the resources and strengths of the community, and outlined a plan of action for activities deemed immediate and needing less financial resources. Despite occasional disagreement among participants and the research team, the process generated some shared concerns on which both groups were able to begin work on. The exercise helped participants to clearly think through how to integrate their unique strengths to work towards a better community, while at the same time becoming well-organized to confront issues of marginalization. In the next chapter, I pull together the major themes of this study, discussing its implications for both research and policy, as well as pointing to some areas for future research 


\section{CHAPTER VIII}

\section{CONCLUSIONS AND FUTURE DIRECTIONS}

\subsection{Introduction}

The central thesis of this study is two-fold. The first is that health problems facing rural communities in northern Ghana cannot be fully understood and solved without situating them in their broader historical, political and socioeconomic contexts. The second is that local people understand why they are ill and why they are poor, and often have ideas about what can be done. If guided democratically, backed legislatively and supported financially, they will be able to contribute meaningfully to their own development.

Since independence, the goal of Ghana's health policy has been to ensure that all Ghanaians enjoy the highest possible level of care that resources permit and also have ready access to basic health care. This goal, though laudable, has been difficult to achieve under the changing economic and political conditions in the country. Though a recent survey shows general improvements in the overall health status of Ghanaians, there are still wide disparities that exist across gender lines, between rural-urban areas, between administrative regions and other socioeconomic groups (World Bank, 2003; WHO, 2001; GPRS, 2003). Rural communities, and in particular those in the northern part of the country, have persistently fared poorly on many health dimensions.

The questions I pose in this thesis are: 1) why does such poor health status seem to persist in these rural communities; 2) why has public health research and intervention not been very successful in reversing these poor health trends; and 3) what alternative 
health interventions can be used to improve rural community health and reduce the existing health disparities?

I examined these questions in light of a political ecology of health perspective. While most public health research points to the influence of a broad range of social and environmental factors on health and their associated social patterning, it provides a limited means for understanding the sociopolitical and economic dimensions underlying people-environment interactions and the health inequalities they produce (Poland et al., 1998). On the contrary, a political ecology approach to health allows for an understanding of the mechanisms through which political and economic processes shape human-environment interactions and how these contribute to disparate environmental exposures and health experiences (Turshen, 1977; Mayer, 1996, 2000; Kalipeni and Oppong, 1998). Following Mayer (1996) and others ${ }^{20}$, I integrate the political ecology approach with an ecosystem health perspective to examine how large-scale social, economic and political, and historical factors shape community health experiences and how local people, in turn, respond to and interpret these experiences.

I began by challenging the dominant, atheoretical and ahistorical modes through which rural health problems are formulated, and acted upon. I examined the impact of colonial and postcolonial policies on rural health development and how these policies created and sustained spatial and socioeconomic inequalities and health disparities in the

\footnotetext{
${ }^{20}$ Other related work using the political ecology of health/disease approach include Hughes and Hunter's (1970) study on the relationship between large-scale development (dam construction) in Africa, and the transmission of malaria and schistosomiasis; Turshen's (1984) work on the implications of political structures on health and disease in Tanzania; Kalipeni and Oppong's (1998) study on the political ecologic circumstances underlying the refugee crisis in Africa; and Hunter's (2003) study on the relationship between agricultural development and the explosion of urinary schistosomiasis in the Upper East Region of Ghana.
} 
country. I situated the failure of most community health efforts in their inability to provide space for indigenous, subjective views and the continuous operation of the health sector along western biomedical lines.

In advocating people-centred health research and development, I employed a community-based participatory approach in a small village in the Upper West Region of Ghana with the view to determining its potential to help generate critical consciousness in community members about their health situations and how they could contribute to resolving them. As such I began with an exploration of people's perceptions of health, ill health and their health problems. This was done with the purpose of ensuring that the research actually addressed people's felt and not imposed needs. I followed this through with an exploration of what community members perceived to be the underlying causes of their health problems. This exercise revealed a complex interplay of factors, which, through a strategic planning process, became the focus for collective community efforts to resolve. In contrast to conventional health interventions, this study allowed participants to articulate their health concerns and develop potential solutions in ways that were meaningful to them culturally and socially, and not externally imposed.

In this concluding chapter, I draw together the main themes of the study, examining their significance and implications for community health research and practice, as well as the theoretical and methodological contributions to the broader fields of public health and medical/health geography. I will conclude by identifying pointers for future research. 


\subsection{Explaining the Persistence of Poor Health in Rural Northern Ghana}

The dominant reasons often offered for poor rural health outcomes and services in Ghana centre on three issues. First is the lack of adequate resources to go around, with rural communities last on the distribution list. Alongside these scarce resources are issues of mismanagement, with health personnel stealing them for their own private 'locum'. The second reason borders on victim-blaming or what Onoge (1973:223) describes as 'socioculturalism'. Local people's cultural practices, customs, traditional values and belief systems are seen as the obstacles to rural health development. These practices are perceived as irrational and self-destructive. They stand in the way of modern medicine (Twumasi, 1979, 1981; Harper, 2004; Farmer, 2001). Thirdly, environmental factors, or the irrational use of environmental resources, explain the predominance of environmental-related diseases in rural communities.

As I have illustrated throughout the thesis, these reasons are flawed in a number of dimensions and should be examined in light of poststructuralist and political ecology critiques of knowledge claims and the so-called 'appropriate' health and environmental practices. Take the first reason that blames rural poor health on resource scarcity. The problem with such conceptions is that they reduce health problems to simple technical and resource-based problems, abstracting them from the impacts of broader historical, national and world-system political-economic forces. The ahistorization of rural health problems does little to draw on the colonial legacy and its associated health policies, the persistence of a similar trend in post-independent Ghana, and the structural adjustment programs of the 1980s and 1990s. During group discussions, participants' reference to 
poverty, rural marginalization, and unaffordable health services requires that we situate health problems squarely within these contexts, and examine how colonial political economy and agricultural policies negatively affected the health and nutritional status of rural Ghanaians; how colonial health policies focused on selected populations and diseases to the detriment of the masses and the broader determinants of health; and how the restriction of services to urban areas has persisted until now. Similarly, questions pertaining to unaffordable health services, poor staffing, and corruption at the work place should be examined within the context of Ghana's socioeconomic problems and the impact of structural adjustment programs. For example, the implementation of a cashand-carry system made drugs and other social amenities unaffordable for poor rural dwellers. The introduction of user fees resulted in a decline in the utilization of healthcare services, including immunization and antenatal services (Anyinam, 1989; 1994).

Although the impact of these economic reforms still exists, there are attempts to alleviate the health burden of the poor through pro-poor health strategies and insurance schemes (GPRS, 2003). We can only wait to see the extent to which these would benefit the poor, given that these proposals stem from the same actors who proposed the SAPs.

Similarly, the second reason that holds 'culture' and peoples' beliefs responsible for poor rural health outcomes relieves the role of structural inequalities and power imbalances in perpetuating uneven patterns of health. It also fails to reckon the discursive means through which local peoples' identities and health practices are constructed to suit the ideological, political and material interests of dominant medical and environmental discourses. As discussed previously, the focus on individual attributes tends to relieve structural imperatives that may be responsible for poor health outcomes (Lee and Garvin, 
2003). Rural people also tend to be perceived as a homogenous group with shared health experiences. It is on this basis that 'packaged' health promotion/protection campaigns, that rebuke local people to change their behaviours, have become the favourable mode of health promotion in these settings. During group discussions, it was apparent that, how people conceptualized health, what they perceived to be indicators of good and poor health, as well as their health problems and needs all varied across gender, age, socioeconomic status and access to social support networks. For example, work-related and psychosocial health problems were widely experienced by women compared to men. Also, those with some formal education tended to conceive health from western perspectives, while the economically advantaged did not consider ready access to social support networks as a necessity for good health. Attention to these particularities, within the common account, can explain certain actions and behaviours and hence can influence how health interventions are planned and implemented.

Finally, explanations for poor rural health status that centre on the irrational use of environmental resources fail to understand the cultural, political and economic contexts in which environmental change and degradation occur and how, in turn, environmental change shapes social and cultural relations. Political ecology contributes to this understanding by illuminating how environmental change is constituted through power imbalances among various actors, and how ill health among some social groups is a product of that politicized environment (Mayer, 1996; Bryant, 1998). The notion of a politicized environment allows for the understanding that problems of land degradation, food insecurity and malnutrition in Northern Ghana are simultaneously politicaleconomic problems and cannot be examined outside these contexts. The story of the 
building contractor and the health implications of his activities are exemplary in this study. It was shown that the dugouts created by the building contractor could have been responsible for the increasing occurrence of acute eye infections among children in the community as they played in these ponds. Yet, health interventions focused on treating the cases, and making no linkages to their underlying cause. The contractor, on the other hand, acted based on his privileged position and took advantage of the lax environmental regulations at the local level, their poor enforcement and the poverty-stricken nature of community members who would accept bribes and pave the way for him to degrade their farmlands.

Also, this explanation fails to take into account how SAPs might have augmented the synergistic relationship between poverty, environmental degradation and poor health outcomes. As pointed out by many authors, the removal of subsidies on basic commodities such as food, agricultural products and fuel increased rural poverty, household food insecurity and increased dependence on natural resources. This forced the rural poor to encroach on marginal lands and fragile ecosystems, while making use of intensive and unsustainable farming practices (Alubo, 1990; Kanji et al., 1991; WHO, 1997; Kessler and Van Dorp, 1998).

\subsection{Re-examining Public Health Research and Intervention in Ghana}

My discussion about poor rural health status does not preclude any past or on-going attempts by the government and other international agencies to improve rural health systems in Ghana. As pointed out in Chapter II, a number of committees and pilot 
projects were formed during the colonial and post-independence era to look into rural health concerns (Aidoo, 1982; Randall, 1998). But as critics point out, these new endeavours seem to be based on the same old western biomedical approach, either focusing on selected cases or populations, although their purposed principles might state otherwise (Randall, 1998). What seem to be happening is pouring back the same old wine into new bottles. For example, while Primary Health Care is still currently in vogue and is supposed to attend to rural health concerns using decentralized and democratic principles, and employ a broad view of health' and disease prevention, these are rarely implemented that way; participation is tokenistic, emphasis is on selected diseases, including HIV/AIDS and maternal and child health, and health education is still the favourable mode of intervention. These failures can also be explained based on the fact that almost all Ghanaian medical professionals are trained within the biomedical framework, and so despite their knowledge and understanding of the various aspects of health, they still operate within the biomedical perspective. Also, the high burden of disease, the seriously ill cases and the limited resources of the health sector encourage preference for curative hospital-based and selective biomedical care compared to broadbased public health preventive programs that target the provision of clean water, adequate food supply, proper sanitation and other basic social services. International health politics continue to play a key role, still dictating many health agendas in developing countries, deciding what the major health concerns are or ought to be, and linking funding to specific diseases and other conditionalities.

In Charia for example, while community members identified their major health problems as malaria, respiratory illnesses and diarrheal diseases, equal or perhaps even 
more emphasis and resources were placed on HIV/AIDS awareness and prevention, despite the acknowledgement that HIV/AIDS prevalence is lowest in the three northern regions (Ghana National AIDS Control Programme, 2005). This misplaced emphasis relates to donor conditionalities and the specification of priority health problems by external 'experts' and organizations. In order not to discount the enormous and potential impact of HIV/AIDS on the lives of Africans, it should, however, not be perceived as affecting every community on the African continent and taking up a substantial portion of the health sector's resources, while neglecting other equally important health problems such as malaria and tuberculosis. HIV/AIDS has ceased to become just a disease, but a mechanism through which global constructions of the 'other' take place. It has become a site through which entire continents and communities are constructed and corrected, and a site of power struggle among the world's finest scientists to find 'global' solutions to the disease. HIV/AIDS has created a 'culture of silence' in communities; local communities are somewhat afraid to speak about it. In my group discussions with participants, rarely could I get participants to speak about HIV/AIDS in their community. They knew all the 'theory' about HIV/AIDS, but would not say whether they knew anyone with the disease. As simply put by one elderly man 'Madam, they say it is a bad disease and we can all get it, but I cannot point to any house or to anybody who has HIV/AIDS or died of the disease in this community.' Whether it is a strategy not to present their community as bad before the world or whether in reality there are rarely any known cases remains a mystery. That is the extent to which the disease has become a mystery given the devastation it leaves behind its trail and the political clout it commands. 


\subsection{In Search of Alternatives: A Community-Based Ecosystem Approach to Health Research}

How then, are we supposed to move forward to reorient community health research and intervention so as to respond meaningfully to rural community health concerns and also reduce the growing health inequalities? Drawing on the findings of this study and others, I point to a number of alternate pathways. First is the move towards conducting research with people rather than on or for people. Most community health research and practice in the developing world is still too often done for, rather than with, those experiencing the problem (Israel et al., 2002). Community members need to express their own views about health, what they consider to be their health problems and participate in finding solutions to those problems. However, in many instances, public health researchers and professionals have defined health problems for communities, and their interpretation and understanding of these health problems have often differed from those of the people concerned (de Koning and Martin, 1996). For example, in this study, there were major differences in the way local people conceived of health and assessed their health status and problems. While most community health professionals continued to place emphasis on physical health, most participants explained health predominantly from psychosocial and ecological perspectives. Health was increasingly seen as the ability to perform social functions, access basic services, meet personal and societal needs, and cope with everyday life circumstances. Participants' conceptualization of health captured the complex, socialized and cultural dimensions of their lived experiences and pointed to the need for public health research and health promotion efforts to give prime consideration 
to local people's subjective views, knowledge and beliefs, and to target improving health from a holistic, gender and community-relevant perspective, and not just focus on treating specific diseases. Kearns (1993) lends his voice to this view when he argues that a geography of health based on socially constructed understandings of health and health experiences is one in which medically recognized disease is a necessary but not a sufficient category. Subjective experience of health, lay experiences, beliefs, and perceptions are important, and 'their existence means that perspectives of the scientist can and should not be granted any special privilege' (Eyles, 1993:51).

Similarly, indicators of health identified by participants raised questions about the usefulness of medical categories for rural community health research. Participants' indicators of health focused on issues of community cohesion, peace and unity among family members, and access to both material and symbolic resources. Such qualitative indicators are meaningful to community members and capture appropriately their sense of health and ill health, as opposed to the use of only quantitative indicators such as infant mortality rate, disease frequency, and average life expectancy, among others. There is therefore the need to identify indicators that are relevant to both community members and also serve the needs of health professionals.

The expression of subjective views of health helps to identify the particular needs of specific individuals and to respond to them. For example, for a more informed analysis of men's and women's health, it is important to recognize the simultaneously diverse roles and identities they assume at various times and places, and how such roles shape their experiences, their struggles, their resistance strategies, their coping mechanisms and how they negotiate power in various spaces (Moss, 2002). Each woman's experience is 
unique and different, and the meaning she creates out of that experience is influenced by her social location and identity in space and time (Mohanty et al., 1991). We should be concerned with listening to different groups of people, documenting their diverse experiences, understanding their daily lives and contextualizing their local health experiences with broader political and socioeconomic forces (Knauft, 1996).

This study also revealed the need to broaden the scope of health problems to include psychosocial health problems that do not conform to the social definition of 'ill health'. As illustrated through discussions, these are often considered illegitimate and have no room in the conventional health system. For example, many women discussed these 'hidden' health problems to include 'the inability to sleep', 'worrying too much', and 'thinking about our children'. Since such complaints do not manifest themselves physically, they are often considered less significant both by the women experiencing them and the health care professionals. They are often seen as acts of a 'lazy woman', and so women are forced to conceal them so as to be perceived as the 'good wife' or incorporate them as symptoms of well-known health problems such as malaria, in order to receive attention. While these problems may not be taken seriously, there are chances that they inhibit some women's ability to function properly. Thus, women's health intervention should not only be limited to maternal and child care, but should create space for women's psychosocial well-being, that would encourage women to speak out about such health concerns without being rebuked. Counseling sessions would also contribute to improving their health.

This study also points to the need to adopt a political and ecologically-based framework that allows for the synthesis of the multiplicity of factors affecting human 
health. Factors causing ill health are often interpreted superficially, but a good understanding of the underlying causes of community health problems requires a framework that clearly depicts the historical, social, political, and economical contexts in which health is produced and its differential impacts on various social groups. As illustrated in this study, such multidimensional factors are better investigated through working with a transdisciplinary team of researchers and actively involving participants in the research process.

In sum then, I join my voice with others in making a renewed call for social health research in general to extend the search for causes of ill health from the individual to the community and to other sociopolitical systems; to broaden its methodologies to include transdisciplinary, qualitative and participatory research methods; and to validate communities' experiential knowledge by integrating lay knowledge into their research practice (Krieger et al., 1993; Schwab and Syme, 1997). It is in so doing that we will give voice and power to those afflicted to participate in taking action to reduce existing health inequalities and improve their overall health status and community well-being (FalsBorda and Rahman, 1991; Gaventa 1993; Hall, 1992; Maguire, 1996; Wallerstein, 1999).

\subsection{Intersectoral Collaboration: Potentials and Limitations}

This study was also aimed at exploring opportunities for developing and implementing an integrated approach to community health research. Many community health problems are influenced by the decisions and practices of a variety of sectors. For example, most diarrheal diseases result from poor water supply and sanitation, but the provision of adequate water supply and waste management services is the responsibility of various 
sectors including the District Assembly, the Environmental Health Division of the Ministry of Health, and the Ghana Water and Sewerage Corporation, while the prevention and management of diarrheal diseases remains the sole responsibility of the health sector. It seems natural, therefore, for these sectors to collaborate in devising solutions to these problems. But as is the case of Ghana and other developing countries, health factors may not play an important role in the policy setting of other ministries, or in some cases they may simply be stated but cannot be enforced because of resource constraints. For example, while the Ministry for Works and Housing is responsible for occupational health and rural water supply, it does not have the expertise to ensure safe working conditions or even preventive remedial measures for water-borne diseases. Similarly, despite the growing evidence linking domestic biofuel use with respiratory diseases and low birth weights, the Ministry of Health has no institutional or legislative power to influence rural energy supply, such as to subsidize alternative energy sources for rural people. Thus, most ministries are mandated to achieve and address issues that are within their jurisdiction while paying less attention to the ripple effect of their decisions and actions. For instance, the Ministry of Education acknowledges the links between female literacy and quality of life, and pledges to increase girl-child enrolment in primary schools. However, questions about how female literacy is linked to good household health, smaller family sizes, better nutrition and healthy child development is left to the health sector, which instills this in women through organized rural health workshops. While some privileged schools have health education in their curriculum, this could be broadened to include schools in rural communities by 1) encouraging an early integration of health education in primary schools, and 2) adopting a more ecological 
focus to health by emphasizing the linkages between human health and environmental degradation; and health improvement through primary environmental care.

The private sector is also an important player in any study using an intersectoral approach. But while some private sector activities tend to have negative effects on the health and livelihoods of communities, they also have the potential to contribute positively to community health by employing local inhabitants. The challenge is often bringing the private sector to the negotiation table. In the case of this study, how can the influential building contractor be held accountable for the devastating effect of his gravel mining activities on community livelihood and health, and be advised to conduct his activities within proper environmental guidelines? While there are no easy answers as to how to involve the private sector in community health issues, this study demonstrates the effectiveness of youth groups in achieving such objectives. Unlike the past when many high profile officials left their communities to pursue higher education and were rarely in touch with activities in their villages of origin, these days they are the backbones of community groups and play very influential roles in youth groups. Their privileged status in government organizations allows them to draw development projects to their communities. As such, the formal request by the youth group of Charia to the contractor to restore topsoil to farmlands, upgrade the main road connecting the village to the regional capital and to supply building materials for the upgrade of a village school, could not go unheeded. Although further requests for him to participate in community meetings went unheeded, the youth had signalled the important role community-based organizations play in community development efforts and so should always form part of intersectoral efforts. After all there were lone voices of protest, especially from women, 
that never made an impact on the soil excavation problem. They only resulted in household squabbles between husbands and wives, and among brothers who shared communal farming lands. Parallels can be drawn between this study and others, in which organized community protests have been effective in challenging powerful actors from destroying livelihood resources, such as in the case of the Ogoni people and the Shell oil company in Nigeria (Watts, 1997; 2001)

Another set of actors who are relevant for community development planning but are often difficult to involve are policy makers. Despite how useful and innovative the findings of this study might be for community members, their dreams of achieving a healthy and sustainable community can only be fully achieved if their recommendations receive policy-backing and are followed through with implementation. But as is common with most Ghanaian communities, officials at the district level are strategically placed to implement national and international policies. Their role in formulating or informing local/district level policies is very limited, albeit the concept of decentralization.

Aside from the bottlenecks associated with implementing local action plans, this study still made policy recommendations within the jurisdiction of the Upper West Region, with participants resolving to strengthen the lobbying capacities of community groups, particularly youth groups, to effect policy changes. The strategic planning process allowed participants to evaluate their resources and strengths and to suggest intervention strategies within their capabilities. This approach was meant to foster community competence and a sense of control over their problems. It was to restrain community members from continuous dependency on external help. Previous community-based studies have shown the disappointment and feelings of bitterness 
displayed by community members when their action plans fail to proceed to the implementation stage. Not only are they angry with themselves, but also with interventionists and researchers who facilitated the process. Such resentment inhibits their participation in future community development efforts. Thus, I tended to encourage more self-dependency from participants than from people with external resources.

Despite the associated challenges with intersectoral and transdisciplinary research, if successfully implemented the benefits often tend to outweigh the costs. This study was instrumental in demonstrating the usefulness of the approach by working with a team of co-investigators from various government departments. Although experts in their various disciplines, the research team focused on understanding and helping community members resolve their health and environment problems. While some officials did work independently with community members prior to this study, the prospect of working together with other team members and with community members in an egalitarian relationship presented different opportunities. For community members, it was rewarding to hold a portion of the 'steering wheel' and be able to specify what they thought were their health problems and the factors perpetuating them. For members of the research team it was an opportunity to learn from members of other departments and to understand community problems from the people's perspective. From a researcher's perspective, I was initially concerned about my own limited experience in working with research teams, the potential impacts of my multiple and sometimes privileged positions on the research process, and the little time available to develop the necessary rapport with team members. But as the study progressed, I continuously adapted to the challenges presented. For instance I played the 'daughter role', when I was referred to as 'my 
daughter' by some members of the research team, which culturally meant assuming a less experienced role and allowing the 'elders' to take full responsibility on specific activities, such as speaking to the chief and some community elders. Similarly, I was faced with uncertain circumstances when my group discussions with the men's group earlier on in the research process was fraught with very cynical and antagonistic responses, partially reflecting their protest to inequitable resource allocation in the community which was oblivious to me at the time. Overall, I thought it was a great learning experience for us all, albeit concerns about moving our plan of action forward.

\subsection{Contributions and Future Directions}

In addition to the practical implications of this study, the findings also contribute to furthering the knowledge base within the broader fields of public health and health promotion research, the geography of health and healthcare, the emerging field of ecosystem approaches to human health, and participatory action research (PAR). Given the growing need for empirical studies within the ecosystem approach to human health framework, this study illustrates, through the use of PAR, how the elements of the ecosystem approach to human health, namely transdisciplinarity and intersectoral collaboration, community participation and attention to social differences including gender, socio-economic, and educational status were integrated to investigate and respond to a community's desire for health and ecological sustainability. Through collaborative investigation by local government departments and community members, the complex and underlying causes of community health problems were identified and 
possible interventions, beyond conventional medical care, explored. The study furthers the understanding of the socioecological approach to health as one that transcends the biomedical model and concerns itself with developing healthy people and places, and not just combating disease. In line with the World Health Organization definition of health promotion as 'a process of enabling people to increase control over and to improve their health' (WHO, 1986: 1), this study demonstrates how the involvement of local people as active participants in the assessment and definition of their own health problems not only endows them with the skills and capabilities of problem solving, but tends to raise their consciousness about primary environmental care as an important strategy to preserve their health.

This study responds to recent calls by health geographers to conduct theoretically informed research that emphasizes disease and health as social constructs, and considers lay views as valid ways of knowing (Kearns, 1993; Jones and Moon, 1993; Dorn and Laws, 1994). Some health geographers have cogently argued that the use of conventional scientific methods has often silenced the 'patient' and granted medical knowledge special privilege (Kearns, 1993; Dorn and Laws, 1994). But as Eyles (1993) and others argue, the existence of lay views and social constructions of health and illness means that the scientist can and should not be given special privilege. Lay experiences, beliefs and perceptions are of crucial importance in gaining contextual knowledge about health problems. In Ghana and other developing countries, most community health problems are often diagnosed and solved sole-handedly through professional expertise, with little community involvement. Most interventions that result from such dominant, externally imposed constructions of community health problems fail to capture the complexity of 
factors influencing health, and are most likely to be ineffective in improving people's health. Also, despite the usefulness of (poststructuralist) political ecology in explaining the contextual factors influencing human-environment relationships among various subgroups, very little has been done by health geographers to adapt this approach to the geography of health and health care (Mayer, 1996; 2000). This study furthers the literature in this field and allows for a better understanding of the interactions between power, the biophysical and social environments and how these influence community health outcomes and well-being.

From a methodological standpoint, very little has been done with respect to the use of PAR for doctoral research in the context of community health (Gibbon, 2002). This is often because of a number of obstacles. First, there is always the difficulty of reconciling the researcher's interests with those of the community (Maguire, 1993; Ulichny, 1997). 'While both community and researcher may have the same research interests....their agendas necessarily differ, as the researcher aims to get a Ph.D. or produce a journal article, while the community wants local action and development' (Attwood, 1997:4). Although this is true to some extent, my motive for using PAR spanned beyond just gathering data to understand the problem. I chose PAR because of my subscription to PAR's philosophy of achieving rural social change through the involvement of the beneficiaries and in generating knowledge about their own conditions and how to change them (Fals-Borda and Rahman, 1991).

Other constraints posed by PAR to students are mainly institutional. For example, there are often conflicts between the researcher's timing of the research and that of the community. While community members might already be in the middle of one project 
and may not be ready to start a new one, the student researcher is working within the timelines of institutional and funding agencies and must initiate his/her research. In my study, I was lucky that many on-going international development projects were environment- and natural resource-oriented, and since my study was in the interface of environment and health, I occasionally made linkages with the on-going projects emphasizing the health aspects. Such timing conflicts can play a big role in the interests, enthusiasm and level of participation showed by participants. In addition to the time consuming nature of PAR, it is not a linear process. It requires on-going monitoring and evaluation, and incorporating lessons learned to improve the situation at hand. But, given that most student researchers probably have enough funds for a one-time entry and for a limited stay, the extent to which propositions and action plans become implemented remains questionable. The time, energy, and expectations of participants also become an ethical issue. According to Chambers $(1993,1997)$, the failure of professionals and researchers to deliver has become frequent in the development field, and has caused many facilitators to self-reflect on their techniques and processes. I was constantly worried about taking so much of participants' time, and wondering whether it was all worth it.

Given such constraints, my study was a modest attempt to raise awareness about the health situation in Charia and to get participants involved in undertaking basic health preventive measures to protect their health, including environmental management. Many government departments are accustomed to using top-down approaches and working in isolation, and this seems to have failed to address community problems effectively. The 
open, frank and enthusiastic dialogue between community members and government workers shows evidence of the importance of the process for both groups.

While this study sought to understand and intervene on the factors influencing health in one rural West African village, the findings might be applicable to other rural African communities facing similar socioeconomic, political and environmental health problems. However, it would be worthwhile for a study that builds on this to focus on the household as the unit of analysis instead of the entire community. My emphasis on the community and the broad picture did not allow for a nuanced analysis of household micro-politics and its implications for environmental health outcomes among various household members. Political ecology analyses that focus on the household have mostly limited their analyses to the material and symbolic struggles within these arenas and their implications for resource use, ownership and labour, without extrapolating them to the health impacts on various family members.

Some caution has to be exercised in generalizing from this study. The particular realities in the community, such as the unfavourable climatic conditions in northern Ghana, and its peculiar historical, political and economic marginalization, and social exclusion, probably made certain issues such as household food insecurity and environmental health problems, more pronounced. But given that many rural communities in Ghana and other developing countries, often lack access to many health enhancing services such as clean water, health, and government services, it is likely that there are similarities in community health concerns, and so the findings of this study can provide pointers for communities to play an active role in community health planning and implementation. 
The study also exhumes some health issues that have either been underresearched or given little attention. For example, there is very little about rural women's psychological health concerns, partly because of the notion that Africans have more pressing health issues to deal with, than to consider issues of psychosocial health. But as this study reveals, psychosocial health problems among women in particular are gaining currency and further research needs to be conducted to explore the extent and impact of this problem on household functioning and well-being. The concept that psychological counseling is a western phenomenon needs to be overcome and rural African women given help. Also, while the arduous workload of the African woman is widely documented, little has been done on the occupational health risks associated with those workloads. Instead, many rural women are socialized to believing that those are the 'rewards or expected duties' of a 'good wife' and a 'caring' mother. Additionally, the health care set-up has little space for such work-related complaints as they are considered signs of a 'lazy' woman. Health awareness sessions on issues such as appropriate methods of lifting heavy weights, and the health consequences of using unwashed fertilizer bags to carry vegetables will go a long way to improve health. Since most occupational health risks occur within the informal sector there are no legislative mechanisms in place to help local people deal with such hazards.

From the perspective of an ecosystem approach to rural health in Ghana, this study constitutes one of the first in such a setting, and provides a foundation for similar, more in-depth studies to be conducted on the myriad health problems that confront both the rural and urban poor in developing countries. Community-oriented approaches to understanding the ecological pathways of many tropical diseases and how to prevent 
them through sustainable environmental management will eventually prove to be more cost effective compared to curative approaches.

This study has a number of implications for policy makers, program developers, government departments, researchers, and those interested in community and environmental health. First, community health programs must incorporate broader notions of health as envisaged by community members. Only then will true, holistic health improvement be achieved, overcoming the excessive focus on therapeutic health care. Second, community members understand and appreciate what community health researchers have understood for years, that their health status is linked to a complex interaction of social, political, economic and environment factors, which cannot be completely understood and solved by the health sector alone. Third, given the opportunity to participate, community members' knowledge, skills and abilities provide a valuable resource base for the achievement of a healthy future. Working within a framework of shared power and collaboration with government departments, community members can use the opportunity to clearly negotiate their position, and signal what their felt needs really are. The ensuing question following such a process is the extent to which the community will be able to implement their action plans. It is one thing envisioning a healthy and sustainable community, and another overcoming the obstacles and constraints to make it a reality. A follow-up to this study to determine the successes and blocks of program implementation would be useful. For the meantime, this study provides alternative views of understanding rural Ghanaian health problems, illustrates the capabilities of community members in responding to their health problems, and 
challenges the notion of community members as passive victims, who are continuously dependent on external help. 


\section{REFERENCES}

Abu-Lughod, L. 1988. Fieldwork of a dutiful daughter. In Soraya Altorki and Camillia Fawzi El-Solh, eds., Arab Women in the Field: Studying Your

Own Society. Syracuse: Syracuse University Press, pp.139-62. . 1993. 'Introduction' In: L. Abu-Lughod, Writing women's world. Bedouin Stories, Berkeley: University of California Press, pp1-42.

Addo, N.A. 1975. Internal migration differentials and their effects on socio demographic change, In: Cadwell, J. C (ed). Population growth and socioeconomic change in West Africa. New York Columbia University Press.

Adjei, S., Owusu, G., Adamafio, J., Akyeh, S. 1988. Primary health care review, Ghana. Accra, Ministry of Health.

Agarwal B. 1992. The gender and environment debate: lessons from India. Feminist Studies. 18:119-58. . 1994. A Field of One's Own: Gender and Land Rights in South Asia. New York: Cambridge Univ. Press. .1997. Environmental action, gender equity and women's participation. Development and Change 28:1-43.

Aidoo, T. A. 1982. Rural health under colonialism and neocolonialism: a survey of the Ghanaian experience. International Journal of Health Services 12:637-57.

Airhihenbuwa, C. 1994. Health promotion and the discourse on culture: implications for empowerment. Health Education Quarterly. 21: 345-53.

Alary, J.1990. Community care and participatory research. Nu-Age Editions, Montreal.

Alubo, S. O. 1990. Debt crisis, health and health services in Africa. Social Science and Medicine 31:639-648.

Amenga-Etego, 2003. Water privatization in Ghana: Women's rights under siege. Paper presented at the World Social Forum on Globalization, Privatization and Poor Women's Rights to Water Seminar. Porto Alegre, Brazil, January 23 - 28th, 2003.

Annandale, E. and J. Clark, 1996. What is gender? Feminist theory and the sociology of reproduction. Sociology of Health and Illness 18(1): 17-44.

Antonovsky, A, 1985. Health, stress and coping. San Francisco: Jossey Bass.

Anyinam, C. A. 1989. The social costs of the International Monetary Fund's adjustment programs for poverty: the case of health care development in Ghana. International Journal Health Service 19:531-47. .1994. Spatial implications of structural adjustment programs in Ghana. Tijdschrift voor economische en social geografie 85: 446-450.

Apple, M.W. 1993. Official knowledge: Democratic education in a conservative age. New York: Routledge.

Arthur, J.A. 1991. Interregional migration of labour in Ghana, West Africa: Determinants, consequences and policy. Review of Black Political Economy. 20: 89-114.

Ashton, J. 1992. The origins of healthy cities In Ashton, J (ed.) Healthy Cities. Open University Press. Milton Keynes, Philadelphia. 
Asthana, S. 1996. Women's health and women's empowerment: a locality perspective. Health and Place 2: 1-14.

Attwood, H. 1997. An overview of issues around the use of participatory approaches by post-graduate students. In IDS, Participatory Research, IDS PRA Topic Pack. Brighton: IDS University of Sussex.

Aviles, L.A. 2001. Epidemiology as discourse: the politics of development institutions in the Epidemiological Profile of El Salvador. Journal of Epidemiology and Community Health 55:164-171.

Avotri, J. Y. and V. Walters. 1999. "You just look at our work and see if you have any freedom on earth": Ghanaian women's accounts of their work and their health. Social Science and Medicine 48 (9):1123-33.

Baer, H. A. 1996. Bringing political ecology into critical medical anthropology: a challenge to biocultural approaches. Medical Anthropology 17 (2):129-41.

Baldwin, S. 1991. The social dimensions of adjustment. Paper presented at the ZCTU/UZ Economics Department Workshop on structural adjustment and health, Harare.

Baker, C., Norton, S., Young, P. and Ward, S. 1998. An exploration of methodological pluralism in nursing research. Research in Nursing and Health 21:545-555.

Bergdall, T.D. 1993. Methods for active participation. Experiences in rural development from East and Central Africa. Oxford University Press, Nairobi, Kenya.

Bernstein, H. 1979. African peasantries: A theoretical framework. Journal of Peasant Studies 6(4): 421-443.

Bird, C.E. and Rieker, P.P. 1999. Gender matters: an integrated model for understanding men's and women's health. Social Science and Medicine 48: 745-755.

Blaikie, P. 1995 Understanding environmental issues, In Morse, S and Stocking M (eds) People and environment University College London Press, London 1-30.

Blaikie, P. and Brookfield, H. 1987. Land degradation and society. London: Methuen

Boachie-Danquah, Y. 1992. Structural adjustment programs and welfare interventions: The case of Ghana. Africa Insight 22 (4): 244-248.

Boakye-Yiadom, L. 2004.The Evolution of Welfare in Ghana: A Rural-Urban Perspective Paper Prepared for the International Conference on Ghana's Economy at the Half Century. July 18-20, 2004. Accra, Ghana.

Bradley, D.J. 1993. Environmental and health problems of developing countries. In Environmental and human health. Wiley, Chichester. Ciba Foundation Symposium 175. pp. 234-246. .1994. Health, Environment, and Tropical Development, In B. Cartledge (ed.) Health and the Environment: The Linacre Lectures (Oxford University Press, Oxford, U.K.,1994), p. 147.

Broad, R. 1994. the poor and the environment: Friend or foes? World Development 22(6):811-822.

Bronfenbrenner, U. 1990. The ecology of human development: Experiments by nature and design. Cambridge, MA: Havard University Press.

Brooks, A and Watkins, K.E. 1994. The emerging power of action inquiry technologies. San Francisco: Jossey-Bass.

Brown, J. and Tandon, R. 1983. Ideology and political economy in inquiry: action 
research and participatory research. Journal of Applied Behavioral Science 19:277-294.

Brownlea, A. 1987. Participation: Myths, realities and prognosis. Soc. Sci. Med. 25(6):605-614.

Bryant, R. L. 1997. Third World political ecology: An introduction, In Bryant, R.L., and S. Bailey. Third World political ecology. London ; New York: Routledge. .1998. Power, knowledge and political ecology in the Third World. Progress in Physical Geography 22:79-94.

Bryant, R.L. and Bailey, S. 1997. Third world political ecology. London: Routledge.

Brydon, L. and Legge, K. 1996. Adjusting society: The World Bank, IMF and Ghana. London: Tauris Academic Studies.

Bruce, N., Nufeld, L, Boy, E. and West, C. 1998 Indoor biofuel air pollution and respiratory health: The role of confounding factors among women in highland Guatemala. International Journal of Epidemiology 27: 454-8.

Bruce, N., Perez-Padilla, R., and Albalak, R. 2000. Indoor air pollution in developing countries: a major environmental and public health challenge. Bulletin World Health Organization. 78: 1078-92. Review.

Butler, J. 1990. Gender Trouble. Routledge, London. 1992. Contingent foundations: feminism and the question of "postmodernism", In Feminists theorize the political, Butler, J and Scott, J.W., (eds). New York: Routledge, pp 3-21.

Caldwell, J C. 1969. African rural-urban migration: the movement to Ghana's towns. Canberra, London,: Australian National University Press; C. Hurst. . 1975. African Migration In Cadwell, J. C (ed). Population growth and socioeconomic change in West Africa. New York Columbia University Press.

Cameron, J. and Gibson, K. 2005. Participatory action research in a poststructuralist vein. Geoforum:36:315-331.

Carney, J.A. 1996. Converting the wetlands, engendering the environment: the intersection of gender with agrarian change in Gambia. In Peet, R. and Watts, M., eds. Liberation ecologies: environment, development and social movements, London: Routledge, 165-87.

Carney, J.A. and Watts, M. 1990. Manufacturing dissent: work, gender and the politics of meaning in a peasant society. Africa $60: 204-41$. 1991.Disciplining women? Rice, mechanization, and the evolution of mandinka gender relations in Senegambia. Signs: Journal of Women in Culture and Society 16: 651-681

Chambers, R. 1993. Challenging the Professions: Frontiers for Rural Development. ITDG, London.

.1997. The primacy of the personal. In M.Edwards and D. Hulmes (eds.) Nongovernmental organizations - performance and accountability: Beyond the magic bullet. P. 207-247. London: Earthscan.

Charlton, B.G. and Kelly, M.P. 1992. Paying for an off-the-peg life, The Times Higher Education Supplement, 1005:19 
Chivian, E. 2001. Environment and health: Species loss and ecosystem disruption - the implications for human health. Canadian Medical Association Journal 164:6669.

Clarke, J.N. 1992. Feminist methods in health promotion research. Canadian Journal of Public Health 83: S54-S57.

Cleveland, D. A. 1991. Migration in West Africa: a savanna village perspective. Africa (London) 61 (2):222-46.

Corcega, T. F. 1992. Participatory research: getting the community involved in health development. International Nursing Review 39 (6):185-8.

Corlett, W. 1989. Community without unity: a politics without Derridian extravagance. Durham, NC: Duke University Press.

Cornia, G., Jolly, R. and Stewart F. 1987. Adjustment with a human face. Clarendon, Oxford, U.K.

Cornwall, A., and R. Jewkes. 1995. What is participatory research? Soc Sci Med 41 (12):1667-76.

Cotterill, P. 1992. Interviewing Women: Issues of Friendship, Vulnerability, and Power. Women's Studies International Forum, 15(5/6), p. 593-606.

Costanza, R. 1992. Toward an operational definition of ecosystem health, In Ecosystem health: new goals for environmental management. Costanza, R., Norton, B.G. and Haskell, B.D. (eds) pp239-256. Island Press.

Cottrell, L.S. 1983. The competent community, In Warren, R. and Lyons, L. (eds.): New perspectives on the American community. Homewood III, Dorsey Presss.

Covalán, C.F., Kjellström, T. and Smith, K.R. 1999. Health, environment and sustainable development: identifying links and indicators to promote action. Epidemiology 10(5): 656-660.

Cruikshank, B. 1999. The will to empower: democratic citizens and other subjects. Cornell. Ithaca.

Dakubo, C. 2004. Ecosystem approach to community health planning in Ghana. EcoHealth 1:50-59.

Dakubo, G.B. and Commey, J.O. 1996. Acute respiratory infections in young children comparative findings in emergency rooms in Accra, (Ghana) and Harare (Zimbabwe). West African Journal of Medicine 1996 Jul-Sep;15(3):181-5.

Davies, J.K and Kelly, M.P.1993. Introduction In Kelly, M.P and Davies, J.K., (eds), Healthy cities: research and practice. London: Routledge, pp 1-13.

De Koning, K. and M. Martin. 1996. Participatory research in health: issues and experiences. London; Atlantic Highlands, N.J. Johannesburg: Zed Books.

De Roux, G. 1991. Together against the computer: PAR and the struggle of Afro_colombiams for public services. In: Fals Borda, O.Rahman (eds), Action and knowledge: Breaking the monopoly with participatory action research. The Apex Press, New York, pp37-53.

Dei, G.J.S. 1992. Hardships and Survival in Rural West Africa: A Case Study of a Ghanaian Community. Dakar: CODESRIA Monograph Series

1993. Learning in the time of Structural Adjustment: The Ghanaian Experience. Canadian and International Education 22 (1): 43-65. 
Dickens, C. 1990. Urban sociology. Society, Locality and human nature. Harvester Wheatsheat. Hemstead.

District Health Management Team. 2002. Trends of top ten diseases seen at the out patient department 1995 - 2001. Wa District.

Dorn, M and G. Laws, 1994. Social theory, body politics, and medical geography:

Extending Kearns Invitation. Professional Geographer 46(1): 106-110.

Doyal, L. 1979. The political economy of health. London, Pluto

Doyal, L. and Pennell, I. 1976. 'Pox Britannica': Health, medicine and underdevelopment. Race and Class 18(2):155-172.

Duhl, L. 1986. The healthy city: its function and its future. Health Promotion 1:55-60.

Dyck, I. 1995. Putting chronic illness 'in place'. Women immigrants' accounts of their health care. Geoforum 26 (3): 247-260. 1999. Using qualitative methods in Medical Geography: Deconstructing moments in a subdiscipline? Professional Geographer 51(2): 243-253.

Dyck, I. and Kearns, R. 1995. Transforming the relations of research: Towards culturally safe geographies of health and healing. Health and Place 1:139-149.

Dyck, I., Davis, N., and McLafferty, S. 2001. (eds) Geographies of women's health. London.

Ekins, P., Hillman, M. and Hutchinson, R. 1992. Wealth Beyond Measure: An Atlas of New Economics. Gaia Books, London.

Eisen, A. 1994. Survey of neighborhood-based, comprehensive community empowerment initiatives. Health Educ $Q 21$ (2):235-52.

Enberg, L. 1993. Women and agricultural work. Occupational Medicine: State of the Art Reviews 8(4): 869-882.

England, K.V.L. 1994. Getting personal: reflexivity, positionality, and feminist research. Professional Geographer 46: 80-89.

Enyimayew, K. 1988. Cost and financing of drugs supplied in Ghana: The Ashanti-Akim experience. Paper presented at WHO Conference, Geneva, June.

Escobar, A. 1995. Imagining a post-development era, in Power of Development, Crush, J. (ed.), London and New York: Routledge Pp.211-227.

Eyles, J. 1988. Interpreting the geographical world: Qualitative approaches in geographical research. In: Eyles, J., Smith, D (eds.) Qualitative methods in human geography. Basil Blackwell, Oxford. P.1-16. . 1993. Feminist and interpretive method: How different? The Canadian Geographer 37: 50-52.

Fairhead, J and Leach, M.1995. False forest history, complicit analysis: rethinking some West African environmental narratives. World Development 23:1023-1035.

Fals-Borda, O, and M. A. Rahman. 1991. Action and knowledge: breaking the monopoly with participatory action research. New York London: Apex Press; Intermediate Technology Publications.

Fanow, M. and Cook, J (eds.) 1991. Beyond methodology: Feminist scholarship as lived research. Indiana University Press. Bloomington.

Farmer, P. 2001. Infections and Inequalities: The Modern Plagues, Updated Edition. Berkeley: University of California Press. 
Fine, M. 1994. Dis-stance and other stances: Negotiations of power inside feminist research. In A. Gitlin (ed.), Power and method: Political activism and educational research (pp. 13-35). New York: Routledge.

Flax, J. 1990. Thinking fragments: Psychoanalysis, feminism, and postmodernism in the contemporary west. Oxford, University of California Press.

Forget, G., and Lebel, J. 2001. An ecosystem approach to human health. International Journal of Occupational Environmental Health 7 (2 Suppl):S3-38.

Foucault, M. 1975. The Birth of a clinic: The archaeology of medical perception. Vintage Books, New York. .1977. In Gordon, C (ed). Power knowledge: selected interviews and other writings. Pantheon, New York. . 1979. Discipline and punishment: The birth of the prison, Trans A. Sheridan. Vintage, New York. . 1980. Power/Knowledge. Pantheon, New York. Foucault, $\mathrm{M}$.

Fox, N.J. 1991. Postmodernism, rationality and the evaluation of health care. Sociological Review 39(4):709-744. 1994. Postmodernism, sociology and health. University of Toronto Press. Toronto.

Freudenberg, N., Eng, E., Flay, B., Parcel, G., Rogers, T., Wallerstein, N. 1995. Strengthening individual and community capacity to prevent disease and promote health: in search of relevant theories and principles. Health Education Quarterly. 22 (3):290-306.

Freire, P. 1972. Pedagogy of the oppressed. New York: Herder and Herder. . 1973. Education for critical consciousness. New York, NY, Seabury Press. .1982. Freire $P$. Creating alternative research methods: learning to do it by doing it. In: Hall B, Gillette A, Tandon R (eds). Creating Knowledge: A Monopoly? Participatory Research in Development. New Delhi: Society for Participatory Research in Asia, 1982, pp. 29-37.

Fuglesang, A. 1973. Applied Communication in Developing Countries. Uppsala: The Dag Hammarskjold Foundation.

Garvin, T. 1995. We're strong women. Building a community-university research partnership. Geoforum 26:273-286.

Gatenby, B. and Humphries, M. 2000. Feminist Participatory action research: Methodological and ethical issues. Women's Studies International Forum 23:89105.

Gaventa, J. 1981. Participatory action research in North America. Convergence 14:30-42. .1993. The powerful, the powerless, and the experts: Knowledge struggles in an information age. In Park, P., Brydon-Miller, M., Hall, B., and Jackson, T. (eds.). 1993. Voices of change: Participatory research in the United States and Canada (p. 21-40). West Port, Conn.: Bergin and Garvey.

Geest van der, K. 2002. "We are managing!?". Vulnerability and responses to climate variability and change among rural households in Northwest Ghana. Unpublished M.A. Thesis. University of Amsterdam. 
George, S. 1976. How the other half dies: The real reasons for world hunger. Penguin Books, Harmondworth, Middlesex.

Ghana National AIDS Control Program, 2001. Estimating National HIV Prevalence in Ghana Using Sentinel Surveillance Data. Accra.

Ghana National Development Planning Commission of Ghana (GNDPC), 2002. Ghana's Report on the Millennium Development Goals, Accra.

Ghana National AIDS Control Programme, 2005.

http://www.ghanaids.gov.gh/main/publications.asp. Accessed March, 15th. 2005.

Ghana Poverty Reduction Strategy (GPRS), 2003. An Agenda for Growth and Prosperity. Vol. 1.Analysis and Policy Statement.

Ghana Statistical Service, 1988. Ghana Living Standard survey. Accra: Ghana Statistical Service.

.1995. The pattern of Poverty in Ghana. Accra: Ghana Statistical Service. . 1998. Core Welfare Indicators Questionnaire (CWIQ) Survey 1997- Main Report. Accra, Ghana. 1998. Ghana Living Standard survey. Accra: Ghana Statistical Service. .1999. Ghana Living Standard survey. Accra: Ghana Statistical Service. .2000a. Poverty trends in Ghana in the 1990s. Ghana Statistical Service, Accra, Ghana. $.2000 \mathrm{~b}$. Ghana Living Standard Survey. Report of the fourth round (GLSS 4). Statistical Service, Accra, Ghana.

Ghana Statistical Service (GSS) and Macro International Inc. (MI). 1994. Ghana Demographic and Health Survey 1998. Carleverton, Maryland:GSS and MI. .1998. Ghana Demographic and Health Survey 1998. Carleverton, Maryland: GSS and MI 1999. Ghana Demographic and Health Survey. Ghana Statistical Service. 2003. Ghana Demographic and Health Survey 2003. Carleverton, Maryland: GSS and MI.

Gibbon, M. 2002. Doing a doctorate using participatory action research framework in the context of community health. Qualitative Health Research 12:546-558.

Gilbert, M.R. 1994. The politics of location: doing feminist research 'at home'. Professional Geographer 46: 90-96.

Gitlin, A. (ed.).1994. Power and method: Political activism and educational research. New York: Routledge.

George, S.1976. How the other half dies. Pelican.

Goldman, M and Schurman, R.A. 2000. Closing the "great divide": New social theory on society and nature. Annual Review of Sociology 26:563-87.

Gordon, D.R. 1988. Tenacious assumptions in Western medicine. In M.Lock and D. Gordon (eds). Biomedicine examined, Dordrecht: Kluwer, pp. 19-56.

Government of Ghana, 1995. Ghana Vision 2020. The first Medium-Term Development Plan (1997-2000). President's report to parliament on coordinated programme of economic and social development policies. Accra, Ghana: GOG.

Green, L.W., George, M.A., Daniel M., Frankish, C.J., Herbert, C.J., et al. 1995 Study of participatory research in health promotion. University of British Columbia, Vancouver: Royal Society of Canada. 
Green, L. W., M. O'Neill, M. Westphal, and D. Morisky. 1996. The challenges of participatory action research for health promotion. Health Promotion Education 3 (4): 3-5.

Green, L.W., and Mercer, S.L. 2001. Participatory research: can public health agencies reconcile the push from funding bodies and the pull from communities? American Journal of Public Health, 91:1926-29.

Greenwood, J. 1994. Action research: A few details, a caution and something new. Journal of Advanced Nursing, 20, 13-18.

Guba, E. (ed). 1990. The paradigm dialogue. Sage Publications, Newbury Park, CA.

Guba, E.G. and Lincoln, Y.S. 1989. Fourth generation evaluation. Newbury Park, California: Sage. 1994. Competing paradigms in qualitative research, In Denzin, N.K. and Lincoln, Y.S. (eds.) Handbook of qualitative research. Thousand Oaks, CA: Sage, pp.105-117.

Guthman, J. 1997. Representing Crisis: The Theory of Himalayan Environmental Degradation and the Project of Development in Post-Rana Nepal. Development and Change 28: 45-69.

Guyer, J and Peters, P.E. 1987. Conceptualising the household. Development and change 18: 197-214

Gyogluu, S and Dakurah, L. 2000. Land use management and the environment in the Nadawli District. A report prepared by the Wa Town and Country Planning Department. Wa. Ghana. Unpublished.

Hagey, R. S. 1997. The use and abuse of participatory action research. Chronic Disease Canada 18 (1):1-4.

Haglund, et. al. 1990. Assessing the community: its services, needs, leadership and readiness. In N. Bracht (ed) Health Promotion at the Community Level. Sage. Newbury Park.

Haile, F. 1994. Occupational participation of women and health. In Wijeyaratne, P., Hatcher, R.J., Jones, A.L., Kitts, J., Gender health and sustainable development: proceedings of a workshop held in Nairobi, Kenya, 5-8 October 1983. IDRC, Ottawa, ON. Canada. pp 129-135.

Hall, B.L. 1992. From margins to center? The development and purpose of participatory research. American Sociologist 23:15-28.

Hall, B.L., Gillete, A., and Tandon, R. (eds). 1982. Creating knowledge: A monopoly? Participatory research in development. New Delhi: Society for participatory research in Asia.

Hancock, T.1993. The healthy city from concept to application: implications for research In Kelly, M.P and Davies, J.K., (eds), Healthy cities: research and practice. London: Routledge, pp 14-24. .2000. Urban ecosystems and human health. A paper presented for the Seminar on CIID-IDRC and urban development in Latin America, Montevideo, Uruguay. April 6-7.

Hancock, T and Duhl, L. 1986. WHO healthy cities paper 1. Healthy Cities: promoting health in the urban context, FADL, Copenhagen. 
Hancock, T and Duhl, L. 1988. Promoting health in the urban context. Copenhagen:FADL for the WHO. Healthy Cities Project Office.

Hancock, T. and Perkins, R.1985. The Mandala of health: a conceptual model and teaching tool. Health Educations 24:8-10.

Hancock, T., Labonte, R. and Edwards, R. 1999. Indicators that count: Population health indicators at the community level. A report for the Knowledge Development Division, Health Canada.

Haningan, J.A. 1995. Environmental sociology. London: Routledge.

Haraway, D. 1988. 'Situated knowledges: the science question in feminism as a site of discourse on the privilege of partial perspective' Feminist Studies 14:575-99.

. 1991. Simians, cyborgs and women: the reinvention of nature. London: Free Association Books.

Harding, S. 1991. Whose science? Whose knowledge? New York: Cornell University Press.

.1992. After the neutrality ideal: science, politics, and "strong objectivity." Social Research 59:567-587.

Harper, J. 2004. Breathless in houston: a political ecology of health approach to understanding environmental health concerns. Medical Anthropology 23 (4):295326.

Hart, K. 1974. Migration and the opportunity structure, in S. Armin (ed), Modern migrations in Western Africa, p.321-329. London: Oxford University Press for the International African Institute.

Hart, E. 1996. Action research as a professionalizing strategy: Issues and dilemmas. Journal of Advanced Nursing, 23, 454-461.

Hart, E., and C. Anthrop. 1996. Action research as a professionalizing strategy: issues and dilemmas. Journal of Advanced Nursing 23 (3):454-61.

Harvey, L. 1990. Critical social research. London: Edward Arnold.

Hawe, P. 1994. Capturing the meaning of 'community' in community intervention evaluation: Some contributions from community psychology. Health Promotion International. 9(3):199-210.

Herbst, J. 1993. The Politics of Reforms in Ghana, 1982-1991, University of California Press, Berkeley, Los Angeles.

Hill-Collins, P. 1990. Learning from the outsider within the sociological significance of black feminist thought. In: Fanow, M. and Cook, J (eds.) 1991. Beyond methodology: Feminist scholarship as lived research. Indiana University Press. Bloomington. P.35-59.

Hitchcock, G., and Hughes, D. 1995. Research and the teacher: A qualitative introduction to school-based research (2nd ed.). London: Routledge.

House, J.S., and Williams, D.R. 2000. Understanding and reducing socio-economic and racial/ethnic disparities in health, In B.D. Smedley and Syme, L.S. (eds), Promoting health: Intervention strategies from social and behavioural research (pp. 81-124). Washington, DC: Institute of Medicine/National Academy Press.

Howard, R. 1978. Colonialism and underdevelopment in Ghana. African Publishing Company, New York. 
Huq, M.M. 1989. The economy of Ghana: The first 25 years. London:Macmillan.

Hughes, C. C., and J. M. Hunter. 1970. Disease and "development" in Africa. Social Science and Medicine 3 (4):443-93.

Hutchful, E. 2002. Ghana's adjustment experience: The Paradox of reform. Geneva: UNRISD. Oxford: In association with James Curry; Portsmouth, N.H.

International Joint Commission (IJC). 1991. A proposed framework for developing indicators of ecosystem health for the Great Lakes Region, IJC. Windsor.

International Labour Organization, 1989. Special protective measures for women and equality of opportunity and treatment. Documents considered at the meeting of experts on special protective measures for women and equality of opportunity and treatment. ILO, Geneva, Switzerland. MEPM/1989/7.

Institute of Statistical, Social and Economic Research (ISSER), 1995. The state of Ghana's Economy in 1994. Legon: ISSER.

Israel, B.A., Checkoway, B., Schulz, A.J. and Zimmerman, M.A. 1994. Health education and community empowerment: conceptualizing and measuring perceptions of individual, organizational, and community control. Health Education Quarterly 21:149-170.

Israel, B. A., A. J. Schulz, E. A. Parker, and A. B. Becker. 1998. Review of communitybased research: assessing partnership approaches to improve public health. Annual Review of Public Health 19:173-202.

Israel, B. A., S. A. Farquhar, A. J. Schulz, S. A. James, and E. A. Parker. 2002. The relationship between social support, stress, and health among women on Detroit's East Side. Health Education and Behavior 29 (3):342-60.

Israel, B.A., Schulz, A., Parker, E., Becker, A., Allen III, A., Guzman, J.R. 2003. Critical issues in developing and following community-based participatoryresearch principles. In Minkler, M. and Wallerstein, N. (eds). Community Based participatory Research for Health p. 53-76. Jossey-Bass.

Jan Slikkerveer, L. 1995. INDAKS: A bibliography and database on indigenous agricultural knowledge systems and sustainable development in the tropics in Warren, D.M., L. Jan Slikkerveer and D. Brokensha (eds.) The cultural dimension of development. Indigenous knowledge systems. Pp. 512-516.

Jasanoff, S. and Wynne, B. 1998. Science and decision-making. In: S.Rayner and E.L. Malone (eds.) Human choice and climate change. Vol. 1: The societal framework. Columbus, OH.: Batelle Press. pp.1-87

Jewkes, R. and Murcott, A.1996. Meanings of community. Social Science and Medicine 43: 555-563.

Joekes S, Leach M, Green C, (eds.) 1995. Gender relations and environmental change. IDS Bulletin. (Suppl.) 26 (1) 102 pp.

Jones, K and Moon, G. 1993. Medical geography, taking space seriously. Progress in Human Geography 17(4): 515-24.

Kalipeni, E and Oppong, J. 1998. The refugee crisis in Africa and implications for health and disease: a political ecology approach. Social Science and Medicine 46:16371653.

Kanji, N., Kanji, N. and F. Manji, 1991. From development to sustained crisis: structural adjustment, equity and health. Social Science and Medicine 33:985-993 
Karr, J.R. 2000. Ecological health, public health, and societal well-being. Washington Public Health, Fall 2000.

Kearns, R. 1993. Place and health: Toward a reformed medical geography. Professional Geographer 45:139-47.

Kearns, R. 1994. Putting health and health care into place: An invitation accepted and declined. Professional Geographer 46 (1): 111-115.

Kearns, R. 1996. Medical geogaraphy: making space for difference. Progress in Human Geography. 19:251-259.

1997. Narrative and metaphor in health geographies. Progress in Human Geography 21(2):269-277.

Kearns, R. and Joseph, A.E. 1997. Restructuring health and rural communities in New Zealand. Progress in Human Geography 21:18-32.

Kelly, M.P. 1990. The role of research in the new public health. Critical Public Health 3:4-9.

Kelly, M.P., Davies, J.K., and Charlton, B.G. 1993. Healthy cities: a modern problem of a postmodern solution? In Kelly, M.P and Davies, J.K., (eds), Healthy cities: research and practice. London: Routledge, pp.159-68.

Kessler, J.J. and Van Dorp, M. 1998. Structural adjustment and the environment: the need for an analytical methodology. Ecological Economics, 27: 267-281.

Kettel, B. 1996. Women, health and the environment. Social Science Medicine, 42: 1367 1379.

Kickbusch, I. 1986. Health promotion: a global perspective. Canadian Journal of Public Health 77:321-327.

.1987. Issues in health promotion. Health Promotion 1:437-442.

1989. Approaches to an ecological base for public health. Health Promotion 4:265-268.

.1999. Good planets are hard to find - Approaches to an ecological base for public health, In Brown, V. (ed). A sustainable healthy future: Toward an ecology of health, LaTrobi University and commission for the future. Pp. 7-30.

Kidd, S. P. and Parshall, B. M. 2000. Getting the focus and the group: enhancing analytical rigor in focus group research. Qualitative Health Research 10(3): 293308.

Kitts, J. and Hatcher, J.R. 1996. The health gap: Beyond pregnancy and reproduction. IDRC, ON, Canada.

Kitzinger, J. 1995. Qualitative research: introducing focus groups. British Medical Journal 311:299-302.

Knauft, B. 1996. Stories, Histories, and Theories: Critically Humanist Sensibilities. In Knauft, B (ed) Genealogies for the Present in Cultural Anthropology Routledge, 9-61.

Konadu-Agyeman, K. 2000. The best of times and the worst of times: Structural adjustment programs and uneven development in Africa: The case of Ghana. The Professional Geographer 52: 469-483. .2001. IMF and World Bank sponsored structural adjustment programs in Africa: Ghana's experience, 1983-1999. Burlington, VT: Ashgate. 
Konadu-Agyemang, K. and B. Takyi, K. 2001. Structural Adjustment Programs and the political economy of development and underdevelopment in Ghana. In K. Konadu-Agyemang (ed) IMF and World Bank Sponsored Structural Adjustment Programs in Africa: Ghana's Experience, 1983-1999, p. 17-40. Burlington, VT: Ashgate Publishing Company.

Kothari, U. 2001. Power, Knowledge and social control in participatory development. In: Cooke, B. and Kothari, U. (eds.) Participation: The New Tyranny? Pp 139-152. London: Zed Books.

Krieger, N., Rowley, D. L., Herman, A. A., Avery, B., Phillips, M. T. 1993. Racism, sexism and social class: Implications for studies of health, disease, and wellbeing. American Journal of Preventive Medicine, 9, 82-122.

Kreiger, N. 1994. Epidemiology and the web of causation: has anyone seen the spider. Social Science and Medicine 39:887-903.

Kretzmann, J. P. and McKnight, J. L. 1993. Building Communities from the Inside Out: A Path Toward Finding and Mobilizing a Community's Assets. Chicago: ACTA Publications.

Kuhn, T. 1970. The structure of scientific revolutions, second edition. University of Chicago Press. Chicago, IL.

Kunfaa E.Y. 1996. Sustainable Rural Health Services through Community-Based Organisations. Spring Research Series No.16, University of Dortmund. Dortmund: SRING Centre, 1996; p25, 54.

Labonte, R. 1989. Community empowerment: the need for political analysis. Canadian Journal of Public Health 80:87-88. 1990. Empowerment: Notes on professional and community dimensions. Canadian Review of Social Policy 26:1-12 .1996. Community development in the public health sector: the possibilities of an empowering relationship between state and civil society, unpublished $\mathrm{PhD}$ dissertation, York University, Toronto. . 1997. Community, community development, and the forming of authentic partnerships, in Minkler, M (ed): Community organizing and community building for health. New Brunswick, NJ, Rutgers University Press, pp. 88-102.

Labonte, R., and A. Robertson. 1996. Delivering the goods, showing our stuff: the case for a constructivist paradigm for health promotion research and practice. Health Education Quarterly 23 (4):431-47.

Labour Resource Centre, 1995. Engendering occupational health and safety In Hatcher, R.J., Kitts, J., Jones, A.L. Gender health and sustainable development: perspectives from Asia and the Carribean. Proceedings of workshops held in Singapore, 23-26 January 1995 and in Bridegetown, Barbados, 6-9 December 1994. IDRC, Ottawa, ON, Canada. pp69-78.

Lalonde, M. 1974. A New Perspective on the Health of Canadians. Ministry of Supply and Services, Canadian Federal Government, Ottawa.

Laverack, G., and R. Labonte. 2000. A planning framework for community empowerment goals within health promotion. Health Policy Plan 15 (3):255-62. 
Lavy, V. and Quigley, J.M., 1993. Willingness to Pay for the Quality and Intensity of Midical Care; Low-Income Households in Ghana, Papers 94, World Bank Living Standards Measurement.

Leach M. 1991. Engendering environments: understanding the West African forest zone. IDS Bulletin. 22:17-24 1994. Rainforest relations: gender and resource use among the Mende of Gola, Sierra Leone. Washington, DC: Smithsonian Institution Press.

Leach M, Joekes S, Green C. 1995. Gender relations and environmental change. IDS Bulletin. 26:1-8

Lebel, J. 2003. In Focus: An Ecosystem Approach. IDRC, Ottawa.

LeCompte, M.D. and McLaughlin, D. 1994. Witchcraft and blessings, science and rationality: Discourses of power and silence in collaborative work with Navajo school. In A. Gitlin (ed.), Power and method: Political activism and educational research (pp. 147-165). New York: Routledge.

Lee, R. G. and Garvin,T. 2003. Moving from information transfer to information exchange in health and health care. Social Science and Medicine 56:449-464.

Leung, M. W., I. H. Yen, and M. Minkler. 2004. Community based participatory research: a promising approach for increasing epidemiology's relevance in the 21 st century. International Journal of Epidemiology 33 (3):499-506.

Levins, R. et al. 1994. The emergence of new diseases. American Scientist 82:52-60.

Lewin, K.1946. Action research and minority problems. Journal of Social Issues 2:34-46. 1997. Resolving Social Conflicts and Field Theory in Social Science. Washington, DC: American Psychological Association, 1997. (Original work published in 1948.)

Light, D.W. 1997. The rhetorics and realities of community health care: the limits of countervailing powers to meeting the health care needs of the $21^{\text {st }}$ century. Journal of Health Politics 21:105-145.

Lincoln, Y. 1992. Fourth generation evaluation, the paradigm revolution and health promotion. Canadian Journal of Public Health 83: S6-S10.

Lincoln, Y.S. and Guba, E.G. 1985. Naturalistic inquiry. Newbury Park, CA: Sage.

Litsios, S. 1997. Malaria Control, Rural Development and the Post-War re-ordering of International Organizations. In Malaria and Development, special issues of Medical Anthropology, 14, 2, 1997.

Litva, A. and J. Eyles. 1995. Coming out: exposing social theory in medical geography. Health and Place, 1(1):5-14.

Loewenson, R. 1993. Structural adjustment and health policy in Africa. International Journal of Health Services 23 (4):717-30.

Luginaah, I. and C. Dakubo. 2003. Consumption and impacts of local brewed alcohol (akpeteshie) in the Upper West Region of Ghana: a public health tragedy. Social Science and Medicine 57 (9):1747-60.

Lunt, P. and Livingston, S. 1996. Rethinking the focus group in media and communications research. Journal of Communication 46: 79-98.

Lupton, D. 1994. Medicine as culture. London: Sage Publications .1995. The imperative of health. Public health and the regulated body. Sage Publications. London. 
Lupton, D. 1998. The emotional self:A socio-cultural exploration. Sage Publications

MacPhail, C. and Campbell, C. 2001. 'I think condoms are good but, aai, I hate those things': condom use among adolescents and young people in a Southern African township. Social Science and Medicine, 52, 1613-1627.

Mackenzie, F. 1993. Exploring the connections: Structural adjustment, gender and the environment. Geoforum 24(1):71-86.

Mackenzie, F. 1995. Selective silence: a feminist encounter with the environmental discourse in colonial Africa. In Power of Development, ed. J Crush, pp. 100-12. New York: Routledge. 324 pp.

Madge, C. 1993. Boundary disputes: comments on Sidaway (1992). Area 25: 294-99.

Maguire, P. 1987. Doing participatory research: a feminist approach. Sch. Educ., Anherst, MA: Univ. Mass. . 1993. Challenges, Contradictions, and Celebrations: Attempting Participatory Research as a Doctoral Student. In Peter Park, Mary Brydon-Miller, Budd Hall, and Ted Jackson (eds.) Voices of Change: Participatory Research in the United States and Canada. Westport, Connecticut: Bergin and Garvey. p. 157-176 .1996. Considering more feminist participatory research: What's congruency got to do with it? Qualitative Inquiry, 2:106-108.

Martin, M. 1993. Neither Phoenix nor Icarus: Negotiating Economic Reforms in Ghana and Zambia 1983-92, In T. Callaghy and J. Ravenhill (eds) Hemmed in: Response to Africa's Economic Decline, New York: Columbia University Press

Martin, A.J., Pitt, and Rich, R.1995. Searching and search conference. The PAR toolbox. http://parnet.org/tools/Tools 2.cfm. Last updated February 5, 1995.

Matomora, M.K., 1986. A people-centered approach to primary health care implementation in Mvumi, Tanzania. Social Science and Medicine 28:10311037.

Mattingly, D. and Falconer-Al-Hindi, K. 1995. Should women count? A context for the debate. Professional Geographer 47, 27-35.

Mayer, J.D. 1992. Challenges to understanding social patterns of disease: philosophical alternatives to logical positivism. Social Science and Medicine 35: 579-587. .1996. The political ecology of disease as one new focus for medical geography. Progress in Human Geography 20(4): 441-456. . 2000. Geography, ecology and emerging infectious diseases. Soc Sci Med $50(7-8): 937-52$.

Mbilinyi, M.1989. 'I'd have been a man' In Interpreting women's lives, Personal Narratives Group, Indiana University Press, Bloomington. Pp. 204-227. 1992. Research methodologies in Gender Issues In Meena, R. ed. Gender in Southern Africa: Conceptual and Theoretical Issues. Harare: SAPES Books.

McDowell, L. 1991. The baby and the bath water: diversity, deconstruction and feminist theory in geography. Geoforum 22:123-133. 1992. Doing gender: feminism, feminists and research methods in human geography. Transactions, Institute of British Geographers 17, 399-416.

McKeown, T. 1971. An historical appraisal of the medical task In Medical History and Medical Care, Oxford University Press, Oxford. 
McKeown, T. 1976. The role of medicine: Dream, mirage, nemesis? Nuffield Provincial Hospital Trust, London.

McKinlay, J.B. 1993. The promotion of health through planned socio-political change:challenges for research and policy. Social Science and Medicine 36:109117.

McKnight, J. L. 1985. Health and empowerment. Can J Public Health 76 Suppl 1:37-8. . 1987. Regenerating community. Soc. Policy (Winter): 54-58.

McLeroy, K.R., Bibeau, D., Steckler, A., Glanz, K. 1988. An ecological perspective on health promotion programs. Health Education Quarterly 15:351-378. . 1976. The role of medicine: Dream, mirage or nemesis? London: Nuffield Provincial Hospitals Trust.

McLeroy, K.R., Clark, N.M., Simons-Morton, B.G., Forster, J., Cornell, C.M., et. al., 1995. Creating capacity: establishing a health education research agenda for special populations. Health Education Quarterly 22:390-405.

McMichael, A.J. 1994. Global environmental change and human health: new challenges to scientist and policy maker. Journal of Public Health Policy 15: 407-419. .2001. Human frontiers, environments and disease. Past patterns, uncertain futures. Cambridge University Press.

McTaggart, R. 1991. Principles for participatory action research. Adult Education Quaterly, 41:168-187. .1997. Participatory action research : international contexts and consequences. Albany: State University of New York Press.

Messing, K. 1991. Occupational safety and health concerns of Canadian women: A background paper. Supply and services Canada, Ottawa, ON, Canada.

Meyer, J. 1993. New paradigm research in practice: The trials and tribulations of action research. Journal of Advanced Nursing, 18, 1066-1072.

Mies, M. 1983. Toward a methodology for feminist research. In G. Bowles and R. Duelli Klein (eds), Theories of women's studies, pp 117-139. London: Routledge and Kegan Paul. .1991. Women's research or feminist research? The debate surrounding feminist science and methodology. In Beyond Methodology: Feminist scholarship as lived research, Fonow, M.M. and Cook, J.A. (eds.) pp 60-84. Bloomington: Indiana University Press.

Minkler, M. 1989. Health education, health promotion and the open society: an Historical perspective. Health Education Quarterly 16(1): 17-30. . 1994. Challenges for health promotion in the 1990s: social inequities, empowerment, negative consequences, and the common good. American Journal of Health Promotion. 8(6):403-13. .2000. Using participatory action research to build healthy communities. Public Health Reports 115:191-197.

Minkler, M, and N. Wallerstein (eds). 2003. Community based participatory research for health. San Francisco, CA: Jossey-Bass.

Ministry of Food and Agriculture Report, 2000. Evaluation of Soya production in the Upper West Reghion of Ghana. Unpublished Report.

Ministry of Health, Ghana. 1992. Country Profile. Accra. Ghana. 
Ministry of Health, Ghana. 1996. Medium Term Strategic Framework for Health Development in Ghana, 1996 - 2000. Accra: Ministry of Health, Ghana . 1996b. Health Sector 5 year Programme of Work. Accra: Ministry of Health, Ghana.

Mishler, E.G. 1981. Critical perspectives on the biomedical. In Mishler, E.G. et al. (eds), Social contexts of health, illness and patient care. Cambridge: Cambridge University Press, 1-23.

Mohan, G. 2001. Beyond participation: strategy for deeper empowerment. In Cooke, B. and Kothari, U. (eds.) Participation: The New Tyranny? Pp 16-35. London: Zed Books.

Mohanty, C. T. 1988. Under Western eyes: Feminist scholarship and colonial discourse. Feminist Review, 30, 61-88.

Mohanty, C.T. et al. 1991. Third World Women and the Politics of Feminism. Indiana. University Press.

Moore, D.S. 1993: Contesting terrain in Zimbabwe's Eastern Highlands: political ecology, ethnography, and peasant resource struggles. Economic Geography $69,380-401$.

. 1996. Marxism, culture, and political ecology: environmental struggles in Zimbabwe's eastern highlands. In Liberation ecologies environment, development, and social movements. Peet, R. and M. Watts. ed. 1996, pp 125-147, London. Routledge

Mosse, D. 1994. Authority, gender and knowledge: theoretical reflections on the practice of participatory rural appraisal. Development and Change 25(2): 497-526. .2001. 'People's knowledge', participation and patronage: operations and representations in rural development. In Cooke, B. and Kothari, U. (eds.) Participation: The New Tyranny? Pp 497-526. London: Zed Books.

Moss, P. 1997. Negotiating spaces in home environments: older women living with arthritis, Social Science and Medicine 45:23-33.

Moss, N.E. 2002. Gender equity and socioeconomic inequality: a framework for the patterning of women's health. Social Science and Medicine 54:649-661.

Mullings, B. 1999. Insider or outsider, both or neither: some dilemmas of interviewing in a cross-cultural setting. Geoforum 30:337-350.

Nabilla, J. 1975. Depopulation in northern Ghana: migration of the Frafra people, in David, A.S et al., Interdisciplinary approaches to population studies p. 70-83. Legon: Population Dynamics Program, University of Ghana.

Narayan, D. 1996. Toward participatory Research. World Bank Technical Paper Number 307. The World Bank. Washington D.C. 265pp.

Nast, H.J. 1994. Opening remarks on 'Women in the field'. Professional Geographer 46: 54-66.

Navarro, V. 1972. Health, health services, and health planning in Cuba. International Journal of health Services 2: 397-432 .1976. Medicine under Capitalism, New York: Neale Watson. 1986. Work, ideology and science: the case of medicine. In Crisis, health and medicine: a social critique. New York: Tavistock, 143-82. 
Naylor, R. 1999. Women farmers and economic change in Ghana. Gender and Development 7(3):35-48.

Neubauer, D. and Pratt, R. 1981. The second public health revolution: a critical appraisal. Journal Health, Politics, Policy and Law, 6(2):205-28.

Neumann, R.P. 1996. Dukes, earls and ersatz Edens: Aristocratic nature preservationists in colonial Africa. Environment and Planning D: Society and Space 14:79-98.

Neumann, R.P. 1997. Primitive ideas: Protected area buffer zones and the politics of Land in Africa. Development and Change 28:559-582.

Nielsen, N. O. 2001. Ecosystem approaches to human health. Cad Saude Publica 17 Suppl: 69-75.

Nilsen, O. 1996. Community health promotion: concepts and lessons from contemporary sociology. Health Policy 36:167-183.

Nutbeam D. 1886. Health promotion glossary. Health Promotion 1:113-127

Nyonator, F. and Kutzin J. 1999. Health for some? The effects of user fees in the Volta Region of Ghana. Health Policy Planning 14:329-41.

Oakley, P et. al. 1991. Projects with people: The practice of participation in rural development. Geneva. International Labour Office.

Odum, E. 1985. Trends expected in stressed ecosystems. BioScience 35:419-422.

O'Fallon, L. R., and A. Dearry. 2002. Community-based participatory research as a tool to advance environmental health sciences. Environ Health Perspect $110 \mathrm{Suppl}$ 2:155-9.

Ollila, E and Hemminki, E. 1997. Does licensing drugs in industrialized Countries guarantee drug quality and safety for third world countries? The case of Norplant licensing in Finland. International Journal of Health Services 27(2):309-328.

Okojie, C.E.E. 1994. Gender inequities of health in the Third World. Social Science and Medicine 39:1237-1247.

Onoge, O.F. 1973. Capitalism and public health: A neglected theme in the medical anthropology of Africa. In Ingman, S.R. and Thomas, A.E (eds.) Topias and Utopias in Health: Policy studies, p.219-232. Aldine Publishing company, Chicago.

Oppong, J. R. 1997. Medical geography of Sub-Saharan Africa. In Aryeetey-Attoh, S. (ed) Geography of Sub-Saharan Africa, , 324-62. Upper Saddle River, NJ: Prentice Hall.

Panford, K. 1994. Structural adjustment, the state and the workers in Ghana. Africa Development XIX (2):71-95.

Parfitt, T. 2004. The ambiguity of participation: a qualified defence of participatory development. Third World Quarterly 25:537-556

Park, P. 1993. What is participatory research? A theoretical and methodological perspective, In Park, P., Brydon-Miller, M., Hall, B., and Jackson, T. (eds.).1993. Voices of change:Participatory research in the United States and Canada. West Port, Conn.: Bergin and Garvey.

Park, P., Brydon-Miller, M., Hall, B., and Jackson, T. (eds.).1993. Voices of change: Participatory research in the United States and Canada. West Port, Conn.: Bergin and Garvey. 
Parkes, M. and Panelli, R. 2001. Integrating catchment ecosystems and community health: The value of participatory action research. Ecosystem Health 7: 85-106.

Payne, G. 1997. Urban Land Tenure and Property Rights in Developing Countries: A Review. IT Publications, ODA.

Pedersen, D.1996. Disease ecology at crossroads: man-made environments, human rights and perpetual development utopias. Social Science and Medicine 43(5):745-758.

Pederson, A., O’Neill, M., Rootman, I. 1994. Health promotion in Canada: Provincial, national and international perspective. Canada: W.B. Saunders.

Peet, R. and M. Watts, 1996. Liberation ecology: Development, sustainability and environment in an age of market triumphalism In: Peet, R. and M. Watts (eds.) Liberation ecologies: environment, development, and social movements. London. Routledge. Pp.1-45.

Peluso, N.L. 1988. Rich forests, poor people and development: forest access control and resistance in Java. $\mathrm{PhD}$ thesis. Cornell University.

. 1992. Rich Forests, Poor People: Resource Control and Resistance in Java. Berkeley, CA: Univ. Calif. Press.

. 1993. Coercing conservation? The politics of state resource control. Global Environmental. Change 3:199-217.

Peters, M and Robinson, V. 1984. The origins and status of action research. Journal of Applied Behavioural Sciences, 20:113-124.

Pierce, N. 1996. Traditional epidemiology, modern epidemiology and public health. American Journal of Public Health 86(5):678-683.

Pile, S. 1991. Practising interpretative geography. Transactions, Institute of British Geographers 16: 458-69.

Plange, N.K. 1979. Underdevelopment in Northern Ghana: Natural Causes or Colonial Capitalism? Review of African Political Economy 15-16: 4-14.

Poland, B.D. 1992. 'Learning to 'walk our talk': the implications of sociological theory for research methodologies in health promotion Canadian Journal of Public Health 83, supplement 2, S31-S46.

. 1993. Some promises and pitfalls of lay perception research in the social and health sciences. The Operational Geographer 11:23-27.

Poland, B.D., Coburn, D., Robertson, A., and Eakin, J. 1998. Wealth, equity and health care: A critique of a "population health" perspective on the determinants of health. Social Science and Medicine 46: 785-798

Puta, A.K. 1994. Occupational health, safety and gender. In Wijeyaratne, P., Hatcher, R.J., Jones, A.L., Kitts, J., Gender health and sustainable development: proceedings of a workshop held in Nairobi, Kenya, 5-8 October 1983. IDRC, Ottawa, ON. Canada. pp 163-170.

Rains, J.W. and Ray, D.W.(1995) Participatory action research for community health promotion. Public Health Nursing 12: 256-261.

Radcliffe, S.A. 1994. (Representing) post-colonial women: authority, difference and feminisms. Area 26, 25-32.

Rajasekaran, B. 1993. A framework for incorporating Indigenous knowledge System into Agricultural Research and Extension Organizations for Sustainable Agricultural Development in India. Ph.D. Dissertation, Iowa State University, Ames, Iowa. 
Randall, P. 1998. Health care systems in Africa: Patterns and Prospects. Report from the workshop, Health Systems and health care: Patterns and Perspectives. 27-29 April 1998. The North-South Co-ordination Group. University of Copenhagan and The ENRCA Health Network.

Rapaport, R. 1970. Three dilemmas in action research. Human Relations 23:499-513. Rappaport, J. 1985. The power of empowerment language. Social Policy 16:15-21. Rappaport, J. 1987. Terms of empowerment/exemplars of prevention: towards a theory for community psychology. American Journal of Community Psychology 15:121144.

Rapport, D.J. 1989. What constitutes ecosystem health? Perspectives Biology and Medicine. 33:120-31

.1992. Evaluating ecosystem health. Journal of Aquatic Ecosystem Health

$1: 15-24$.

. 1995. Ecosystem health: An emerging integrative science. NATO ASI Series. Global environmental change, I 28:5-31. 1-2. 2000. A new strategy for public health. Editorial. Ecosystem Health 6(1):

Rapport, D.J., Costanza, R., McMichael, A.J. 1998. Assessing ecosystem health. Trends in Ecology and Evolution 13:397-402.

Rapport, D.J., Bohm, G., Buckinham, D., et al. 1999. Ecosystem health: the concept, the ISEH, and the important tasks ahead. Ecosystem Health 5:82-90.

Ray, D.I. 1986. Ghana: Politics, economics and society. London: Frances Pinter.

Reason, P. 1988. Experience, action, and metaphor as dimensions of post-positivist inquiry. Research in Organizational Change and Development 2:195-233. . 1994. Three approaches to participatory inquiry. In Denzin, N.K. and Lincoln, Y.S. (eds.). Handbook of qualitative research. Sage, Thousand Oaks, CA. pp324339.

Reason, P. and Rowan, J. (eds.) 1981. Human inquiry: a sourcebook of new paradigm research. Chichester, Wiley.

Reason, P. and Bradbury, H. 2001. Introduction: inquiry and participation in search of a world worthy of human aspiration. In: Reason, P. and Bradbury, H. (eds.)

Handbook of action research: Participative inquiry and practice. Sage, London, pp 1-14.

Redckift, M. 1984. Development and the Environmental Crisis: Red or Green Alternatives. Methuen, London. .1987. Sustainable development: exploring the contradictions. London: Methuen.

Rifkin S. 1990. Community participation in MCH/FP programmes: an analysis based on case study material. WHO, Geneva. .1994. Participtory research and health. Proceedings of the international symposium on participtory research in Health Promotion. Liverpool School of Hygiene and Tropical Medicine . 1996. Paradigms lost: toward a new understanding of community participation in health programmes. Acta Tropica 61 (2): 79-92. 
Rifkin, S.B., Muller, F., Bichmann W. 1988. Primary health care: On measuring participation. Social Science Medicine 29:931-940.

Rimmer, D. 1992. Staying poor: Ghana's political economy 1950-1990. Oxford: Pergamon Press.

Robertson, R and Minkler, M. 1994. New health Promotion Movement: A critical examination. Health Education Quarterly 21(3): 295-312.

Rocheleau, D. E. 1995. Gender and biodiversity: a feminist political ecology perspective. IDS Bulletin. 26:9-16.

Rocheleau, D. and Ross, L. 1995. Trees as tools, trees as text: struggles over resources in Zamrana-Chacuey, Dominican Republic. Antipode 27:407-28.

Rocheleau, D., Thomas-Slayter, B. and Wangari, E.(eds.) 1996. Feminist political ecology: global issues and local experiences. London: Routledge.

Rose, G. 1993. Feminism and geography: The limits of geographical knowledge. Minneapolis: University of Minnesota Press. 1997. Situating knowledges: positionality, reflexivities and other tactics Progress in Human Geography 21:305-320

Rosenau, P.V. 1994. Health politics meets post-modernism: its meaning and implications for community health organizing. Journal of Health Politics, Policy and Law 19:303-327.

Sachs, C. 1996. Gendered Fields. Rural Women, Agriculture, and Environment. Rural Studies Series. Westview Press, Inc.

Sanders, D and Sambo, A. 1991. AIDS in Africa: the implications of economic recession and structural adjustment. Health Policy and Planning, 6 (2): 157-65.

Schaik van, A and H. Reitsma. 1992. Agriculture in dry-season environments. In: Reitsma, Henk, Ton Dietz and Leo de Haan (eds). Coping with semiaridity: How the rural poor survive in dry-season environments. Utrecht: Netherlands Geographical Society. pp.19-36.

Schrag, S.J. and Wiener, P. 1995. Emerging infectious diseases: What are the relative roles of ecology and evolution? Trends in Ecology and Evolution 10:319-324.

Schimink and Wood, 1987. The 'political ecology' of Amazonia. In: Little, P.D. and Horowitz, M.M., (eds.) Lands at risk in the third world: local-level perspectives. Boulder, CO: Westview Press, pp. 38-57.

Schroeder, R.A. 1993. Shady practice: gender and the political ecology of resource stabilization in Gambian garden/orchards. Economic Geography 69(3): 349-65. .1995. Contradictions along the commodity road to environmental stabilization: foresting Gambian gardens. Antipode 27:325-42. 1999. Geographies of environmental intervention in Africa. Progress in Human Geography 23 (3): 359-378.

Schulz, A. J., J. Krieger, and S. Galea. 2002. Addressing social determinants of health: community-based participatory approaches to research and practice. Health Education and Behavior 29 (3):287-95.

Schulz, A., and M. E. Northridge. 2004. Social determinants of health: implications for environmental health promotion. Health Education and Behavior 31 (4):455-71. 
Schwab, M., and S. L. Syme. 1997. On paradigms, community participation, and the future of public health. American Journal of Public Health 87 (12):2049-51; discussion 2051-2.

Scott, J.C. 1990. Domination and the arts of resistance. Yale University Press, New Haven.

Scriven, A and Stiddard, L. 2003. Empowering schools: translating principles into practice. Health Education 103:110-19.

Seedhouse, D. 1986. Health: the foundations of achievement. Chichester: Wiley.

Shah, M.K and Shah, P. 1995. Gender, environment and livelihood security: an alternative viewpoint from India. IDS Bulletin. 26:75-82

Shiva, V. 2002. Water wars: Privatization, pollution and Profit. South End Press.

Sidel,V. and Sidel, R. 1973. Serve the People. Observations on Medicine in the People's Republic of China. Beacon press.

Songsore, J. 1983. Intraregional and interregional labour migrations in historical perspective : the case of north-western Ghana. [Port Harcourt, Nigeria]:

University of Port Harcourt, Faculty of Social Sciences. . 1989. The Spatial Impress and Dynamics of Underdevelopment in Ghana. In: Swindell, K., Baba, J.M., Mortimore M. J. (Eds.), Inequality and Development: Case Studies from the Third World. Macmillan Publishers, London.

Songsore, J., and Denkabe, A., 1995: Challenging Rural Poverty in Northern Ghana. The Case of the Upper West Region, CED, University of Trondheim, Report No. 6/95.

Smith, D. 1990. the conceptual practices of power: A feminist sociology of knowledge. Boston. North Eastern University Press.

Spencer, L. 1989. Winning through participation. Kendall/Hunt Publishing Company, Dubuque, Iowa.

Staeheli, L.A. and Lawson, V.A. 1994. A discussion of 'Women in the field': the politics of feminist fieldwork. Professional Geographer 46: 96-102.

Stark, O. 1976. Rural to Urban migration and some economic issues: A review utilizing findings of surveys and empirical studies. Geneva: ILO.

Staudt, K. 1987. Uncaptured or unmotivated? Women and the food crisis in Africa, Rural Sociology 52(1), 37-55.

Stevens, P.E. 1992. Who gets health care? Access to health care as an arena for nursing action. Scholarly Inquiry for Nursing Practice, 6, 185-200.

Stevenson, H. M., and M. Burke. 1992. Bureaucratic logic in new social movement clothing: the limits of health promotion research. Canadian Journal of Public Health 83 Suppl 1:S47-53.

Stock, R. 1986. 'Disease and development' or 'the underdevelopment of health': A critical review of geographical perspectives on African health problems. Social Science and Medicine, 23 (7): 689-700.

Stock, R. 1995. Africa South of the Sahara: A geographic interpretation. New York: Guiford Press.

Stokols, D. 1992. Establishing and maintaining healthy environments: toward a social ecology of health promotion. American Psychologist 47:6-22.

1996. Translating social ecological theory into guidelines for community health promotion. American Journal of Health Promotion 10:282-298. 
Strasser, R. 2003. Rural health around the world: Challenges and solutions. Family Practice: $457-463$.

Strauss, A. Cobin, J. 1990. Basics of Qualitative Research. Grounded Theory Procedures and Techniques, California: Sage

Susser, M. and Susser, E. 1996. Choosing a future for epidemiology: eras and paradigms. American Journal of Public Health 86:668-673.

Sutton, I. 1989. Colonial Agricultural Policy: The Non-Development of the Northern Territories of the Gold Coast. The International Journal of African Historical Studies. Vol.22, No.4, pp.637-669.

Swyngedouw. E., Kaika, M. and Castro, E. 2002. Urban water: a political-ecology perspective Built Environment $28124-37$.

Syme, S.L. 1998. Social and economic disparities in health: thoughts about intervention. Milbank Quarterly 76(3): 493-505.

Tandon, R. 1981. Participatory evaluation and research: main concepts and issues. In Fernandes, W., and Tandon, R. (eds.) Participatory research and evaluation, pp.15-34. New Delhi: Indian Soc. Inst. 1988. Social transformation and participatory research. Convergence 2:5-15. 1996. The historical roots and contemporary tendencies in participatory research: implications for health care. In: de Koning K, Martin M (eds). Participatory Research in Health: Issues and Experiences. New Jersey: Zed Books, 1996, pp. 19-26.

Thomas, R.G. 1973. Forced Labour in British West Africa: The Case of the Northern Territories of the Gold Coast 1906-1927. Journal of African History, Vol. 16, (1): 79-103.

Thompson, B. and Kinne, S. 1990. Social change theory: applications to community health In: N. Bracht (ed) Health Promotion at the Community Level. Sage. Newbury Park.

Thurston, D. 1992. Sustainable Practices for Plant Disease Management in Traditional Farming Systems. Boulder, Colorado: Westview Press.

Turshen, M. 1977. The political ecology of disease. Review of Radical Political Economics 9: 45-60.

Turshen, M. 1984. The political ecology of disease in Tanzania. New Brunswick, N.J.: Rutgers University Press. .1999. Privatizing health services in Africa. New Brunswick, NJ: Rutgers. University Press.

Twumasi, P. A. 1975. Medical systems in Ghana: A study in medical sociology. Ghana Publishing Corporation. Tema.

.1979. A social history of the Ghanaian pluralistic medical system. Social Science and Medicine. 13B (4): 349-356.

.1981. Colonialism and international health: a study in social change in Ghana. Social Science and Medicine [Med Anthropol] 15B (2):147-51.

Ulichny, P. 1997. When critical ethnography and action collide. Qualitative Inquiry 3(2):139-168.

United Nations (UN). 1992. Rio declaration on environment and development. UN. New York, USA. 
United Nations. 1993. Earth Summit-Agenda 21. UN. New York, USA.

UNCED, 1992. The global partnership for environment and development. A guide to agenda 21.

United Nations Development Programme (UNDP), 1997. Human Development Report. UNDP, New York.

UNECA, 1989. African alternative framework to structural adjustment programmes for socio-economic recovery and transformation (AAF-SAP) Addis Ababa, Ethiopia:

United Nations Environment Prograamme (UNEP) 1999. Global Outlook 2000. UNEP, Geneva, Switzerland.

UNICEF, 1996. The State of the World's Children. Oxford University Press.

VanLeeuwen, J., Waltner-Toews, D., Abernathy, T., and Smith, B. 1999. Evolving models of human health toward an ecosystem context. Ecosystem Health 5: 204219.

Vitousek, P.M. et al. 1997. Human domination of earth's ecosystems. Science 277:494499.

Vlassoff, C. 1994. Gender inequalities in health in the third world: unchartered ground. Social Science and Medicine 39:1249-1259.

Vogel, R.J. 1988. Cost recovery in the health sector: Selected country studies in West Africa. Washington, DC: World Bank Technical paper. No. 82.

von Schirnding, Y.E.R. 1997. Addressing health and environment concerns in sustainable development with special reference to participatory planning initiatives such as health cities. Ecosystem Health 3:221-228.

von Schirnding, Y. and Bruce, N. 2000. Household energy use, health and development. Background Paper prepared for the USAID/WHO Global Consultation on Indoor Air Polluiton and Household Energy in Developing Countries, Washington D.C.

Vrijheid, M. 2000. Health effects of residence near hazardous waste landfill sites: A review of epidemiologic literature. Environmental Health Perspectives 108: Suppl. 1

Wallack, L. and Montgomery, K. 1996. Advertising for all by the year 2000: public health implications for less developed countries. Journal of Public Health Policy, 13(2):204-23.

Wallerstein, N. 1992. Powerlessness, empowerment, and health: implications for health promotion programs. American Journal of Health Promotion 6 (3):197-205.

- 1999. Power between evaluator and community: research relationships within New Mexico's healthier communities. Social Science and Medicine 49 (1):39-53. . 2002. Empowerment to reduce health disparities. Scandinavian Journal of Public Health 30 (Supplement 59):72-77.

Wallerstein, N., and E. Bernstein. 1988. Empowerment education: Freire's ideas adapted to health education. Health Education Quarterly 15 (4):379-94.

-1994. Introduction to community empowerment, participatory education, and health. Health Education Quarterly 21 (2):141-8.

Wallerstein, N and Duran, B. 2003. The conceptual, historical, and practice roots of community-based participatory research and related participatory traditions. In Minkler, M, and N. Wallerstein. 2003 (eds). Community based participatory research for health. San Francisco, CA: Jossey-Bass 
Walsh, J.A and Waren, K.S. 1979. Selective primary health care: an interim strategy for disease control in developing countries. New England Journal of Medicine. 301(18): 967-74.

Waltner-Toews, D. 2001. An ecosystem approach to health and its applications to tropical and emerging diseases. Cad Saude Publica 17 Suppl:7-22; discussion 2336.

Watts, M. 1983. Silent violence: food, famine, and peasantry in northern Nigeria. Berkely, CA: University of California Press. . 1997. Black gold, white heat. State violence, local resistence and national question in Nigeria, In S. Pile and M.Keith (eds), Geographies of Resistance, London, Routledge, p.33-67.

1998. Nature as artifice and artifact. In B. Braun, and N. Castree (eds). Remaking Reality: Nature at the Millennium, p. 243-68. New York: Routledge.

Watts, M. 2001. Petro-violence: community, extraction and political ecology of a mythic commodity, In N.L. Peluso and M. Watts (eds) Violent environments, Ithaca and London, Cornell University Press p.189-212.

Weedon, C. 1987. Feminist practice and poststructuralist theory. Oxford, UK ; New York, NY, USA: B. Blackwell.

Weiss, H. 1997. "Flight to Survive": Migrations during Times of Drought and Famine in Early Colonial West Africa. Working Paper no. 13. Helsinki: Institute of Development Studies.

Werlin, H. 1994. Ghana and South Korea: Explaining development disparities. Journal of African and Asian Studies, 3-4:205-225

White, N. 1981. Modern health concepts. In Norman, W (ed)The Health Conundrum, 5-18. Toronto, Ontario: OECA.

Whitehead, A. 1981. 'I'm hungry, Mum': The politics of domestic budgeting, In Young, $\mathrm{K}$, Wolkowitz, C, and McCullagh, R. (Eds): Of marriage and the market. p.88111 CSE Books, London.

Whittle, K.S. and Inhorn, M.C. 2001. Rethinking difference: A feminist reframing of gender/race/class for improvement of women's health research. International Journal of health Services, 31(1): 147-165.

Whyte, W. F. 1991. Participatory action research. Newbury Park, Calif.: Sage Publications.

Whyte, W.F., Greenwood, D.J. and Lazes, P. 1989. Participatory action research: through practice to science in social research. American Behavioral Scientist 32:513-551.

Williams, G. 2004. Evaluating Participatory Development: Tyranny, power, and (re)politicisation. Third World Quarterly 25:557-578.

Wilson, M.E. 2000. Environmental Change and infectious diseases. Ecosystem Health 6:7-12.

Woodward, D. 1992. Debt, adjustment and poverty in developing countries. London: Frances Pinter in association with Save the Children.

Wohl, A.S. 1983. Endangered lives: Public health in Victorian Britain. Dent, London.

World Bank, 1992. World Development Report 1992: Development and the environment. The World Bank, Washington, D.C. 
World Bank. 1993. World Development Report 1993: Investing in Health. The World Bank, Washington, D.C.

1995. World Development Report. New York: Oxford University Press.

World Bank. 1995. Monitoring environmental progress. A report on work in progress. Washington, D.C.

1996. World Development Report. New York: Oxford University Press. 1997. Clear Water, Blue Skies. The World Bank, Washington, D.C. 2003. Ghana-Second Health Program Support Project. Project Appraisal

Document. Project \# 24842-GH

World Commission on Environment and Development. 1987. Our common future. New York, Oxford University Press.

World Health Organization, 1948. The Constitution. Geneva, Switzerland 1978. Alma-Ata 1978. Primary health care. Geneva. . 1981. Health For All: Global strategy for Health For All by the Year 2000. WHO, Geneva, Switzerland. . 1986. Health Promotion: Ottawa Charter. International Conference on Health Promotion, Ottawa, 17-21 November 1986. Geneva, Switzerland. . 1986a. A discussion document on the concept and principles of health promotion. Health Promotion 1:73-78.

World Health Organization. 1992. Our planet, Our health. Report of the commission on health and environment, Geneva.

1994. Women's health: towards a better world. Global Commission on Women's Health, WHO, Geneva, Switzerland.

. 1995 a. The World Health Report 1995: Bridging the Gaps WHO, Geneva, 1995 b. Our planet, our health. Report of the WHO commission on health and environment. WHO, Geneva.

1997. Health and Environment in Sustainable Development: Five Years After the Earth Summit.WHO, Geneva.

1998. The Jakarta declaration on leading health promotion into the $21^{\text {st }}$ century. http://www.who.ch/hpr/WHO_HPR.

. 1999. World Health Report 1999 database. World and United Nations Children's Fund, Sanitation for All: Promoting dignity and human rights, UNICEF, New York, 2000. .2001 WHO Country Cooperation Strategy: Ghana 2002-2005. WHO Regional Office for Africa. Brazzaville.

WHO/UNAIDS, 2004. Epidemiological fact sheets on HIV/AIDS and sexually transmitted infections. WHO, Geneva.

World Resources Institute (WRI) 1992. World resources 1992-93: a guide to the global environment. Oxford University Press. .1996. World Resources Institute in collaboration with the United Nations Environment Programme, the United Nations Development Programme, and The World Bank, World Resources Report 1996-97. Oxford University Press, New York, 1996.

World Watch Institute 1994. State of the world 1994. Earthscan Publications Ltd., London. 
Wuest, J. 1993. Removing the shackles: A feminist critique of noncompliance. Nursing Outlook, 41, 217-224.

Yassi, A., Mas, P., Bonet, M., Tate, R.B., Fernandez, N., Spiegel, J., and Perez, M. 1999. Applying an ecosystem approach to the determinants of health in Centro Habana. Ecosystem Health 5: 3-19.

Yeich, S. and Levine, R. 1992. Participatory research's contribution to a conceptualization of empowerment. Journal of Applied Social Psycholology 22:1894-908.

Zakus, J. D. 1998. Resource dependency and community participation in primary health care. Social Science and Medicine 46 (4-5):475-94.

Zakus, J.D. and Lysack, L.C. 1998. Revisiting community participation. Health Policy and Planning 13 (1): 1-12. 


\section{APPENDIX I: FOCUS GROUP DISCUSSION CHECKLIST}

\section{A. SOCIO-DEMOGRAPHIC}

1. How long have you been living in this community?

2. Do you live in the community all-year round?

3. How old are you?

4. Are you married, widowed, or divorced?

5. Have you ever attended school?

6. How many years have you spent in school?

7. What is your religion?

8. What is your main occupation?

9. What is your wife or husband's occupation?

10. If retired, what was your occupation (e.g., mining) before you retired?

11. Can you describe what sorts of activities you carry out in a typical day?

12. How many people live in your household including yourself?

13. How many have attended and are attending school?

14. How many children do you have?

15. Are all of them alive?

16. What sorts of work do your children do?

17. What is your current income source?

18. What is your approximate total household income (E.g. the past year?)

19. Are there any things you worry about, in particular?

20. How is life in general? 


\section{B. CONCEPTS \& INDICATORS OF HEALTH AND ILL HEALTH}

1. What do you understand by health?

2. What do you understand by ill health?

3. How would you describe your health?

4. How would you describe the health of the rest of your family members?

5. How would describe someone who is healthy?

6. How would you describe someone who is not healthy?

7. What sorts of things do you do to become unhealthy?

8. What do you do or can do to become healthy?

\section{PERCEPTIONS OF COMMUNITY HEALTH}

1. How would you describe the general health and well-being of people in this community?

2. What health problems face adults in this community?

3. What health problems face women in particular? How about men?

4. What health problems face children in this community?

5. What would you say are the major health problems in your community?

6. Explain why you said so.

7. How will you rank the major health problems in this community, beginning with the most serious and common one?

8. What factors do you think are responsible for each of these major health problems? (Further probes on factors identified).

9. Based on your experience, what can you do to improve health in the community? 


\section{HISTORICAL ANALYSIS}

1. How would you describe the environment and health conditions in Charia over the past $50,40,30,20,10,5$ years?

2. What significant changes have you noticed?

3. Can you describe how things have changed over the years?

4. What do you think are the causes of those changes?

5. How might you explain the current conditions we are experiencing?

6. What do you think will happen if things continue this way?

7. What should/can we do to improve our living conditions in this community?

\section{E. FRAMEWORK FOR A STRATEGIC PLANNING PROCESS}

\section{Step 1: Visioning Exercise}

Imagine that we are five years into the future, and all the health problems and their underlying causes identified in our previous discussions have been solved. What noticeable features and conditions would you want to see in Charia and in the people of Charia?

\section{Step 2: Identifying the Obstacles}

What obstacles or roadblocks obstruct the realization of the vision we mapped out during our last meeting?

\section{Step 3: Assessing Strengths and Resources}

What resources, abilities, skills and strengths can we draw on to overcome the obstacles we have identified?

\section{Step 4: Strategic Directions}

What new activities must we undertake to overcome the barriers and roadblocks identified in our previous discussion? What new activities (projects, programs, committees) must we undertake to achieve our vision? 


\section{Step 5: Systematic Actions and Implementation Plan}

What are the practical and attainable actions that we can begin to implement so as to achieve the strategic directions (proposals, programs, etc.) that we mapped out during our last discussion? What can we do now?

\section{F. QUESTIONS WITH GOVERNMENT DEPARTMENTS ${ }^{21}$}

1. How are you involved with the study community?

2. What programs do you implement in the community?

3. What do you think are the major concerns and challenges facing the community with respect to your area?

4. How do you work with community members?

5 . What challenges do you encounter?

6. What activities can be supported to improve the living conditions of community members?

7. Do you work with other government departments in trying to solve community problems?

8. What challenges might you encounter through such a working relationship? Is it feasible?

${ }^{21}$ Forestry, Ministry of Agriculture, Ministry of Health, Town and Country Planning, and Environmental Protection Agency 


\section{APPENDIX II: COVER LETTERS AND CONSENT FORMS}

\section{A. COVER LETTER FOR RESEARCH PARTICIPANT}

Dear Participant,

I am a Ph.D. Candidate in the Department of Geography and Environmental Studies at Carleton University, Ottawa, Canada. I am working under the supervision of Professor Fiona Mackenzie. As part of my research, I am conducting a study on exploring the health consequences of rural people's interaction with their local environments, and their role in preventing, mitigating and adapting to those health consequences.

A participatory action research approach will be used for this study. Extension officers working in this community will be recruited to form a research team. The research team will conduct a number of community workshops and focus group discussions, during which participants will contribute to identifying their health priorities, the underlying barriers to achieving those priorities, and develop strategies to overcoming those barriers. In addition, the research will use group-based problem solving tools such as participatory mapping and transect walks. Farms and households will also be visited. Group discussions will be tape-recorded and photographs taken.

The study will take three months, with six community workshops planned. Although your active participation will be appreciated through the entire research process, you are free to withdraw at any time, or participate at your own convenience. Any information you provide will be confidential, and I will not refer to you by name or describe you in any way that will let others identify you, thus complete anonymity will be guaranteed in the study. Further, you will not be identified by name in my thesis, report or publication resulting from this study.

This project has been reviewed by, and received ethics clearance from the Carlton University Ethics Committee. If you have any questions about the study, or would like additional information to assist you in reaching a decision to participate, please feel free to contact me or Professor Fiona Mackenzie at the address below, or the Carleton University Ethics Committee. Upon completion of the study, a summary of the thesis will be given to the community leader, and can also be accessed at the Carleton University Library and the International Development Research Centre, Ottawa, the funding agency of this project.

Thank you for your consideration of this request. I hope this study will prove to be a learning experience for all participants. Please indicate on the attached page your willingness to participate and how we can get in touch with you. For those who are not literate, this letter will be read to them in the local language and consent sought by informing me of their desire to participate. 
Yours sincerely,

Crescentia Dakubo

Department of Geography \& Environmental Studies

Carleton University

B349 Loeb Building

1125 Colonel By Drive

Ottawa, Ontario

Canada, KIS 5B6

\section{B. RESEARCH PARTICIPANT CONSENT FORM}

By signing this form, I agree to participate in a study being conducted by Crescentia Dakubo of the Department of Geography and Environmental Studies, Carleton University, Ottawa, under the supervision of Professor Fiona Mackenzie. I have made this decision based on the information I have read or been read to in the cover letter.

As a participant in this study, I realize that I will participate in community workshops in identifying community health needs and strategies to achieving those needs, participate in group-based problem solving exercises, such as mapping and transect walks and that my farm or home may be visited. I realize group discussions will be tape-recorded and some photographs taken. I also understand that I may decline to participate in any activities or answer any questions, if I so choose, or withdraw my consent completely. All information I provide will be held in confidence and I will not be identified during the research, in the thesis, report or publication. I understand that this project has been reviewed by and received ethics clearance from the Carleton University Ethics Committee and that I may contact this office at 1125 Colonel By Drive, Office of Research Services, Dunton Tower 1501, Carleton University, Ottawa, Ontario, Canada, should I have any concerns or questions about this study, or contact the principal investigator or her supervisor at the address in the cover letter.

Signature of research participant 


\section{COVER LETTER FOR MEMBERS OF THE RESEARCH TEAM}

Dear Co-researcher,

I am a Ph.D. Candidate in the Department of Geography and Environmental Studies at Carleton University, Ottawa, Canada. I am working under the supervision of Professor Fiona Mackenzie. As part of my research, I am conducting a study on exploring the health consequences of rural people's interaction with their local environments, and their role in preventing, mitigating and adapting to those health consequences. Given that you are an extension worker in this community, I will be happy to work with you as one of the members of a research team for this study. As part of the research team, you will participate in conducting community workshops, hold group discussions, and conduct farm and household visits. You will participate in all stages of the research process, including developing a research agenda for three months; identifying the research methods to be used; and participate in investigating, interpreting and analysing the information gathered. Group-based problem solving tools such as participatory mapping and transect walks will also be carried out. Group discussions will be tape-recorded and photographs taken.

Your active participation in the entire research process will be greatly appreciated, although you are free to withdraw at any time, or participate at your own convenience. Any information you provide will be confidential, and I will not refer to you by name or describe you in any way that will let others identify you, thus complete anonymity will be guaranteed in the study. Further, you will not be identified by name in my thesis, report or publication resulting from this study, if you so choose. Any information you collect from participants during the study must be confidential, and no participant should be referred to in a way that will allow for identification.

This project has been reviewed by, and received ethics clearance from the Carleton University Ethics Committee. If you have any questions about the study, or would like additional information to assist you in reaching a decision to participate, please feel free to contact me or Professor Fiona Mackenzie, at the address below, or the Carleton University Ethics Committee. Upon completion of the study, a summary of the thesis will be given to the community leader, and can also be accessed at the Carleton University Library and the International Development Research Centre, Ottawa, the funding agency of this project.

Thank you for considering this request. I hope this study will prove to be a learning experience for you and all the participants. Please indicate your consent to participate by signing the attached consent form and indicate how we can get in touch with you. 
Yours sincerely,

Crescentia Dakubo

Department of Geography \& Environmental Studies

Carleton University, B349 Loeb Building

1125 Colonel By Drive, Ottawa, Ontario

Canada, KIS 5B6

\section{CO-RESEARCHER CONSENT FORM}

By signing this form, I agree to participate as a member of a research team in a study conducted by Crescentia Dakubo of the Department of Geography and Environmental Studies, Carleton University, under the supervision of Professor Fiona Mackenzie. I have made this decision based on the information I have read in the cover letter.

As a member of the research team, I realize that I will participate in all stages of the research process, including developing a research agenda for three months, identifying the research methods to be used during the study, and participate in investigating, interpreting and analysing the information gathered. I will also conduct group-based problem solving exercises such as mapping, transect walks, farm and household visits. I realize that any information I collect from participants during the study must be confidential, and no participant should be referred to in a way that will allow for identification.

I also understand that I am a volunteer and may decline to participate in any activities or answer any questions, if I so choose, or withdraw my consent completely. All information I provide will be confidential and I will not be identified in the thesis, report or publication, if I so desire. I understand that this project has been reviewed by and received ethics clearance from the Carleton University Ethics Committee and that I may contact this office at, 1125 Colonel By Drive, Office of Research Services, Dunton Tower 1501, Carleton University, Ottawa, Ontario, Canada, should I have any concerns or questions about this study, or contact the principal investigator or her supervisor at the address on the cover letter.

Signature of co-researcher 